\title{
Epidemiologie, Diagnostik, antimikrobielle Therapie und Management von erwachsenen Patienten mit ambulant erworbenen unteren Atemwegsinfektionen sowie ambulant erworbener Pneumonie - Update 2009
}

S3-Leitlinie der Paul-Ehrlich-Gesellschaft für Chemotherapie, der Deutschen Gesellschaft für Pneumologie und Beatmungsmedizin, der Deutschen Gesellschaft für Infektiologie und vom Kompetenznetzwerk CAPNETZ

Epidemiology, Diagnosis, Antimicrobial Therapy and Management of Community-acquired Pneumonia and Lower Respiratory Tract Infections in Adults

Guidelines of the Paul-Ehrlich-Society for Chemotherapy, the German Respiratory Society, the German Society for Infectiology and the Competence Network CAPNETZ Germany

Autoren

G. Höffken ${ }^{1}$, J. Lorenz ${ }^{2}$, W. Kern ${ }^{3}$, T. Welte ${ }^{4}$, T. Bauer, K. Dalhoff, E. Dietrich, S. Ewig, P. Gastmeier, B. Grabein,

E. Halle, M. Kolditz, R. Marre, H. Sitter

Sprecher für die Paul-Ehrlich-Gesellschaft für Chemotherapie e. V. (federführend)

Sprecher für die Deutsche Gesellschaft für Pneumologie und Beatmungsmedizin e. V.

3 Sprecher für die Deutsche Gesellschaft für Infektiologie e. V.

Sprecher für das Kompetenz-Netzwerk CAPNETZ Deutschland e.V.

Bibliografie

DOI $10.1055 / \mathrm{s}-0029-1215037$

Pneumologie 2009; 63:

e1-e68 () Georg Thieme

Verlag KG Stuttgart · New York

ISSN 0934-8387

Korrespondenzadresse

Prof. Dr. med. G. Höffken

Fachkrankenhaus Coswig

Universitätsklinikum

Carl Gustav Carus Dresden,

Medizinische Klinik I

Fetscherstr. 74

01307 Dresden

gert.hoeffken@uniklinikumdresden.de

\begin{tabular}{|c|c|c|}
\hline \multicolumn{3}{|l|}{ Inhalt } \\
\hline 1. & Struktur der Leitlinie & e6 \\
\hline 1.1 . & Vorwort & e6 \\
\hline 1.2. & Ziele der Leitlinie & e6 \\
\hline 1.3. & Erstellung der Leitlinie & e7 \\
\hline 1.3.1. & Literaturrecherche & e7 \\
\hline 1.3.2. & Formulierung der Empfehlungen & e7 \\
\hline 1.4. & Finanzierung & e8 \\
\hline 1.5. & Implementierung/Publikation & e8 \\
\hline 1.6. & Planmäßige Überarbeitung & e8 \\
\hline 1.7. & Prozessqualität & e8 \\
\hline 2. & Definitionen & e8 \\
\hline 3. & Epidemiologie und sozialmedizinische & \\
\hline & Bedeutung & e9 \\
\hline 4. & Erregerspektrum & e9 \\
\hline 5. & Resistenzsituation & e10 \\
\hline 5.1. & $\begin{array}{l}\text { Resistenzsituation bei Streptococcus } \\
\text { pneumoniae }\end{array}$ & e10 \\
\hline 5.1.1. & Resistenz gegenüber Penicillin G & e10 \\
\hline 5.1.2. & Resistenz gegenüber Makroliden & e 10 \\
\hline 5.1.3. & Resistenz gegenüber Fluorchinolonen & e11 \\
\hline 5.1.4. & Resistenz gegenüber Tetracyclinen & e11 \\
\hline 5.2. & $\begin{array}{l}\text { Resistenzsituation bei Haemophilus } \\
\text { influenzae }\end{array}$ & e11 \\
\hline 5.3. & $\begin{array}{l}\text { Resistenzsituation bei Moraxella } \\
\text { catarrhalis }\end{array}$ & e11 \\
\hline 5.4. & $\begin{array}{l}\text { Resistenzsituation bei Enterobacte- } \\
\text { riaceae und Pseudomonas aeruginosa }\end{array}$ & e11 \\
\hline 5.5. & $\begin{array}{l}\text { Resistenzsituation bei Influenza-Viren } \\
\text { und nicht primär respiratorischen Viren }\end{array}$ & $\mathrm{e} 12$ \\
\hline 6. & Mikrobiologische Diagnostik & e12 \\
\hline 6.1 . & Diagnostik schnell wachsender Bakterien & e12 \\
\hline 6.2. & Diagnostik spezieller Erreger & e13 \\
\hline 6.2.1. & Diagnostik von Legionella pneumophila & e13 \\
\hline 6.2.2. & Diagnostik von Mycoplasma pneumoniae & e14 \\
\hline 6.2.3. & $\begin{array}{l}\text { Diagnostik von Chlamydophila } \\
\text { pneumoniae }\end{array}$ & e15 \\
\hline 6.2.4. & Diagnostik respiratorischer Viren & e15 \\
\hline
\end{tabular}

\begin{tabular}{|c|c|c|}
\hline Inhalt & & \\
\hline 7. & Antiinfektiva zur Behandlung tiefer & \\
\hline & Atemwegsinfektionen & e16 \\
\hline 7.1. & Betalaktamantibiotika & e16 \\
\hline 7.1.1. & Orale Basispenicilline: & \\
\hline & Penicillin V und Amoxicillin & e16 \\
\hline 7.1.2. & Parenterale Basispenicilline: & \\
\hline & Penicillin G und Ampicillin & e16 \\
\hline 7.1.3. & $\begin{array}{l}\text { Aminopenicillin-Betalaktamaseinhibitor- } \\
\text { Kombinationen }\end{array}$ & e16 \\
\hline 7.1.4. & Oralcephalosporine & e16 \\
\hline 7.1.5. & Parenterale Cephalosporine & e17 \\
\hline 7.1.6. & Ertapenem & e17 \\
\hline 7.1.7. & Pseudomonaswirksame Betalaktame & e18 \\
\hline 7.2. & Tetracycline: Doxycyclin & e18 \\
\hline 7.3. & Makrolide und Azalide & e18 \\
\hline 7.4. & Lincosamide: Clindamycin & e19 \\
\hline 7.5. & Fluorchinolone & e19 \\
\hline 7.5.1. & Levofloxacin und Moxifloxacin & e19 \\
\hline 7.5.2. & Ciprofloxacin & e20 \\
\hline 7.6. & Oxazolidinone: Linezolid & e20 \\
\hline 7.7. & Influenzaviruswirksame Virustatika & e20 \\
\hline 7.8. & Aciclovir & e21 \\
\hline 8. & $\begin{array}{l}\text { Symptomatik und Befunde bei } \\
\text { unteren Atemwegsinfektionen }\end{array}$ & e21 \\
\hline 8.1. & Symptomatik & e21 \\
\hline 8.2. & Untersuchung & e22 \\
\hline 9. & $\begin{array}{l}\text { Behandlung Non-CAP: akute Bronchitis, } \\
\text { Influenzainfektion, andere }\end{array}$ & \\
\hline & respiratorische Virusinfektionen & e22 \\
\hline 9.1. & Akute Bronchitis & e22 \\
\hline 9.2. & Influenzainfektion & e23 \\
\hline 9.3. & Andere respiratorische Virusinfektionen & e24 \\
\hline 10. & Akute Exazerbation der COPD (AECOPD) & e24 \\
\hline 10.1 . & Definition der AECOPD & e24 \\
\hline 10.2. & Ätiologie der AECOPD & e24 \\
\hline 10.3. & Klinische Symptomatik der AECOPD & e25 \\
\hline 10.4 . & Mikrobiologische Diagnostik der AECOPD & e26 \\
\hline 10.5. & $\begin{array}{l}\text { Indikation zur antimikrobiellen Therapie } \\
\text { bei AECOPD }\end{array}$ & e26 \\
\hline 10.5.1. & Pathogenetische Überlegungen zur & \\
\hline & Therapieindikation bei AECOPD & e26 \\
\hline 10.5.2. & Begründung der Therapieempfehlung & e27 \\
\hline 10.6. & $\begin{array}{l}\text { Auswahl der antimikrobiellen Therapie } \\
\text { bei AECOPD }\end{array}$ & e28 \\
\hline 10.7. & $\begin{array}{l}\text { Verlauf der antimikrobiellen Therapie } \\
\text { bei AECOPD }\end{array}$ & e29 \\
\hline
\end{tabular}




\begin{tabular}{|c|c|c|}
\hline \multicolumn{3}{|l|}{ Inhalt } \\
\hline 11. & Risikostratifizierung der CAP & e30 \\
\hline 11.1. & Entscheidung zur stationären Einweisung & $\mathrm{e} 30$ \\
\hline 11.2. & $\begin{array}{l}\text { Entscheidung zur Aufnahme auf eine Intensivstation (ITS), } \\
\text { Intermediärstation bzw. Station mit intensivierter } \\
\text { Überwachung }\end{array}$ & $\mathrm{e} 30$ \\
\hline 11.3 & Einteilung der CAP & e32 \\
\hline 12. & Ambulantes Management der CAP & e32 \\
\hline 12.1. & CAP bei ambulanten Patienten ohne Risikofaktoren & e32 \\
\hline 12.1.1. & $\begin{array}{l}\text { Erregerspektrum bei ambulanten CAP-Patienten } \\
\text { ohne Risikofaktoren }\end{array}$ & e32 \\
\hline 12.1.2. & Diagnostik bei ambulanten Patienten ohne Risikofaktoren & e33 \\
\hline 12.1.3. & $\begin{array}{l}\text { Die bei ambulanten CAP-Patienten } \\
\text { isikofaktoren }\end{array}$ & e33 \\
\hline 12.1.4. & Verlauf bei ambulanten CAP-Patienten ohne Risikofaktoren & e33 \\
\hline 12.2. & CAP bei ambulanten Patienten mit Risikofaktoren & e34 \\
\hline 12.2.1. & $\begin{array}{l}\text { Erregerspektrum bei ambulanten CAP-Patienten } \\
\text { mit Risikofaktoren }\end{array}$ & e34 \\
\hline 12.2.2. & $\begin{array}{l}\text { Diagnostik bei ambulanten CAP-Patienten } \\
\text { mit Risikofaktoren }\end{array}$ & e34 \\
\hline \multirow{2}{*}{$\begin{array}{l}12.2 .3 \\
12.2 .4\end{array}$} & Therapie bei ambulanten CAP-Patienten mit Risikofaktoren & e34 \\
\hline & ten CAP-Patienten mit Risikofaktoren & e35 \\
\hline 13. & Management bei hospitalisierten CAP-Patienten & e35 \\
\hline 13.1. & Erregerspektrum bei hospitalisierten CAP-Patienten & e35 \\
\hline 13.2. & Diagnostik bei hospitalisierten CAP-Patienten & e36 \\
\hline \multirow{2}{*}{$\begin{array}{l}13.3 . \\
13.4\end{array}$} & Therapie bei hospitalisierte & e36 \\
\hline & Verlauf bei hospitalisierten CAP-Patienten & e39 \\
\hline \multirow[t]{2}{*}{14.} & Management der schweren ambulant erworbenen & \\
\hline & Pneumonie (schwere CAP) & e40 \\
\hline \multirow[t]{2}{*}{14.1} & Erregerspektrum der schweren ambulant erworbenen & \\
\hline & Pneumonie (sCAP) & $\mathrm{e} 40$ \\
\hline \multirow[t]{2}{*}{14.2} & Diagnostik bei schwerer ambulant erworbener & \\
\hline & Pneumonie (sCAP) & e41 \\
\hline \multirow[t]{2}{*}{14.3.} & Therapie der schweren ambulant erworbenen & \\
\hline & & $\mathrm{e} 42$ \\
\hline 15. & Therapieversagen bei CAP & e45 \\
\hline 15.1. & Häufigkeit und Ursachen des Therapieversagens & $\mathrm{e} 45$ \\
\hline 15.2. & Diagnostisches Vorgehen & e45 \\
\hline 15.3. & Antibiotikatherapie bei Therapieversagen & e46 \\
\hline
\end{tabular}

\section{Zusammenfassung}

$\nabla$

Definition: Inhalt der Leitlinie sind Epidemiologie, Diagnostik, Therapie und Management von akuten unteren Atemwegsinfektionen (akute Bronchitis, akute Exazerbation einer chronischen Bronchitis, akute virale Atemwegsinfektionen durch Influenzaund Non-Influenzaviren) mit Schwerpunkt der ambulant erworbenen Pneumonie (CAP - englisch: community-acquired pneumonia), definiert als akute mikrobielle Infektion des Lungenparenchyms des erwachsenen Patienten ohne Abwehrschwäche und unter Ausschluss einer im Krankenhaus bzw. innerhalb der ersten vier Wochen nach Entlassung erworbenen Pneumonie (Kap. 2).

Epidemiologie: Die Daten des Bundesinstituts für Qualitätssicherung dokumentieren jährlich etwa 200000 Patienten, die wegen einer CAP in Deutschland im Krankenhaus behandelt werden. Die Gesamthäufigkeit der CAP in Deutschland kann auf 400000 bis 600000 Patienten pro Jahr geschätzt werden. Die Letalität liegt bei stationär behandelten Patenten bei $13-14 \%$, bei ambulant behandelten Patienten ist sie mit $<1 \%$ dagegen gering (Kap. 3 ).

Erregerspektrum: Das Erregerspektrum der CAP weist in Abhängigkeit regionaler, saisonaler, epidemiologischer und demografischer Faktoren große Variationen auf, die durch klinische und pathophysiologische Parameter zusätzlich modifiziert werden. In
Inhalt

16. Besondere Verlaufsformen der CAP

16.1. Pleuraerguss

16.2. Aspirationspneumonie

16.3. Retentionspneumonie

16.4. Lungenabszess

16.5. Pseudo-Therapieversager durch nichtinfektiöse Lungenerkrankungen, die initial wie eine Pneumonie imponieren

17. Besonderheiten der Therapie der CAP bei bekanntem Erreger

17.1. Legionellen

17.2. Chlamydien und Mykoplasmen

17.3. Ambulant erworbener methicillin-resistenter Staphylococcus aureus

17.4. Pseudomonas aeruginosa

17.5. Coxiella burnetii

18. Prävention der CAP

18.1. Influenzavirus-Impfung

18.2. Pneumokokken-Impfung

18.3. Sonstige präventive Maßnahmen

19. Pharmakoökonomische Bewertung der Evidenzlage zur CAP

20. CAP als terminales Ereignis bei hohem

Lebensalter und/oder schwerer fortgeschrittener Komorbidität

21. Anhang

21.1. Autoren der Leitlinie

21.2. Zur Konsensuskonferenz am 9. 12. 2008 eingeladene und vertretene Fachgesellschaften und Einrichtungen

21.3. Teilnehmer der Konsensuskonferenz

21.4. Erklärung über mögliche Interessenkonflikte

21.5. Abkürzungsverzeichnis

22. Literaturverzeichnis

Die nach der Literaturstelle in Klammern gesetzte Ziffer mit Buchstaben bezieht sich auf die Evidenzbewertung nach Oxford Centre of Evidence Based Medicine (1999).

Deutschland wurde durch die Daten von CAPNETZ die herausragende Bedeutung von S. pneumoniae als Haupterreger der CAP bestätigt. Deutlich seltener sind Infektionen durch M. pneumoniae, H. influenzae, Enterobacteriaceae, Legionella spp., S. aureus oder respiratorische Viren (Kap. 4).

Erregerspezifische Variable: In der Regel ist die Antibiotikatherapie der CAP empirisch. Faktoren wie Grunderkrankung, Alter, Antibiotikavortherapie u.a. sind mit einem gehäuften Auftreten bestimmter Erreger bzw. mit einem besonderen Erregerspektrum assoziiert, die bei der Auswahl geeigneter Antibiotika berücksichtigt werden sollten. Die Spezifität dieser Assoziation ist gering. Unter therapeutischen Aspekten ist die Definition von Risikofaktoren für eine Pneumonie durch $P$. aeruginosa von Bedeutung, dieser Erreger ist jedoch in Deutschland bei CAP sehr selten und nur bei wenigen Patienten mit schwerer CAP empirisch zu berücksichtigen (Kap. 4).

Resistenz: Antibiotikaresistenzen haben in den letzten Jahren bei den klassischen Erregern von unteren Atemwegsinfektionen wie S. pneumoniae oder H. influenzae sowohl in Deutschland, Europa als auch weltweit zugenommen. In Deutschland spielt die Penicillin-Resistenz der Pneumokokken zur Zeit eine untergeordnete Rolle. Die Makrolidresistenz der Pneumokokken hat dagegen eine höhere klinische Relevanz. Infektiologische Überwachungsund Verlaufsuntersuchungen sind notwendig, um die Bedeutung der Resistenzentwicklung abschätzen zu können (Kap. 5). 
Mikrobiologische Diagnostik: Ausmaß und Intensität der Diagnostik bzw. Ausbeute und klinische Relevanz mikrobiologischer Befunde orientieren sich am klinischen Schweregrad der CAP. Die Daten bestimmen die lokale Kleinraumepidemiologie und bilden zusammen mit überregional aus epidemiologischen Studien erhobenen Befunden die Basis zur rationalen Formulierung empirischer Therapieempfehlungen. Die Durchführung von epidemiologischen Untersuchungen wird dringend empfohlen (Kap. 6).

Klinische Symptome und Befunde einer unteren Atemwegsinfektion: Es gibt keine Symptom- bzw. Befundkonstellation mit einer ausreichenden Aussagekraft, um die Diagnose CAP klinisch stellen zu können. Der Anfertigung einer Röntgenthorax-Aufnahme kommt bei einem lokalisierten Auskultationsbefund, bei Vorliegen von Begleiterkrankungen bzw. Vitalfunktionsstörungen oder aus differenzialdiagnostischen und klinischen Erwägungen eine wichtige Steuerungsfunktion zur Differenzierung von zwei Krankheitsentitäten zu: Vorliegen einer CAP bzw. einer akuten unteren Atemwegsinfektion (Non-CAP). Bei Patienten mit NonCAP werden folgende Erkrankungen unterschieden: akute Bronchitis, akute Exazerbation einer chronischen Bronchitis (AECOPD) sowie andere virale Infektionen (z.B. Influenzainfektion (Kap. 8) (Empfehlungsgrad B).

Management bei akuten unteren Atemwegsinfektionen: Bei Patienten mit akuter Bronchitis ohne chronisch obstruktive Lungenerkrankung sollte symptomatisch ohne antimikrobielle Substanzen behandelt werden (Empfehlungsgrad A). Interventionsstrategien zur Vermeidung unnötiger Antibiotikaverordnungen werden empfohlen (Kap. 9).

Bei Vorliegen einer Influenzainfektion sind antivirale Substanzen nicht generell zu empfehlen, da die Diagnose nur bei einer aktuellen Influenzaepidemie mit ausreichender Sicherheit klinisch zu stellen ist und den nicht unbeträchtlichen Therapiekosten und der Möglichkeit einer Resistenzselektion eine Verkürzung der Krankheitsdauer um höchstens 1,5 Tage gegenübersteht. Bei Hochrisikopatienten und bei schwerem Verlauf kann die Gabe eines geeigneten Virustatikums erwogen werden (Kap. 9) (Empfehlungsgrad D).

Für die Therapie einer Varizellen-Zoster-Virus- oder Herpes-simplex-Virus-Infektion steht Aciclovir zur Verfügung.

Akute Exazerbation der chronischen Bronchitis (AECOPD): Schwerpunkt dieser Leitlinie ist die antibakterielle Behandlung der AECOPD. Annähernd die Hälfte aller AECOPD werden durch infektiöse Ursachen ausgelöst, wobei nach neueren Untersuchungen Viren die führende Ursache sind. Die häufigsten bakteriellen Erreger sind H. influenzae, S. pneumoniae, M. catarrhalis, Enterobacteriaceae und P. aeruginosa (Kap. 10.2).

Eine mikrobiologische Sputumuntersuchung wird nur bei Patienten mit schwerem Verlauf, mit häufigen $(>2)$ Exazerbationen pro Jahr oder bei Verdacht auf multiresistente Erreger empfohlen (Kap. 10.4) (Empfehlungsgrad C).

Die Indikation zur Antibiotikatherapie bei AECOPD ist umstritten. Bei Patienten mit leichter AECOPD, die ambulant behandelt werden können, wird sie nur empfohlen bei zu Grunde liegender schwerer COPD und Vorliegen von purulentem Sputum. Hospitalisierte Patienten sollten ebenfalls bei Vorliegen von purulentem Sputum behandelt werden. Wurde die Serumkonzentration von Procalcitonin bestimmt, kann bei einem Wert $<0,1 \mathrm{ng} / \mathrm{ml}$ auf eine Antibiotikagabe verzichtet werden. Patienten mit einer schweren AECOPD, die auf einer ITS behandelt werden, sollten generell eine antimikrobielle Therapie erhalten (Kap. 10.5) (Empfehlungsgrad B).

Für Patienten mit leichter AECOPD (ambulante Behandlung) ist ein Aminopenicillin ohne Betalaktamaseinhibitor das Mittel der Wahl. Alternativen sind Makrolide und Doxycyclin (Empfehlungsgrad C).

Bei mittelschwerer oder schwerer AECOPD (hospitalisierte Patienten) wird ein Aminopenicillin mit Betalaktamaseinhibitor oder ein parenterales Cephalosporin der Gruppe II oder III empfohlen. Alternativen bestehen mit den pneumokokkenwirksamen Fluorchinolonen (Empfehlungsgrad C).

Patienten mit bekannter Kolonisation durch P. aeruginosa, Bronchiektasen oder maschineller Beatmung sollten eine pseudomonaswirksame Therapie (Acylureidopenicillin plus Betalaktamaseinhibitor, pseudomonaswirksames Carbapenem, pseudomonaswirksames Cephalosporin oder pseudomonaswirksames Fluorchinolon) erhalten (Kap. 10.6) (Empfehlungsgrad C).

Die Therapiedauer sollte 7 Tage betragen, für neuere Substanzen sind kürzere Therapiezeiten möglich (Kap. 10.7) (Empfehlungs$\operatorname{grad}$ C).

Management der CAP: Das Management der CAP umfasst die Einschätzung des individuellen Risikos eines Patienten für krankheitsbedingte Komplikationen und der Pneumonie-assoziierten Sterblichkeit, die Beurteilung seiner sozialen Situation, die Erfassung individueller Risikofaktoren für bestimmte Erreger bzw. Erregerspektren, die Antibiotikatherapie, die Festsetzung von Verlaufsuntersuchungen und der Dauer der Therapie, die Bestimmung der notwendigen Dauer des Krankenhausaufenthaltes sowie das Vorgehen bei Therapieversagen und bei besonderen Verlaufsformen.

Krankenhauseinweisung: Die Krankenhauseinweisung beruht auf dem klinischen Urteil des Arztes. Diese Entscheidung kann objektiviert werden durch die Verwendung des CRB-65-Index, bei einem Wert über 0 sollte die Notwendigkeit einer Einweisung erwogen werden (Kap. 11.1) (Empfehlungsgrad B).

Entscheidung zur Aufnahme auf eine Intensivstation (ITS), Intermediärstation bzw. Station mit intensivierter Überwachung: Wesentlich für die Entscheidung zu einer intensivierten Überwachung (ITS, Intermediärstation oder ähnliche Einrichtungen) ist die klinische Einschätzung durch den behandelnden Arzt, modifiziert durch lokale strukturelle Gegebenheiten. Zur Unterstützung und Absicherung dieser Entscheidung wird die Verwendung des modifizierten ATS-Scores, evtl. des CRB-65-Scores empfohlen (Kap. 11.2) (Empfehlungsgrad B).

Einteilung der CAP: Die Einteilung der CAP erfolgt unter Zuhilfenahme der genannten Scoresysteme in die Risikogruppen leichtgradige CAP mit und ohne Risikofaktoren (Management im ambulanten Bereich möglich), mittelschwere CAP (Management im Krankenhaus auf Normalstation) und schwergradige CAP mit und ohne Indikation für eine empirische antipseudomonale Therapie (Management im Krankenhaus auf einer Überwachungsoder Intensivstation) (Kap. 11.3).

Ambulantes Management der CAP (aCAP): CAP-Patienten, bei denen eine Behandlung ambulant durchgeführt wird, werden in zwei Gruppen eingeteilt: Patienten ohne und Patienten mit den Risikofaktoren Antibiotikavortherapie, chronische internistische und neurologische Begleiterkrankungen oder Herkunft aus ei- 
nem Pflegeheim, da diese Faktoren Einfluss auf die Ätiologie und das diagnostische und therapeutische Vorgehen besitzen (Kap. 12) (Empfehlungsgrad A).

Die Diagnostik bei aCAP-Patienten sollte sich auf eine gründliche klinische Untersuchung, Anfertigen einer Röntgenthorax-Aufnahme und einer Laboruntersuchung zur Erfassung wichtiger biologischer Parameter begrenzen. Eine mikrobiologische Diagnostik wird nicht empfohlen. Bei aCAP-Patienten mit Risikofaktoren sollte die Labordiagnostik entsprechend der Risikokonstellation erweitert und eine mikrobiologische Diagnostik (z.B. aus Sputum) erwogen werden (Kap. 12.1 .2 und 12.2.2) (Empfehlungsgrad A).

Als Therapie der Wahl für die unkomplizierte aCAP im ambulanten Bereich bei Patienten ohne Risikofaktoren wird eine Monotherapie mit einem hochdosierten Aminopenicillinpräparat empfohlen, bei Penicillinunverträglichkeit kann mit einem neueren Makrolid oder Doxycyclin behandelt werden. Fluorchinolone werden bei dieser Patientengruppe nicht empfohlen (Kap. 12.1.3) (Empfehlungsgrad A).

Als Therapie der Wahl für die aCAP bei Patienten mit Risikofaktoren wird eine Monotherapie mit einer hochdosierten Aminopenicillin/Betalaktamaseinhibitor-Kombination empfohlen. Bei Therapieversagen oder Penicillinunverträglichkeit kann ein pneumokokkenwirksames Fluorchinolonen eingesetzt werden. Bei Verdacht auf eine Infektion durch Mykoplasmen, Chlamydien oder Legionellen kann auch eine Kombinationstherapie in Form einer Betalaktam-Makrolid-Kombination durchgeführt werden (Kap. 12.2.3) (Empfehlungsgrad A).

Die antibiotische Therapie kann 48-72 h nach klinischer Besserung mit Entfieberung, jedoch frühestens nach 5 Tagen beendet werden. Eine Therapiedauer von mehr als 7 Tagen ist im Regelfall nicht erforderlich (Empfehlungsgrad A).

Eine gute häusliche Versorgung und engmaschige Überwachung der aCAP-Patienten, die Gewährleistung einer ausreichenden Oxygenierung, einer stabilen Kreislaufsituation und einer sicheren Medikamenteneinnahme und -resorption sind Voraussetzungen für eine ambulante Therapie. Im Zweifelsfall sollte eine kurzfristige Hospitalisierung erwogen werden. Eine Reevaluation der Patienten nach $48(-72) \mathrm{h}$ ist notwendig (Kap. 12.2.4) (Empfehlungsgrad B).

Management der CAP im Krankenhaus: Die Diagnostik bei hospitalisierten CAP-Patienten umfasst neben der Anamnese und der körperlichen Untersuchung die konventionelle Röntgenaufnahme des Thorax in zwei Ebenen, laborchemische und Blutbilduntersuchungen mit Differenzialblutbild, Bestimmung des C-reaktiven Proteins oder des Procalcitonins zur Verlaufsbeurteilung sowie die Analyse der arteriellen oder kapillären Blutgase bzw. der Sauerstoffsättigung (Kap. 13.2) (Empfehlungsgrad A).

Eine antimikrobielle Therapie sollte so früh wie möglich eingeleitet werden. Diagnostische Maßnahmen dürfen den Therapiebeginn nicht verzögern (Kap. 13.3) (Empfehlungsgrad B).

Als gesicherte adjuvante Behandlungsmaßnahmen bei hospitalisierten CAP-Patienten gelten eine Thromboseprophylaxe und eine frühzeitige Mobilisierung und Atemtherapie; empfohlen wird zusätzlich die Verabreichung von Sauerstoff bei Patienten mit arterieller Hypoxämie (Kap. 13.3) (Empfehlungsgrad A).

Kriterien zur Entlassung von CAP-Patienten nach klinischer Stabilisierung sind konstant stabile Vitalzeichen, Fähigkeit zur oralen Nahrungsaufnahme, sichere orale Medikamenteneinnahme, normaler Bewusstseinszustand sowie das Fehlen anderer klinischer oder psychosozialer Gründe für eine stationäre Behand- lung. Zur Beurteilung des klinischen Zustandes wird eine kurzfristige klinische Verlaufskontrolle 3 bis 7 Tage nach Entlassung empfohlen (Kap. 13.4) (Empfehlungsgrad B).

Eine radiologische Abschlussuntersuchung frühestens 2 Wochen nach Ende der Antibiotikatherapie sollte insbesondere bei aktiven Rauchern und älteren Patienten (> 65 Jahre) bzw. Patienten mit schweren Begleiterkrankungen zum Ausschluss von nichtinfektiösen Lungeninfiltraten (z. B. Lungenkarzinom) erwogen werden (Kap. 13.4) (Empfehlungsgrad B).

Management der CAP im Krankenhaus auf einer Normalstation: Die klinische Bedeutung mikrobiologischer Untersuchungen bei CAP-Patienten auf einer Normalstation hinsichtlich Therapieentscheidung bzw. Prognose ist ungesichert. Empfohlen werden die Entnahme von zwei Blutkulturen (Empfehlungsgrad C), eine diagnostische Pleurapunktion (Empfehlungsgrad B), die Durchführung des L. pneumophila-Antigentest aus Urin (Empfehlungsgrad B) sowie eine mikrobiologische Sputumuntersuchung bei nicht antibakteriell vorbehandeltem Patienten mit purulentem Sputum und Gewährleistung der notwendigen logistischen Voraussetzungen (Kap. 13.2) (Empfehlungsgrad B).

Bei CAP-Patienten, die auf einer Normalstation behandelt werden, wird eine Kombinationstherapie bestehend aus einem nicht pseudomonasaktiven Betalaktamantibiotikum plus einem Makrolid empfohlen. Eine Monotherapie mit einem Betalaktamantibiotikum ist ebenfalls möglich. Eine Alternative stellt die Therapie mit einem pneumokokkenwirksamen Fluorchinolon dar (Kap. 13.3) (Empfehlungsgrad A).

In den ersten Tagen im Krankenhaus sollte die Verabreichung der Antibiotika parenteral erfolgen. Ausnahmen bestehen - je nach klinischer Konstellation - für Fluorchinolone aufgrund ihrer hohen oralen Bioverfügbarkeit sowie für die orale Gabe von Makroliden im Rahmen einer Kombinationstherapie mit gleichzeitiger parenteraler Verabreichung der Betalaktamantibiotika (Kap. 13.3) (Empfehlungsgrad B).

Bei einer parenteralen Initialtherapie sollte eine frühe Therapieumstellung auf eine orale Therapie angestrebt werden (Kap. 13.3) (Empfehlungsgrad A).

Die antibiotische Therapie kann 48-72 h nach klinischer Besserung mit Entfieberung, jedoch frühestens nach 5 Tagen beendet werden. Eine Therapiedauer von mehr als 7 Tagen ist im Regelfall nicht erforderlich (Kap. 13.3) (Empfehlungsgrad A).

Management der CAP im Krankenhaus auf einer Intensivstation, Intermediärstation bzw. unter intensivierter Überwachung (sCAP): Patienten mit sCAP werden in solche ohne und mit Indikation für eine gegen $P$. aeruginosa wirksame empirische Therapie unterteilt. Das Auftreten einer Pneumonie durch P. aeruginosa ist in Deutschland selten und nur bei Vorliegen von Risikofaktoren (insbesondere schwere strukturelle Lungenerkrankung in Kombination mit Antibiotikavortherapien/vorangegangener Hospitalisierung) anzunehmen. (Kap. 4, Kap. 14.1) (Empfehlungsgrad C). Der mikrobiologischen Diagnostik kommt bei sCAP-Patienten eine größere Bedeutung zu, da sowohl die diagnostische Ausbeute als auch die klinische Relevanz höher ist. Folgende mikrobiologische Diagnostik wird empfohlen: Blutkulturen, Sputum oder Trachealsekret, Pleurapunktion, $L$. pneumophila-Antigentest aus Urin, Bronchoskopie (BAL, geschützte Bürste) bei Verdacht auf Vorliegen eines seltenen Erregers oder einer Bronchusstenose. Eine Verbesserung der Prognose der sCAP durch routinemäßige bronchoskopische Diagnostik konnte bis jetzt nicht nachgewiesen werden (Kap. 14.2) (Empfehlungsgrad B). 
Da das Risiko eines ungünstigen Ausgangs durch eine inadäquate Therapie wegen Vorliegen einer Resistenz bei sCAP besonders hoch ist, sCAP-Patienten unter einer Monotherapie in einzelnen Studien eine höhere Letalität aufwiesen, sowie zur Erfassung des breiten bakteriellen Erregerspektrums der sCAP sollte grundsätzlich am Konzept der Kombination von Betalaktamantibiotika mit Nicht-Betalaktamantibiotika festgehalten werden (Empfehlungs$\operatorname{grad} B$ ).

Bei sCAP ohne Indikation für eine empirische Therapie gegen $P$. aeruginosa wird eine Kombinationstherapie mit einem Breitspektrum-Betalaktamantibiotikum und einem Makrolid empfohlen. Die Monotherapie mit einem pneumokokkenwirksamen Fluorchinolon ist eine mögliche Alternative für Patienten ohne septischen Schock bzw. ohne invasive Beatmung (Kap. 14.3) (Empfehlungsgrad B).

Bei Patienten mit Indikation für eine empirische Therapie gegen $P$. aeruginosa wird eine Kombinationstherapie mit einem pseudomonaswirksamen Betalaktamantibiotikum und einem pseudomonaswirksamen Fluorchinolon empfohlen. Die Kombination aus einem pseudomonaswirksamen Betalaktamantibiotikum mit einem Aminoglykosid (für 3 Tage) und einem Makrolid ist eine mögliche Alternative. Nach klinischer Besserung und/oder Erregernachweis mit Empfindlichkeitsprüfung soll im Regelfall eine Deeskalation auf eine Monotherapie erfolgen (Kap. 14.3) (Empfehlungsgrad B).

Eine Therapiedauer von 8-10 Tagen bzw. 5 Tagen nach Entfieberung wird bei Patienten ohne Komplikationen empfohlen. Bei nachgewiesener Infektion durch $P$. aeruginosa sollte die Therapiedauer 8-15 Tage betragen (Empfehlungsgrad B).

Therapieversagen: Aus prognostischer und therapeutischer Sicht ist die Unterteilung des primären Therapieversagens in die progrediente Pneumonie und die klinisch verzögert ansprechende Verlaufsform sinnvoll. Eine progrediente Pneumonie ist definiert als klinische Zustandsverschlechterung mit Entwicklung einer respiratorischen Insuffizienz und/oder einer schweren Sepsis oder eines septischen Schockes trotz empirischer antimikrobieller Therapie, sie entwickelt sich bei $5-10 \%$ aller hospitalisierten Patienten. Eine verzögert ansprechende Pneumonie ist definiert als fehlendes Erreichen klinischer Stabilität nach $72 \mathrm{~h}$ antimikrobieller Therapie. Die möglichen Ursachen für ein Therapieversagen können infektiöser oder nicht-infektiöser Natur sein, wobei in $2 / 3$ infektiologische Probleme vorliegen (Kap. 15).

Das diagnostische Vorgehen bei Therapieversagen ist komplex und beinhaltet neben einer gründlichen Anamnese, körperlichen Untersuchung, Berücksichtigung epidemiologischer Daten und Überprüfung der bisherigen Antibiotikaauswahl und -dosierung den Ausschluss nichtinfektiologischer Ursachen durch geeignete bildgebende Verfahren bzw. den Ausschluss einer Immunsuppression und von extrapulmonalen Infektionen. Ferner können mikrobiologische Untersuchungen aus Sputum, Trachealsekret, bronchoalveolärer Lavage, Blut, Urin, Pleurapunktat bzw. Lungenbiopsat notwendig werden - in Abhängigkeit von der klinischen Konstellation auch auf seltene Erreger wie Mykobakterien und Pilze (Kap. 15.2) (Empfehlungsgrad B).

Bei der progredienten Pneumonie stehen die Überwachung und rasche Stabilisierung der Organfunktionen sowie die prompte parenterale Verabreichung einer adäquaten empirischen antibiotischen Kombinationstherapie entsprechend der Empfehlungen für eine sCAP im Vordergrund. Als Therapieoptionen bei Therapieversagen kommen in Abhängigkeit von der Klinik eine Umstellung auf eine Antibiotikatherapie gemäß den Empfehlungen dieser Leitlinie im Falle einer nicht Leitlinien-gerechten initialen kalkulierten Behandlung, die Überprüfung der Antibiotikatherapie auf bestehende Erregerlücken im antimikrobiellen Spektrum, eine parenterale Verabreichung bzw. eine Kombinationstherapie in Betracht. Eine Wirksamkeit gegen S. pneumoniae sollte auf jeden Fall auch nach der Umstellung beibehalten und AntibiotikaKombinationen mit einem breiten antimikrobiellen Spektrum unter Einschluss von P. aeruginosa, S. aureus (MRSA), Legionella spp. und Anaerobiern verabreicht werden (Kap. 15.3) (Empfehlungsgrad B).

Pleuraerguss: Die Risikostratifizierung erfolgt anhand der Kriterien Ergussmenge, Bakteriologie und pH der Ergussflüssigkeit. Folgende Optionen stehen in Abhängigkeit hiervon zur Verfügung: Keine Intervention, Entlastungspunktion, Anlage einer Thoraxsaugdrainage ohne lokale Fibrinolyse, Anlage einer Thoraxsaugdrainage mit lokaler Fibrinolyse, Video-assistierte Thorakoskopie sowie Thorakotomie (Kap. 16.1) (Empfehlungsgrad C).

Aspirationspneumonie: Die Aspiration stellt einen Risikofaktor für Enterobacteriaceae dar, sodass eine kalkulierte Therapie diese Erreger berücksichtigen muss. Da eine ätiologische Rolle von anaeroben Bakterien nicht grundsätzlich ausgeschlossen ist, sollte ein Betalaktam-Antibiotikum mit einem Betalaktamaseinhibitor kombiniert werden. Alternativ können eine Kombination aus einem Cephalosporin mit Clindamycin, das Fluorchinolon Moxifloxacin oder ein Carbapenem eingesetzt werden (Kap. 16.2) (Empfehlungsgrad D)

Lungenabszess: Bakterielle Mischinfektionen sind bei Lungenabszessen häufig, in 20-90\% werden obligate Anaerobier nachgewiesen. Andere Ätiologien wie Pilze (z.B. nekrotisierende Aspergillose) und Echinococcus spp. müssen jedoch in Betracht gezogen werden.

Die Bronchoskopie ist bei Verdacht auf Lungenabszess unerlässlich, um eine bronchiale Obstruktion auszuschließen und ggf. auch zu beseitigen. Eine Ableitung des Sekretes ist notwendig. Die Durchführung eines CT-Thorax wird empfohlen (Empfehlungsgrad $C$ ).

Zur Therapie des Lungenabszesses wird ein Aminopenicillin zusammen mit einem Betalaktamasehemmer bzw. die Kombination eines Cephalosporins der Gruppe 2 oder 3 mit Clindamycin empfohlen (Kap. 16.4) (Empfehlungsgrad B).

Besondere Erreger: Fluorchinolone sind Mittel der Wahl bei der Legionellenpneumonie (Kap. 17.1).

Gegenüber Mykoplasmen und Chlamydien sind Makrolide, Fluorchinolone und Tetracycline wirksam (Kap. 17.2).

Beim Nachweis von MRSA aus respiratorischen Sekreten von Patienten mit CAP ist zwischen den häufigen nosokomial erworbenen Erregern und den in Deutschland bisher sehr seltenen, „echten“ ambulant erworbenen MRSA (c-MRSA) zu unterscheiden. Bei nachgewiesener MRSA-Pneumonie sollte bei intakter Nierenfunktion mit Vancomycin (bei $\mathrm{MHK}<2 \mathrm{mg} / \mathrm{l}$ ), alternativ mit dem Oxazolidinon Linezolid behandelt werden. Bei CAP durch Methicillin-sensible $S$. aureus (MSSA) besitzt das Flucloxacillin als Therapie die höchste Wirksamkeit (Kap. 17.3).

Bei einer gesicherten Pneumonie durch $P$. aeruginosa wird zur Vermeidung einer inadäquaten empirischen Therapie bei Infektion durch resistente Erreger bis zum Vorliegen des Resistogramms eine Kombinationstherapie aus zwei pseudomonaswirksamen Antibiotika empfohlen. Als Alternativen stehen Kombinationen 
von einem pseudomonaswirksamen Betalaktamantibiotikum mit einem pseudomonaswirksamen Fluorchinolon oder einem Aminoglykosid zur Verfügung (Kap. 17.4) (Empfehlungsgrad D). Die empfohlenen Antiinfektiva bei Pneumonie durch Coxiella burnetii (Q-Fieber) sind Tetracycline (Kap. 17.5).

Prävention der CAP: Studien und Metaanalysen zeigen eine ausreichende Schutzwirkung der Influenza-Vakzine für respiratorische Erkrankungen, für Pneumonien, für Hospitalisation und für einen tödlichen Ausgang. Die absolute Risikoreduktion ist dabei zwei- bis fünfmal höher bei Hochrisiko-Gruppen als bei gesunden älteren Personen. Es wird in Übereinstimmung mit der STIKO eine jährliche Influenza-Impfung im Herbst für alle Personen mit einem erhöhten Risiko für Influenza-Komplikationen empfohlen (Kap. 18.1) (Empfehlungsgrad A).

Studien zeigen, dass der 23-valente kapsuläre PneumokokkenPolysaccharid-Impfstoff wirksam invasive Pneumokokkenerkrankungen verhindert. Es wird in Übereinstimmung mit der STIKO eine Pneumokokkenschutzimpfung für alle Personen mit einem erhöhten Risiko für eine Pneumokokkenerkrankung empfohlen (Kap. 18.2) (Empfehlungsgrad A).

Inhalatives Zigarettenrauchen ist als Risikofaktor bekannt. Aufgabe des inhalativen Tabakkonsums sollte daher angestrebt werden (Kap. 18.3) (Empfehlungsgrad A).

Pharmakoökonomie: Die aktuell vorhandenen pharmakoökonomischen Untersuchungen können die Erstellung einer Empfehlung nur bedingt unterstützen, da nur eine kleine Menge relevanter Therapieszenarien abgebildet werden, kaum Head-to-HeadVergleiche von in Deutschland konkurrierenden Therapien vorliegen, die Therapiebedingungen nicht auf deutsche Verhältnisse übertragbar sind, die untersuchten Patientengruppen keine validen Schlussfolgerungen für die Praxis zulassen oder die gewählte Methodik intransparent oder im Sinne des Auftraggebers der Studie ausgerichtet ist (Kap. 19).

CAP als terminales Ereignis bei hohem Lebensalter und/oder schwerer fortgeschrittener Komorbidität: Eine Änderung des Therapiezieles im Sinne eines palliativen Behandlungskonzeptes kann auf vielen Ebenen, zum Beispiel durch Verzicht oder durch Initiierung bestimmter medizinischer und pflegerischer Maßnahmen, erfolgen. Zur Identifizierung der Patienten, bei denen eine palliative Behandlung als ärztlich und medizinisch sinnvoll betrachtet wird, ist der Wille des Patienten entscheidend. Eine gewissenhafte klinische und apparative Dokumentation des $\mathrm{Zu}$ stands des Patienten sowie der Entscheidung zu einer palliativen Behandlung wird empfohlen. Für eine angemessene palliative medizinische und pflegerische Versorgung des Patienten ist neben der Berücksichtigung der psychologischen, spirituellen und sozialen Dimension des Leidens im Bereich der physischen Beschwerden eine optimale Symptomenkontrolle wesentlich. Als häufigste Symptome sind Dyspnoe, Fieber, Husten, Schwäche, Schmerzen und neuropsychiatrische Beschwerden mit Verwirrtheit, Agitation und Unruhe zu nennen (Kap. 20).

Planmäßige Überarbeitung: Die Leitlinie hat eine Gültigkeit bis 31.12.2012. Bei neuen, relevanten und anerkannten Erkenntnissen, die im Gegensatz zu Aussagen der Leitlinie stehen, sind umgehende Berichtigungen in den Fachzeitschriften vorgesehen.

\section{Struktur der Leitlinie}

$\nabla$

\subsection{Vorwort}

Im Namen der Paul-Ehrlich-Gesellschaft für Chemotherapie e.V. (PEG), der Deutschen Gesellschaft für Pneumologie und Beatmungsmedizin e.V. (DGP), der Deutschen Gesellschaft für Infektiologie e.V. (DGI) sowie des Kompetenz-Netzwerkes CAPNETZ Deutschland wurde im Jahr 2005 eine gemeinsame Leitlinie über „Ambulant erworbene Pneumonie/untere Atemwegsinfektionen“ publiziert. Die Leitlinien-Arbeitsgruppe setzte sich aus Vertretern der drei beteiligten Fachgesellschaften sowie je einem Vertreter von CAPNETZ und der Arbeitsgemeinschaft Wissenschaftlicher Medizinischer Fachgesellschaften (AWMF) zusammen (s. Kapitel 21.1). Fachlich repräsentierten die Mitglieder die Disziplinen Pneumologie, Infektiologie, Klinische Mikrobiologie, Epidemiologie, Pharmakoökonomie sowie Internistische Intensivmedizin. Die personell identische Arbeitsgruppe war für die geplante und routinemäßige Aktualisierung der Leitlinie verantwortlich.

\subsection{Ziele der Leitlinie}

Ziel der S3-Leitlinie ist die Etablierung von Standards in Diagnostik und Therapie von ambulant erworbenen Pneumonien/unteren Atemwegsinfektionen zum rationalen Einsatz der antimikrobiellen und antiviralen Substanzen, zur Reduktion des Gebrauchs von Antibiotika bei fehlender Indikation und zur Vermeidung eines extensiven Einsatzes von Antibiotika bzw. eines einseitigen Einsatzes von bestimmten Antibiotikaklassen und damit die Vermeidung der Entwicklung von Resistenzen. Dies beinhaltet eine kritische Würdigung der klinischen, radiologischen, mikrobiologischen und virologischen Diagnostik, eine transparente Stadieneinteilung und Risikostratifizierung und die Empfehlung einer risikoadaptierten antimikrobiellen Therapie mit dem Ziel, einen bestmöglichen Behandlungserfolg in Verbindung mit einem auf Wirtschaftlichkeit ausgerichteten Management der Patienten zu ermöglichen. Die Erstellung erfolgte nach den Kriterien der Arbeitsgemeinschaft Wissenschaftlicher Medizinischer Fachgesellschaften e.V. (AWMF) für die Entwicklung einer S3-Leitlinie, um eine nach Evidenz-basierten Kriterien orientierte, hochwertige medizinische Versorgung und gutes ärztliches Handeln im Management ambulant erworbener tiefer Atemwegsinfektionen zu ermöglichen sowie um medizinische Entscheidungen in diesem Kontext auf eine rationale Basis zu stellen.

Die Leitlinie soll dem behandelnden Arzt eine rationale und evidenzbasierte Handlungsanweisung geben, um eine ausreichende, angemessene und wirtschaftliche Therapie dieser Erkrankungen sicherzustellen. Die Leitlinie fokussiert den „Standard“-Patienten und kann daher nicht auf alle Möglichkeiten und spezifischen Fragen eine Antwort geben; sie ist als eine strukturierte Matrix zu verstehen, unter deren Zuhilfenahme medizinische Probleme und Fragen sachgerecht gelöst werden können.

Sie wendet sich an alle niedergelassenen und am Krankenhaus tätigen Ärzte, an Krankenpflegekräfte sowie an Mitarbeiter von Organisationen als auch an alle Akteure, die im Bereich des Gesundheitswesens tätig sind bzw. in direkter oder indirekter Weise in die Behandlung und Betreuung von Patienten mit akuten Atemwegsinfektionen eingebunden sind. Gleichzeitig bildet die Leitlinie eine Grundlage zur Definition und Fortschreibung der externen Qualitätssicherung für die ambulant erworbene Pneumonie nach §137 SGB V. 


\subsection{Erstellung der Leitlinie}

Die Entwicklung der Leitlinie wurde in zwei Stufen durchgeführt. Das Resultat des Entwicklungsprozesses ist eine Leitlinie der Stufe 3 im Kontext des Drei-Stufen-Konzeptes der Arbeitsgemeinschaft Wissenschaftlicher Medizinischer Fachgesellschaften e.V. (s. Tab. 1). Kernpunkt ist ein kombinierter formaler Konsensusfindungsprozess aus nominalem Gruppen- und Konsensusprozess, der multidisziplinär ausgerichtet war.

\subsubsection{Literaturrecherche}

Nach Auswahl und Definition des Leitlinienthemas und Gliederung des Arbeitsprogramms wurden den Autoren Aufgabenbereiche mit einem Koreferenten zugeordnet. Die Literaturrecherche wurde mittels Datenbanken, z.B. Cochrane Library, DIMDILiteraturdatenbanken-Superbases, Medline, NHS-Database PubMed sowie mit der eigenen Handbibliothek, über Internetsuchmaschinen und individueller Suche bei in Frage kommenden Einrichtungen und Organisationen (Universitätsklinika, Forschungseinrichtungen, pharmazeutische Industrie) durchgeführt. Die in Frage kommende Literatur wurde systematisch gesammelt, gesichtet und nach einem einheitlichen Klassifikationsschema bewertet.

Der vorliegenden Aktualisierung liegt eine systematische Literaturrecherche zugrunde, die die neu erschienene Literatur im Zeitraum 02/2004-12/2007 erfasste. Folgende Suchwörter (deutsch und englisch) wurden verwendet: „Bronchitis, Pneumonia, Bronchiectasis, Whooping Cough, Influenza, Legionellosis, Common Cold, Cough, Sputum, Community-Acquired Infections, English, guideline, practice guideline, health planning guidelines, consensus development conference, consensus development conference, nih consensus development conferences, consensus development conferences, nih guidelines, practice guidelines, consensus, statement, meta-analysis, quantitative review, quantitative overview, systematic review, systematic overview, methodologic review, methodologic overview, review, cohort studies, risk, odds ratio, case control, case-control studies, relative risk, incidence, mortality, follow-up studies, mortality, prognosis, predictive course, sensitivity and specificity, sensitivity, diagnosis, diagnostic use, specificity, randomized controlled trial, drug therapy, therapeutic use, randomization."

Die Klassifizierung der Evidenz und des Empfehlungsgrades erfolgte nach dem Oxford Centre of Evidence Based Medicine (1999) (http://www.cebm.net/levels_of_evidence.asp). @ Tab.2 zeigt das Klassifizierungschema für Therapiestudien, für Diagnose-Studien wurde die entsprechend modifizierte Klassifikation des Oxford Centre of Evidence Based Medicine verwendet. Die Literatur wurde von jedem Autor bewertet und mit dem Koreferenten abgeglichen. Sie wurde gleichzeitig durch ein Mitglied der Leitlinien-Arbeitsgruppe verblindet bewertet und abschließend mit der Bewertung der Autoren verglichen. Bei Diskrepanzen wurde ein Konsens innerhalb der Arbeitsgruppe erzielt.

\subsubsection{Formulierung der Empfehlungen}

Die vorliegende Aktualisierung der Leitlinie wurde am 9.1.2008 begonnen und am 17.7.2009 formal abgeschlossen.

Die aktualisierte Fassung der Leitlinie ambulant erworbene Pneumonie wurde nach Literaturrecherche zunächst von den Vertretern der vier beteiligten Fachgesellschaften DGP, PEG, DGI und CAPNETZ Stiftung vorformuliert und die neu eingearbeitete Literatur nach Evidenzlevel und Empfehlungsgrad ( $\bullet$ Tab.2) durch zwei Gutachter unabhängig bewertet. Anschließend wur-
Tab. 1 Drei-Stufen-Konzept der Leitlinienentwicklung der AWMF.

$\begin{array}{ll}\begin{array}{ll}\text { 1. Stufe (S1): } \\ \text { Expertengruppe }\end{array} & \begin{array}{l}\text { Eine repräsentativ zusammengesetzte Exper- } \\ \text { tengruppe der Wissenschaftlichen Medizini- } \\ \text { schen Fachgesellschaften erarbeitet im formel- } \\ \text { len Konsens eine Leitlinie, die vom Vorstand } \\ \text { der Fachgesellschaft verabschiedet wird. }\end{array} \\ \begin{array}{ll}\text { 2.Stufe (S2): } & \text { Vorhandene Leitlinien der Stufe 1 werden in } \\ \text { Formale } & \text { einem der bewährten formalen Konsensusver- } \\ \text { Konsensusfindung } & \text { fahren beraten und als Leitlinien der Stufe 2 } \\ & \text { verabschiedet. Formale Konsensusfindung- } \\ & \text { methoden sind nominaler Gruppenprozess, } \\ & \text { Delphimethode und Konsensuskonferenz. Sie } \\ & \text { enthalten eine Diskussion der Evidenz für die } \\ & \text { verabschiedeten Statements. Für die Durch- } \\ & \text { führung ist die Mitarbeit von Methodikern hilf- } \\ & \text { reich. }\end{array} \\ \begin{array}{l}\text { 3. Stufe (S3): } \\ \text { Deitlinie mit allen }\end{array} & \text { folgende systematische Elemente erweitert: } \\ \text { Elementen } & \text { - logische Analyse (klinischer Algorithmus) } \\ \text { systematischer } & \text { - Evidenz-basierte Medizin } \\ \text { Erstellung } & \text { - Entscheidungsanalyse } \\ & \text { - Outcomeanalyse }\end{array}$

Tab. 2 Klassifizierung der Evidenz: Evidenzlevel (1 - 5) und Empfehlungsgrade (A-D) nach Oxford Centre of Evidence Based Medicine (1999) [6].

\begin{tabular}{|c|c|c|}
\hline $\begin{array}{l}\text { Empfehlungs- } \\
\text { grad }\end{array}$ & $\begin{array}{l}\text { Evidenz- } \\
\text { grad }\end{array}$ & Beschreibung \\
\hline \multirow[t]{3}{*}{ A } & $1 \mathrm{a}$ & $\begin{array}{l}\text { Evidenz durch systematisches Review } \\
\text { randomisierter kontrollierter Studien } \\
\text { (RCT) }\end{array}$ \\
\hline & $1 \mathrm{~b}$ & $\begin{array}{l}\text { Evidenz durch eine geeignet geplante } \\
\text { RCT }\end{array}$ \\
\hline & $1 c$ & Alle-oder-Keiner-Prinzip \\
\hline \multirow[t]{5}{*}{ B } & $2 a$ & $\begin{array}{l}\text { Evidenz durch systematisches Review } \\
\text { gut geplanter Kohortenstudien }\end{array}$ \\
\hline & $2 b$ & $\begin{array}{l}\text { Evidenz durch eine gut geplante } \\
\text { Kohortenstudie/RCT mäßiger } \\
\text { Qualität (z. B. }<80 \% \text { Follow-up) }\end{array}$ \\
\hline & $2 c$ & $\begin{array}{l}\text { Evidenz durch Outcome-Research- } \\
\text { Studien }\end{array}$ \\
\hline & $3 a$ & $\begin{array}{l}\text { Evidenz durch systematisches Review } \\
\text { gut geplanter Fall-Kontrollstudien }\end{array}$ \\
\hline & $3 b$ & Evidenz durch eine Fall-Kontrollstudie \\
\hline C & 4 & $\begin{array}{l}\text { Evidenz durch Fallserien/Kohorten- } \\
\text { und Fall-Kontrollstudien mäßiger } \\
\text { Qualität }\end{array}$ \\
\hline D & 5 & $\begin{array}{l}\text { Expertenmeinung ohne explizite } \\
\text { kritische Bewertung oder basierend } \\
\text { auf physiologischen Modellen, Labor- } \\
\text { forschungsresultaten oder "first } \\
\text { principles“ }\end{array}$ \\
\hline
\end{tabular}

de in einem Delphi-Verfahren diese Arbeitsversion den Autoren zur Überarbeitung vorgelegt, korrigiert und neu formuliert. Dieses Manuskript wurde unter Zurverfügungstellung der relevanten Literatur in einer Konsensuskonferenz am 9.12.2008 (s. Anhang 21.2.) unter Beteiligung aller an der ursprünglichen Leitlinie mitwirkenden Fachgesellschaften überarbeitet, verändert und ergänzt. Mitglieder der Konsensuskonferenz waren Experten auf den Gebieten der Infektiologie, Pneumologie, Intensivmedizin, Anästhesiologie, Allgemeinmedizin, Pharmakologie, Mikrobiologie, Virologie, antibakteriellen Chemotherapie, Epidemiologie, Pharmakoökonomie sowie Qualitätsmanagement. Änderungen und Korrekturen erfolgten in einem sich der Konsensuskon- 
ferenz anschließenden Delphi-Verfahren. Nach Überprüfung und Begutachtung der Leitlinie durch die federführenden Fachgesellschaften wurde die Leitlinie von den Vorständen der vier federführenden sowie allen auf der Konsensuskonferenz vertretenen Fachgesellschaften als offizielle Verlautbarung autorisiert.

\subsection{Finanzierung}

Die Finanzierung der Leitlinien-Erstellung erfolgte über die beteiligten Fachgesellschaften und die CAPNETZ-Stiftung sowie durch Verkauf einer Kurzversion der Leitlinie an einen wissenschaftlichen Verlag. Alle Mitglieder der Arbeitsgruppe arbeiteten ehrenamtlich, eine Vergütung erfolgte nicht. Reisekosten und anderweitige Auslagen wurden entsprechend dem Bundes-Dienstreisegesetz bzw. nach den im Hochschulbereich üblichen Richtlinien abgerechnet. Themen und Inhalte der Leitlinie wurden in keiner Weise beeinflusst. Um eine größtmögliche Unabhängigkeit zu erreichen, wurde ausdrücklich auf eine Finanzierung durch die pharmazeutische Industrie verzichtet.

\subsection{Implementierung/Publikation}

Die Leitlinie „Ambulant erworbene Pneumonie/untere Atemwegsinfektionen“ wird in den Fachzeitschriften „Chemotherapie-Journal“, „Pneumologie“ und als englische Version in einer europäischen Zeitschrift der Fachöffentlichkeit zur Kenntnis gebracht. Eine Kurzversion wird über einen wissenschaftlichen Verlag in den Handel kommen. Eine englische Version und Publikation wird angestrebt, um den wissenschaftlichen Dialog mit den europäischen Fachgesellschaften zu gewährleisten. Die Leitlinie wird im Internet auf den Seiten der AWMF (http://awmf.org) einsehbar sein.

\subsection{Planmäßige Überarbeitung}

Die aktualisierte Leitlinie hat eine Gültigkeit bis 31.12. 2012. Bei neuen, relevanten und anerkannten Erkenntnissen, die im Gegensatz zu Aussagen der Leitlinie stehen, sind umgehende Berichtigungen in den Fachzeitschriften vorgesehen.

\subsection{Prozessqualität}

Untersuchungen über die Bedeutung von Leitlinien in der Medizin weisen darauf hin, dass die Implementierung von Leitlinien die Prognose der Patienten verbessern kann [1,2]. Studien zur Kosteneffektivität von Leitlinien in der Behandlung von Pneumonien zeigen unterschiedliche Effekte. In Abhängigkeit von Alter und Grunderkrankungen und logistischen Bedingungen vor Implementierung sind sowohl Kosteneinsparungen als auch Kostensteigerungen bei Leitlinien-orientierter Behandlung beschrieben worden [1,3]. Günstig beeinflusst wurden Endpunkte wie Dauer des stationären Aufenthaltes, Häufigkeit parenteraler Antibiotikagaben, Dauer parenteraler Antibiotikagaben bzw. Rate an Behandlungsfehlern und Letalität $[1,4,5]$. Diese eignen sich daher als Qualitätsindikatoren für Outcome-Analysen. Nach Einführung und Einsatz in der täglichen Praxis wird ein positiver, kosteneinsparender Effekt der Leitlinie auf die Hospitalisierungsrate von Patienten mit unteren Atemwegsinfektionen, auf die Dauer der stationären Behandlung sowie auf Letalität und Mortalität im weiteren Verlauf erwartet.

\section{Definitionen}

$\nabla$

Schwerpunkt der Leitlinie ist die Epidemiologie, Diagnostik, Therapie und das Management der ambulant erworbenen Pneumonie (CAP - englisch: community-acquired pneumonia) des erwachsenen Patienten, definiert als eine akute mikrobielle Infektion des Lungenparenchyms und angrenzender Organe. Der Ausdruck „ambulant erworben“ grenzt sich von einer im Krankenhaus erworbenen Pneumonie in der Weise ab, dass die Infektion im privaten oder beruflichen Umfeld „zu Hause“ erworben wurde, während sich die klinische Symptomatik bei Vorliegen einer nosokomial erworbenen Pneumonie nach stationärer Aufnahme im Krankenhaus entwickelt haben muss [7]. Pneumonien, die nach stationärer Entlassung auftreten, werden auch als ambulant erworben definiert, wobei diese Unterscheidung unscharf ist. Daher werden alle Patienten, die innerhalb der ersten vier Wochen nach stationärer Entlassung eine Pneumonie entwickeln, in dieser Leitlinie nicht berücksichtigt; aufgrund eines höheren Risikos für das Auftreten multiresistenter Erreger gelten für sie die Empfehlungen analog zur im Krankenhaus erworbenen Pneumonie $[8-10]$.

Die Leitlinie gilt hingegen für Patienten mit CAP in Alten- und Pflegeeinrichtungen. Für die Einführung einer eigenen Subgruppe für Pneumoniepatienten mit regelmäßigem Kontakt zum Gesundheitssystem, der sogenannten „health care-associated pneumonia" (HCAP), wie sie die aktuellen Leitlinien aus den USA vornehmen (Kriterien: stationärer Aufenthalt > 2 Tage in den vorausgegangenen 90 Tagen; Bewohner eines Pflegeheimes; häusliche Antibiotika-Infusionstherapie oder Chemotherapie oder Wundpflege innerhalb der letzten 30 Tage vor Auftreten der akuten Erkrankung; chronische Hämodialyse) [8], gibt es in Deutschland keine ausreichende Datenbasis. Sie beruht im Wesentlichen auf einer retrospektiven amerikanischen Studie, die für diese Patienten ein häufigeres Auftreten multiresistenter Erreger zeigte [11]. Diese Studie weist jedoch methodische Mängel auf und ist nicht auf die Situation in Deutschland übertragbar. Eine spanische Studie fand dagegen bei Patienten mit HCAP ein insgesamt der CAP ähnliches Erregerspektrum mit S. pneumoniae als dominierendem Erreger. Bei HCAP fanden sich jedoch häufiger resistente Pneumokokken, Staphylokokken, gramnegative Erreger und Aspirationspneumonien sowie ein höheres Risiko, mit einer inadäquaten antibiotischen Initialtherapie behandelt zu werden [12].

Risikofaktoren für das Auftreten multiresistenter Erreger bei Patienten aus Alten- und Pflegeeinrichtungen sind ein eingeschränkter funktioneller Status (z.B. chronische Bettlägerigkeit) und eine antibiotische Vortherapie [13]. Die Besonderheiten dieser Patientengruppe sind daher durch Einbeziehung von Alter und Grunderkrankung sowie Antibiotikavortherapie in die Empfehlungen zur Behandlung der CAP in dieser Leitlinie wahrscheinlich hinreichend berücksichtigt [14].

Da in der Praxis nicht routinemäßig eine Differenzierung zwischen akuter tiefer Atemwegsinfektion und Pneumonie erfolgt, wurde die Leitlinie auf akute Infektionen im Bereich der unteren Atemwege mit Betonung der antimikrobiellen Therapie erweitert. Für alle nichtinfektiologischen Aspekte wird auf die Leitlinie der Deutschen Atemwegsliga und der Deutschen Gesellschaft für Pneumologie und Beatmungsmedizin zur Diagnostik und Therapie von Patienten mit chronisch-obstruktiver Bronchitis und Lungenemphysem verwiesen $[15,16]$.

Die Leitlinie bezieht sich auf Patienten ohne Abwehrschwäche. Patienten mit primären oder sekundären Immundefekten nach 
Organtransplantation, mit Neutropenie < 1.0/nl, HIV-Infektion, hämatologischen Systemerkrankungen bzw. unter medikamentöser Immunsuppression sind ausdrücklich ausgenommen. Es wird auf die Empfehlungen der Deutschen Gesellschaft für Pneumologie und Beatmungsmedizin sowie der Deutschen Gesellschaft für Hämatologie und Onkologie verwiesen [17]. Ebenfalls ausgenommen sind Patienten mit behandlungsbedürftiger Tuberkulose. Patienten, bei denen eine Therapiebegrenzung oder Therapiebeendigung vorgesehen ist, sollen nach den in Abschnitt 20 formulierten palliativmedizinischen Grundsätzen betreut und dokumentiert werden.

\section{Epidemiologie und sozialmedizinische Bedeutung}

Die CAP ist die häufigste registrierte Infektionserkrankung weltweit [18]. Ergebnisse der externen stationären Qualitätssicherung in Deutschland, die durch die Bundesgeschäftsstelle für Qualitätssicherung BQS erhoben werden, zeigen für die Jahre 2005 bis 2007 erstmals exakte Daten über die Häufigkeit einer im Krankenhaus behandelten ambulant erworbenen Pneumonie von jeweils etwa 200000 Patienten. Die Gesamthäufigkeit einer CAP kann daher auf ca. 400000 bis 600000 Patienten pro Jahr geschätzt werden, wenn eine Hospitalisierungsrate von 30-50\% angenommen wird [19]. Weiterhin zeigen die in Deutschland im Rahmen der externen Qualitätssicherung gewonnenen Daten, dass mit zunehmendem Alter die Inzidenz von CAP ansteigt. Die Letalität an CAP im ambulanten Bereich ist nach Daten von CAPNETZ gering und lag in einer ersten Auswertung bei 0,6\% (3/538 Patienten) [20]. Bei stationär behandelten Patienten steigt die Letalität jedoch deutlich an. Nach den in Deutschland im Rahmen der externen Qualitätssicherung gewonnenen Daten liegt in sie bei 13,7 bis $14,4 \%$ und zeigt eine signifikante Altersabhängigkeit (BQS-Qualitätsreport 2007. ISBN 978-3-9-812-495-0-7).

Verlässliche epidemiologische Daten zur akuten Exazerbation (AECOPD) einer chronisch obstruktiven Lungenerkrankung (englisch: „chronic obstructive pulmonary disease“, COPD) aus Deutschland sind wegen der unterschiedlich verwendeten Definitionen nur eingeschränkt vorhanden. Zudem ist von einer hohen Dunkelziffer von Patienten, die noch nicht diagnostiziert wurden, auszugehen. Neuere Untersuchungen aus Deutschland belegen bei über 40-Jährigen eine COPD-Prävalenz von 13,3\% (5,9\% mit mittelschwerer bis schwerer Obstruktion GOLD II - IV), was die volkswirtschaftliche Bedeutung dieser Erkrankung unterstreicht [21]. Die durchschnittliche Anzahl an akuten Exazerbationen ist nicht exakt bekannt und dürfte bei 0,6-2,7 Exazerbationen pro Patient und Jahr liegen [22].

\section{Erregerspektrum}

$\nabla$

Das Erregerspektrum der CAP weist erhebliche Variationen auf, die auf geografische und saisonale Unterschiede, die lokale epidemiologische Situation sowie auf Unterschiede hinsichtlich der untersuchten Patientenpopulationen (Alter, Begleiterkrankungen, Art der häuslichen Unterbringung), Einsatz diagnostischer Verfahren bzw. Schweregrad und Ort der Behandlung zurückzuführen sind. Die meisten publizierten Daten zur Ätiologie der CAP wurden in Untersuchungen in den USA [23], Großbritannien [24] und Spanien [25] erhoben; es handelte sich überwiegend um stationäre Patienten. Auch wenn sich dabei in Teilbereichen nationale Besonderheiten zeigen, ist die Grundtendenz in allen
Tab. 3 Häufigkeit von Erregern der ambulant erworbenen Pneumonie in Deutschland im Rahmen des CAPNETZ [26]

$\begin{array}{ll}\text { Häufigkeit } & \text { Erreger } \\ \text { sehr häufig }(40-50 \%) & \text { S. pneumoniae } \\ \text { gelegentlich }(5-10 \%) & \text { H. influenzae } \\ & \text { M. pneumoniae } \\ & \text { Enterobacteriaceae } \\ & \text { Respiratorische Viren: RS-Viren, } \\ & \text { Adenoviren, Influenzaviren } \\ & \text { Legionella spp. } \\ & \text { S. aureus } \\ \text { selten }(<5 \%) & \text { C. pneumoniae } \\ & \text { Erreger ungeklärt } \\ \text { ca. } 20-25 \% & \end{array}$

Ländern ähnlich. S. pneumoniae (25-45\% aller gesicherten Fälle) ist der wichtigste Erreger. Bei jüngeren Patienten kommt $M$. pneumoniae eine nennenswerte Bedeutung zu.

Für Deutschland bestätigen die Daten von CAPNETZ die herausragende Bedeutung von $S$. pneumoniae als Haupterreger der CAP für ambulante und stationäre Patienten, sie sind für bis zu $50 \%$ der Fälle verantwortlich. Wesentlich seltener werden $M$. pneumoniae, $H$. influenzae, Enterobacteriaceae oder S. aureus nachgewiesen [26]. Legionellen sind ebenfalls seltene Erreger einer CAP. Neuere CAPNETZ-Daten sprechen dafür, dass im Gegensatz zu früheren Vorstellungen Legionellen sowohl mit leichten als auch mit schweren Verläufen assoziiert sein können [26,27]. Die Inzidenz von Chlamydieninfektionen ist dagegen unter Anwendung einer validen Diagnostik sehr gering $(<1 \%)$ [28]. Im Unterschied zu Studien aus Spanien $[29,30]$ kommt $P$. aeruginosa als Erreger einer CAP in Deutschland keine größere Bedeutung zu [26]. Eine Berücksichtigung in der empirischen Therapie ist daher im Regelfall nicht erforderlich und wird nur bei schwer erkrankten Patienten mit Risikofaktoren, insbesondere bei struktureller Lungenerkrankung, empfohlen (siehe Tab.5) [29,30]. Auch die Rolle von Anaerobiern als Pneumonieerreger ist umstritten [31].

- Tab. 3 zeigt das Erregerspektrum der ambulant erworbenen Pneumonie in Deutschland anhand der aktuellen Daten von CAPNETZ. In Tab. 4 ist der Einfluss demografischer, epidemiologischer und klinischer Konstellationen auf das Erregerspektrum exemplarisch dargestellt. Tab. 5 listet die Indikationen für eine gegen $P$. aeruginosa wirksame empirische antimikrobielle Therapie bei CAP auf.

Ein Überblick über das Erregerspektrum der anderen in dieser Leitlinie behandelten unteren Atemwegsinfektionen ist in den einzelnen Kapiteln angeführt.

Sowohl mit serologischen Methoden als auch durch Direktnachweis oder Nukleinsäure-Amplifikations-Techniken (NAT) konnte in einer Vielzahl von Studien in ca. 10 -34\% aller Fälle ein Virusnachweis geführt werden $[54,55]$. In der deutschen CAPNETZStudie lag die Häufigkeit viraler Pneumonien bei 3,5\% bezogen auf alle bis 31.12.2007 eingeschlossenen Patienten, bzw. bei $11,6 \%$ bezogen auf die Gesamtzahl mikrobiologisch gesicherter CAP-Fälle. Neben Influenzaviren als häufigste Viren kommen Respiratory Syncytial- (RS)-, Adeno-, Corona-, Parainfluenza-, und Enteroviren sowie den humanen Metapneumoviren eine Bedeutung zu [24,54-57]. Der Virusnachweis ist häufig mit einem gleichzeitigen Bakteriennachweis gekoppelt, wobei S. pneumoniae und S. aureus im Vordergrund stehen $[56,58]$. Isolierte primäre Viruspneumonien dürften eher selten sein. Häufig führt jedoch die virusbedingte Schädigung des Bronchialepithels zu bakteriellen Superinfektionen mit klinisch schwererem Verlauf. 
Tab. 4 Zusammenhang zwischen Erregerspektrum und anamnestischen Angaben.

Antibiotika-Vortherapie: Der sorgfältigen Evaluation vorausgegangener Antibiotikatherapien kommt in der Anamnese eine besondere Bedeutung zu. Eine Antibiotika-Vortherapie innerhalb der letzten 3 Monate prädisponiert zu Infektionen durch resistente Erreger besonders gegenüber der verwendeten Substanzgruppe, dieser Zusammenhang ist für Betalaktam-, Makrolid- und Fluorchinolonantibiotika belegt [32 - 34]. Eine Vortherapie mit Fluorchinolonen ist ferner mit dem vermehrten Auftreten multiresistenter Erreger inkl. MRSA (letztere bisher für Deutschland ohne klinische Relevanz), eine Vortherapie mit Cephalosporinen mit extended-spectrum $\beta$-Laktamasen bildenden gramnegativen Erregern assoziiert [34-38].

Reiseanamnese: Bei Reiseanamnese in Länder mit hoher LegionellosePrävalenz und/oder Exposition gegenüber Wasser aus speziellen Aufbereitungsanlagen ist eine Infektion durch Legionella spp. differenzialdiagnostisch zu berücksichtigen [39].

Alter: Bei älteren Patienten über 65 Jahren werden vermehrt gramnegative Erreger gefunden, wobei diese Assoziation nicht konstant in allen Untersuchungen beobachtet wird [40 - 43]. Es konnte bisher nicht überzeugend gezeigt werden, ob das Alter einen unabhängigen Risikofaktor für diese Erreger darstellt oder ob die Kofaktoren Komorbidität und Antibiotika-Vorbehandlung bzw. vorangegangene Hospitalisation hierfür ausschlaggebend sind $[30,44]$.

Alten- und Pflegeeinrichtungen bzw. Krankenhausvorbehandlung: Bei Patienten aus einem Pflegeheim/Altersheim ist vermehrt mit Infektionen durch resistente bzw. multiresistente Enterobacteriaceae und $S$. aureus sowie mit Aspirationspneumonien zu rechnen $[11,12,45,46]$. Diese Assoziation wurde bisher vor allem in Untersuchungen in den USA gefunden. Risikofaktoren für das Auftreten multiresistenter Erreger sind eine bestehende Antibiotikavortherapie und ein eingeschränkter funktioneller Status (chronische Bettlägerigkeit) [13]. Risikofaktoren für das Auftreten von Aspirationspneumonien sind neurologische Grunderkrankungen und eingeschränkte Dentalhygiene [46].

Chronische Lungenerkrankungen: Bei strukturellen Lungenerkrankungen wie chronisch-obstruktiver Bronchitis sind vermehrt Infektionen durch $H$. influenzae und bei fortgeschrittener Erkrankung der COPD, Mukoviszidose oder Bronchiektasen S. aureus und $P$. aeruginosa zu berücksichtigen [29, 30, 47, 48] ( Tab. 5). P. aeruginosa wird in Deutschland nur sehr selten als Erreger einer CAP nachgewiesen [26]

Tierkontakte: Bei Kontakten zu Vögeln ist C. psittaci, bei Kontakt zu Schafen C. burnetii zu berücksichtigen [49].

Steroid-Vortherapie: Bei Patienten mit einer vorbestehenden Steroidtherapie von mindestens $10 \mathrm{mg} / \mathrm{d}$ Prednisolonäquivalent über eine Dauer von mindestens vier Wochen ist ein gehäuftes Auftreten von P. aeruginosa und Legionella spp. beschrieben worden [50,51].

Tab. 5 Indikationen für eine empirische Therapie mit gegenüber Pseudomonas aeruginosa wirksamen antimikrobiellen Substanzen bei CAP in Deutschland $[25,26,29,30,52,53]$.

schwere strukturelle chronische Lungenerkrankungen wie schwere COPD mit Antibiotikavortherapie oder vorausgegangener Hospitalisierung jeweils in den letzten 3 Monaten

bekannte Kolonisation durch P. aeruginosa

Bronchiektasen

Mukoviszidose
Für aktuelle Informationen zur Influenza wird auf die Internetadresse des Robert-Koch-Institutes (www.RKI.de) der World Health Organization (www.who.org) und der Centers for Disease Control and Prevention (www.cdc.gov) verwiesen.

\section{Resistenzsituation}

Antibiotikaresistenzen haben in den letzten zehn Jahren bei den klassischen Erregern von unteren Atemwegsinfektionen wie $S$. pneumoniae, $H$. influenzae und $M$. catarrhalis regional und weltweit zugenommen.

\subsection{Resistenzsituation bei Streptococcus pneumoniae}

\subsubsection{Resistenz gegenüber Penicillin G}

Die verminderte Empfindlichkeit (minimale Hemmkonzentration [MHK] - mit Grenzwerten des Clinical and Laboratory Standards Institute [CLSI] der USA zwischen 0,125 und $1 \mathrm{mg} / \mathrm{l}$ ) und die Penicillinresistenz (definiert ab MHK: $\geq 2,0 \mathrm{mg} / \mathrm{l}$ ) von S. pneumoniae hat eine geringe klinische Relevanz bei respiratorischen Infektionen [59-64]. In einer Publikation der Centers for Disease Control (CDC, Atlanta, USA) wurde die Penicillin-Resistenz erst bei einer $\mathrm{MHK}$ von $\geq 4 \mathrm{mg} / \mathrm{l}$ als klinisch relevant eingeschätzt [65].

Sowohl Penicillin G als auch Aminopenicilline und Cephalosporine der Gruppe 3a (Cefotaxim und Ceftriaxon) sind auf Grund ihrer günstigen pharmakokinetischen und -dynamischen Eigenschaften in der Lage, Infektionen der Atemwege durch S. pneumoniae mit verminderter Penicillin- und Cephalosporin-Empfindlichkeit effektiv zu sanieren. Das trifft für Cephalosporine der Gruppen 1 und 2 wegen der schlechteren In-vitro-Aktivität und ungünstigerer pharmakodynamischer Eigenschaften nicht zu. Insgesamt ist die Rate von S. pneumoniae mit verminderter Empfindlichkeit gegenüber Penicillin in Deutschland nach derzeitiger CLSI-Definition im Vergleich zu anderen europäischen Ländern (z.B. Frankreich und Spanien) mit einem Anteil von 6,3\% niedrig, Isolate mit Penicillinhochresistenz (MHK > 2 mg/l) kommen praktisch nicht vor (s. Tab. 6) $[66,67]$

\subsubsection{Resistenz gegenüber Makroliden}

Die Resistenz von S. pneumoniae gegenüber Erythromycin und parallel dazu gegenüber den neueren Makroliden (Roxythromycin, Clarithromycin, Azithromycin) hat in Deutschland deutlich zugenommen (siehe Tab.6). In der Langzeitstudie „Invasive Pneumokokkeninfektionen bei Erwachsenen“ des Deutschen Nationalen Referenzzentrums (NRZ) für Streptokokken ist die Erythromycin-Resistenz von 2,2\% 1992 auf 15,3\% im Jahr 2000 und auf $17 \%$ im Jahr 2004 angestiegen ( $p<0,001$ ), hat sich aber in den letzten Jahren auf diesem Level stabilisiert (2007: 18\%) [69,70]. Die Makrolidresistenz von S. pneumoniae hat bei respiratorischen Infektionen vermutlich eine höhere klinische Relevanz als die Penicillin-Resistenz. Verschiedene Autoren berichteten über einen therapeutischen Misserfolg im Zusammenhang mit einer Makrolidtherapie bei CAP durch Makrolid-resistente S. pneumoniaeStämme [71-75]. In Studien aus den USA und Europa kam es während einer Makrolidtherapie zu Durchbruch-Bakteriämien und damit zu Therapieversagen [76, 77]. Eine bestehende Makrolidresistenz ist ein Risikofaktor für ein Therapieversagen bei Pneumokokkenbakteriämie [78].

Die vorausgegangene Makrolidtherapie ist der wichtigste Risikofaktor für den Nachweis resistenter S. pneumoniae [33]. Nach Makrolidgabe entwickelt sich eine rasche und lang anhaltende Ver- 
Tab. 6 Resistenzsituation bei S. pneumoniae gegenüber Betalaktamantibiotika, Makroliden und Tetracyclinen in Deutschland.

\begin{tabular}{|c|c|c|c|c|c|c|c|c|c|}
\hline \multirow[t]{2}{*}{ Zeitraum } & \multirow{2}{*}{$\begin{array}{l}\text { Isolate } \\
\text { (n) }\end{array}$} & \multicolumn{3}{|c|}{ Penicillin G } & Makrolide & \multirow[t]{2}{*}{ Tetracycline } & \multirow{2}{*}{$\begin{array}{l}\text { Invasiv| } \\
\text { noninvasiv }\end{array}$} & \multirow{2}{*}{$\begin{array}{l}\text { Kinder| } \\
\text { Erwachsene }\end{array}$} & \multirow[t]{2}{*}{ Studie (Autor) } \\
\hline & & $S(\%)$ & I (\%) & $\mathbf{R}^{*}(\%)$ & $\mathbf{R}(\%)$ & & & & \\
\hline $2001-2003$ & 530 & 94 & $?$ & $\begin{array}{l}I+R \\
6,0\end{array}$ & 10,6 & 11,3 & $\begin{array}{l}\text { invasiv/ } \\
\text { noninvasiv }\end{array}$ & Erwachsene & $\begin{array}{l}\text { PneumoWorld } \\
\text { Study [68] }\end{array}$ \\
\hline $2005-2006$ & 82 & 95,1 & 2,5 & 2,5 & 13,6 & 9,9 & CAP & Erwachsene & $\begin{array}{l}\text { CAPNETZ (Reinert } \\
\text { pers. Mitteilung) }\end{array}$ \\
\hline $2005-2006$ & 1208 & 93,7 & 4,6 & 1,7 & 18,4 & 7,2 & invasiv & Erwachsene & $\begin{array}{l}\text { Jahresbericht des } \\
\text { NRZ für Pneumo- } \\
\text { kokken }\end{array}$ \\
\hline
\end{tabular}

${ }^{*}$ keine Isolate mit Penicillin-Hochresistenz (MHK> 2 mg/l); $\mathrm{S}=$ sensibel; $\mathrm{I}$ = intermediär; $\mathrm{R}=$ resistent.

mehrung Makrolid-resistenter S. pneumoniae in der oropharyngealen Flora $[33,79]$. Die Resistenzselektion scheint bei Präparaten mit längerer Halbwertszeit (Azithromycin) im Vergleich zu solchen mit kürzerer Halbwertszeit (Clarithromycin) besonders ausgeprägt zu sein.

Bei 430 S. pneumoniae-Isolaten aus der deutschen NRZ-Langzeitstudie wurde in 35,6\% das Resistenzgen erm (B) nachgewiesen, $63,5 \%$ waren mef positiv [69]. Das erm (B)-Gen kodiert für eine 23S rRNA-Methylase und führt zu high-level-Resistenzen gegenüber allen Makroliden, Lincosamiden (Clindamycin) und Streptograminen (sog. $\mathrm{MLS}_{\mathrm{B}}$-Resistenz). Die mef (A)- bzw. mef (E)-Gene kodieren für einen Effluxmechanismus, d.h. das Makrolid wird aus der Pneumokokkenzelle herausgepumpt. Stämme mit diesem Resistenzmechanismus weisen häufig eine low-level-Resistenz (MHK unter $16 \mathrm{mg} / \mathrm{l}$ ) auf [80]. Der Resistenzmechanismus ist jedoch nicht entscheidend für die klinische Bedeutung der Resistenz: Bei S. pneumoniae-Stämmen, die Durchbruchbakteriämien verursachen, kann es sich sowohl um S. pneumoniae mit erm (B) als auch mit mef handeln [76,78].

\subsubsection{Resistenz gegenüber Fluorchinolonen}

Fluorchinolone der Gruppe 2 (z.B. Ciprofloxacin) haben eine geringe In-vitro-Aktivität bei $S$. pneumoniae und sind aus diesem Grund bei Patienten mit CAP ohne Risikofaktoren für P. aeruginosa oder Enterobacteriaceae nicht indiziert.

Der Fluorchinolon-Resistenz liegt bei S. pneumoniae häufig eine Doppelmutation im parC-Gen (kodiert für die Topoisomerase IV) und gyrA-Gen (kodiert für die Subeinheit A der DNA-Gyrase) zu Grunde.

Die Resistenz von S. pneumoniae gegenüber Fluorchinolonen der Gruppe 3 (Levofloxacin) und Gruppe 4 (Moxifloxacin) ist weltweit noch selten. Eine Selektion resistenter Stämme nach Therapie mit Fluorchinolonen der Gruppe 2 ist aber möglich [81].

Kasuistiken über Therapiemisserfolge mit Levofloxacin bei Infektionen durch Levofloxacin-resistente S. pneumoniae sind mehrfach publiziert worden [82-84].

In der PROTEKT-Studie (1999 und 2000) mit 3362 weltweit gesammelten S. pneumoniae-Isolaten lag die Fluorchinolon-Resistenzrate unter $1 \%[85,86]$.

Die Resistenz gegenüber Fluorchinolonen der Gruppe 3 und 4 ist derzeit in Deutschland sehr selten [87]. In der PneumoWorldStudy 2001 bis 2003 lag die Levofloxacin-Resistenz-Rate der Isolate aus Deutschland bei 0,4\% [68].

\subsubsection{Resistenz gegenüber Tetracyclinen}

Zur Tetracyclin (Doxycyclin)-Resistenz liegen insgesamt weniger Daten vor als zur Penicillin-G- bzw. Makrolid-Resistenz von $S$. pneumoniae, die Resistenz-Raten liegen in den neueren Studien zwischen 10 und 15\% (s. Tab. 6).

\subsection{Resistenzsituation bei Haemophilus influenzae}

Die Prävalenz Betalaktamase-produzierender $H$. influenzaeStämme liegt in Deutschland (PROTEKT-Studie, Alexander-Projekt) unter $8 \%$, wobei regionale Unterschiede bekannt sind. Der Anteil Betalaktamase-negativer, Ampicillin-resistenter Isolate ist zu vernachlässigen; d.h. Aminopenicilline sind bei $>90 \%$ der Isolate wirksam $[87,88]$. In der globalen SENTRY-Studie wurden zwischen 1997 und 20012702 H. influenzae-Stämme aus Europa getestet. Der Anteil der Betalaktamaseproduzenten betrug 16,2\%. $10,4 \%$ der Stämme waren gegenüber Clarithromycin, 3,0\% gegenüber Tetracyclin und 1,7\% gegenüber Cefuroxim resistent. Resistenzen gegenüber den Fluorchinolonen Levofloxacin und Moxifloxacin wurden nicht nachgewiesen [89]. In einer weiteren Studie aus Europa von 2000 - 2001 wurden 210 H. influenzae-Stämme aus Deutschland getestet. 8,1\% waren gegenüber Ampicillin resistent, diese waren alle $\beta$-Laktamase-positiv. Keine Resistenzen traten gegenüber Cefuroxim, Ciprofloxacin und Levofloxacin auf. Gegenüber Clarithromycin waren 82,9\% der Stämme sensibel (0,5\% resistent) [90].

\subsection{Resistenzsituation bei Moraxella catarrhalis}

Bei $M$. catarrhalis ist der Anteil der Betalaktamase-bildenden Stämme (Penicillin- und Aminopenicillin-Resistenz) weltweit sehr hoch, er beträgt zwischen 90 und 95\%, d.h. Aminopenicilline sind für die kalkulierte Initialtherapie nicht geeignet $[87,88]$. Im Rahmen des SENTRY-Programms wurden 1068 M. catarrhalis-Stämme aus Europa getestet. 2,2\% der Isolate waren gegenüber Tetracyclin resistent. Resistenzen gegenüber Cefuroxim, Amoxicillin/Clavulansäure, Erythromycin und Fluorchinolonen wurden nicht nachgewiesen [89].

\subsection{Resistenzsituation bei Enterobacteriaceae und Pseudomonas aeruginosa}

Für Enterobacteriaceae und P. aeruginosa wurden von der Arbeitsgemeinschaft „Empfindlichkeitsprüfungen und Resistenz“ der Paul-Ehrlich-Gesellschaft für Chemotherapie e.V. aus Mitteleuropa (Deutschland, Schweiz und Österreich) 2006 Daten veröffentlicht, die sich auf 6343 Bakterienstämme beziehen. Bei den Untersuchungsmaterialien handelte es sich in $22 \%$ um Atemwegsmaterialien und in $11 \%$ um Blut, wobei nur $15 \%$ der Bakterienstämme aus dem ambulanten Bereich stammten [91]. Von 
Tab. 7 Resistenzraten von P. aeruginosa aus Atemwegsmaterialien $(\mathrm{n}=266)$ in Deutschland, Schweiz und Österreich [91] in resistent \%.

\begin{tabular}{|l|c|}
\hline & $\mathbf{2 0 0 4}$ \\
\hline Cefepim & $8,3 \%$ \\
\hline Ceftazidim & $11,3 \%$ \\
\hline Meropenem & $6,0 \%$ \\
\hline Piperacillin/Tazobactam & $10,2 \%$ \\
\hline Ciprofloxacin & $16,2 \%$ \\
\hline Amikacin & $\mathrm{b} 6,0 \%$ \\
\hline Gentamicin & $15,8 \%$ \\
\hline Tobramycin & $7,1 \%$ \\
\hline
\end{tabular}

den 74 getesteten $E$. coli-Stämmen aus Atemwegsmaterialien waren nach DIN 58940 nur noch 25,7\% gegenüber Ampicillin sensibel, $14,9 \%$ verhielten sich intermediär und 55,4\% waren resistent. Auch gegenüber Amoxicillin/Clavulansäure waren nur 20,3\% der Stämme sensibel. Eine sehr gute in-vitro-Aktivität zeigten Piperacillin/Tazobactam (Sensitivität von 91,9\%), die Cephalosporine Ceftriaxon (94,6\%), Cefotaxim (94,6\%), Ceftazidim (94,6\%) und Cefepim (97,3\%) sowie Carbapeneme (Ertapenem- und Meropenem-Sensibilität jeweils $100 \%$ ). Gegenüber Cefuroxim war eine Resistenz der E. coli-Isolate von 16,2\% und gegenüber Ciprofloxacin von 21,6\% (14,5\% in 2001 bezogen auf alle getesteten Stämme) zu verzeichnen. Bei 5,1\% (im Vergleich zu 1,8\% 2001, resp.) der Stämme traten Plasmid-kodierte Breitspektrum-Betalaktamasen (sog. ESBL) auf. Bei Klebsiella spp. betrug der Anteil der ESBL-Bildner zwischen 7,3 und 12,4\%. Von den 83 getesteten $K$. pneumoniae Stämmen aus Atemwegsmaterialien waren $94 \%$ sensibel gegenüber Ciprofloxacin, 63,7\% gegenüber Ampicillin/Sulbactam, 83,1\% gegenüber Piperacillin/Tazobactam und 100\% gegenüber Ertapenem und Meropenem. Aktuelle Daten belegen die Bedeutung einer vorausgegangenen Antibiotikatherapie als Risikofaktor für das Auftreten resistenter Enterobacteriaceae. Insbesondere bei Vortherapie mit Fluorchinolonen und Cephalosporinen wurde ein erhöhtes Risiko für eine Infektion mit ESBL-Bildnern oder Ciprofloxacin-resistenten $P$. aeruginosa beschrieben $[34,35,38]$. Zur aktuellen Resistenzsituation von P. aeruginosaAtemwegsisolaten s. Tab. 7.

\subsection{Resistenzsituation bei Influenza-Viren und nicht primär respiratorischen Viren}

Bei Influenzaviren (Influenzavirus Typ A) wird unter einer Amantadin-Behandlung eine rasche Resistenzentwicklung beobachtet, was die Therapiemöglichkeit mit M2-Kanal-Inhibitoren deutlich begrenzt [92]. Seit Anwendung der Neuraminidase-Inhibitoren zirkulieren Oseltamivir-resistente Influenzaviren (durchschnittliches Niveau von ca. 15\%, WHO: Influenza A(H1N1) virus resistance to oseltamivir, update 13. June 2008, www.who.int). Es wird daher notwendig werden, zur Surveillance Resistenzbestimmungen durchzuführen [92]. Bei Pneumonien durch Varizella-Zosteroder Herpes-simplex-Viren sind keine klinisch relevanten resistenten Virusmutanten nachzuweisen.

\section{Mikrobiologische Diagnostik}

Die Indikationen für die mikrobiologische Diagnostik werden in den jeweiligen Kapiteln beschrieben.

\subsection{Diagnostik schnell wachsender Bakterien}

Die mikrobiologische Diagnostik schnell wachsender Bakterien, die als Erreger der CAP in Frage kommen, wie S. pneumoniae, $H$. influenzae, M. catarrhalis, S. aureus, Klebsiella spp. und andere Enterobacteriaceae oder P. aeruginosa, erfolgt über die Mikroskopie und die Kultur.

Geeignete Proben sind Materialien aus den unteren Atemwegen, Pleuraflüssigkeit oder Blutkulturen. Als respiratorisches Material kommt Sputum als einfach gewinnbare Probe in Frage, aber auch invasiv gewonnenes Material wie bronchoalveoläre Lavageflüssigkeit (BAL) oder Biopsien.

Sputumproben sind häufig mit der physiologischen Flora des Mund-Rachenraums kontaminiert. Um die Untersuchung von Speichelproben zu vermeiden, sollte nur makroskopisch eitriges Sputum für die Diagnostik verwendet werden.

Die Proben sollten vor Beginn einer antimikrobiellen Therapie gewonnen werden und umgehend - möglichst innerhalb von 2 Stunden - im Labor bearbeitet werden [93].

Mikroskopie: Bei Sputumproben ermöglicht die mikroskopischzytologische Begutachtung des Präparates die Beurteilung der Untersuchungswürdigkeit der Probe [93]. Proben mit mehr als 25 Granulozyten und weniger als 10 (-25) Plattenepithelzellen pro Gesichtsfeld bei 100-facher Vergrößerung erfüllen die Qualitätskriterien für eine Sputumkultur und weisen auf geringe Speichelbeimengungen hin [94,95]. Diese Kriterien gelten nicht für Patienten mit Immunsuppression und bei Verdacht auf seltene Pneumonieerreger wie z.B. Nokardien, Mykobakterien und Schimmelpilze [93]. Die Untersuchung auf Mikroorganismen erfolgt in der Gramfärbung bei 1000-facher Vergrößerung.

Die Sensitivität der Mikroskopie von Sputumproben für die Pneumoniediagnostik wird in Studien mit 50-60\% angegeben, die Spezifität mit mehr als 80\% [49]. Die Sensitivität steigt auf bis zu $85 \%$, wenn die zytologischen Kriterien für die Qualität der Sputumprobe erfüllt sind. Die Interpretation des Grampräparates hängt allerdings maßgeblich von der Erfahrung des Untersuchers ab [49]. Das Ergebnis der Gramfärbung liegt in der Regel innerhalb von 10 bis 15 Minuten vor. Die positiven und negativen prädiktiven Werte für S. pneumoniae bzw. H. influenzae betragen 95\% und $71 \%$ (bzw. $93 \%$ und $98 \%$ ) [96].

Kultur: S. pneumoniae, H. influenzae, M. catarrhalis, S. aureus, Enterobacteriaceae und $P$. aeruginosa lassen sich grundsätzlich aus Materialien des Respirationstrakts, Blutkulturen und Pleuraflüssigkeit mittels mikrobiologischer Standardverfahren anzüchten. Der Nachweis aus Blutkulturen oder anderen Materialien aus primär sterilen Kompartimenten ist diagnostisch beweisend. Der Nachweis aus respiratorischem Material per se lässt hingegen keine Unterscheidung zwischen Infektion und Besiedelung zu. Die Wertigkeit der (semi-) quantitativen Kultur für diese Differenzierung ist umstritten.

Das Hauptproblem der Kultur liegt - neben der Dauer von 24-48 Stunden bis zum Vorliegen des Ergebnisses - in der niedrigen Sensitivität.

Blutkulturen sind im Durchschnitt nur bei 0 -16\% der Patienten mit CAP positiv [97 - 100]. Der Wert der positiven Blutkultur liegt insbesondere im Nachweis anderer Spezies als S. pneumoniae. 
Sputumkulturen weisen bei hospitalisierten Patienten je nach Studie in 29-90\% irgendeinen Erreger nach, bei ambulanten Patienten in weniger als $20 \%$ [49]. Selbst bei bakteriämisch verlaufenden Pneumokokkenpneumonien gelingt der Erregernachweis über die Sputumkultur nur in 40-50\% der Fälle [101]. Erreger werden häufiger kulturell in transthorakalen Biopsien oder in quantitativen Kulturen von bronchoalveolärer Lavageflüssigkeit nachgewiesen [49].

Wesentliche Gründe für die niedrige Sensitivität der Kultur liegen in einer nicht optimalen Entnahmetechnik, ungeeignetem Probenmaterial, zu langer Transportzeit oder einer vorausgehenden Antibiotikatherapie.

Die Kultur ist jedoch nach wie vor das einzige Verfahren, das Isolate für die Empfindlichkeitsprüfung liefern kann, die wegen zunehmender Resistenzprobleme bei Erregern von Atemwegsinfektionen immer größere Bedeutung gewinnt.

\section{Pneumokokken-Antigennachweis aus Urin}

Verfahren: Bei dem Test handelt es sich um einen immunchromatografischen Membrantest (ICT), der das Pneumokokken-Zellwand-Polysaccharid nachweist, das bei allen Serotypen von $S$. pneumoniae - und auch bei S. oralis und S. mitis - vorhanden ist [102].

Das Testergebnis liegt im Mittel nach 15 Minuten vor. Eine Konzentrierung des Urins verlängert den Arbeitsablauf, verbessert nicht wesentlich das Testergebnis und wird daher nicht empfohlen [103].

Die Sensitivität des ICT betrug bei Erwachsenen, verglichen mit konventionellen diagnostischen Methoden, 50 bis $80 \%$, die Spezifität wurde mit etwa $90 \%$ angegeben. In einer japanischen Studie an 349 Patienten wurde der positive prädiktive Wert mit 91,3\% ermittelt, der negative prädiktive Wert mit 82,6\% [103 - 107].

Der Test kann auch bei Patienten, die zum Zeitpunkt der Probenahme bereits eine Antibiotikatherapie erhalten, positiv ausfallen, sodass bei einem Teil der Patienten, bei denen die Kultur keinen Erregernachweis erbrachte, mittels des Antigen-Nachweises im Urin eine Pneumokokkenpneumonie wahrscheinlich gemacht werden kann $[103,105,108]$.

Aufgrund der Daten zu Sensitivität und Spezifität schließt ein negativer Test eine Pneumokokken-Pneumonie nicht sicher aus und ein positiver Test kann auch ein falsch-positives Resultat bedeuten, sodass der Antigen-Nachweis im Urin zum jetzigen Zeitpunkt nur als Ergänzung zu den konventionellen Verfahren betrachtet werden kann. Er kann zur Erleichterung von Entscheidungen zur Fokussierung der Therapie beitragen, wobei die Möglichkeit polymikrobieller Infektionen zu bedenken ist (Evidenzgrad 5).

Die Arbeitsgruppe empfiehlt (Empfehlungsgrad B) den Pneumokokken-Antigen-Nachweis im Urin derzeit nicht als Routine-Diagnostik. Da S. pneumoniae im antimikrobiellen Spektrum der initialen kalkulierten Antibiotikatherapie liegt, ist der klinische Nutzen einer Antigenbestimmung im Urin begrenzt. Ein positiver Ausfall des Antigentests kann zur Erleichterung von Entscheidungen zur Fokussierung der Therapie beitragen, wobei die Möglichkeit polymikrobieller Infektionen zu bedenken ist. Ein negativer Test schließt eine Pneumokokken-Pneumonie nicht sicher aus.

\subsection{Diagnostik spezieller Erreger}

\subsubsection{Diagnostik von Legionella pneumophila}

Diagnostische Verfahren

Kultur: Die Kultur muss auf einem Spezialmedium mit Zusatz von Holzkohle und Hefeextrakt (BCYE-Agar) durchgeführt werden. Durch Zusatz von Antibiotika (z.B. BMPA-Agar) kann die störende Begleitflora unterdrückt werden. Zur Anzucht ist eine 3- bis 7tägige Bebrütung notwendig. Die Sensitivität schwankt zwischen $<10 \%$ und $80 \%$, die Spezifität beträgt 100\% [109]. Der Vorteil der Kultur ist die Anzuchtmöglichkeit für alle Serotypen von L. pneumophila und für andere Legionella spp. Angezüchtete LegionellaStämme können durch Feintypisierung mit Stämmen aus verdächtigen Wasserreservoiren verglichen werden. Hierdurch kann eine Übertragung wahrscheinlich gemacht bzw. ausgeschlossen werden.

Nachweis von L. pneumophila mit der direkten Immunfluoreszenz (DIF) aus Materialien der unteren Atemwege: Die Sensitivität der DIF verglichen mit der Serologie beträgt ca. 25-66\% $[23,110,111]$, wobei der Aussagewert des DIF-Tests stark abhängig von der Expertise des Labors ist. Die Spezifität wird mit ca. 95\% angegeben [110]. Durch die niedrige Sensitivität und Probleme bei der Auswertung ist der DIF-Test in der Aussage limitiert und als alleiniger Test für die Diagnose einer Legionella-Infektion nicht ausreichend [112].

Antigennachweise aus Urin: Seit einigen Jahren stehen kommerzielle Test-Kits auf der Basis von Enzym-Immuno-Assays (EIA) sowie ein immunchromatografischer Schnelltest (ICT) zur Verfügung. Der Test weist ausschließlich L. pneumophila der Serogruppe 1 nach.

Die Sensitivität im Vergleich zur Kultur liegt bei Reise-assoziierten Legionella-Infektionen mit dem Binax-EIA bei 93,7\% und dem Biotest-EIA bei 94,4\%, bei ambulant erworbenen Infektionen bei $86,5 \%$ und $76,0 \%[113,114]$. Da bei Reise-assoziierten und ambulant erworbenen Legionellosen Stämme der Serogruppe 1 (monoklonale Subgruppe MAb 3/1) eindeutig dominieren, ist der Urin-Antigen-Nachweis die Methode der Wahl.

Die Spezifität liegt bei $99-100 \%$, d. h. ein positives Testergebnis beweist das Vorliegen einer Legionella-Infektion [115].

Für den immunchromatografischen Schnelltest (ICT) wurde eine Sensitivität von ca. $80 \%$ bestimmt, bei Vorliegen von Stämmen der Serogruppe 1 sogar von $94 \%$, die Spezifität lag bei $100 \%$ [116]. Die Übereinstimmung des ICT mit den EIA der Firmen Binax und Biotest ist hoch $[102,117]$. Die Sensitivität der Antigennachweise wird höher, wenn der Urin durch Ultrafiltration konzentriert wird [102,118,119]. Ein negativer Antigennachweis schließt eine Legionellose nicht aus; daher sind bei entsprechendem klinischem Verdacht Mehrfachuntersuchungen sinnvoll.

Nukleinsäureamplifikationsverfahren aus Materialien der unteren Atemwege: Legionella spp. sind nicht in der Lage, den Respirationstrakt zu besiedeln, d. h. bei Nachweis des Erregers handelt es sich um eine Infektion. Diese Tatsache und die relativ schlechte Anzüchtbarkeit sind eine gute Voraussetzung für den Einsatz von NAT wie der Polymerasekettenreaktion (PCR). Da Legionellen aber häufig in der Umwelt bzw. im Wasser vorkommen, besteht eine erhöhte Gefahr von Kontaminationen.

Konventionelle PCR-Techniken zum Nachweis aus Sputum, BAL, Rachenabstrich, Trachealsekret, Urin und Leukozyten liefern eine vergleichbare Sensitivität wie die kulturellen Verfahren [120-122]. Bei nicht aus dem Respirationstrakt stammenden 
Proben sind die Nukleinsäureverfahren noch nicht ausreichend validiert [123].

Im Vergleich zur konventionellen PCR liegen mit der real-time PCR (Light-Cycler-Technik) die Testergebnisse mit Speziesidentifizierung und Quantifizierung schon nach 1-2 Stunden vor [124 - 126]. Die Spezifität beträgt 100\%, die Sensitivität liegt zwischen 90 und 100\%, wobei bisher nur kleine Fallzahlen untersucht wurden. Weitere Validierungen und Standardisierungen der PCR-Assays sind notwendig und sollten einer Etablierung dieser viel versprechenden Methode in der Routinediagnostik vorausgehen.

Antikörpernachweise aus dem Serum: Aus dem Serum können IgG-, IgM- und IgA-Antikörper mit der indirekten Immunfluoreszenztechnik bestimmt werden. Ein vierfacher Titeranstieg bei einem Serumpaar im Abstand von 10 bis 14 Tagen ist beweisend für eine Infektion. Der Nachweis von IgM-Antikörpern als Einzeltiter kann zwar zu einer schnelleren Diagnose führen, allerdings ist dieser Test nicht ausreichend validiert, IgM-Antikörper können zwei Jahre und länger persistieren [127]. Daher ist die Interpretation von Einzeltitern insbesondere bei schwach positiven Resultaten schwierig.

Mit einer Antikörperbildung ist frühestens nach 10 Tagen zu rechnen und der Nachweis eines 4-fachen Titeranstieges gelingt oft erst nach 3 bis 6 Wochen [128]. Limitiert sind die Antikörper-Nachweise dadurch, dass bei ca. $20 \%$ der Patienten keine Serokonversion innerhalb 4-6 Wochen nach Erkrankung auftritt [111,129].

Die Sensitivität der Antikörpernachweise von L. pneumophila der Serogruppen 1-4 betrug verglichen mit der Kultur 75\% [110]. Über die Sensitivität des Antikörpernachweises für andere Legionella spp. liegen keine aussagekräftigen Daten vor.

Mehrfach wurde über falsch-positive Ergebnisse durch kreuzreaktive Antikörper nach Infektion durch andere Bakterienspezies berichtet [130,131].

Wegen der verzögert auftretenden Antikörperbildung, der teilweise fehlenden Serokonversion sowie der niedrigen Sensitivität bzw. Spezifität wird die Antikörper-Diagnostik bei CAP nicht empfohlen [132].

Die Arbeitsgruppe empfiehlt (Empfehlungsgrad B) den AntigenNachweis aus Urin als diagnostische Methode der Wahl bei Verdacht auf Legionelleninfektion. Für die Klärung epidemiologischer Zusammenhänge ist die Kultur erforderlich, während Nukleinsäure-Amplifikationsverfahren bislang für den Routine-Einsatz nicht ausreichend validiert und standardisiert sind. Der Antikörper-Nachweis aus Serum und der direkte Immunfluoreszenztest aus Materialien der unteren Atemwege werden nicht empfohlen.

\subsubsection{Diagnostik von Mycoplasma pneumoniae} Diagnostische Verfahren

Kultur: M. pneumoniae ist ein zellwandloses, schwer anzüchtbares Bakterium. Die Kultur von Rachen- oder Nasopharyngealabstrichen auf Spezialnährmedien benötigt mindestens 10 bis 14 Tage und kann bis zu 5 Wochen dauern. Sie wird nur in wenigen Speziallaboratorien durchgeführt. Die Sensitivität ist relativ gering, da erst ab $10^{5} \mathrm{CFU} / \mathrm{ml}$ der Nachweis gelingt. Im Vergleich zur PCR beträgt die Sensitivität des kulturellen Nachweises von M. pneumoniae aus Atemwegen nur 61\% [133]. Aus diesen Gründen ist die Kultur für die Diagnostik einer CAP nicht geeignet.
Antikörpernachweise im Serum: Die Komplement-Bindungs-Reaktion hat eine unzureichende Sensitivität und Spezifität $[134,135]$.

Kälte-Agglutinin-Titer von $\geq 1: 64$ korrelieren zwar mit dem Schweregrad der Erkrankung, sind aber nicht ausreichend sensitiv und spezifisch [136].

Mit der Enzymassay (EIA)-Technik sind IgG-, IgM- und IgA-Antikörper-Nachweise entwickelt worden. Verschiedene kommerzielle EIA-Kits stehen zur Verfügung, deren unterschiedliche cut offs berücksichtigt werden müssen. IgM-Antikörper sind häufig nur bei Kindern nach Erstkontakt mit M. pneumoniae nachweisbar, ein negativer IgM-Nachweis schließt eine M. pneumoniae-Infektion, insbesondere bei Erwachsenen, nicht aus. Der IgA-Antikörper-Nachweis mit dem EIA weist bei Erwachsenen eine höhere Sensitivität und Spezifität als die anderen Testverfahren auf [137]. Für das akute Management einer CAP kommt eine Mykoplasmen-Serodiagnostik häufig zu spät. Eine Studie mit begrenzter Fallzahl aus Deutschland zeigte bei Patienten mit längerer klinischer Symptomatik der CAP (>12 Tage) für den Einzelnachweis von IgM-Antikörpern gegen $M$. pneumoniae mittels particle agglutination assay (Serodia-Myco II) im Vergleich zur PCR eine Sensitivität von $90 \%$ und eine Spezifität von 100\% [138]. In einer weiteren Untersuchung konnte gezeigt werden, dass eine Therapieumstellung bei CAP-Patienten (bei gleichem Outcome) unter einer empirischen $\beta$-Laktam-Monotherapie häufiger notwendig war als bei Patienten, die gezielt gegen M. pneumoniae bzw. $C$. pneumophila behandelt worden waren [139].

Nukleinsäureamplifikationsverfahren aus Atemwegsmaterialien: Durch die schwierige Anzüchtbarkeit von M. pneumoniae bieten sich NAT als diagnostische Verfahren an. Ein Nachteil ist allerdings, dass M. pneumoniae im Gegensatz zu L. pneumophila den Respirationstrakt besiedeln kann, ohne eine Erkrankung hervorzurufen. Zahlreiche Studien belegen eine höhere Sensitivität und Spezifität der in-house PCR-Assays bei M. pneumoniae-Infektionen als die Kultur [140-143]. Über den Einsatz der real-time PCR zur Diagnostik von M. pneumoniae liegen mehrere Publikationen vor [126,144-146]. Die M. pneumoniae-PCR aus dem Rachenabstrich scheint z.Z. der beste Test für die Diagnose einer Mykoplasmen-Pneumonie zu sein, unter der Voraussetzung, dass eine strenge Qualitätskontrolle durchgeführt wird und die Tests von Labor zu Labor vergleichbar sind $[112,144]$. Eine weitere Validierung bei der Probenaufbereitung, der Amplifikation und der Detektion sowie eine Standardisierung der schon verfügbaren (auch kommerziellen) PCR-Assays ist notwendig, ehe diese Verfahren außerhalb von Speziallaboratorien eingesetzt werden können [147].

Die Arbeitsgruppe empfiehlt (Empfehlungsgrad B) keine routinemäßige Untersuchung auf Mycoplasma pneumoniae bei CAP. Für eine schnelle Diagnose einer M. pneumoniae-Pneumonie ist die PCR aus Rachenabstrichen bei ausreichender Validierung und Standardisierung des Verfahrens am besten geeignet. Als konventionelle Methode kann bei Patienten mit einer Symptomdauer der CAP > 12 Tage und/oder Therapieversagen nach Betalaktam-Antibiotikagabe sowie für epidemiologische Analysen auch der Nachweis von IgMAntikörpern im Serum eingesetzt werden. 


\subsubsection{Diagnostik von Chlamydophila pneumoniae}

Diagnostische Verfahren

Kultur: C. pneumoniae kann als obligat intrazellulärer Erreger nur in Zellkulturen eukaryontischer Zellen angezüchtet werden. Die Methodik ist nur in wenigen Speziallaboratorien verfügbar, verlässliche Angaben zu Spezifität und Sensitivität fehlen aufgrund erheblicher Unterschiede in den Protokollen für Anzucht, Passage und Bestätigungstests $[148,149]$. Trotzdem ist die Kultur das einzige Verfahren, das die Empfindlichkeitsprüfung der Isolate sowie die Möglichkeit der Bestätigung des mikrobiologischen Erfolgs in Therapiestudien ermöglicht [150].

Antikörpernachweise aus dem Serum: Aus dem Serum können prinzipiell IgG-, IgM- und IgA-Antikörper bestimmt werden.

Probleme ergeben sich aus der hohen Prävalenz von IgG-Antikörpern bei Erwachsenen, aus der Kinetik der Antikörper-Antwort bei der Erst-Infektion und der Reinfektion sowie aus dem Fehlen standardisierter Testsysteme. IgM-Antikörper treten in der Regel 2-3 Wochen nach Erkrankungsbeginn auf und sind nach 2-6 Monaten nicht mehr nachweisbar, IgG-Antikörper erreichen oft erst 6-8 Wochen nach Erkrankungsbeginn hohe Titer. Bei Reinfektionen ist eine IgM-Antwort häufig nicht vorhanden und die IgG-Titer steigen rasch innerhalb von 1-2 Wochen. Serologische Tests sind daher in erster Linie für die retrospektive Bestätigung der Diagnose oder für epidemiologische Studien geeignet [151].

Kommerziell erhältlich sind verschiedene Enzym-Immuno-Assays, die jedoch bezüglich Sensitivität und vor allem Spezifität nicht ausreichend validiert sind, um eine Empfehlung auszusprechen [149].

Der einzige von den Centers for Disease Control der USA und dem Laboratory Centre for Disease Control Canada empfohlene serologische Test ist der Mikroimmunfluoreszenztest, da er der einzige Spezies-spezifische Antikörper-Test ist. Allerdings ist der Test technisch aufwendig, die Interpretation ist von der subjektiven Betrachtung des Ablesenden abhängig und weder Reagenzien noch Kriterien für die Testdurchführung sind standardisiert. Ein IgM Titer von $\geq 1: 16$ oder ein 4 -facher IgG-Titeranstieg in einem Serumpaar gilt als beweisend für eine akute Infektion [152].

Nukleinsäure-Amplifikationsverfahren aus Atemwegsmaterialien: Aufgrund der Probleme bei der Kultur und den Antikörpertests scheinen NAT geeignete diagnostische Verfahren für den Nachweis von $C$. pneumoniae zu sein. Angaben zu Sensitivität und Spezifität sind allerdings kaum möglich, da es keinen „Goldstandard" als Vergleich gibt und selbst Studien, die das gleiche PCR-Protokoll verwendet haben, zu sehr unterschiedlichen Resultaten kommen [109,133,151].

C. pneumoniae kann den Respirationstrakt besiedeln. Die klinische Bedeutung dieses Trägerstatus ist unklar. Der Einsatz hochsensitiver PCR-Techniken kann die Nachweisrate hier erhöhen, ohne dass sich diagnostische Schlussfolgerungen bezüglich einer Infektion ziehen lassen.

Die Centers for Disease Control der USA und das Laboratory Centre for Disease Control Canada geben Empfehlungen für die Standardisierung der NAT zum Nachweis von C. pneumoniae, doch bisher sind keine standardisierten Tests verfügbar, die sich für die Routinediagnostik eignen [151]

Auch für die Diagnostik von C. pneumoniae-Infektionen gilt, dass die Einführung der real-time-PCR die Diagnostik weiter beschleunigen und quantifizieren kann, aber auch hier sind bisher nur Studien mit kleinen Fallzahlen publiziert, sodass eine An- wendung in der Routinediagnostik noch nicht empfohlen werden kann $[126,153]$.

Die Arbeitsgruppe empfiehlt (Empfehlungsgrad B) keine routinemäßige Untersuchung auf $C$. pneumoniae bei ambulant erworbenen Atemwegsinfektionen, da derzeit keine Methode der Wahl für die Diagnostik dieses Erregers existiert. Wenn überhaupt eine Untersuchung für notwendig erachtet wird, sind der Mikroimmunfluoreszenztest und die PCR aus respiratorischem Material - soweit die Kriterien für die Testvalidierung eingehalten werden - vorzuziehen.

\subsubsection{Diagnostik respiratorischer Viren}

\section{Diagnostische Verfahren}

Antigen-Nachweis aus respiratorischem Material: Für InfluenzaViren stehen Schnelltests zur Verfügung, die innerhalb von 15 bis 20 Minuten eine ätiologische Diagnose mit einer Sensitivität von 70 -90\% erlauben [154].

Auch für das Respiratory Syncytial Virus (RSV) sind kommerzielle Antigen-Tests verfügbar, allerdings liegt die Sensitivität bei Erwachsenen unter $15 \%$ [150].

Direkte Immunfluoreszenztests (DIF): Der Nachweis in der direkten Immunfluoreszenz ist möglich für Influenza-Viren, Parainfluenza-Viren, Adenoviren und RSV. Valide Daten zu Sensitivität und Spezifität sind nicht vorhanden [154].

Kultur: Grundsätzlich ist eine Virusisolierung mittels Zellkultur für alle genannten respiratorischen Viren möglich. Als Routinemethode kommt dieses Verfahren wegen des hohen methodischen Aufwands und der langen Dauer jedoch nicht in Frage [154].

Nukleinsäure-Amplifikationstechniken: Unabhängig von der Bedeutung der Nukleinsäure-Amplifikationstechniken für epidemiologische Fragestellungen werden sie neben dem direkten Antigennachweis für die Diagnose respiratorischer Virusinfektionen zunehmend zur Methode der Wahl. Ein Vorteil besteht in ihrer höheren Sensitivität im Vergleich zu den herkömmlichen Nachweisverfahren. Dies gilt auch für die Therapie-relevante Influenzavirus-Infektion, bei der diese Technik den kommerziellen Schnelltests, vor allem bei älteren Menschen, überlegen ist. Als sensitives und auch schnelles Verfahren hat sie als MultiplexPCR noch den Vorteil, dass sie auch die häufig auftretenden Virusdoppelinfektionen erfasst.

Wegen derzeit mangelnder therapeutischer Konsequenz und fehlender Standardisierung haben diese Verfahren jedoch bislang vielerorts keinen Eingang in die Routinediagnostik bei respiratorischen Infektionen gefunden $[133,155,156]$.

Die Arbeitsgruppe empfiehlt (Empfehlungsgrad B) keine routinemäßige Diagnostik respiratorischer Viren. In Ausbruchssituationen ist ein Schnellnachweis von Influenza-Viren - möglichst differenzierend zwischen Influenza A und B - sinnvoll. Im Hinblick auf die aktuelle Influenza-Situation wird auf die jeweils aktuellen Informationen des RKI, der WHO und der CDC im Internet verwiesen. 


\section{Antiinfektiva zur Behandlung tiefer Atemwegs- infektionen \\ $\nabla$}

\subsection{Betalaktamantibiotika}

Betalaktamantibiotika wirken über eine Hemmung der bakteriellen Zellwandsynthese. Sie sind nicht wirksam gegen die intrazellulären Chlamydien, Coxiellen und Legionellen und die zellwandlosen Mykoplasmen. Unter den Basispenicillinen sind Penicillin G, Oralpenicilline (Phenoxymethylpenicillin) und Aminopenicilline dosisabhängig gut wirksam gegen $S$. pneumoniae und penicillinempfindliche Staphylokokken. Die Aminopenicilline Amoxicillin und Ampicillin haben ein erweitertes Wirkspektrum vor allem gegen Haemophilus-Arten, soweit diese keine Betalaktamasebildner sind (in Deutschland $\sim 3-7 \%$ ). Sie gelten aufgrund der sehr häufigen Betalaktamaseproduktion bei M. catarrhalis und bei Klebsiellen als in der Regel unwirksam gegenüber diesen Pathogenen. Die Aktivität von Aminopenicillinen gegenüber diesen Erregern von Atemwegsinfektionen kann mittels Kombination mit einem Betalaktamaseinhibitor wiederhergestellt werden. Solche Kombinationen sind auch sehr gut wirksam gegen Anaerobier. Ein ähnliches Wirkspektrum besitzt auch Ertapenem, ein Carbapenem, wobei die Aktivität gegenüber Enterobacteriaceae höher ist.

Unter den Cephalosporinen sind Cefuroxim, Ceftriaxon und Cefotaxim relevante Substanzen zur Therapie von ambulant erworbenen Atemwegsinfektionen. Ceftriaxon und Cefotaxim besitzen hohe Aktivität gegenüber S. pneumoniae, Haemophilus spp., Moraxella spp. und Klebsiella spp. Cefuroxim hat eine sehr gute Wirksamkeit gegenüber methicillinsensiblen Staphylokokken, die Aktivität gegenüber S. pneumoniae ist hier etwas schwächer. Bei Ceftriaxon und Cefotaxim verhält es sich umgekehrt, hier ist die Aktivität gegenüber methicillinsensiblen Staphylokokken schwächer als bei Cefuroxim. Alle drei Cephalosporine haben keine ausreichende Wirksamkeit gegenüber Anaerobiern.

Bei der schweren ambulant erworbenen Pneumonie und Risikofaktoren für $P$. aeruginosa-Infektion kommen pseudomonaswirksame Betalaktame zur Anwendung. Dazu gehören Piperacillin, Ceftazidim und Cefepim sowie die beiden Carbapeneme Imipenem und Meropenem.

\subsubsection{Orale Basispenicilline: Penicillin V und Amoxicillin}

Durch die höheren Serum- und Gewebespiegel gilt Amoxicillin bei $S$. pneumoniae als am besten geeignetes Oralpenicillin bei Pneumonien; zusätzlich werden damit die meisten Haemophilus spp. erfasst. Mit einer Dosis von $750 \mathrm{mg}$ alle $8 \mathrm{~h}$ bei einem Körpergewicht von $<70 \mathrm{~kg}$ bzw. $1000 \mathrm{mg}$ alle $8 \mathrm{~h}$ bei einem Körpergewicht von $\geq 70 \mathrm{~kg}$ sind in der Regel ausreichende Wirkspiegel erreichbar (erwartete mittlere Serumspitzenspiegel: 10$15 \mathrm{mg} / \mathrm{l})$. Atemwegsinfektionen durch S. pneumoniae mit verminderter Penicillinempfindlichkeit (MHK-Werte 0.125-1 mg/l) können mit Amoxicillin oral in der angegebenen Dosis durchaus noch adäquat behandelbar sein. Niedrigere Dosen können das Risiko für das Auftreten von penicillinminderempfindlichen $S$. pneumoniae erhöhen und sollten heute bei Pneumonien nicht mehr verwendet werden [157]. Zu den häufigsten unerwünschten Wirkungen zählt das Arzneimittelexanthem. Es ist mit einer Frequenz von $5-10 \%$ etwas häufiger als bei Cephalosporinen. Gastrointestinale Störungen sind die zweithäufigsten unerwünschten Wirkungen.

\subsubsection{Parenterale Basispenicilline: Penicillin G und} Ampicillin

Die Halbwertszeit dieser Substanzen nach intravenöser Applikation ist sehr kurz ( $<1 \mathrm{~h}$ ). Um ausreichende Serum- und Gewebekonzentrationen zu erreichen, die auch adäquat für Atemwegsinfektionen durch S. pneumoniae mit verminderter Penicillinempfindlichkeit sind, sind höhere Dosen alle 6-8h oder sehr kurze Dosierungsintervalle (z.B. 2 Mio IE alle 4 h) nötig. In vielen Kliniken hat sich die Gabe von 5 Mio. IE Penicillin G (erwartete mittlere Serumspitzenspiegel: $>50 \mathrm{mg} / \mathrm{l}$ ) alle $6-8 \mathrm{~h}$ oder Ampicillin $2 \mathrm{~g}$ (erwartete mittlere Serumspitzenspiegel: $>50 \mathrm{mg} / \mathrm{l}$ ) alle $6-$ $8 \mathrm{~h}$ als gut wirksam, verträglich und ökonomisch bewährt.

Beide Substanzen sind bei Raumtemperatur wenig stabil und sollten spätestens innerhalb $1 \mathrm{~h}$ nach Herstellen der Infusionslösung appliziert werden. Häufigste Nebenwirkungen sind auch hier allergische Exantheme - oft erst nach einigen Tagen Behandlung auftretend. Akutreaktionen, insbesondere anaphylaktoide Reaktionen sind selten $(<0,1 \%)$, ein anaphylaktischer Schock ist seltener (<0,01\%). Bei Ampicillin werden auch nicht-allergische Exantheme (typisch bei infektiöser Mononukleose) beobachtet.

\subsubsection{Aminopenicillin-Betalaktamaseinhibitor- Kombinationen}

Zwei verschiedene Kombinationspräparate sind jeweils oral und parenteral erhältlich, Amoxicillin/Clavulansäure und Ampicillin/ Sulbactam (in der oralen Form als Sultamicillin, eine Doppelesterverbindung von Ampicillin und Sulbactam). Vorteil dieser Substanzen in der Behandlung von ambulant erworbenen Pneumonien ist das um Moraxella spp., Klebsiella spp., S. aureus und Anaerobier erweiterte Spektrum; die gelegentlich auftretenden Betalaktamase-positiven Haemophilus spp. werden ebenfalls erfasst. Nachteile sind die gastrointestinalen Störungen, die häufiger im Vergleich zu Basispenicillinen zu sein scheinen. Bei beiden Substanzen ist eine Kontrolle von Blutbild, Serum-Kreatinin und Leberfunktionsparametern bei längerer Anwendung empfohlen. Bei Amoxicillin/Clavulansäure sollte an die erhöhte Kaliumzufuhr gedacht werden. Die Resorption von Amoxicillin/Clavulansäure wird bei Einnahme kurz vor dem Essen verbessert, die Resorption der Wirkstoffe aus der Sultamicillin-Zubereitung scheint nahrungsunabhängig.

\subsubsection{Oralcephalosporine}

Gegenüber S. pneumoniae stellen Oralcephalosporine Mittel der zweiten Wahl dar; die MHK-Werte bei penicillinempfindlichen und penicillinresistenten S. pneumoniae liegen bei allen Präparaten deutlich über denen von Amoxicillin. Hinsichtlich erreichbarer Spiegel nach oraler Verabreichung (z.B. 10-15 mg/l nach $500 \mathrm{mg}$ Cefaclor oder Cefuroximaxetil) im Verhältnis zur MHK sind die Substanzen daher dem Amoxicillin unterlegen. Unter den verschiedenen Gruppen von Oralcephalosporinen gelten die Substanzen der Gruppe 1 (Cefalexin, Cefaclor, Cefadroxil) als nicht gut geeignet zur kalkulierten Behandlung der ambulant erworbenen Pneumonie, vor allem aufgrund ihrer schlechten Wirksamkeit bei Haemophilus spp. Bei Präparaten der Gruppe 2 (u.a. Cefuroxim-Axetil) bestehen diese Wirklücken nicht, wenngleich die Aktivität gegenüber Haemophilus spp. unter den gegebenen pharmakokinetischen/pharmakodynamischen Bedingungen nicht bei allen Substanzen zuverlässig ist. Die Gruppe 3-Präparate (z.B. Cefpodoximproxetil, Cefixim u.a.) sind stärker wirksam gegenüber Haemophilus spp., Moraxella spp. und vor allem auch Klebsiella spp., dabei sind jedoch einige Substanzen (Cefetamet, Ceftibuten und Cefixim) klinisch nicht wirksam gegenüber 


\begin{tabular}{|c|c|c|c|}
\hline \multirow{3}{*}{$\begin{array}{l}\text { Nichtbreitspektrum- } \\
\text { Betalaktame }\end{array}$} & \multirow{3}{*}{$\begin{array}{l}\text { Substanz } \\
\text { Penicillin G }\end{array}$} & \multicolumn{2}{|c|}{ Empfohlene Initialdosis (pro Tag) } \\
\hline & & parenteral & oral \\
\hline & & \multicolumn{2}{|l|}{$3-4 \times 5$ Mio IE } \\
\hline & \multicolumn{2}{|l|}{ Amoxicillin } & $\begin{array}{l}\geq 70 \mathrm{~kg}: 3 \times 1,0 \mathrm{~g} \\
<70 \mathrm{~kg}: 3 \times 750 \mathrm{mg}\end{array}$ \\
\hline & Ampicillin & $3-4 \times 2,0 \mathrm{~g}$ & \\
\hline & Cefuroxim-Axetil & & $2 \times 500 \mathrm{mg}$ \\
\hline & Cefuroxim & $3 \times 1,5 \mathrm{~g}$ & \\
\hline & Amoxicillin-Clavulansäure & $3 \times 2,2 \mathrm{~g}$ & $2 \times 875 / 125 \mathrm{mg}$ \\
\hline & Ampicillin-Sulbactam & $3 \times 3,0 \mathrm{~g}$ & $2 \times 750 \mathrm{mg}$ \\
\hline \multirow[t]{9}{*}{ Breitspektrum-Betalaktame } & Ceftriaxon & $1 \times 2,0 \mathrm{~g}$ & - \\
\hline & Cefotaxim & $3 \times 2,0 \mathrm{~g}$ & - \\
\hline & Ertapenem & $1 \times 1,0 \mathrm{~g}$ & - \\
\hline & Piperacillin-Tazobactam & $3 \times 4,5 \mathrm{~g}$ & - \\
\hline & Piperacillin/Sulbactam & $3 \times 4,0 / 1,0 \mathrm{~g}$ & - \\
\hline & Ceftazidim & $3 \times 2,0 \mathrm{~g}$ & - \\
\hline & Cefepim & $3 \times 2,0 \mathrm{~g}$ & - \\
\hline & Imipenem & $3 \times 1,0 \mathrm{~g}$ & - \\
\hline & Meropenem & $3 \times 1,0 \mathrm{~g}$ & - \\
\hline \multirow[t]{4}{*}{ Makrolide } & Azithromycin & $1 \times 500 \mathrm{mg}$ & $1 \times 500 \mathrm{mg}$ \\
\hline & Clarithromycin & $2 \times 500 \mathrm{mg}$ & $2 \times 500 \mathrm{mg}$ \\
\hline & Roxithromycin & & $1 \times 300 \mathrm{mg}$ \\
\hline & Erythromycin & $3 \times 1,0 \mathrm{~g}$ & - \\
\hline Tetracycline & Doxycyclin & $1 \times 200 \mathrm{mg}$ & $1 \times 200 \mathrm{mg}$ \\
\hline \multirow[t]{3}{*}{ Fluorchinolone } & Ciprofloxacin & $3 \times 400 \mathrm{mg}$ & $2 \times 500-750 \mathrm{mg}$ \\
\hline & Levofloxacin & $1-2 \times 500 \mathrm{mg}^{*}$ & $1-2 \times 500 \mathrm{mg}^{*}$ \\
\hline & Moxifloxacin & $1 \times 400 \mathrm{mg}$ & $1 \times 400 \mathrm{mg}$ \\
\hline Nucleosid-Analoga & Aciclovir & $3 \times 10 \mathrm{mg} / \mathrm{kg} \mathrm{KG}$ & - \\
\hline
\end{tabular}

Tab. 8 Dosisempfehlungen bei der kalkulierten Initialtherapie der ambulant erworbenen Pneumonie (Tagesdosis bei Erwachsenen mit einem KG von 50 - $85 \mathrm{~kg}$ sowie normaler Nieren- und Leberfunktion).

*Höhere Initialdosis $(2 \times 500 \mathrm{mg}$ ) bei schwerer CAP empfohlen.

S. aureus, und auch die Wirksamkeit gegenüber S. pneumoniae im Verhältnis zu den erreichbaren Serum- und Gewebekonzentrationen ist nicht bei allen Präparaten vergleichbar. Zur Therapie ambulant erworbener Pneumonie als geeignet und klinisch gut untersucht kann in erster Linie Cefuroxim-Axetil gelten. Die empfohlene Tagesdosis von Cefuroxim-Axetil bei ambulant erworbener Pneumonie beträgt $2 \times 500 \mathrm{mg}$. Diese Dosierung sollte nicht unterschritten werden. Die Resorption ist am besten bei Einnahme nach den Mahlzeiten; die Bioverfügbarkeit ist in dieser Situation 50-60\%. Häufigere Nebenwirkungen sind gastrointestinale Störungen und Exantheme.

\subsubsection{Parenterale Cephalosporine}

Zu den prinzipiell geeigneten und klinisch gut untersuchten Substanzen gehören Cefuroxim sowie Ceftriaxon und Cefotaxim. Zur gezielten Therapie bei nachgewiesener in vitro-Empfindlichkeit können auch andere Präparate verwendet werden wie beispielsweise Cefazolin (Dosierung: $3 \times 2 \mathrm{~g}$ ), bei notwendiger Pseudomonaswirksamkeit kommen nur Ceftazidim oder Cefepim in Frage. Die für Cefuroxim bei normaler Nierenfunktion empfohlene Tagesdosis ist $3 \times 1,5 \mathrm{~g}$ (bei invasiver Staphylokokkeninfektion: $4 \times 1,5 \mathrm{~g}$ ). Damit werden $1 \mathrm{~h}$ nach Infusion Plasmaspiegel von $\sim 40 \mathrm{mg} / \mathrm{l}$ erreicht. Die Serumhalbwertzeit beträgt etwa 1,5 h. Bei ambulant erworbener Pneumonie liegen auch Erfahrungen mit geringeren Dosen vor (z. B. $2-3 \times 750 \mathrm{mg}$ ); allerdings war in einer retrospektiven Studie diese Dosierung bei der Behandlung von Infektionen durch penicillinminderempfindliche $S$. pneumoniae mit vermehrten Versagern assoziiert [64]. Diese niedrige Dosis wird zur kalkulierten Therapie daher nicht empfohlen. Die Cephalosporine Ceftriaxon und Cefotaxim unterscheiden sich in erster Linie durch ihre Halbwertszeit, die bei Ceftriaxon mit $8 \mathrm{~h}$ wesentlich länger ist. Beide Substanzen sind in vitro wirksamer als Cefuroxim gegen Haemophilus spp., Moraxella spp., Klebsiella spp. und gegen S. pneumoniae. Dies gilt auch für penicillinminderempfindliche S. pneumoniae. S. pneumoniae mit intermediärer Penicillinempfindlichkeit gelten bei den derzeitigen Grenzwerten $\mathrm{zu} \sim 50 \%$ bereits als cefuroximresistent. Penicillinresistente $S$. pneumoniae sind dagegen noch in etwa 90-95\% empfindlich bzw. intermediär gegenüber Ceftriaxon und Cefotaxim (MHK $<4 \mathrm{mg} / \mathrm{l})$.

Eine Tagesdosis von $1 \times 1 \mathrm{~g}$ Ceftriaxon hat sich bei ambulant erworbener Pneumonie als ausreichend gezeigt. Für die kalkulierte Initialtherapie wird eine Tagesdosis von $1 \times 2 \mathrm{~g}$ empfohlen. Die Erfahrungen mit niedrig dosiertem Cefotaxim i.v. $(2 \times 1 \mathrm{~g})$ bei dieser Indikation sind geringer; bei der kurzen Halbwertszeit von Cefotaxim wird daher ein Dosierungsintervall von mindestens $8 \mathrm{~h}$ empfohlen. Bei der gezielten Behandlung von S. pneumoniae-Pneumonien mit verminderter Penicillinempfindlichkeit sowie bei Haemophilus- und Klebsiellen-Pneumonie sollte ähnlich wie bei einer kalkulierten initialen Therapie eine höhere Tagesdosis verwendet werden (s. Tab. 8).

\subsubsection{Ertapenem}

Es handelt sich um ein Carbapenem mit langer Halbwertszeit ohne relevante Aktivität gegenüber $P$. aeruginosa, jedoch mit guter Aktivität gegenüber Streptokokken, Enterobacteriaceae und Anaerobiern. Ertapenem wird einmal täglich in einer Dosis von $1,0 \mathrm{~g}$ intravenös infundiert. Nach Infusion von $1 \mathrm{~g}$ Ertapenem liegen die mittleren Plasmakonzentrationen bei $\sim 150 \mu \mathrm{g} / \mathrm{ml}$; nach 12 Stunden sind $\sim 10 \mu \mathrm{g} / \mathrm{ml}$ und nach 24 Stunden $\sim 1 \mu \mathrm{g} / \mathrm{ml}$ zu erwarten. Die Halbwertszeit beträgt etwa vier Stunden, die Proteinbindung ist mit 90-95\% hoch, die Ausscheidung erfolgt überwie- 
gend renal. Wirksamkeit bei ambulant erworbener Pneumonie sowie Häufigkeit und Art von Nebenwirkungen waren bei einer Dosierung von $1 \times 1 \mathrm{~g}$ ähnlich wie bei Ceftriaxon. Selten werden Haut- (Exantheme, Juckreiz) und ZNS-Reaktionen, wie Kopfschmerzen, Verwirrtheitszustände und Krampfanfälle während der Behandlung beobachtet.

\subsubsection{Pseudomonaswirksame Betalaktame}

Hierzu gehört Piperacillin, ein Ureidopenicillin, das eine gute bis sehr gute Aktivität gegenüber $P$. aeruginosa besitzt. Das sonstige Wirkspektrum ähnelt dem der Aminopenicilline, obwohl die Invitro-Aktivität gegenüber Enterobacteriaceae höher ist. In Kombination mit Sulbactam oder Tazobactam erweitert sich das Wirkspektrum und umfasst auch $S$. aureus und Anaerobier, die Aktivität gegenüber $P$. aeruginosa ist jedoch nur unwesentlich verbessert. Der als freier Kombinationspartner angebotene Betalaktamaseinhibitor Sulbactam hat mit Piperacillin in vitro eine deutlich geringere Wirksamkeit gegen Enterobacteriaceae als Piperacillin-Tazobactam; eine Übertragbarkeit der in-vitro-Testergebnisse für Piperacillin-Tazobactam auf Piperacillin-Sulbactam ist für Enterobacteriaceae nicht zulässig. Die fixe Kombination ist gut untersucht, während ausführliche Studien zur freien Kombination mit z.B. Sulbactam fehlen. Die Piperacillin-Dosierung beträgt $3 \times 4 \mathrm{~g}$ täglich, bei fixer Kombination mit Tazobactam $3 \times 4,5 \mathrm{~g}$, in Kombination mit Sulbactam $3 \times 4 \mathrm{~g}+1 \mathrm{~g}$. Die Nebenwirkungen sind ähnlich den Aminopenicillinen.

Cephalosporine mit Pseudomonas-Wirksamkeit sind Ceftazidim und Cefepim. Ceftazidim hat allerdings keine ausreichende Aktivität gegenüber grampositiven Kokken wie S. pneumoniae und methicillinsensiblen $S$. aureus und ist daher für die kalkulierte Monotherapie ambulant erworbener Atemwegsinfektionen nicht geeignet. Beide Substanzen werden bei schweren Infektionen in einer Dosis von $3 \times 2 \mathrm{~g}$ täglich verabreicht. Sie werden nahezu vollständig renal ausgeschieden und ihre Dosis muss an die Nierenfunktion angepasst werden. Häufige Nebenwirkungen sind Durchfall, Exantheme und Reaktionen an der Injektionsstelle.

Die beiden Carbapeneme Imipenem und Meropenem besitzen ein breites antibakterielles Spektrum. Die MHK-Werte bei gramnegativen Bakterien sind für Meropenem um etwa zwei Verdünnungsstufen niedriger als für Imipenem. Bei beiden ist die Aktivität gegen $P$. aeruginosa relativ geringer; die MHK-Werte gruppieren sich um 0,5 (Meropenem) bzw. $1 \mathrm{mg} / \mathrm{l}$ (Imipenem), die klinische Aktivität ist jedoch in den meisten Fällen ausreichend. Die Aktivität von Meropenem bei Streptokokken, Staphylokokken und Acinetobacter spp. ist geringer als die des Imipenems. Beide wirken gut auf Anaerobier. Beide haben als Wirklücke Stenotrophomonas maltophilia.

Nach 30-minütiger Infusion von $1 \mathrm{~g}$ der Substanzen liegen die Spitzenkonzentrationen im Plasma bei etwa 50 bis $60 \mathrm{mg} / \mathrm{l}$. Bei einer Halbwertszeit von $1 \mathrm{~h}$ bei Nierengesunden sinken nach 46 Stunden die wirksamen Plasmaspiegel auf $\sim 1 \mathrm{mg} / \mathrm{l}$. Meropenem kann auch als Bolus verabreicht werden.

Übelkeit und Erbrechen bei ca. 3-4\% der Patienten sowie Diarrhöen in einer ähnlichen Inzidenz sind die häufigsten unerwünschten Reaktionen. In sehr seltenen Fällen wurden unter der Therapie mit Imipenem Krampfanfälle gesehen.

\subsection{Tetracycline: Doxycyclin}

Doxycyclin ist ein Proteinbiosyntheseinhibitor mit einem anderen Angriffspunkt als Makrolide oder Linezolid und ebenfalls bakteriostatisch wirksam. Die meisten Haemophilus spp. und Moraxella spp. sind empfindlich, weniger sicher ist die Aktivität ge- genüber $S$. pneumoniae und $S$. aureus mit MHK-Werten bei empfindlichen Isolaten meist $<0,5 \mathrm{mg} / \mathrm{l}$. Die Substanz ist aktiv gegenüber M. pneumoniae (MHK-Werte meist $0,25-0,5 \mathrm{mg} / \mathrm{l}$ ) sowie gegen $C$. pneumoniae (MHK-Werte bis $0,25 \mathrm{mg} / \mathrm{l}$ ) und Rickettsien incl. Coxiella burnetii. Doxycyclin ist mäßig aktiv auch gegen Legionellen (MHK-Werte 1 bis $4 \mathrm{mg} / \mathrm{l}$ ). Die Empfindlichkeit von $S$. aureus gegenüber Doxycyclin hat sich in den letzten Jahren eher verbessert; die in-vitro-Resistenzrate in Deutschland beträgt $<10 \%$.

Es existieren nur wenige neuere klinische Studien zur Wirksamkeit in der kalkulierten oder gezielten Therapie der ambulant erworbenen Pneumonie. Die Substanz ist Mittel der Wahl bei QFieber. Bei Rickettsia conori-Infektionen scheinen die Behandlungsergebnisse mit neueren Makroliden denen von Doxycyclin vergleichbar. Tierexperimentell ist Doxycyclin bei C. pneumoniae-Infektionen nicht schlechter wirksam als neuere Makrolide. Die Plasmaspitzenspiegel nach oraler Einnahme von $200 \mathrm{mg}$ liegen bei 3-4 mg/l. Die Halbwertszeit beträgt $16 \mathrm{~h}$. Die empfohlene tägliche Dosierung bei Patienten mit einem Körpergewicht $>70 \mathrm{~kg}$ ist $1 \times 200 \mathrm{mg}$; bei leichteren Patienten wird $1 \times 100 \mathrm{mg}$ täglich nach einer initialen Gabe von $1 \times 200 \mathrm{mg}$ empfohlen. Eine tägliche Dosis von $300 \mathrm{mg}$ sollte bei mehrtägiger Behandlung nicht überschritten werden.

Häufigste Nebenwirkungen sind gastrointestinale Störungen. Die Einnahme sollte mit einer Mahlzeit und reichlich Flüssigkeit erfolgen. Die gleichzeitige Einnahme von aluminium-, calcium(auch Milch) und magnesiumhaltigen Nahrungszusatzstoffen oder Arzneimitteln führt über Komplexbildung zur abgeschwächten Resorption und Wirksamkeit. Eine Reihe anderer Arzneimittelinteraktionen ist zu beachten. Sonnenbäder und andere UV-Lichtexposition unter Doxycyclin-Behandlung sollten vermieden werden wegen der Gefahr der Photosensibilisierung. Schwere Lebererkrankungen stellen eine relative Kontraindikation dar. Nicht verwendet werden darf die Substanz in der Schwangerschaft und bei Kindern $<8$ Jahre. Intravenöse Behandlung ist möglich, die Injektion muss langsam (über mehrere Minuten) erfolgen.

\subsection{Makrolide und Azalide}

Makrolide sind wie Doxycyclin Proteinbiosynthesehemmer. Ihr Angriffspunkt ist die 50 s-Ribosomenuntereinheit. Sie wirken bakteriostatisch. Die neueren Substanzen zeichnen sich im Vergleich zu Erythromycin durch vermehrte Säurestabilität und bessere orale Bioverfügbarkeit aus, teilweise auch durch ein geringeres Potential zu Arzneimittel-Interaktionen. In Deutschland ist neben Erythromycin auch Clarithromycin und Azithromycin zur parenteralen Anwendung verfügbar.

Die Serumspitzenspiegel nach Infusion über $1 \mathrm{~h}$ von $1 \mathrm{~g}$ Erythromycin betragen etwa $30-40 \mathrm{mg} / \mathrm{l}$; die Halbwertszeit beträgt $\sim 2 \mathrm{~h}$; das empfohlene Dosierungsintervall ist 6-8h. Bei oraler Gabe von $500 \mathrm{mg}$ erreicht man eine Serumspitzenkonzentration von 1 - $2 \mathrm{mg} / \mathrm{l}$. Das Verteilungsvolumen ist $\sim 0,7 \mathrm{l} / \mathrm{kg}$. Höhere Serumkonzentrationen lassen sich mit Roxithromycin erreichen ( 10 mg/l nach $300 \mathrm{mg}$ ). Die Halbwertszeit dieser Substanz beträgt $\sim 12 \mathrm{~h}$; sie muss insofern nur einmal am Tag verabreicht werden. Das Verteilungsvolumen ist geringer als das von Erythromycin; unter pharmakodynamischen Gesichtspunkten sind die beiden Substanzen bei oraler Gabe üblicher Dosen vergleichbar.

Die Verteilungsvolumina von Clarithromycin sind größer, die von Azithromycin erheblich größer. Relativ niedrige Serumspiegel dieser Substanzen bei sehr hohen Gewebespiegeln sind die Folge. 
Nach Gabe von 500 mg Clarithromycin erreicht man entsprechend der besseren oralen Bioverfügbarkeit im Vergleich zum Erythromycin Serumkonzentrationen von 3-4 mg/l. Die Halbwertszeit der Substanz beträgt $\sim 3-4 \mathrm{~h}$. Für Azithromycin liegen die Serumspitzenkonzentrationen nach Einnahme von $500 \mathrm{mg}$ bei $0,4 \mathrm{mg} / \mathrm{l}$. Charakteristisch für Azithromycin sind die sehr lange Eliminationshalbwertzeit von etwa 20 bis 40 Stunden und die hohen Konzentrationen im Gewebe. Das Verteilungsvolumen wird mit 23 bis 31 l/kg angegeben. Die subinhibitorischen Wirkstoffkonzentrationen, wie sie infolge dieser langen Halbwertszeit vorkommen, sind mit einer vermehrten Resistenzselektion bei $S$. pneumoniae assoziiert worden $[33,79]$.

Im Vergleich zu Erythromycin sind die MHK-Werte gegenüber $S$. pneumoniae bei den neueren Substanzen ähnlich bzw. etwas geringer. Die Erythromycinresistenz gilt hierbei als Marker für eine komplette in-vitro-Kreuzresistenz gegenüber allen Makroliden/ Azaliden, nicht jedoch gegenüber den Ketoliden. Bei den üblicherweise empfohlenen oralen Dosen sind unter Berücksichtigung der pharmakokinetischen/pharmakodynamischen Aspekte bei Pneumokokken-Pneumonien mit den neueren Substanzen keine besseren Behandlungserfolge zu erwarten. Vorteile der Substanzen liegen beim längeren Dosierungsintervall bzw. kürzerer Behandlungsdauer sowie bei geringeren Nebenwirkungen. Die Aktivität der neueren Makrolide gegenüber Haemophilus spp. ist nicht sehr hoch (bei Clarithromycin oft im Bereich $8-16 \mathrm{mg} / \mathrm{l}$, bei Roxithromycin etwas höher, bei Azithromycin etwas niedriger) und die klinische Wirkung entsprechend unsicher. Im Fall von Clarithromycin wirkt in vivo zusätzlich der 14-OH-Metabolit. Gut ist die Aktivität dagegen gegenüber Moraxella spp. (mit mittleren MHK-Werten <0,25 mg/l).

Exzellent ist die Aktivität von Clarithromycin gegenüber C. pneumoniae (MHK-Werte $\leq 0,015 \mathrm{mg} / \mathrm{l}$ ). Die Aktivität von Azithromycin ist vergleichsweise schwächer und derjenigen von Erythromycin vergleichbar (MHK-Werte $\leq 0,25 \mathrm{mg} / \mathrm{l}$ ); Roxithromycin zeigt MHK-Werte $\leq 0,5 \mathrm{mg} / \mathrm{l}$.

Gegenüber M. pneumoniae hat Azithromycin die relativ stärkste Aktivität $\left(\mathrm{MHK}_{90}<0,001 \mathrm{mg} / \mathrm{l}\right)$. Die MHK-Werte der anderen Makrolide unterscheiden sich wenig. Makrolid-resistente $M$. pneumoniae-Varianten wurden vereinzelt beschrieben.

Gegenüber Legionella spp. ist Clarithromycin die in vitro wirksamste Substanz $\left(\mathrm{MHK}_{90} \leq 0.004 \mathrm{mg} / \mathrm{l}\right)$. Die MHK-Werte von Erythromycin, Azithromycin und Roxithromycin sind höher ( $\mathrm{MHK}_{90^{-}}$ Werte $\sim 0,125 \mathrm{mg} / \mathrm{l})$. Die Wirkung von Clarithromycin auf intrazelluläre Legionellen sowie im Tiermodell scheint allerdings nicht besser als die der anderen Makrolide zu sein und ist nach bisherigen Daten der Fluorchinolonwirkung unterlegen.

Dosisempfehlungen sind in Tab. 8 aufgeführt. Azithromycin wird in einer Gesamtdosis von 1,5 g über einen Zeitraum von 3 bis 5 Tagen verabreicht. Bei allen Substanzen stehen gastrointestinale Beschwerden als unerwünschte Wirkungen im Vordergrund. Im Vergleich zu Erythromycin sind diese unerwünschten Wirkungen bei allen neueren Makroliden seltener. Selten kann es zu ZNS-Wirkungen oder Hautreaktionen kommen. Die Venenverträglichkeit bei i.v. Gabe von Erythromycin und Clarithromycin ist schlecht. Alle Makrolide können selten eine Verlängerung der QTc-Zeit im EKG verursachen. Vorsicht ist entsprechend geboten bei Patienten mit koronarer Herzkrankheit, bekannten ventrikulären Arrhythmien, Hypokaliämie, Bradykardie oder gleichzeitige Anwendung von anderen Substanzen, die die QTc-Zeit verlängern.

\subsection{Lincosamide: Clindamycin}

Clindamycin ist ein halbsynthetisches Derivat des Lincomycins. Es ist gegen S. pneumoniae (MHK-Werte deutlich unter $0,5 \mathrm{mg} / \mathrm{l}$ ) und $S$. aureus (MHK-Werte bis $0,5 \mathrm{mg} / \mathrm{l}$ bei Empfindlichkeit) wirksam, außerdem gegen die meisten Anaerobier (Resistenzen möglich vor allem bei Clostridien und Bacteroides spp.). Es hat keine ausreichende Wirkung gegen $M$. pneumoniae, $C$. pneumoniae und Legionella spp. Es ist nicht wirksam gegen Haemophilus spp., Moraxella spp. und andere aerobe gramnegative Bakterien. Erythromycinresistente Staphylokokken sind in aller Regel auch clindamycinresistent, werden jedoch in Routine-Resistenztests nicht immer als solche erkannt.

Die orale Bioverfügbarkeit ist mit $75 \%$ gut. Nach oraler Einnahme von $300 \mathrm{mg}$ wird ein mittlerer Serumspitzenspiegel von $\sim 4 \mathrm{mg} / \mathrm{l}$ erreicht. Bei intravenöser Gabe von $600 \mathrm{mg}$ beträgt die mittlere Serumspitzenkonzentration $\sim 9-12 \mathrm{mg} / \mathrm{l}$. Die Halbwertszeit ist etwa $2,5 \mathrm{~h}$. Ein Dosierungsintervall von $8 \mathrm{~h}$ ist ausreichend. Klinische Erfahrungen bei der Behandlung von Pneumokokkenpneumonien sind gering.

\subsection{Fluorchinolone}

\subsubsection{Levofloxacin und Moxifloxacin}

Beide gehören zu den auf dem deutschen Markt erhältlichen Fluorchinolonen, die als geeignet und in klinischen Studien ausreichend validiert zur Behandlung der ambulant erworbenen Pneumonie gelten. Beide Substanzen sind oral und parenteral verfügbar.

Die Aktivität von Moxifloxacin gegenüber S. pneumoniae ist stärker als die von Levofloxacin. Die $\mathrm{MHK}_{90}$-Werte betragen für Moxifloxacin $\sim 0,125 \mathrm{mg} / \mathrm{l}$ und für Levofloxacin $\sim 1 \mathrm{mg} / \mathrm{l}$. Ähnliche MHK-Werte finden sich auch für M. pneumoniae. Unter Berücksichtigung pharmakokinetisch-pharmakodynamischer Eigenschaften sind beide Präparate dosisabhängig bei Infektion durch diese Erreger als ähnlich effektiv zu betrachten. Experimentelle Daten zeigen allerdings bei einer Dosissimulation von $1 \times 400 \mathrm{mg}$ (Moxifloxacin) versus $1 \times 500 \mathrm{mg}$ (Levofloxacin) eine leichte Überlegenheit von Moxifloxacin bei fluorchinolonempfindlichen S. pneumoniae, was bei S. pneumoniae mit einer oder mehreren Fluorchinolonresistenz-assoziierten Mutationen eine höhere Behandlungssicherheit bieten könnte. In klinischen Studien wurden jedoch mit einer Dosierung von $1 \times 500 \mathrm{mg}$ Levofloxacin sehr gute Resultate erzielt, sodass diese Dosierung bei der nicht schweren ambulant erworbenen Pneumonie empfohlen werden kann. Bei der schweren ambulant erworbenen Pneumonie wird dagegen eine höhere Dosis von Levofloxacin für die initiale Gabe empfohlen. Im Unterschied zu Moxifloxacin kann Levofloxacin in dieser höheren Dosis als für fluorchinolonempfindliche P. aeruginosa klinisch ausreichend wirksam betrachtet werden.

Fluorchinolone sind hochaktiv gegen Haemophilus spp., Moraxella spp. und in der Regel auch gegen Klebsiella spp. Die Aktivität von Levofloxacin und Moxifloxacin gegenüber Legionellen ist besser $\left(\mathrm{MHK}_{90}\right.$-Werte $\sim 0,06 \mathrm{mg} / \mathrm{l}$ ) als die von Clarithromycin; auch in Zellkulturinfektionsmodellen wirken sie besser als Makrolide. Levofloxacin und Moxifloxacin sind ebenfalls aktiv gegen C. pneumoniae. Ähnlich den Makroliden scheinen sie dabei nur zur Keimzahlreduktion, jedoch nicht zur Eradikation geeignet. Das Wirkspektrum von Moxifloxacin umfasst auch Anaerobier.

Die orale Bioverfügbarkeit beider Substanzen ist sehr gut. Der mittlere Serumspitzenspiegel nach oraler Einnahme von $500 \mathrm{mg}$ Levofloxacin beträgt 5-6 mg/l; entsprechende Werte nach Einnahme von $400 \mathrm{mg}$ Moxifloxacin sind $3 \mathrm{mg} / \mathrm{l}$. Die Konzentrationen in der bronchopulmonalen Epithelflüssigkeit sind deutlich 
höher als die Serumkonzentrationen. Die Verteilungsvolumina betragen $\sim 1,2$ l/kg (Levofloxacin) bzw. 2,5 l/kg (Moxifloxacin). Die Eliminationshalbwertzeit für Levofloxacin beträgt $\sim 7 \mathrm{~h}$, die Proteinbindung ist mit Werten zwischen 24 und 38\% relativ niedrig. Die Elimination von Levofloxacin erfolgt fast ausschließlich renal und ist daher von der Nierenfunktion abhängig. Moxifloxacin dagegen wird mit einer Halbwertszeit von etwa $13 \mathrm{~h}$ überwiegend hepatisch eliminiert. Nur etwa 20\% lassen sich unverändert im Urin nachweisen. Da der Metabolismus der Substanz unabhängig von der Aktivität hepatischer Monooxygenasen ist, sind entsprechende Interaktionen nicht zu erwarten. Bei eingeschränkter Nierenfunktion muss die Dosierung von Moxifloxacin nicht reduziert werden.

Häufigste unerwünschte Wirkungen sind bei beiden Substanzen gastrointestinale Störungen (Übelkeit, Diarrhö, Erbrechen, Bauchschmerzen) sowie Leberfunktionsstörungen. Es sind Fälle von tödlicher Hepatitis im Zusammenhang mit Moxifloxacin berichtet worden. Moxifloxacin sollte nur angewendet werden, wenn andere Antibiotika, die für die initiale Behandlung üblicherweise empfohlen werden, bei der ambulant erworbenen Pneumonie für ungeeignet erachtet und bei der akuten Exazerbation der chronischen Bronchitis für ungeeignet erachtet werden oder versagt haben.

Für alle Fluorchinolone wurde ein erhöhtes Risiko für das Auftreten von Diarrhöen durch Clostridium difficile beschrieben [158160]. Gelegentliche bis seltene Nebenwirkungen bei nahezu allen Fluorchinolonen sind eine Verlängerung der QTc-Zeit im EKG sowie schmerzhafte Sehnenentzündungen (incl. sehr selten Sehnenruptur, meist bei längerer Anwendung), ZNS-Reaktionen (Krampfanfälle, Erregungszustände, Verwirrtheit und Halluzinationen, Sehstörungen), Hautreaktionen und auch Hyperglykämie oder Hypoglykämie. Bei Moxifloxacin wird häufiger auch über Kopfschmerzen berichtet. Vorsicht ist geboten bei Hypokaliämie, erworbener QTc-Intervall-Verlängerung, Bradykardie und schwerer Herzinsuffizienz, symptomatischen Herzrhythmusstörungen sowie gleichzeitiger Anwendung von Arzneimitteln, die das QTcIntervall verlängern.

\subsubsection{Ciprofloxacin}

Ciprofloxacin wird aufgrund seiner schwachen Wirkung gegenüber S. pneumoniae nicht für die Monotherapie der ambulant erworbenen Pneumonie empfohlen. Dagegen kann es als Kombinationspartner bei der schweren, ambulant erworbenen Pneumonie eingesetzt werden. Hier ist seine Wirkung gegenüber $P$. aeruginosa, den meisten Enterobacteriaceae sowie Legionella spp. hervorzuheben. Ciprofloxacin kann oral oder intravenös verabreicht werden. Die Dosierung bei schweren Infektionen beträgt $3 \times 400$ mg. Damit werden nach einer Stunde Plasmakonzentrationen von $\sim 4 \mathrm{mg} / \mathrm{l}$ erreicht. Die orale Bioverfügbarkeit beträgt 60-80\%. Nach oraler Gabe einer Einzeldosis von 750 mg können nach einer Stunde im Plasma Spitzenkonzentrationen von 2,5$3 \mathrm{mg} / \mathrm{l}$ erwartet werden. Die Eliminationshalbwertzeit wurde mit 3 bis 4,5 Stunden bestimmt. Das Nebenwirkungsprofil entspricht den Angaben, die bereits bei anderen Fluorchinolonen gemacht wurden.

\subsection{Oxazolidinone: Linezolid}

Die neue Klasse der Oxazolidinone (in Deutschland verfügbar: Linezolid p.o. und i.v.) wurde in erster Linie zur Behandlung von MRSA-Infektionen entwickelt. Linezolid ist aktiv gegenüber den meisten grampositiven Kokken. Es existiert keine Kreuzresistenz zwischen Linezolid und Makroliden/Ketoliden. Der Wirkungs- mechanismus ist die Proteinbiosynthesehemmung. Die orale Bioverfügbarkeit ist sehr gut. Nach oraler Gabe von $600 \mathrm{mg}$ alle $12 \mathrm{~h}$ werden Spitzenkonzentrationen von $\sim 20 \mu \mathrm{g} / \mathrm{ml}$ erzielt; die Halbwertszeit beträgt 5-7 h, die Substanz wird in Form der Hauptmetaboliten vorwiegend über die Niere eliminiert. Dennoch ist eine Dosisanpassung bei eingeschränkter Nierenfunktion nicht notwendig. Bei den unerwünschten Nebenwirkungen stehen gastrointestinale und zentralnervöse Beschwerden im Vordergrund. Bei längerer Behandlungsdauer ( $>2$ Wochen) wurden Blutbildveränderungen gesehen. Aufgrund dieser beobachteten myelotoxischen Nebenwirkungen sind wöchentliche Blutbildkontrollen während einer Therapie angezeigt; eine Therapiebegrenzung auf maximal 14 Tage wird empfohlen. Unter den seltenen Nebenwirkungen wurden auch lang anhaltende Neuropathien beobachtet. Linezolid ist ein Hemmstoff der Monaminoxidase. Aufgrund dieser Wirkung können Interaktionen mit Sympathomimetika und anderen Arzneimitteln vorkommen. Die gleichzeitige Einnahme übermäßiger Mengen tyraminhaltiger Lebensmittel (z. B. Sojasoße, reifer Käse) sollte vermieden werden. Im Tierversuch wurde eine verminderte Fertilität beobachtet; mögliche Auswirkungen auf die reproduktiven Organe beim Menschen sind nicht bekannt.

\subsection{Influenzaviruswirksame Virustatika}

Medikamente mit zwei verschiedenen Angriffspunkten sind derzeit verfügbar: der M2-Inhibitor Amantadin (oral und parenteral), wirksam gegen Influenza A-Viren, sowie die Neuraminidase-Inhibitoren Zanamivir (inhalative Verabreichung) und Oseltamivir (orale Verabreichung); die beiden letzteren Substanzen sind aktiv gegen Influenza A und B. Alle drei Substanzen wirken nur, wenn sie innerhalb von $48 \mathrm{~h}$ nach Krankheitsausbruch gegeben werden.

Die empfohlene Dosierung für Amantadin beträgt $100 \mathrm{mg}$ alle $12 \mathrm{~h}$ für 5 Tage. Bei eingeschränkter Nierenfunktion muss eine Dosisreduktion erfolgen. Herzrhythmusstörungen, schwere Herzinsuffizienz, gleichzeitige Behandlung mit Arzneimitteln, für die eine QTc-Verlängerung im EKG bekannt ist, sowie Hypokaliämie und Hypomagnesiämie sind Kontraindikationen. Die Verträglichkeit von Amantadin ist mäßig. Häufig kommt es zu Schlafstörungen, Unruhe, Harnretention, Schwindel, Mundtrockenheit, Übelkeit, orthostatischer Dysregulation.

Die empfohlene Dosis für Zanamivir beträgt $2 \times 2$ Inhalationen täglich über 5 Tage (eine Einzeldosis entspricht $5 \mathrm{mg}$ ); problematisch ist die Anwendung für ältere Personen (Anwendungsfehler) sowie bei Patienten mit Asthma bronchiale und chronisch-obstruktiven Atemwegserkrankungen (selten Gefahr des Bronchospasmus).

Oseltamivir liegt als Phosphat vor, das rasch resorbiert und nahezu vollständig in den aktiven Metaboliten (Oseltamivir-Carboxylat) umgewandelt wird. Der Wirkstoff wird unverändert renal mit einer Halbwertzeit von etwa 6-10 h eliminiert; eine Dosisanpassung bei Niereninsuffizienz wird empfohlen (KreatininClearance $>30 \mathrm{ml} / \mathrm{min}$ : $2 \times 75 \mathrm{mg}$ täglich, $10-30 \mathrm{ml} / \mathrm{min}$ : $1 \times 75 \mathrm{mg}$ täglich, < $10 \mathrm{ml} / \mathrm{min}$ : Gabe nicht empfohlen). Die empfohlene Behandlungsdauer ist 5 Tage. Bei prophylaktischer Indikation genügt die halbe Tagesdosis bei einer empfohlenen Gesamtbehandlungsdauer von 7 Tagen; abhängig von der jeweiligen Indikation (postexpositionelle Prophylaxe versus kontinuierliche Prophylaxe) ist eine längere Anwendung notwendig und möglich. Übelkeit und Erbrechen, vor allem an den ersten beiden Behandlungstagen, sind häufig. Sie lassen sich bei gleichzeitiger Medikamenteneinnahme mit den Mahlzeiten reduzieren. 


\begin{tabular}{|c|c|}
\hline Substanz & Einnahmebesonderheiten und Interaktionen \\
\hline Cefuroxim-Axetil & Resorptionsverbesserung bei Einnahme kurz nach den Mahlzeiten \\
\hline Amoxicillin-Clavulansäure & $\begin{array}{l}\text { - auf erhöhte Kalium-Zufuhr achten } \\
\text { - Resorptionsverbesserung bei Einnahme kurz vor dem Essen }\end{array}$ \\
\hline Ceftriaxon & hohe Eiweißbindung \\
\hline Ertapenem & hohe Eiweißbindung \\
\hline Imipenem & kann die Krampfschwelle senken \\
\hline Meropenem & auch Bolusgabe möglich \\
\hline Makrolide & $\begin{array}{l}\text { - Vorsicht bei Herzrhythmusstörungen, gleichzeitiger Behandlung mit anderen } \\
\text { Substanzen, die die QTc-Zeit im EKG verlängern können } \\
\text { - mäßige Venenverträglichkeit bei i.v. Gabe von Clarithromycin und Erythromycin } \\
\text { - die Konzentration von Ciclosporin A und anderen Immunsuppressiva kann } \\
\text { erhöht werden } \\
\text { - kann zur Erhöhung der Konzentration von Simvastatin und Lovastatin führen } \\
\text { - bei Gabe hoher Dosen von Erythromycin i.v. ototoxische Reaktionen beachten }\end{array}$ \\
\hline Clindamycin & $\begin{array}{l}\text { hat neuromuskulär blockierende Eigenschaften, daher Vorsicht bei Myasthenie } \\
\text { und M. Parkinson }\end{array}$ \\
\hline Doxycyclin & $\begin{array}{l}\text { - Einnahme mit der Mahlzeit und reichlich Flüssigkeit empfohlen } \\
\text { - die gleichzeitige Einnahme von aluminium-, calcium- (auch Milch) und } \\
\text { magnesiumhaltigen Nahrungszusatzstoffen oder Arzneimitteln und Eisen } \\
\text { führt über Komplexbildung zur abgeschwächten Resorption } \\
\text { - Sonnenbäder und andere UV-Lichtexposition meiden } \\
\text { - schlechte Venenverträglichkeit bei rascher i.v. Gabe } \\
\text { - keine Anwendung in Schwangerschaft und Stillzeit }\end{array}$ \\
\hline Fluorchinolone & $\begin{array}{l}\text { - nicht bei Epilepsie } \\
\text { - keine gleichzeitige Einnahme von Eisen, magnesium- und aluminium-haltigen } \\
\text { Antazida incl. Sucralfat, von zinkhaltigen Mitteln } \\
\text { - Sehnenentzündungen und -rupturen können auftreten } \\
\text { - Vorsicht bei Herzrhythmusstörungen, gleichzeitiger Behandlung mit anderen } \\
\text { Substanzen, die die QTc-Zeit im EKG verlängern können }\end{array}$ \\
\hline Linezolid & $\begin{array}{l}\text { - gleichzeitige Einnahme übermäßiger Mengen tyraminhaltiger Lebensmittel } \\
\text { (z. B. Sojasoße, reifer Käse) meiden } \\
\text { - Blutbildkontrollen bei Behandlung > } 10 \text { Tage notwendig } \\
\text { - Wirkungen im Sinne reduzierter Fertilität bei Männern nicht auszuschließen } \\
\text { - Interaktionen mit verschiedenen psychoaktiven Substanzen incl. MAO-Hemmer } \\
\text { und Sympathikomimetika beachten }\end{array}$ \\
\hline Amantadin & $\begin{array}{l}\text { - Vorsicht bei Herzrhythmusstörungen, gleichzeitiger Behandlung mit anderen } \\
\text { Substanzen, die die QTc-Zeit im EKG verlängern können } \\
\text { - verminderte Alkoholtoleranz }\end{array}$ \\
\hline Aciclovir & $\begin{array}{l}\text { - zentralnervöse Wirkungen wie Tremor, Halluzinationen, Krämpfe } \\
\text { - passagere Nierenfunktionseinschränkung, durch ausreichende Hydrierung und } \\
\text { langsame Infusionsgeschwindigkeit vermeidbar }\end{array}$ \\
\hline
\end{tabular}

Tab. 9 Wichtige Einnahmebesonderheiten und Interaktionen.

\subsection{Aciclovir}

Aciclovir ist ein Nukleosid-Derivat und steht für die parenterale und orale sowie topische Behandlung zur Verfügung. Es ist eine pharmakologisch inaktive Substanz, die nach Penetration in eine virusinfizierte Zelle von der viruseigenen Thymidinkinase aktiviert werden muss. Varicella Zoster-Virus (VZV) ist mit Hemmkonzentrationen in der Größenordnung von $3 \mu \mathrm{mol} / \mathrm{L}$ weit weniger empfindlich gegenüber Aciclovir als Herpes simplex-Virus (HSV) Typ I (Hemmkonzentrationen $<0,3 \mu \mathrm{mol} / \mathrm{L}$ ).

Die orale Bioverfügbarkeit ist schlecht. Bei schweren Infektionen wie der VZV-Pneumonie ist daher eine parenterale Behandlung in hoher Dosierung empfohlen, entsprechend $10 \mathrm{mg} / \mathrm{kg}$ Körpergewicht alle $8 \mathrm{~h}$ als Infusion jeweils über $1 \mathrm{~h}$. Bei nierengesunden Erwachsenen werden nach einer solchen 1-stündigen Infusion von $10 \mathrm{mg} / \mathrm{kg}$ Spitzenwerte im Plasma von $\sim 50 \mu \mathrm{mol} / \mathrm{L}$ erzielt. Die Plasmahalbwertszeit ist mit $\sim 3$ h relativ kurz. Als Infusionslösung wird eine isotonische Natriumchlorid-Lösung ohne weitere Zusätze empfohlen. Fertige Infusionslösungen sind bei Raumtemperatur bis zu $12 \mathrm{~h}$ stabil; sie dürfen nicht im Kühlschrank aufbewahrt werden.
Die wichtigsten Nebenwirkungen sind Übelkeit und Erbrechen, Zytopenien sowie Leberfunktionsstörungen. Seltener treten allergische Hautreaktionen auf, gelegentlich werden Nierenfunktionsstörungen und vorübergehende neurologische Ereignisse (Verwirrtheit, Halluzination, Unruhe, Tremor, Schläfrigkeit) beobachtet.

- Tab. 9 listet die wichtigsten Einnahmebesonderheiten und Interaktionen der für die Behandlung von Atemwegsinfektionen in Frage kommenden Antiinfektiva auf.

\section{Symptomatik und Befunde bei unteren Atemwegs- infektionen \\ $\nabla$}

\subsection{Symptomatik}

Es gibt keine Symptomkonstellation, die eine sichere klinische Diagnose einer Pneumonie ermöglicht. Entsprechend ist auch die Symptomatik anderer Infektionen der unteren Atemwege diagnostisch unspezifisch.

Folgende Symptome können bei unteren Atemwegsinfektionen vorgefunden werden: 
- allgemeines Krankheitsgefühl („malaise“)

- Fieber oder Hypothermie

- Husten

- eitriger Auswurf

- Dyspnoe

- „grippale“ Symptome wie Myalgien, Arthralgien, Cephalgien

Sie sind nicht spezifisch für die Abgrenzung einer CAP von anderen unteren Atemwegsinfektionen. Ihr positiver Vorhersagewert allein oder in Kombination ist mit $<50 \%$ unzureichend [161 165].

\subsection{Untersuchung}

Folgende Befunde können bei Verdacht auf CAP erhoben werden:

- Inspektion

- Dyspnoe mit erhöhter Atemfrequenz

- Palpation

- Tachykardie

- ggf. arterielle Hypotonie

- Perkussion

- ggf. abgeschwächter Klopfschall (bei ausgedehnten

Infiltrationen und/oder parapneumonischem Pleuraerguss)

- Auskultation

- fein- bis mittelblasige klingende ohrnahe Rasselgeräusche

- Bronchialatmen

Keiner dieser Befunde erreicht allein oder in Kombination eine ausreichende diagnostische Aussagekraft, um die Diagnose CAP klinisch stellen zu können. Die positiven Vorhersagewerte bleiben unter Berücksichtigung der im ambulanten Bereich gegebenen Inzidenz der CAP unter 50\% [161-166].

Die Zuverlässigkeit der physikalisch erhobenen Lungenbefunde ist begrenzt [167,168]. Nur der lokalisierte Auskultationsbefund (Rasselgeräusche) hat einen relativ hohen negativen Prädiktionswert, $d$.h. eine CAP ist eher unwahrscheinlich ohne einen solchen Auskultationsbefund. Dies gilt nur eingeschränkt bei CAP durch Mykoplasmen oder Chlamydien [169,170]. Besondere Beachtung verdient die Tatsache, dass sich die klinische Präsentation der CAP mit steigendem Alter verändert. Es werden zunehmend oligosymptomatische Verläufe sowie extrapulmonale Symptome wie zunehmende Schwäche oder Hinfälligkeit beobachtet $[165,171]$.

Aufgrund dieser Sachlage wird für eine sichere Diagnose einer CAP der Nachweis eines Infiltrats in der Röntgen-Thoraxaufnahme gefordert. Sensitivität und Spezifität sowie Zuverlässigkeit des Infiltratnachweises in der Röntgen-Thoraxaufnahme sind allerdings ebenfalls begrenzt $[172,173]$, vor allem bei leichtgradiger CAP mit nur geringer Infiltratausbildung. In der ambulanten Praxis kommt erschwerend hinzu, dass nicht immer die zeitnahe Durchführung und Befundung einer Röntgen-Thoraxaufnahme sichergestellt werden kann. In einer niederländischen Studie konnte jedoch gezeigt werden, dass die Durchführung einer Röntgen-Thoraxaufnahme im ambulanten Bereich bei Patienten mit Verdacht auf Pneumonie in mehr als 50\% der Fälle die endgültige Diagnose und in 69\% das weitere Management des anfordernden Hausarztes beeinflusste, was insbesondere zu einer Vermeidung einer unnötigen antimikrobiellen Therapie bei fehlendem Infiltratnachweis führte [174]. Vor diesem Hintergrund und zur Erkennung von Komplikationen wie einem Pleuraerguss oder einem Lungenabszess sowie von Begleiterkrankungen, die sich im Rahmen einer Pneumonie erstmals manifestieren können [175], sollte eine Röntgenaufnahme auch im ambulanten Bereich angestrebt werden.
Die Arbeitsgruppe empfiehlt (Empfehlungsgrad B):

(๑ s. Abb. 1):

1. Bei Patienten mit

- einem lokalisierten Auskultationsbefund oder

- aufgrund der klinischen Einschätzung oder

- dem Vorliegen von Komorbiditäten oder

- aus differenzialdiagnostischen Überlegungen oder

- insbesondere bei schwerer Erkrankung mit Störung vitaler Funktionen

die Anfertigung einer Röntgen-Thoraxaufnahme in zwei Ebenen.

2. Die unter 1) nicht erfassten Patienten benötigen in der Regel im ambulanten Bereich keine Röntgen-Thorax-Aufnahme.

In der Konsequenz ergeben sich zwei Gruppen ( $\bullet$ Abb. 1):

1. Patienten mit der Diagnose „akute untere Atemwegs-

infektion“ (,Non-CAP“)

Diese Patienten sind sehr wahrscheinlich nicht an CAP erkrankt. Folgende Subgruppen werden unterschieden:

- Patienten mit akuter Bronchitis

- Patienten mit akuter Exazerbation einer COPD (AECOPD)

- Patienten mit Influenza (ohne oder mit Obstruktion)

2. Patienten mit der Diagnose CAP

Diese Patienten weisen mit überwiegender Wahrscheinlichkeit (Schweregrad der klinischen Präsentation und/oder Infiltratnachweis in der Röntgen-Thoraxaufnahme) eine Pneumonie auf.

Für Patienten, die aufgrund einer akuten unteren Atemwegsinfektion im Krankenhaus vorstellig werden, empfiehlt die Arbeitsgruppe grundsätzlich die Anfertigung einer Röntgen-Thorax-Aufnahme in zwei Ebenen (Empfehlungsgrad B).

\section{Behandlung Non-CAP: akute Bronchitis, Influenza- infektion, andere respiratorische Virusinfektionen} $\nabla$

\subsection{Akute Bronchitis}

In aller Regel handelt es sich bei den Erregern einer akuten Bronchitis um virale Erreger, sodass eine Antibiotikabehandlung nicht indiziert ist. Einer der wesentlichen Gründe, die für eine gegenteilige Verschreibungspraxis von Antibiotika bei akuter Bronchitis verantwortlich gemacht werden, ist von Seiten der Ärzte die Annahme einer entsprechenden Erwartungshaltung der Patienten. Untersuchungen zeigen jedoch, dass der patientenseitige Wunsch nach einer Antibiotikaverordnung bei Atemwegsinfekten durch die behandelnden Ärzte häufig falsch eingeschätzt und damit überschätzt wird $[176,177]$. Um die Rate unnötiger Antibiotikaverordnungen in der Praxis zu reduzieren, zeigten sich zwei Interventionsansätze als besonders Erfolg versprechend.

- Eine Strategie ist das „delayed prescribing“ oder „Vorbehaltliche Verschreiben“: Hierbei wird zunächst kein Antibiotikum verordnet, dem Patienten jedoch ermöglicht, nach Ablauf von 2-3 Tagen in der Praxis ein Antibiotika-Rezept ohne Wartezeit und ohne weitere Rücksprache mit dem Arzt zu erhalten [178].

- Der zweite Ansatz, der auch in Deutschland erfolgreich getestet wurde, zielt auf eine grundlegende Veränderung im ärztlichen Kommunikationsverhalten ab [179]. Die Erwartungshaltung des Patienten wird exploriert und dann die Therapieentscheidung für und wider ein Antibiotikum im Sinne einer partizipativen Entscheidung offen thematisiert, nachdem für den Patienten in nachvollziehbarer Weise ein abwendbar gefährlicher Verlauf ausgeschlossen wurde. 
Symptome und Befunde einer akuten

tiefen Atemwegsinfektion (Kap. 8.1, Kap. 8.2)

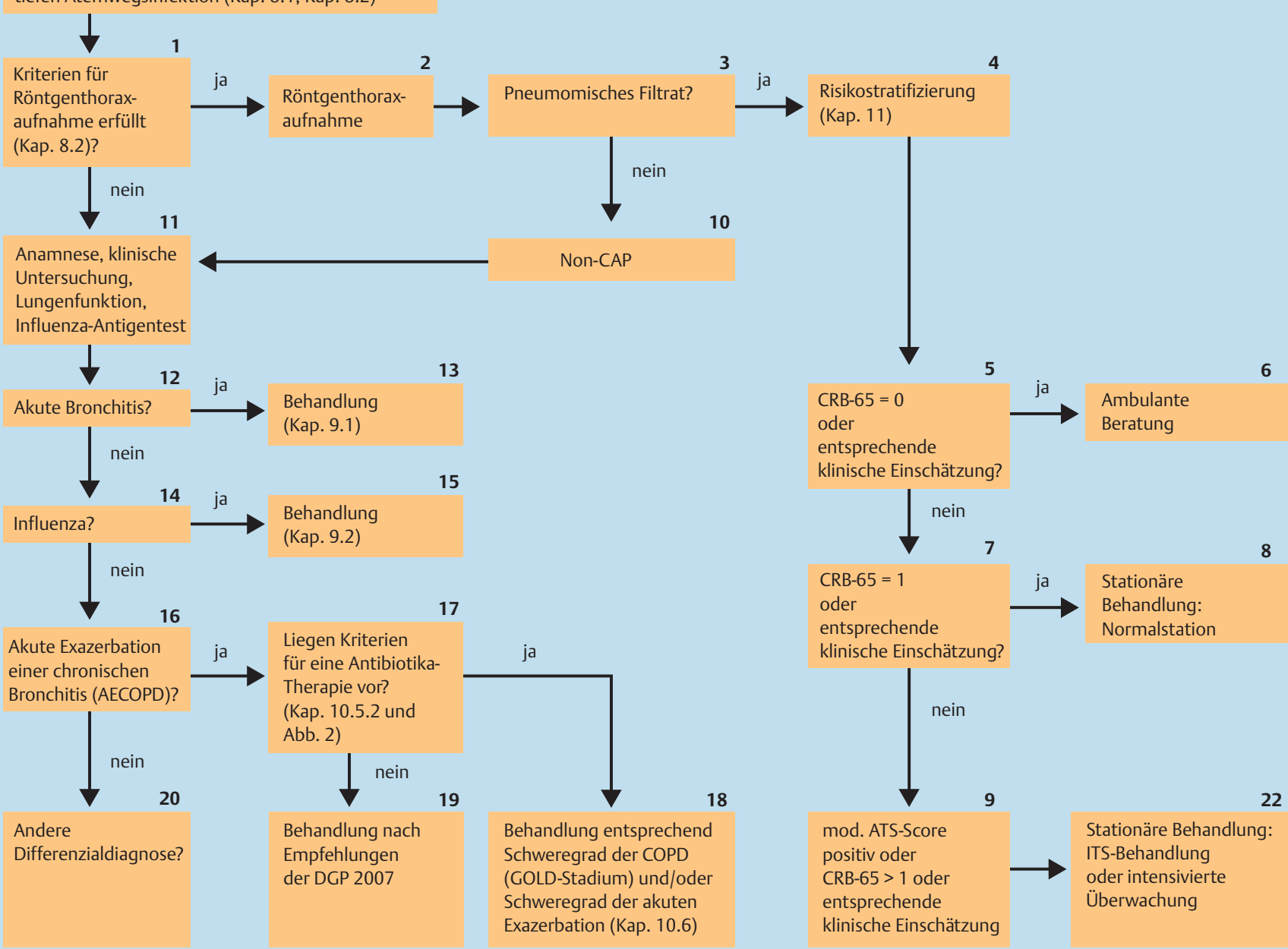

Abb. 1 Algorithmus zur Differenzierung einer akuten unteren Atemwegsinfektion (akute Bronchitis, akute Exazerbation einer chronischen Bronchitis, Influenzainfektion, ambulant erworbene Pneumonie).

Bei Patienten mit exazerbiertem Asthma bronchiale fand eine randomisierte, placebokontrollierte Studie unter antibiotischer Therapie mit Telithromycin zusätzlich zur Standardtherapie zwar eine leichte Verbesserung der Asthmasymptome nach Therapieende, dieser geringe Therapieeffekt war aber mit einer erhöhten Nebenwirkungsrate verbunden [180], sodass eine Therapie mit antibiotischen Substanzen auch bei dieser Patientengruppe im Regelfall weiterhin nicht empfohlen wird.

Die Arbeitsgruppe empfiehlt (Empfehlungsgrad A): Die akute Bronchitis eines Patienten ohne chronisch obstruktive Lungenerkrankung sollte nicht mit antimikrobiellen Substanzen behandelt werden, da es sich in der Regel um eine Virusinfektion handelt. In mehreren Studien konnte gezeigt werden, dass diese Patienten nicht von dieser Therapie profitieren [181-183]. Strategien, die zur Reduktion unnötiger antimikrobieller Therapien führen können, wie das vorbehaltliche Verordnen von Antibiotika oder ein ärztliches Kommunikationsverhalten mit dem Ziel einer partizipativen Entscheidungsfindung zwischen Patient und Arzt gegen eine Antibiotikaverordnung werden empfohlen $[178,179]$.

Bei Patienten mit Asthma bronchiale oder mit schwerem und langanhaltendem Verlauf von mehr als 7 Tagen ist die Rolle einer Antibiotikatherapie nicht geklärt, sie kann im Einzelfall nach klinischer Einschätzung erwogen werden (C).

\subsection{Influenzainfektion}

Die klinische Diagnose einer Influenza basiert auf zwei Bausteinen:

- der aktuellen epidemiologischen Situation; diese kann im Internet abgefragt werden unter www.rki.de/INFEKT/INFEKT/ HTM

- der klinischen Symptomatik einer plötzlichen Erkrankung mit Fieber und Schüttelfrost, Muskel- und Gliederschmerzen, Müdigkeit, Abgeschlagenheit, Kopfschmerzen, Husten, Heiserkeit und Bettlägerigkeit.

Die korrekte Diagnose einer Influenza hat deshalb große Bedeutung, weil die zur Verfügung stehenden antiviralen Substanzen nur wirksam sind, wenn sie früh nach Symptombeginn gegeben werden. Allerdings lag die Sensitivität klinischer Zeichen in kontrollierten Studien nicht über 60-70\%. Sofern Therapieabsicht besteht, ist aufgrund

- der begrenzten diagnostischen Aussagekraft klinischer Symptome und Untersuchungsbefunde sowie

- der Notwendigkeit einer Behandlung innerhalb von 24-36 h nach Symptombeginn

die Anwendung eines Schnelltests (aus Rachenabstrich bzw. nasaler Lavage) zu empfehlen. Hierzu existieren verschiedene 
Schnelltestsysteme (Antigennachweis, Nukleinsäure-Amplifikationsverfahren).

Für die Therapie der Influenza stehen drei antivirale Substanzen zur Verfügung: Amantadin, Zanamivir und Oseltamivir. Amantadin ist aufgrund seiner begrenzten Wirksamkeit (nur Influenzavirus A), raschen Resistenzentwicklung und Toxizität (vor allem im Bereich des ZNS) nicht zu empfehlen. Zanamivir (inhalativ) und Oseltamivir (oral) sind beide Inhibitoren der viralen Neuraminidase und haben eine vergleichbar gute Wirksamkeit bzw. akzeptable Toxizität.

Die Wirksamkeit von Zanamivir (inhalativ) und Oseltamivir (oral) ist gesichert. Ein therapeutischer Nutzen zeigt sich nur, wenn die Behandlung innerhalb von 24-48 h nach Beginn der Symptomatik begonnen wird [184-187]. Bei Patienten, die innerhalb dieser Zeitspanne nach Erkrankungsbeginn behandelt werden, kann eine Reduktion der Krankheitstage von 1 bis 1,5 Tagen erreicht werden. Darüber hinaus vermindern sich Komplikationen der Influenza wie Sinusitis, Otitis media, purulente Bronchitis und der Antibiotika-Verbrauch. Dies gilt dokumentiert für Zanamivir auch bei Hochrisiko-Patienten [188]. In einer prospektiven Beobachtungsstudie (keine Interventionsstudie) führte bei hospitalisierten Patienten mit einer schweren Influenzainfektion eine Oseltamivirbehandlung, die sowohl innerhalb der ersten 2 Tage als auch erst 48 Stunden nach Beginn der Symptomatik eingeleitet wurde, zu einer Reduktion der Letalität [189].

Die Arbeitsgruppe empfiehlt (Empfehlungsgrad D): Die Diagnose einer Influenzavirusinfektion ist anhand der klinischen Symptome bei sporadischen Erkrankungen schwer zu stellen, da die Klinik der anderer respiratorischer Erkrankungen ähnelt. Während einer Influenzavirusepidemie hat die klinische Symptomatik jedoch einen guten Vorhersagewert, sodass die Erkrankung mit hinreichender Wahrscheinlichkeit allein klinisch diagnostiziert werden kann. Im Fall einer Behandlungsintention bei Risikopatienten wie älteren Personen mit Grundkrankheiten (chronische Herz- oder Lungen-Erkrankungen, Stoffwechselerkrankungen wie z. B. Diabetes, Immundefekte) sollte eine labordiagnostische Sicherung des Erkrankungsfalles (mit Differenzierung in Influenzavirus A und B sowie Subtyp) angestrebt werden.

Bei milder verlaufenden Influenzaerkrankungen ist der Einsatz antiviraler Substanzen in aller Regel nicht indiziert. Den nicht unbeträchtlichen Therapiekosten und der Möglichkeit einer weiteren Resistenzentwicklung steht eine zu erwartende Verkürzung der Krankheitsdauer um lediglich 1 bis 1,5 Tage gegenüber. Daher werden antivirale Substanzen bei dieser Indikation nicht generell empfohlen. Eine spezifische Therapie mit antiviralen Arzneimitteln ist insbesondere bei Risikopersonen sinnvoll und sollte den Influenza-Subtyp berücksichtigen. Empfohlen wird die Behandlung mit NeuraminidaseInhibitoren (Oseltamivir oder Zanamivir), mit der so früh wie möglich, spätestens 48 Stunden nach Einsetzen der Symptome, begonnen werden sollte.

(Weitere Informationen zur aktuellen Influenzasaison bzw. Vorgehen bei neuen Influenza-Virustypen www.rki.de)

\subsection{Andere respiratorische Virusinfektionen}

Relevant sind hier Viren wie Parainfluenzaviren, RS-Virus, Adenoviren, Metapneumoviren (HMPV), Coronaviren und Rhinoviren sowie selten das Masernvirus, HSV oder VZV.

Für die Therapie einer VZV- oder HSV-Infektion steht Aciclovir zur Verfügung (siehe Kap. 7.8.). Ribavirin zur Therapie des RS-Virus ist bislang nur bei Kindern untersucht worden. Aufgrund begrenzter Wirksamkeit bzw. seiner Toxizität [190] wird Ribavirin nur bei immunsupprimierten Patienten empfohlen. Zur Therapie der anderen Virusinfektionen existieren bisher keine antiviralen Substanzen.

\section{Akute Exazerbation der COPD (AECOPD)}

Einzelheiten zur Epidemiologie, zur Diagnostik und zum Management der chronisch-obstruktiven Bronchitis und der AECOPD sind den Empfehlungen der Deutschen Atemwegsliga und der Deutschen Gesellschaft für Pneumologie und Beatmungsmedizin [16] sowie der Nationalen Versorgungsleitlinie COPD 2006 der Bundesärztekammer ( http://www.copd.versorgungsleitlinien.de) zu entnehmen. Grundlage der Therapie der AECOPD ist die Optimierung der antiobstruktiven Therapie, die Gabe systemischer Kortikosteroide und die kontrollierte Sauerstoffgabe. Schwerpunkte dieser Leitlinie sind die Indikation zur antibakteriellen Behandlung der akuten Exazerbation einer chronischen Bronchitis und die an den Schweregrad adaptierte Auswahl der Antiinfektiva.

\subsection{Definition der AECOPD}

Unter einer akuten Exazerbation wird im klinischen Alltag ein Zustand verstanden, der durch eine akute, über das normale Maß der täglichen Schwankungen hinausgehende Zunahme der Dyspnoe und/oder des Auswurfs und/oder eine Änderung der Sputumfarbe gekennzeichnet ist. Mithin wird jeder Zustand als akute Exazerbation bezeichnet, der eine Änderung der regelmäßigen Medikation erforderlich macht. Auch in Studien wird eine solche Definition gebraucht, allerdings unterscheidet sich die konkrete Ausgestaltung der genannten Kriterien deutlich. Dadurch wird eine Vergleichbarkeit der Studien erschwert.

Eine valide Definition für eine akute Exazerbation ist zur Zeit nicht in Sicht. Die von Anthonisen et al. erstmals 1987 im Rahmen einer Doppelblindstudie zur antimikrobiellen Therapie vorgeschlagenen Kriterien

- Zunahme der Dyspnoe

- Zunahme der Sputummenge

- Vorliegen eines eitrigen Sputums

eignen sich, um Patienten zu identifizieren, die von einer antimikrobiellen Therapie profitieren [191].

Unter Bezugnahme auf die Arbeiten von Stockley et al. [192] wird die Differenzierung in zwei Typen der akuten Exazerbation einer chronisch-obstruktiven Bronchitis vereinfacht $(\boldsymbol{Q}$ Abb. 2):

Die Arbeitsgruppe empfiehlt (Empfehlungsgrad B):

Die AECOPD wird nach Stockley in 2 Typen unterteilt [192]:

- Typ I: Zunahme der Dyspnoe, ggf. auch der Sputummenge

- Typ II: Zunahme der Dyspnoe, ggf. auch der Sputummenge und Vorliegen eitrigen Sputums

\section{2. Ätiologie der AECOPD}

Annähernd die Hälfte aller Fälle mit einer akuten Exazerbation werden durch infektiöse Ursachen ausgelöst, wobei nach neueren Untersuchungen Viren die führende Ursache sind [193 - 195]. In systematischen Untersuchungen werden sie in bis zu $75 \%$ der Fälle nachgewiesen [194,196]. Isolierte Bakterien sind dabei offenbar keineswegs immer auch ursächlich für eine Exazerbation. Diese Untersuchungen sprechen dafür, dass die Pathogenität der isolierten Bakterien eng an eine Neuinfektion gebunden ist, während kolonisierende Keime zwar quantitativ zunehmen, aber keine relevante inflammatorische Reaktion verursachen [197-200]. In ca. 20-30\% der Fälle kann jedoch die Ursache nicht identifiziert werden $[195,201]$. 
Akute Exazerbation der chronischen obstruktiven Lungenerkrankung AECOPD Kap. 10.

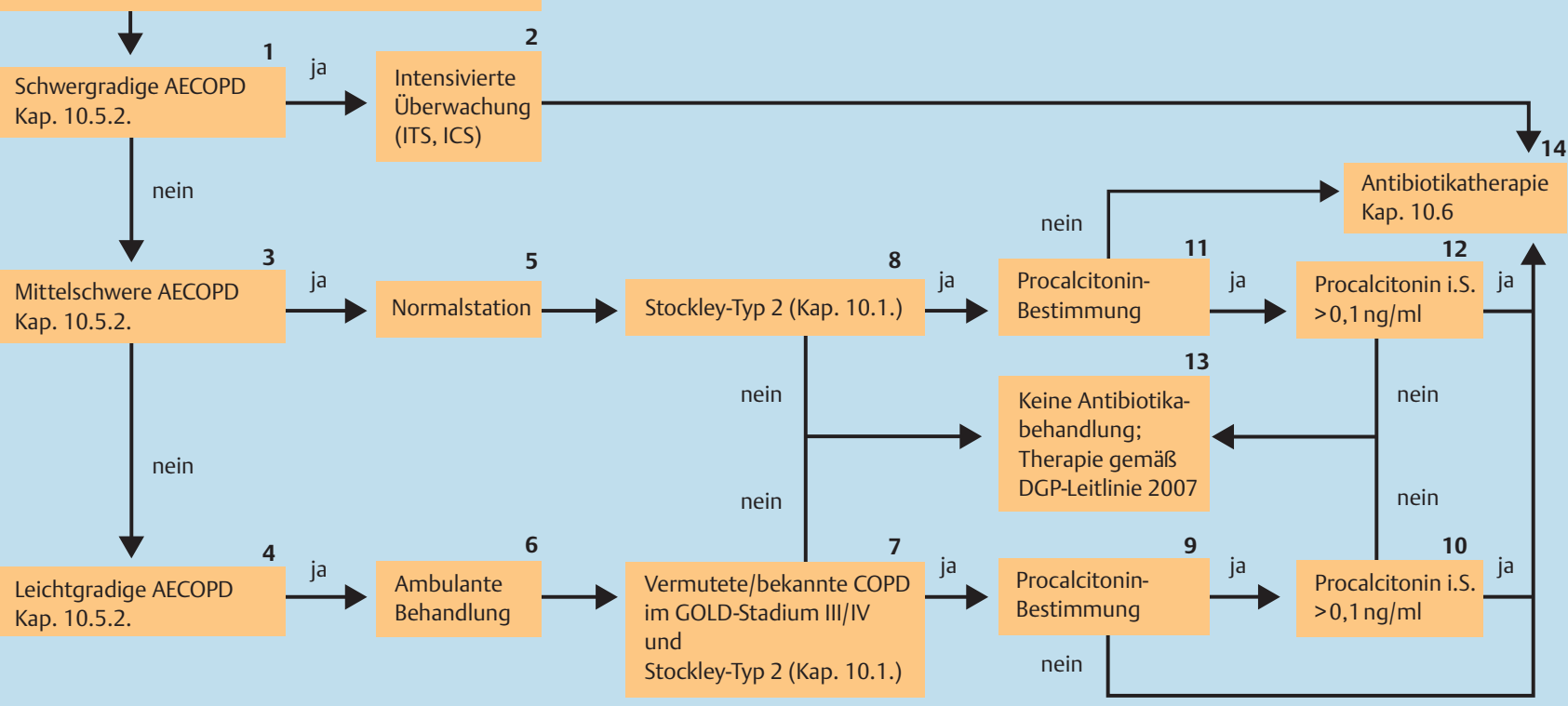

Abb.2 Algorithmus zur Schweregradeinteilung, zum logistischen Management und zur Differenzialtherapie bei akuter Exazerbation einer chronisch-obstruktiven Lungenerkrankung (AECOPD).

Die häufigsten bakteriellen Erreger sind H. influenzae, S. pneumoniae, M. catarrhalis, Enterobacteriaceae und P. aeruginosa [202207]. Mykoplasmen, Chlamydien und Legionellen können zwar als Erreger einer ambulant erworbenen Pneumonie nachgewiesen werden, ihre Bedeutung bei der AECOPD ist aber unklar [24]. Befunde aus Italien, die eine nennenswerte Bedeutung von Chlamydieninfektionen für die AECOPD beschreiben, sollten zunächst von anderen Arbeitsgruppen bestätigt werden [208], denn nach dem aktuellen Stand ist die ursächliche Bedeutung der serologisch in ca. 5-10\% nachweisbaren bakteriellen Erreger wie $C$. pneumoniae, M. pneumoniae oder Legionella spp. weitgehend unklar [209-212].

Als virale Erreger kommen neben Influenzaviren vor allem das Respiratory Syncytial Virus (RSV), Rhino-, Corona- und HMP-Viren in Betracht [193-194]. Parainfluenzaviren und Adenoviren werden seltener nachgewiesen. Bei ca. $20 \%$ sind gleichzeitig mehrere virale Erreger an der akuten Exazerbation beteiligt. Die Prävalenz der genannten Viren kann in Abhängigkeit von der geografischen und lokalen epidemiologischen Situation stark variieren. Eine bakterielle und virale Koinfektion wurde in einer Studie bei $25 \%$ der Patienten nachgewiesen und war mit schwereren Exazerbationen und längerer Hospitalisierung assoziiert [195]. Die Häufigkeit von Influenzavirusinfektionen im Rahmen einer akuten Exazerbation einer chronisch-obstruktiven Bronchitis ist von der Influenzaimpfrate innerhalb der Patientenpopulation abhängig.

\subsection{Klinische Symptomatik der AECOPD}

Leitsymptome der AECOPD sind:

- zunehmende Atemnot

- vermehrt Husten

- Zunahme von Sputummenge und/oder Viskosität

- und/oder gelb-grüne Verfärbung des Auswurfs

- Brustenge
Unspezifische Zeichen wie leichtere Ermüdbarkeit, Schlafstörungen oder Depressionen bzw. Bewusstseinstrübungen bis hin zum Koma können hinzutreten. Für eine schwere akute Exazerbation sprechen eine zentrale Zyanose, periphere Ödeme, der Einsatz der so genannten „Atemhilfsmuskulatur“ bei der Inspiration sowie eine hämodynamische Instabilität.

Differenzialdiagnostisch spielen kardiale Erkrankungen (Herzinsuffizienz, Pleuraergüsse, Herzrhythmusstörungen) und andere pulmonale Komplikationen (Pneumonie, Pneumothorax, Lungenembolie) die wichtigste Rolle.

Als Risikofaktoren für Exazerbationen gelten:

- Alter des Patienten

- Untergewicht

vorbestehende Ruhe- oder Belastungsdyspnoe

- Hyperkapnie

- Vorliegen einer COPD-bedingten pulmonalen Hypertonie [213]

Die schwere AECOPD stellt einen vital bedrohlichen Zustand dar. Die berichteten Letalitätsraten schwanken jedoch zwischen $3 \%$ und 50\% erheblich [207,214]. Nach Einführung der nicht-invasiven Beatmung ist es in vielen Fällen möglich geworden, die ITSbzw. Krankenhaus-assoziierte Letalität zu verringern. Die Langzeitprognose (über 6 Monate) dieser Patienten bleibt jedoch sehr eingeschränkt [215].

Unabhängige Risikofaktoren für einen ungünstigen Verlauf sind dabei:

- Alter

- Hyperkapnie

- vorbestehende Dauertherapie mit oralen Steroiden [216]

- Vorliegen anderer schwerwiegender Begleiterkrankungen wie Herzinsuffizienz oder Diabetes mellitus [217]

- Nachweis multiresistenter Erreger [52,218] 


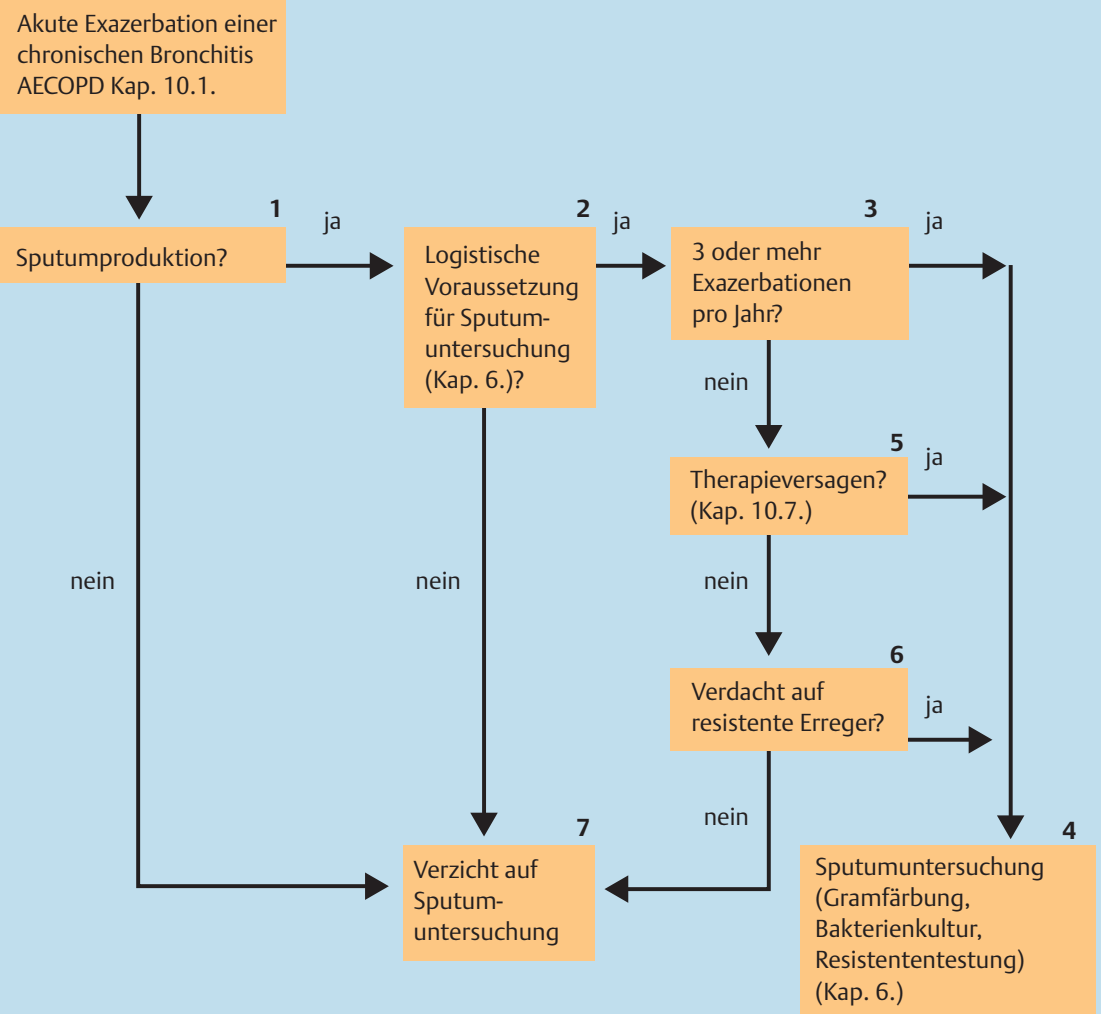

Abb.3 Algorithmus zur mikrobiologischen Sputumdiagnostik bei akuter Exazerbation einer chronischen Bronchitis.

\subsection{Mikrobiologische Diagnostik der AECOPD}

Die Möglichkeiten der mikrobiologischen Diagnostik sind gerade bei Atemwegsmaterialien von ambulanten Patienten häufig durch Mängel in der Präanalytik eingeschränkt. So kann insbesondere die Verlängerung der Transportzeit über 4 Stunden zu einer geringeren Nachweisrate von S. pneumoniae und H. influen$z a e$ führen. Im Allgemeinen ist deshalb eine mikrobiologische Sputumuntersuchung für die Behandlung der AECOPD nicht hilfreich.

Die Arbeitsgruppe empfiehlt (Empfehlungsgrad C) ( Abb. 3): Eine mikrobiologische Sputumuntersuchung (Gramfärbung und Bakterienkultur mit Resistenztestung) wird bei Patienten mit häufigen Exazerbationen (z. B. $\geq 3 /$ Jahr), Therapieversagern und/oder bei besonders schweren Erkrankungen mit Verdacht auf multiresistente Bakterien empfohlen. Voraussetzungen sind das Vorliegen von makroskopisch purulentem Sputum und die Gewährleistung der notwendigen logistischen Voraussetzungen (Transport und Verarbeitung innerhalb von 2 bis 4 Stunden, s. Kap. 6).

\subsection{Indikation zur antimikrobiellen Therapie bei AECOPD \\ 10.5.1. Pathogenetische Überlegungen zur Therapie- indikation bei AECOPD}

Im Gegensatz zu Patienten mit CAP besteht bei Patienten mit einer akuten bakteriellen Exazerbation ihrer chronisch-obstruktiven Bronchitis immer eine lokal begrenzte Infektion. Die Patienten sind daher eher durch ein akutes respiratorisches Versagen gefährdet, weniger durch eine generalisierte systemische inflammatorische Reaktion mit der Folge einer schweren Sepsis oder eines septischen Schocks. Die Behandlung bzw. Verhinderung des respiratorischen Versagens steht daher durch Sauerstoffgabe und ventilatorische Unterstützung sowie ggf. Maßnahmen zur Bronchialtoilette im Vordergrund. Die Rationale für eine kalkulierte antimikrobielle Therapie, nämlich die möglichst frühzeitige Unterbrechung der inflammatorischen Reaktion mit gesichertem prognostischen Vorteil, ist im Falle der AECOPD in dieser Form nicht gegeben. Die Antibiotikatherapie bei der AECOPD bleibt daher umstritten, beweisende Studien fehlen [216]. Das Hauptproblem der Antibiotikastudien besteht darin, dass verschiedene Studien unterschiedliche Definitionen der Exazerbation verwenden und unterschiedliche Schweregrade der COPD untersuchen. Die Studien sind daher nicht vergleichbar.

Die verfügbare Evidenz über die Indikationen zur antibakteriellen Therapie basiert auf verschiedenen Überlegungen:

- Rezidivierende akute Exazerbationen einer COPD beschleunigen den Verlust an $\mathrm{FEV}_{1}$ im natürlichen Verlauf der Erkrankung um ca. $7 \mathrm{ml} / \mathrm{Jahr}[219,220]$. Serielle molekulare Typisierungen von bakteriellen Erregern aus Sputen von Patienten in der stabilen Phase der COPD sowie bei akuten Exazerbationen weisen darauf hin, dass gehäuft Subtypen der kolonisierenden Erreger zu akuten Exazerbationen führen. Im Rahmen einer akuten Exazerbation kommt es dabei zu einer akuten inflammatorischen Reaktion und der Bildung einer spezifischen Immunantwort gegen neu erworbene Erreger [197-199]. Allerdings gilt dies nur für akute Exazerbationen, bei denen ein bakterieller Erreger nachgewiesen werden kann.

- Erhöhte Entzündungsparameter legen den Verdacht auf eine bakterielle Infektion nahe, ohne dass dies im Einzelfall als zuverlässiges Zeichen gelten kann. Sowohl ein erhöhtes CRP als auch eine Leukozytose sind daher zur Therapiesteuerung nicht geeignet. Mit Procalcitonin III steht jedoch ein Parameter zur Verfügung, der besser zwischen viraler und bakterieller Infektion unterscheiden kann. Eine Strategie, bei der die Antibiotikagabe von der Höhe des Serum-Procalcitoninwertes ge- 
leitet wurde (Procalcitonin < 0,1 $\mu \mathrm{g} / \mathrm{l}$ : Antibiotika nicht empfohlen; Procalcitonin > 0,25 $\mu \mathrm{g} / \mathrm{l}$ : Antibiotika empfohlen; Procalcitonin $>0,1 \mu \mathrm{g} / \mathrm{l}$ und $<0,25 \mu \mathrm{g} / \mathrm{l}$ : klinische Entscheidung), führte zu einer signifikanten Reduktion des Antibiotikaverbrauchs bei gleichem klinischem Kurzzeit- und Langzeit-Therapieerfolg [221]. Allerdings sind weitere Daten zu Methodik und Kosteneffektivität der Procalcitoninbestimmung sowie zum Umgang mit Patienten mit intermediären Procalcitoninwerten erforderlich, ehe dieser Parameter für die Routinediagnostik empfohlen werden kann. Wird das Procalcitonin bestimmt, kann bei einem Wert von $<0,1 \mu \mathrm{g} / \mathrm{l}$ davon ausgegangen werden, dass eine antimikrobielle Therapie nicht erforderlich ist [221,222].

- Zur antimikrobiellen Therapie der AECOPD liegen mehrere Placebo-kontrollierte Studien sowie zwei Metaanalysen vor [191,223 - 227]. Eine aktuelle Metaanalyse fand für Patienten, die mit Antibiotika behandelt wurden, eine verminderte Letalität im Vergleich zur Placebogabe bei AECOPD [227]. Dieser Effekt beruhte jedoch vorrangig auf einer Studie bei beatmeten Patienten auf Intensivstation und kann nicht auf alle Schweregrade der AECOPD verallgemeinert werden. Außerdem weisen die ausgewerteten Studien zum Teil deutliche methodische Mängel auf: Die meisten dieser Studien sind mehr als 30 Jahre alt und genügen heutigen Qualitätsanforderungen nicht mehr, haben überwiegend Patienten mit chronischer Bronchitis (nicht notwendigerweise COPD) untersucht und haben antimikrobielle Substanzen eingesetzt, die heute nicht mehr empfohlen werden können. Gegen eine generelle antimikrobielle Therapie bei AECOPD sprechen auch Studiendaten, die zeigen, dass bei Patienten mit einer ProcalcitoninKonzentration $<0.1 \mu \mathrm{g} / \mathrm{l}$ im Serum eine Antibiotikabehandlung nicht notwendig erscheint [221].

- Typischerweise zeigen Studien, die sowohl vermehrte Luftnot und vermehrten Auswurf als auch eine Verfärbung des Sputums als Einschlusskriterien forderten, einen positiven Effekt der Antibiotikatherapie, während Studien, die nur ein oder zwei dieser Kriterien berücksichtigen, zu negativen Resultaten kommen [191]. Die makroskopische Purulenz des expektorierten Sputums (gelbe oder grüne Farbe) besitzt dabei einen hohen prädiktiven Wert für den Nachweis eines bakteriellen Erregers [192,228].

- Darüber hinaus existieren Zulassungs- und Beobachtungsstudien, die Hinweise auf bestimmte Untergruppen geben, die von einer antimikrobiellen Therapie profitieren könnten [201,229 - 232]. Adams et al. konnten zeigen, dass die Rezidivrate von Patienten mit akuter Exazerbation geringer war, wenn diese mit Antibiotika behandelt worden waren; dies galt allerdings nicht für alle antimikrobiellen Substanzen [230]. Darüber hinaus konnte gezeigt werden, dass das Intervall bis zur nächsten Exazerbation durch Fluorchinolone wie Ciprofloxacin und Moxifloxacin verlängert werden kann $[201,231,232]$.

\subsubsection{Begründung der Therapieempfehlung}

- Die Studienlage zur Indikation der antimikrobiellen Therapie der COPD hat sich nicht verbessert.

- Allerdings hat zumindest eine Studie zeigen können, dass eine über den Biomarker Procalcitonin gesteuerte Therapie zu einer deutlichen Reduktion des Einsatzes antimikrobieller Substanzen ohne schlechtere Kurzzeit- oder Langzeitergebnisse führen kann [221]. Im Rahmen dieser Studie konnte allerdings nicht belegt werden, was ein erhöhter PCT-Wert eigentlich anzeigt. Die Daten erlauben allerdings schon heute, NiedrigRisikopatienten zu identifizieren, die sehr wahrscheinlich nicht von einer antimikrobiellen Therapie profitieren.

- Eine Schwäche vieler bisheriger Empfehlungen liegt darin, dass sie eine Orientierung der Indikationsstellung zur antimikrobiellen Therapie entsprechend dem Schweregrad der COPD vorgeben. Dieser ist jedoch nicht immer vorher bekannt. Lungenfunktionsmessungen im Rahmen der AECOPD können diese fehlende Vorinformation naturgemäß nicht ausgleichen. Andererseits dürfte der mögliche Vorteil einer antimikrobiellen Therapie auch vom Schweregrad der aktuellen Komplikation, also der akuten Exazerbation selbst abhängen. Auch wenn die Schweregrade der COPD sowie der akuten Exazerbation eng zusammenhängen, können jedoch auch disparate Kombinationen vorkommen (leichte COPD - schwere AECOPD und umgekehrt).

- Eine allgemein anerkannte Klassifizierung des Schweregrads einer akuten Exazerbation liegt bisher nicht vor. Allerdings finden sich in der Leitlinie „Diagnostik und Therapie von Patienten mit chronisch obstruktiver Bronchitis und Lungenemphysem (COPD)“ der Deutschen Gesellschaft für Pneumologie und Beatmungsmedizin und der Deutschen Atemwegsliga (http://www.awmf.de) bzw. der Nationalen Versorgungsleitlinie COPD der Bundesärztekammer 2007 Kriterien zur Hospitalisation und Intensivtherapie, die hier herangezogen werden können [16]. Dabei sollten von den Hospitalisationskriterien nur Kriterien zur Geltung kommen, die den akuten Schweregrad reflektieren (nicht also solche, die eher soziale Kriterien oder differenzialdiagnostische Schwierigkeiten reflektieren).

Mittelschwere AECOPD (Indikation zur Hospitalisation):

- schwere Atemnot

- schlechter Allgemeinzustand

- rasche Progression der Symptomatik

- Bewusstseinstrübung

- Zunahme von Ödemen/Zyanose

- neu aufgetretene Arrhythmien

- schwere Komorbidität

Schwere AECOPD (Indikation zur Intensivtherapie):

- schwere Atemnot mit fehlendem Ansprechen auf die Notfalltherapie

- komatöser Zustand

- persistierende Hypoxämie $\left(\mathrm{paO}_{2}<50 \mathrm{~mm} \mathrm{Hg}\right.$ trotz $\mathrm{O}_{2}$-Gabe)

- schwere progrediente Hyperkapnie $\left(\mathrm{paCO}_{2}>70 \mathrm{~mm} \mathrm{Hg}\right)$

- respiratorische Azidose $(\mathrm{pH}<7,35)$

- Kreislaufinsuffizienz

Leichtgradige AECOPD entsprechen somit Fällen, die weder Kriterien der Hospitalisation noch der Intensivtherapie erfüllen. 


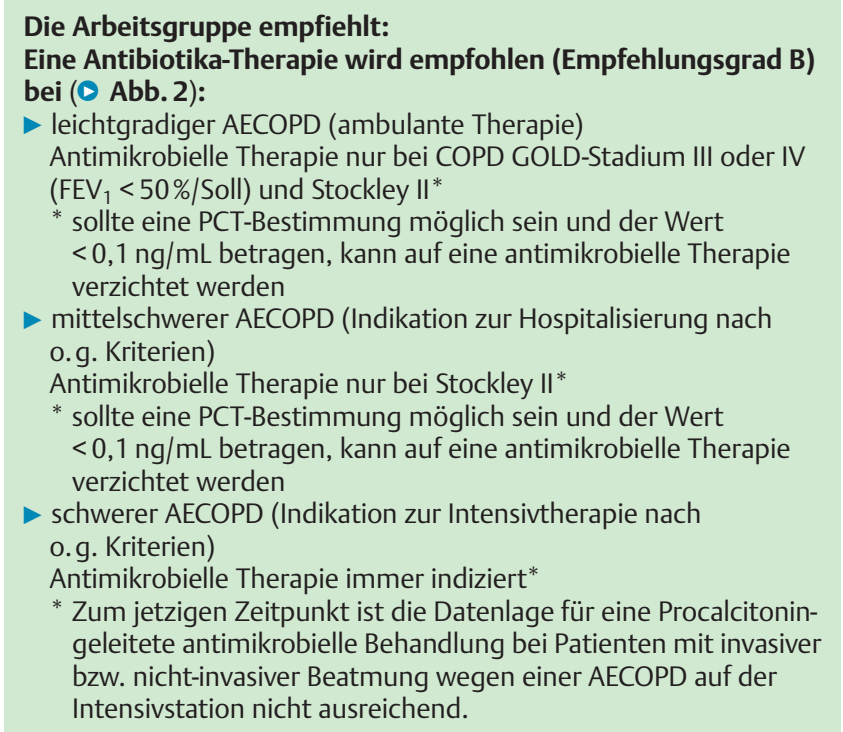

Zusammengefasst beruht die Indikation zur antimikrobiellen Therapie jedoch auf überwiegend vorläufigen Daten und/oder indirekter Evidenz.

\subsection{Auswahl der antimikrobiellen Therapie bei AECOPD}

Die Auswahl des Antibiotikums sollte sich am Schweregrad der akuten Exazerbation der chronisch-obstruktiven Bronchitis gemessen anhand der Einteilung nach der Nationalen Versorgungsleitlinie COPD der Bundesärztekammer 2007 (http://www.copd. versorgungsleitlinien.de) orientieren.

Bei Patienten mit Exazerbation und vorbestehender $\mathrm{FEV}_{1}>50 \%$ des Solls wurden in der Regel S. pneumoniae oder H. influenzae isoliert. Gegen diese Spezies sind Betalaktamantibiotika und mit Einschränkungen - neuere Makrolide gut wirksam, wenn sie ausreichend dosiert werden (s. Tab. 8 und $\bullet$ Tab. 10). Bei einer $\mathrm{FEV}_{1}<50 \%$ des Solls und bei Patienten mit häufigen Exazerbationen überwiegen Enterobacteriaceae [203-207]. Aminopenicilline mit Betalaktamaseinhibitor, Cephalosporine der Gruppe II und III sowie Fluorchinolone zeigen hier eine breitere Wirksamkeit.

Es wird empfohlen, eine Therapie gegen $P$. aeruginosa nur

- bei bekannter Kolonisation mit P. aeruginosa [233],

- im Falle von Bronchiektasen,

- gezielt im Falle eines Erregernachweises sowie

- bei beatmeten Patienten

einzuleiten.

Pseudomonaswirksame Substanzen stehen mit Ausnahme von Ciprofloxacin und Levofloxacin jedoch ausschließlich als intravenöse Applikationsform zur Verfügung [234]. Eine Fluorchinolontherapie im Krankenhaus führt jedoch zu einem deutlich erhöhten Risiko für eine Infektion mit gegenüber Ciprofloxacin resistenten $P$. aeruginosa [34].

Es muss ausdrücklich davor gewarnt werden, Breitspektrumantibiotika wie die oralen Fluorchinolone bei allen Formen der AECOPD - auch bei leichter erkrankten Patienten ohne erhebliche Lungenfunktionseinschränkung - einzusetzen. Gerade durch den vermehrten Einsatz von Ciprofloxacin, das nach Auslaufen des Patents preiswert geworden ist und daher häufig bei ambu- lanten Patienten eingesetzt wird, ist eine schnelle Resistenzentwicklung gegenüber allen Fluorchinolonen zu beobachten [235]. Grundsätzlich geeignete Substanzen bzw. Substanzklassen für die orale Therapie sind:

- Penicilline (Amoxicillin bzw. Amoxicillin + Clavulansäure, Sultamicillin)

- Makrolide (Azithromycin, Clarithromycin, Roxithromycin)

- Tetracycline (Doxycyclin)

- Fluorchinolone (Ciprofloxacin, Levofloxacin, Moxifloxacin) Eine intravenöse Therapie wird nur empfohlen, wenn der Patient die Tabletten nicht oral zu sich nehmen kann, unsichere Resorptionsverhältnisse bestehen oder eine schwergradige AECOPD vorliegt. Grundsätzlich geeignet für die intravenöse Therapie sind:

- Penicilline (Ampicillin bzw. Amoxicillin + Clavulansäure, Ampicillin + Sulbactam; Piperacillin + Tazobactam oder + Sulbactam)

- Cephalosporine (Cefuroxim, Ceftriaxon, Cefotaxim, Cefepim, Ceftazidim)

- Fluorchinolone (Ciprofloxacin, Levofloxacin, Moxifloxacin)

- Carbapeneme (Ertapenem, Imipenem, Meropenem)

Die Arbeitsgruppe empfiehlt (Empfehlungsgrad C) folgende Antibiotika zur Therapie der AECOPD:

Für Patienten mit leichtgradiger AECOPD (ambulante Therapie) mit Stockley Typ 2 und COPD GOLD-Stadium III oder IV (FEV $<50 \%$ Soll):

Mittel der Wahl: Aminopenicillin ohne Betalaktamaseinhibitor (Amoxicillin)

- Alternativen: Makrolid (Azithromycin, Clarithromycin, Roxithromycin) oder Tetracyclin (Doxycyclin)

Für Patienten mit mittelschwerer und schwergradiger AECOPD (hospitalisierte Patienten auf Normal- bzw. Intensivstation) mit Stockley Typ 2 ohne bekannte Kolonisation durch P. aeruginosa, ohne Bronchiektasen, ohne Beatmung bzw. ohne individuellen $P$. aeruginosa-Nachweis:

- Mittel der Wahl: Aminopenicillin mit Betalaktamaseinhibitor (Amoxicillin + Clavulansäure oder Sultamicillin) oder parenterale Cephalosporine der II. oder III. Generation

- Alternative*: Pneumokokkenwirksames Fluorchinolon (Levofloxacin, Moxifloxacin)

Für AECOPD- Patienten mit Stockley Typ 2 und mit bekannter Kolonisation durch $P$. aeruginosa oder mit Bronchiektasen oder mit individuellem $P$. aeruginosa-Nachweis oder bei beatmeten Patienten:

- Acylureidopenicillin + Betalaktamaseinhibitor

(Piperacillin/Tazobactam)

- Pseudomonaswirksames Carbapenem (Imipenem, Meropenem)

- Pseudomonaswirksames Cephalosporin (Ceftazidim** , Cefepim)

- Pseudomonaswirksames Fluorchinolon (Ciprofloxacin**, Levofloxacin)

* bei Therapieversagen oder Unverträglichkeit der anderen Substanzen

** in Kombination mit einer pneumokokkenwirksamen Substanz

Ein wesentliches Entscheidungskriterium zwischen den genannten Alternativen bildet eine vorausgegangene Antibiotikatherapie bei Patienten mit rezidivierenden Exazerbationen: Es wird ein Wechsel der zuletzt verwendeten Substanzgruppe empfohlen, dies gilt insbesondere für Therapien innerhalb der letzten 3 Monate [33, 34].

Hinsichtlich Substanzklassen und Dosierungen s. $\bullet$ Tab. 10 bzw. - Tab. 8. 


\begin{tabular}{|c|c|c|c|}
\hline Substanzen* & $\begin{array}{l}\text { Dosierung* oral (pro } \\
\text { Tag) }\end{array}$ & $\begin{array}{l}\text { Dosierung* i.v. (pro } \\
\text { Tag) }\end{array}$ & Therapiedauer \\
\hline \multicolumn{4}{|c|}{$\begin{array}{l}\text { Bei leichtgradiger AECOPD (ambulante Therapie) mit Stockley Typ } 2 \text { und COPD GOLD-Stadium III oder IV } \\
\left(\text { FEV }_{1}<50 \% / \text { Soll }^{* *} \text { : }\right.\end{array}$} \\
\hline \multicolumn{4}{|c|}{ Mittel der Wahl } \\
\hline Amoxicillin & $\begin{array}{l}\geq 70 \mathrm{~kg}: 3 \times 1,0 \mathrm{~g} \\
<70 \mathrm{~kg}: 3 \times 750 \mathrm{mg}\end{array}$ & & 7 Tage \\
\hline \multicolumn{4}{|l|}{ Alternativen } \\
\hline Azithromycin & $1 \times 500 \mathrm{mg}$ & & 3 Tage \\
\hline Clarithromycin & $2 \times 500 \mathrm{mg}$ & & 7 Tage \\
\hline Roxithromycin & $1 \times 300 \mathrm{mg}$ & & 7 Tage \\
\hline Doxycyclin & $\begin{array}{l}1 \times 200 \mathrm{mg} \text { initial, dann } \\
\geq 70 \mathrm{~kg}: 1 \times 200 \mathrm{mg} \\
<70 \mathrm{~kg}: 1 \times 100 \mathrm{mg}\end{array}$ & & 7 Tage \\
\hline \multicolumn{4}{|c|}{$\begin{array}{l}\text { Bei mittelschwerer (ambulante und hospitalisierte Patienten) und schwergradiger AECOPD (hospitalisierte } \\
\text { Patienten auf Normal- bzw. Intensivstation) mit Stockley Typ } 2 \text { ohne bekannte Kolonisation durch P. aeruginosa } \\
\text { ohne Bronchiektasen, ohne Beatmung bzw. ohne individuellen P. aeruginosa -Nachweis** }\end{array}$} \\
\hline \multicolumn{4}{|l|}{ Mittel der Wahl } \\
\hline $\begin{array}{l}\text { Amoxicillin + Clavulan- } \\
\text { säure }\end{array}$ & $\begin{array}{l}\geq 70 \mathrm{~kg}: 3 \times 875 / 125 \mathrm{mg} \\
<70 \mathrm{~kg}: 2 \times 875 / 125 \mathrm{mg}\end{array}$ & $3 \times 2,2 \mathrm{~g}$ & 7 Tage \\
\hline Sultamicillin & $2 \times 750 \mathrm{mg}$ & & 7 Tage \\
\hline Ampicillin + Sulbactam & & $3 \times 3,0 \mathrm{~g}$ & 7 Tage \\
\hline Ceftriaxon & & $1 \times 2,0 \mathrm{~g}$ & 7 Tage \\
\hline Cefotaxim & & $3 \times 2,0 \mathrm{~g}$ & 7 Tage \\
\hline \multicolumn{4}{|l|}{ Alternativen ${ }^{* * *}$ : } \\
\hline Levofloxacin & $1 \times 500 \mathrm{mg}$ & $1 \times 500 \mathrm{mg}$ & 5 Tage \\
\hline Moxifloxacin & $1 \times 400 \mathrm{mg}$ & $1 \times 400 \mathrm{mg}$ & 5 Tage \\
\hline \multicolumn{4}{|c|}{$\begin{array}{l}\text { Bei AECOPD mit Stockley Typ } 2 \text { mit bekannter Kolonisation durch P. aeruginosa bzw. mit Bronchiektasen bzw. } \\
\text { mit individuellem P. aeruginosa -Nachweis sowie bei beatmeten Patienten**: }\end{array}$} \\
\hline Piperacillin/Tazobactam & & $3 \times 4,5 \mathrm{~g}$ & 8 Tage \\
\hline Cefepim & & $3 \times 2,0 \mathrm{~g}$ & 8 Tage \\
\hline Ceftazidim**** & & $3 \times 2,0 \mathrm{~g}$ & 8 Tage \\
\hline Imipenem & & $3 \times 1,0 \mathrm{~g}$ & 8 Tage \\
\hline Meropenem & & $3 \times 1,0 \mathrm{~g}$ & 8 Tage \\
\hline \multicolumn{4}{|l|}{ oder } \\
\hline Levofloxacin & $2 \times 500 \mathrm{mg}$ & $2 \times 500 \mathrm{mg}$ & 8 Tage \\
\hline Ciprofloxacin $* * * *$ & $2 \times 750 \mathrm{mg}$ & $3 \times 400 \mathrm{mg}$ & 8 Tage \\
\hline
\end{tabular}

Tab. 10 Therapieempfehlung für Patienten mit AECOPD bei Vorliegen einer Indikation zur Antibiotikatherapie.

$\left(\mathrm{FEV}_{1}<50 \% /\right.$ Soll) **

Mittel der Wahl

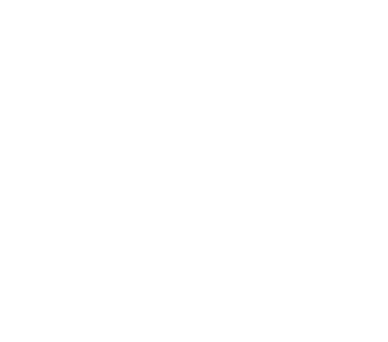


Evaluation des Therapieansprechens: Kriterien des Ansprechens sind unzureichend definiert. Theoretisch lassen sich symptombezogene und lungenfunktionelle Erfolgskriterien definieren. Die Übereinstimmung von beiden ist begrenzt. Über das Zeitfenster, innerhalb dessen ein Therapieansprechen zu erwarten ist, gibt es keine Daten. Analog zur Pneumonie wird ein solches Ansprechen in ca. $48-72 \mathrm{~h}$ zu erwarten sein.

Zeichen des klinischen (symptombezogenen) Ansprechens umfassen:

- Rückgang der Dyspnoe

- Rückgang der Sputummenge

- Aufklaren der Sputumfarbe

- Besserung der respiratorischen Azidose

- Besserung des Bewusstseinszustands

- Stabilisierung der komorbiden Dekompensation

Ein signifikanter Anteil von Patienten weist nur eine inkomplette Remission der Exazerbations-Symptome auf. Das therapeutische Vorgehen bei diesen Patienten ist nicht etabliert. In jedem Fall sollte eine protrahierte Gabe antimikrobieller Substanzen (über 10 Tage) vermieden werden, da die Wahrscheinlichkeit einer Resistenzzunahme nach diesem Zeitraum ansteigt.

Therapieversagen: Ein Therapieversagen äußert sich in einer persistierenden Symptomatik trotz adäquater Therapie von mindestens 48 - 72 h Dauer. Zum Vorgehen im Rahmen eines Therapieversagens liegen keine Studien vor.

\section{Entsprechend den klinischen Erfahrungen empfiehlt die Arbeitsgruppe die Erwägung folgender Maßnahmen (Empfehlungsgrad D): \\ Bronchoskopie zur Gewinnung respiratorischer Sekrete für die mikrobiologische Diagnostik (und zur Bronchialtoilette bei Sekretretention) \\ - Echokardiografie zum Ausschluss einer Linksherzdekompen- sation/pulmonalen Hypertonie \\ - Röntgenthorax zum Ausschluss einer Pneumonie (primär ambulant erworben bzw. nosokomial) \\ - Angio-Computer-Tomografie des Thorax zum Ausschluss von Lungenembolien [240].}

\section{Risikostratifizierung der CAP}

Die Entscheidung über den Ort der Behandlung ist eine der wichtigsten im Management der Pneumonie. Daher kommt der objektiven Schweregradbestimmung eine wichtige Rolle zu.

\subsection{Entscheidung zur stationären Einweisung}

In Ergänzung zur klinischen Einschätzung durch den erfahrenen Arzt steht mit dem CRB-65-Index ( $\bullet$ Tab. 11) [241] ein einfach anwendbares und in Studien gut untersuchtes Instrument zur Schweregradbestimmung bei CAP zur Verfügung.
Der CRB-65-Index (die Akronyme stehen für confusion, respiratory rate, blood pressure, Alter $\geq \mathbf{6 5}$ Jahre) besteht aus den vier klinischen Variablen Verwirrtheit, Atemfrequenz, Blutdruck und Alter. Diese Variablen sind wiederholt als unabhängige Prädiktoren für einen letalen Ausgang der CAP hospitalisierter Patienten identifiziert worden ( $\bullet$ Tab. 11) [20,242-245]. Sie reflektieren die akute respiratorische Insuffizienz sowie Symptome der schweren Sepsis bzw. des septischen Schocks. Patienten, die keine dieser Variablen aufweisen, haben ein minimales LetalitätsRisiko (ca. 1\%), während solche mit einer oder zwei bzw. drei oder vier ein Letalitätsrisiko von ca. $8 \%$ bzw. ca. 30\% aufweisen. Diese Variablen sind mehrfach als Teil von prädiktiven Scores für das individuelle Letalitätsrisiko validiert worden [20,241,244248]. Der CRB-65-Index weist gegenüber anderen vorgeschlagenen Indizes den Vorteil auf, dass er komplett auf klinischen bzw. anamnestischen Parametern beruht und ohne Laboruntersuchung im Rahmen der Erstuntersuchung des Patienten bestimmt werden kann. Er zeigte in Studien eine gegenüber aufwendiger zu bestimmenden Indizes (PSI-Score und CURB-Index) vergleichbare gruppenspezifische Prädiktion des Letalitätsrisikos $[20,245,248]$ und wurde im Rahmen von CAPNETZ für den stationären und eingeschränkt auch den ambulanten Bereich in Deutschland validiert [20].

Allerdings wurde der CRB-65-Index primär zur Beurteilung des Letalitätsrisikos und nicht zur Entscheidung über eine Krankenhausbehandlung entwickelt und noch nicht an ausreichend großen Patientenzahlen in der ambulanten Praxis validiert.

Die Arbeitsgruppe empfiehlt (Empfehlungsgrad B) ( $\bullet$ Abb. 4) die Verwendung des CRB-65-Index für die Praxis und die Notaufnahme des Krankenhauses (s. Tab. 11). Bei einem CRB-65-Index $\geq 1$ sollte die Notwendigkeit einer stationären Einweisung erwogen werden. Die Verwendung des Score-Systems ersetzt allerdings nicht das klinische Urteil des Arztes, sondern sollte die eigene klinische Einschätzung objektivieren und validieren helfen. Ohne Zweifel müssen klinische (Komorbiditäten wie z. B. chronische Herzinsuffizienz) und nicht-klinische (z. B. soziale) Gründe bei jeder Entscheidung über eine Hospitalisierung mitbedacht werden. Auf der anderen Seite stellt ein Alter > 65 Jahre allein keinen zwingenden Grund zur stationären Einweisung bei leichter CAP und fehlenden instabilen Begleiterkrankungen dar.

Im Falle einer Entscheidung für eine ambulante Behandlung (CRB$65=0$ ) sollte eine Reevaluation der Patienten nach $48(-72)$ h erfolgen, da eine klinische Verschlechterung häufig in diesem Zeitrahmen eintritt [249]. Im Zweifelsfall sollte der Patient in das Krankenhaus aufgenommen werden, da die medizinischen und ökonomischen Kosten einer kurzfristigen Hospitalisierung geringer ins Gewicht fallen als eine notfallmäßige sekundäre Hospitalisierung.

\subsection{Entscheidung zur Aufnahme auf eine Intensiv-} station (ITS), Intermediärstation bzw. Station mit intensivierter Überwachung

Als gruppenspezifische Risikoscores sind weder der PSI- noch CRB-65-Index geeignet, um individuelle Patienten zu identifizieren, die auf eine ITS aufgenommen werden sollten. Die Entwicklung von entsprechenden Kriterien ist aus folgenden Gründen methodisch schwieriger:

- Als Referenzkriterium für die Aufnahme auf die ITS steht lediglich die jeweilige ärztliche Entscheidung zur Verfügung. Diese kann jedoch neben objektiven Kriterien des CAPSchweregrades auch lokale oder regionale Besonderheiten der Versorgung schwerer Erkrankter reflektieren und daher 
0

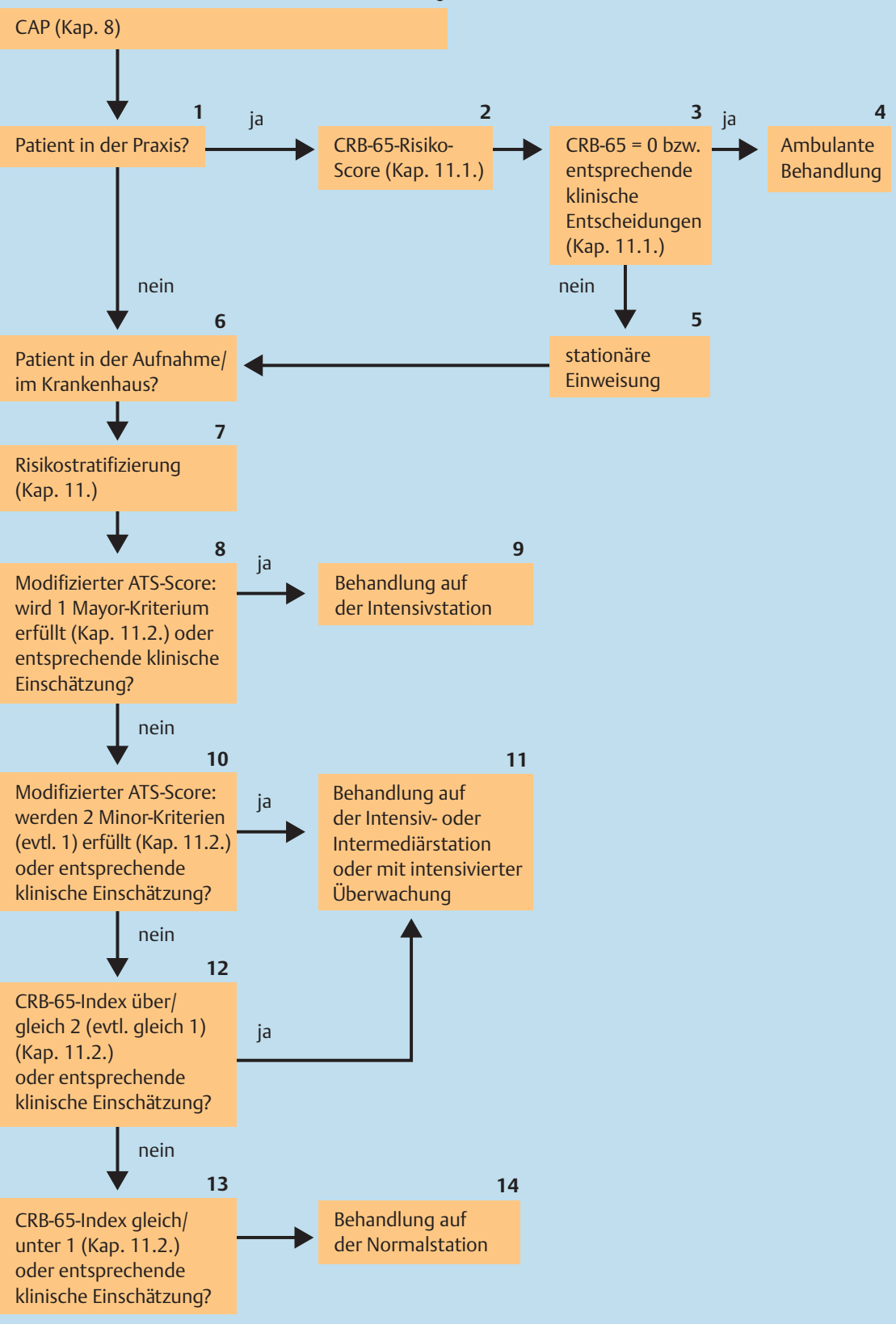

Abb. 4 Algorithmus zur Risikoabschätzung und Logistik bei CAP-Patienten. nicht ohne Weiteres allgemein zur Anwendung empfohlen werden.

- Die Existenz so genannter Überwachungsstationen oder Intermediärstationen (,intermediate care“) verändert die Kriterien der Aufnahme auf eine ITS derart, dass als nahezu einziges absolutes Kriterium die Intubation und maschinelle Beatmung verbleibt.

- Die Praxis der „nicht-invasiven Beatmung“ erlaubt bei geschultem Personal und ausreichendem Personalschlüssel sogar die Versorgung auf Normalstationen.

In den bisher durchgeführten Untersuchungen zur Identifikation von Kriterien für eine schwere CAP (SCAP) sind folgende Variablen beschrieben worden ( Tab. 12) [51]:

Diese Kriterien haben eine unzureichende Spezifität und sind daher nicht als Entscheidungskriterien für eine ITS-Aufnahme geeignet.
Tab. 12 Unabhängige Variable für einen letalen Ausgang bei hospitalisierten CAP-Patienten [51].

Respiratorisches Versagen
- Atemfrequenz $>30 /$ min
- Oxigenierungsindex $\mathrm{PaO}_{2} / \mathrm{F}_{1} \mathrm{O}_{2}<250$ ( $<200$ bei COPD)
- Notwendigkeit eines Atmungs-Supports
Radiologische Kriterien
- $50 \%$ Zunahme des Infiltrats innerhalb $48 \mathrm{~h}$ nach Aufnahme
- multilobäre oder bilaterale Infiltrate
Zeichen der schweren Sepsis oder des septischen Schocks mit hämo-
dynamischer Instabilität oder Organversagen
- RR syst. $<90 \mathrm{~mm} \mathrm{Hg} \mathrm{oder} \mathrm{RR} \mathrm{diast.}<60$ mm Hg
- Katecholamingabe $>4 \mathrm{~h}$
- Harnproduktion $<20 \mathrm{ml} / \mathrm{h}$ (keine gleichzeitige Hypovolämie)
- schwere Azidose ( $\mathrm{pH}<7,3$ )
- schwere disseminierte intravasale Gerinnung
- akutes Nierenversagen mit Nierenersatztherapie
- veränderter Bewusstseinszustand (Verwirrtheit)
Multiorganversagen


Ein Score, der aus diesen Variablen abgeleitet und auf einer pneumologisch geführten ITS entwickelt und validiert wurde (modifizierter ATS-Score), definiert eine sCAP (d.h. Pneumonie, die auf der ITS behandelt werden sollte) bei Vorliegen von mindestens zwei „Minor-Kriterien“ oder einem „Major-Kriterium“ (s. - Tab. 13) [247,249]. Er wies mittlere positive $(70-75 \%)$ und hohe negative (95\%) Prädiktionswerte auf [249].

Tab. 13 Modifizierte ATS-Kriterien für eine schwergradige Pneumonie (sCAP) [249].

„Major“-Kriterien, bestimmt bei Aufnahme oder im weiteren Verlauf
(positiv, wenn 1 von 2 Variablen vorhanden)
1. Notwendigkeit der Intubation und maschinellen Beatmung
2. Notwendigkeit der Gabe von Vasopressoren $>4 \mathrm{~h}$ (septischer Schock)
"Minor“-Kriterien, bestimmt bei Aufnahme
(positiv, wenn 2 von 3 Variablen vorhanden)
1. schwere akute respiratorische Insuffizienz $\left(\mathrm{PaO}_{2} / \mathrm{F}_{1} \mathrm{O}_{2}<250\right)$
2. multilobäre Infiltrate in der Röntgen-Thoraxaufnahme
3. systolischer Blutdruck $<90 \mathrm{mmHg}$

Derselbe Score erreichte jedoch in einer anderen Untersuchung nur unbefriedigende positive Vorhersagewerte [250]. Wahrscheinlich sind die Vorhersagewerte der Scores abhängig von der jeweiligen Struktur der ITS und daher nicht ohne Weiteres auf alle ITS übertragbar. Obwohl dieser Score eine Hilfe bei der Entscheidung über die Aufnahme auf eine Intensivstation sein kann, bleibt die Berücksichtigung der Kriterien für eine sCAP bestimmend. Ein erweiterter Score, der von einer spanischen Arbeitsgruppe abgeleitet und validiert wurde, zeigte eine höhere Falschpositivrate ohne signifikante Unterschiede in der Genauigkeit im Vergleich zum modifizierten ATS-Score [251]. Ein neuer, erweiterter Score der ATS/IDSA für eine ITS-Aufnahme wurde bisher nicht prospektiv validiert und wird daher dem etablierten modifizierten ATS-Score nicht vorgezogen [252].

Die Arbeitsgruppe empfiehlt (Empfehlungsgrad B) ( $\bullet$ Abb. 4) zur Aufnahme auf eine Intensivstation den modifizierten ATS-Score (s. Tab. 13): mindestens 1 Major-Kriterium positiv; sowie zur intensivierten Überwachung (je nach Einrichtung ITS, Intermediärstation bzw. Normalstation mit entsprechender Überwachung): mindestens 2 Minor-Kriterien positiv. Diese Regel ist für die Aufnahme auf eine ITS evaluiert. Für eine intensivierte Überwachung kann aber auch schon ein Minorkriterium ausreichen. Ein weiteres Kriterium zur intensivierten Überwachung besteht bei einem CRB-65-Index 22; im Einzelfall kann bereits ein CRB-65-Index von 1 ausreichend für eine intensivierte Überwachung sein.

Unabhängig von diesen Score-Systemen ist eine gründliche klinische Einschätzung des Schweregrads der CAP für die Entscheidung über eine intensivmedizinische Betreuung maßgeblich.

Über die initiale Bestimmung des Schweregrades hinaus werden kurzfristige Reevaluationen jedes hospitalisierten Patienten innerhalb der ersten 4-8 h empfohlen. Der frühzeitigen Erkennung und Behandlung einer schweren Sepsis als Vorstufe eines septischen Schocks kommt dabei eine zentrale Bedeutung zu. Es wird daher empfohlen, jeden Patienten mit schwerer Sepsis zumindest auf einer Überwachungsstation oder auf einer ITS zu behandeln, auf der frühzeitige zielgerichtete Interventionen durchgeführt werden können [253].

\subsection{Einteilung der CAP}

Die Einteilung der CAP erfolgt in die Risikogruppen

- leichtgradige ambulant-erworbene Pneumonie: Management im ambulanten Bereich möglich (ambulante CAP): Klinische Entscheidung unter Zuhilfenahme des CRB-65-Scores

- ohne Risikofaktoren (s. 12.1)

- mit Risikofaktoren (s. 12.2)

- mittelschwere ambulant-erworbene Pneumonie: Management im Krankenhaus auf Normalstation (hospitalisierte CAP): Klinische Entscheidung unter Zuhilfenahme des CRB65-Score

- schwergradige ambulant-erworbene Pneumonie: Management im Krankenhaus auf einer Überwachungsstation (Intensivstation, Intermediate Care u.a.) (schwere CAP): Klinische Entscheidung unter Zuhilfenahme des CRB-65-Scores und des mod. ATS-Scores

- ohne Indikation für eine gegen P. aeruginosa wirksame empirische Therapie (s. 14.1.)

- mit Indikation für eine gegen P. aeruginosa wirksame empirische Therapie (s. 14.1. und $\odot$ Tab. 5)

\section{Ambulantes Management der CAP}

$\nabla$

Definition: Patienten mit einer akuten unteren Atemwegsinfektion mit oder ohne lokalem Auskultationsbefund mit Nachweis eines Infiltrates im Röntgenthoraxbild und einem Risikoscore von CRB-65 = 0, ggf. auch einem CRB-65 $=1$ bei einem Alter $>65$ Jahre und fehlenden instabilen Begleiterkrankungen (s. $\odot$ Tab. 11).

\section{Die Arbeitsgruppe empfiehlt (Empfehlungsgrad A):}

Für die Auswahl von Diagnostik und kalkulierter Therapie sollten die Patienten eingeteilt werden in:

- ambulante Patienten ohne Risikofaktoren: Hierbei handelt es sich um Patienten

- ohne schwere Begleiterkrankungen

- ohne Antibiotikavortherapien in den letzten 3 Monaten und

- in stabilem klinischen Zustand

- ambulante Patienten mit folgenden Risikofaktoren:

- Antibiotikavortherapie (in den letzten 3 Monaten) und/oder

- Bewohner von Pflegeheimen und/oder

- chronische internistische (Herzinsuffizienz, Leberzirrhose, terminale Niereninsuffizienz) oder neurologische Begleiterkrankungen (wie Z.n. Schlaganfall mit neurologischem Defektsyndrom)

- ohne dass eine akute hämodynamische oder respiratorische Beeinträchtigung die stationäre Aufnahme erforderlich macht,

- da diese Risikofaktoren Einfluss auf die Ätiologie und das diagnostische und therapeutische Vorgehen besitzen (s. Tab. 4).

\subsection{CAP bei ambulanten Patienten ohne Risikofaktoren} 12.1.1. Erregerspektrum bei ambulanten CAP-Patienten ohne Risikofaktoren

Zur Ätiologie der CAP wird im Kapitel 3 Stellung genommen. Der häufigste Erreger der CAP in dieser Patientengruppe ist S. pneumoniae. Zur zweithäufigsten Erregergruppe gehören M. pneumoniae, L. pneumophila und respiratorische Viren. Mykoplasmeninfektionen treten vorrangig bei jüngeren Erwachsenen auf, lokale Ausbrüche kommen vor [254]. C. pneumoniae spielt in Deutschland als Erreger einer CAP nur eine untergeordnete Rolle [28]. 
12.1.2. Diagnostik bei ambulanten Patienten ohne Risikofaktoren

Da das Erregerspektrum in dieser Patientengruppe eng ist und die Letalität unter $2 \%$ liegt, ist eine minimale Diagnostik ausreichend.

Die Arbeitsgruppe empfiehlt (Empfehlungsgrad B) eine eingehende klinische Untersuchung mit Bestimmung des CRB-65-Index (s. Tab. 11) und eine Röntgenthorax-Aufnahme in zwei Ebenen (nach dem Algorithmus Abb. 1). Die Durchführung von Laboruntersuchungen zur Therapiesteuerung (z. B. Blutbild, Kreatinin, Harnstoff) und weitere Untersuchungen in Abhängigkeit von Grunderkrankung oder Begleitmedikation (z. B. Transaminasen) können indiziert sein. (A)

Eine mikrobiologische Diagnostik wird bei Patienten mit leichter CAP nicht empfohlen (A).

\subsubsection{Therapie bei ambulanten CAP-Patienten}

ohne Risikofaktoren

Die kalkulierte Initialtherapie soll die in dieser Gruppe häufigen Erreger erfassen und bei oraler Applikation eine gute Bioverfügbarkeit aufweisen, ohne unnötig breit zu sein (s. $\odot$ Tab. 14).

In kontrollierten Therapiestudien war eine Monotherapie mit hochdosiertem Amoxicillin mit oder ohne Betalaktamaseinhibitor gut wirksam $[255,256]$. Die hierbei in Kauf zu nehmende Wirkungslücke gegenüber $M$. pneumoniae, $C$. pneumoniae und $L$. pneumophila scheint bei unkomplizierter CAP die Effektivität dieser Therapie nicht zu beeinträchtigen [257,258]. Eine hochgradige Penicillinresistenz von S. pneumoniae ist weiterhin so selten, dass bei ausreichender Dosierung nicht mit resistenzbedingtem Therapieversagen bei Pneumokokkeninfektionen zu rechnen ist (s. Kap. 5). Amoxicillin ist daher das Mittel der Wahl bei Patienten mit ambulant behandelter CAP ohne Risikofaktoren.

Alternativ können bei Penicillinunverträglichkeit die neueren Makrolide Azithromycin, Clarithromycin und Roxithromycin eingesetzt werden. Die Erfolgsraten klinischer Studien bei Patienten mit unkomplizierten, ambulant therapierbaren Pneumonien lagen mit einer Makrolid-Monotherapie um 90\%, ohne dass Unterschiede gegenüber Vergleichssubstanzen (u.a. Fluorchinolone, Ketolide) gefunden wurden [259]. Als problematisch muss jedoch angesehen werden, dass die Rate Makrolid-resistenter $S$. pneumoniae bei CAP in Deutschland aktuell ca. 15\% beträgt (s. ( Tab. 6). In Studien aus den USA und Europa kam es während einer Makrolidtherapie zu Durchbruch-Bakteriämien und damit zu Therapieversagen [76,77], und eine bestehende Makrolidresistenz wurde als Risikofaktor für ein Therapieversagen bei Pneumokokkeninfektion identifiziert, wobei kein Unterschied zwischen Erregern mit „high-level“- und „low-level“-Resistenz besteht [78]. Die Makrolidtherapie selbst ist dabei der wichtigste Risikofaktor für die Resistenzentstehung [33], nach Makrolidgabe wurde eine rasche und lang anhaltende Vermehrung Makrolidresistenter S. pneumoniae in der oropharyngealen Flora bei Probanden nachgewiesen [79].

Eine weitere Alternative ist Doxycyclin. Die Resistenzraten von $S$. pneumoniae gegenüber Doxycyclin sind derzeit günstiger als die gegenüber Makroliden. In einer randomisierten Studie fand sich mit Doxycyclin bei hospitalisierten Patienten mit CAP eine vergleichbare Ansprechrate wie mit einer konventionellen Antibiotikatherapie [260]. Aktuelle klinische Studien aus Deutschland fehlen.
Tab. 14 Therapieempfehlung für ambulante Patienten mit CAP ohne Risikofaktoren (s. Abschnitt 12).

\begin{tabular}{|c|c|c|}
\hline Substanzen* & Dosierung (pro Tag)* & Therapiedauer \\
\hline \multicolumn{3}{|l|}{ Mittel der Wahl } \\
\hline \multicolumn{3}{|l|}{ Aminopenicillin } \\
\hline - Amoxicillin & $\begin{array}{l}\geq 70 \mathrm{~kg}: 3 \times 1 \mathrm{~g} \text { oral } \\
<70 \mathrm{~kg}: 3 \times 0,75 \mathrm{~g} \text { oral }\end{array}$ & 5-7 Tage \\
\hline \multicolumn{3}{|l|}{ Alternativen } \\
\hline \multicolumn{3}{|l|}{ Makrolid } \\
\hline - Azithromycin & $1 \times 500 \mathrm{mg}$ oral & 3 Tage \\
\hline - Clarithromycin & $2 \times 500 \mathrm{mg}$ oral & 5-7 Tage \\
\hline - Roxithromycin & $1 \times 300 \mathrm{mg}$ oral & 5-7 Tage \\
\hline \multicolumn{3}{|l|}{ oder } \\
\hline \multicolumn{3}{|l|}{ Tetracyclin } \\
\hline - Doxycyclin & $\begin{array}{l}1 \times 200 \mathrm{mg} \text { oral initial, } \\
\geq 70 \mathrm{~kg}: 1 \times 200 \mathrm{mg} \\
<70 \mathrm{~kg}: 1 \times 100 \mathrm{mg}\end{array}$ & 5-7 Tage \\
\hline
\end{tabular}

Bei Unverträglichkeit gegenüber den genannten Substanzklassen können die Oralcephalosporine Cefuroxim-Axetil oder Cefpodoxim-Proxetil eingesetzt werden. Problematisch ist allerdings ihre unsichere orale Bioverfügbarkeit.

Für die Überlegenheit einer Kombinationstherapie von Betalaktam-Antibiotika mit Makroliden gibt es bei dieser Patientengruppe keine Evidenz aus kontrollierten Studien.

Die Therapie mit den Fluorchinolonen Levofloxacin und Moxifloxacin ist eine weitere Alternative, erfasst aber ein unnötig breites Spektrum und wird, um Resistenzentwicklungen zu vermeiden und aufgrund des Toxizitätsprofils (s. Kap. 7.5.1.), für diese Patientengruppe nicht empfohlen. Der Einsatz von Ciprofloxacin ist wegen der bekannten unzureichenden Aktivität gegenüber $S$. pneumoniae, der Dokumentation von Therapieversagen und der Entwicklung von Resistenzen gegenüber modernen Fluorchinolonen in der Therapie der CAP grundsätzlich nicht indiziert [261].

Die Arbeitsgruppe empfiehlt (Empfehlungsgrad A) als Therapie der Wahl für die unkomplizierte CAP im ambulanten Bereich bei Patienten ohne Risikofaktoren die Monotherapie mit einem hochdosierten Aminopenicillinpräparat. Alternativ kann bei Penicillinunverträglichkeit ein neueres Makrolid (Azithromycin, Clarithromycin, Roxithromycin) oder Doxycyclin verabreicht werden (s. Tab. 14). Fluorchinolone werden bei dieser Patientengruppe nicht empfohlen. Die Arbeitsgruppe geht auch von der Überlegung aus, dass ein übermäßiger oder einseitiger Einsatz einzelner Substanzgruppen wie Makrolide, Doxycyclin oder Fluorchinolone zu einer weiteren Resistenzentwicklung beiträgt.

\subsubsection{Verlauf bei ambulanten CAP-Patienten ohne Risikofaktoren}

Die Arbeitsgruppe empfiehlt (Empfehlungsgrad A): Eine ausreichende häusliche Versorgung und Überwachung jedes Patienten mit ambulant behandelter CAP ist erforderlich. Eine Reevaluation der Patienten nach $48(-72)$ h ist notwendig. Falls zu diesem Zeitpunkt kein Fieberrückgang und klinische Besserung vorliegen, müssen Diagnose und eingeleitete Therapie überprüft sowie die stationäre Einweisung erwogen werden [262]. 


\section{Therapiedauer:}

Die Arbeitsgruppe empfiehlt (Empfehlungsgrad A): Die antibiotische Therapie kann 48 - 72 h nach klinischer Besserung mit Entfieberung, jedoch frühestens nach 5 Tagen, beendet werden. Eine Therapiedauer von mehr als 7 Tagen ist im Regelfall nicht erforderlich [263 - 265]. Die empfohlene Therapiedauer für Azithromycin beträgt drei Tage.

Radiologische Verlaufsuntersuchung (Empfehlungsgrad D): Für einen Nutzen radiologischer Verlaufskontrollen gibt es keine gute Evidenz, bei Vorliegen von Risikofaktoren für eine Tumorerkrankung kann eine radiologische Abschlussuntersuchung im Verlauf, jedoch nicht vor 2 Wochen nach Therapieende, sinnvoll sein.

Therapieversagen: Therapieversagen ist in dieser Patientengruppe mit 3-6\% selten. Es liegen keine ausreichenden Daten über die Ursachen bei ambulanten Patienten vor. Empfehlungen zum praktischen Vorgehen finden sich in Kapitel 15.

\subsection{CAP bei ambulanten Patienten mit Risikofaktoren} 12.2.1. Erregerspektrum bei ambulanten CAP-Patienten mit Risikofaktoren

Bei Patienten mit Risikofaktoren ist das ätiologische Spektrum vielfältiger und umfasst neben $S$. pneumoniae und $H$. influenzae auch $S$. aureus und Enterobacteriaceae. Dies trifft insbesondere für Patienten aus einem Pflegeheim/Altersheim oder multimorbide Patienten mit einer leichtgradigen CAP zu. Besondere Aufmerksamkeit sollte der Evaluation von Antibiotika-Vortherapien in den letzten 3 Monaten zukommen, welche für Infektionen mit resistenten Erregern prädisponieren [33,34]. Ein weiterer Risikofaktor für das Auftreten resistenter Erreger ist ein eingeschränkter funktioneller Status (chronische Bettlägerigkeit) [13]. An eine Aspirationspneumonie sollte bei neurologischen Grunderkrankungen und eingeschränkter Dentalhygiene gedacht werden [46]. Bei Aspirationspneumonien sind vermutlich Anaerobier bzw. Mischinfektionen ätiologisch von Bedeutung. Anaerobier werden wahrscheinlicher, wenn ein protrahierter Verlauf vorliegt oder einschmelzende Infiltrate in abhängigen Lungensegmenten nachgewiesen werden. Die Assoziation der Risikofaktoren mit bestimmten Erregern sind in $\bullet$ Tab. 4 aufgeführt.

\subsubsection{Diagnostik bei ambulanten CAP-Patienten mit Risikofaktoren}

\section{Die Arbeitsgruppe empfiehlt (Empfehlungsgrad A):}

Die Röntgenuntersuchung der Thoraxorgane ist immer anzustreben. Eine umfangreichere Labordiagnostik als bei unkomplizierter CAP kann in Abhängigkeit von den Grunderkrankungen der Patienten notwendig sein. Eine mikrobiologische Diagnostik ist auch in dieser Gruppe nicht generell indiziert. Nach Vorbehandlung mit Antibiotika, bei struktureller Lungenerkrankung oder rezidivierenden Pneumonien sollte wegen des höheren Risikos resistenter Erreger eine mikrobiologische Diagnostik (Gramfärbung und Bakterienkultur mit Resistenztestung) aus Sputum oder bronchoalveolärer Lavage (BAL) in Erwägung gezogen werden, auch wenn die Effektivität dieses Vorgehens nicht durch Daten aus prospektiven Studien belegt ist.

Die Abnahme von Blutkulturen wird in dieser Risikogruppe aufgrund geringer therapeutischer Konsequenzen $(<2 \%)$ nicht empfohlen [266].

\subsubsection{Therapie bei ambulanten CAP-Patienten} mit Risikofaktoren

Wegen des erweiterten Erregerspektrums wird für die kalkulierte Therapie in dieser Gruppe primär die Gabe eines auch gegenüber Enterobacteriaceae wirksamen Betalaktamantibiotikums empfohlen (s. Tab. 15). Eine Aminopenicillin/Betalaktamaseinhibitor-Kombination ist auch gegenüber $S$. aureus, den meisten betalaktamasebildenden Enterobacteriaceae sowie Anaerobiern wirksam [267,268].

Tab. 15 Therapieempfehlung für ambulante Patienten mit CAP mit Risikofaktoren (s. Abschnitt 12).

\begin{tabular}{l}
$\begin{array}{l}\text { Substanzen* } \\
\text { Mittel der Wahl }\end{array}$ \\
$\begin{array}{l}\text { Betalaktam } \\
\text { - Amoxicillin/ } \\
\text { Clavulansäure }\end{array}$ \\
$\begin{array}{l}\text { - Sultamicillin } \\
\text { Alternative }\end{array}$ \\
$\begin{array}{l}\text { Fluorchinolon** } \\
\text { - Levofloxacin }\end{array}$ \\
$\begin{array}{l}\text { - Moxifloxacin } \\
\text { - } 2 \times 0,75 \text { Tage }\end{array}$ \\
$\begin{array}{l}\text { * Weiterführende Angaben zur Pharmakologie, Verträglichkeit, Interaktionen } \\
\text { und Dosierung finden sich in Kapitel 7. Bei vorausgegangener Antibiotika- } \\
\text { therapie wird ein Wechsel der zuletzt verwendeten Substanzklasse empfohlen. } \\
\text { ** bei Therapieversagen oder Unverträglichkeit der anderen Substanzen. }\end{array}$ \\
\hline
\end{tabular}

Wenn Legionella spp., C. pneumoniae und M. pneumoniae ebenfalls erfasst werden sollen, kann zusätzlich ein Makrolidantibiotikum gegeben werden. Für die Notwendigkeit einer generellen Kombinationstherapie liegen allerdings für den ambulanten Bereich keine ausreichenden Daten vor.

Eine Alternative stellt die Monotherapie mit einem pneumokokkenwirksamen Fluorchinolon (Levofloxacin, Moxifloxacin) dar. Diese Substanzen sind gegenüber allen relevanten Erregern wirksam und haben sich in randomisierten Studien als mindestens so effektiv wie die teils in Kombination eingesetzten Vergleichssubstanzen erwiesen [269-271]. Darüber hinaus besteht der Vorteil einer einmal täglichen Einnahme und einer hohen Bioverfügbarkeit. Gegen einen zu breiten Einsatz spricht allerdings das Risiko von Resistenzentwicklungen sowie das Toxizitätsprofil dieser Substanzklasse vor dem Hintergrund der sehr guten Prognose der ambulanten CAP [272]. Eine Alternative bei Unverträglichkeit gegenüber den zuvor genannten Substanzklassen besteht mit den Cephalosporinen Cefuroxim-Axetil und Cefpodoxim-Proxetil $[269,273]$. Problematisch ist allerdings die unsichere orale Bioverfügbarkeit beider Substanzen.

Wichtiges differenzialtherapeutisches Entscheidungskriterium ist eine vorausgegangene Antibiotikatherapie. In diesem Fall wird ein Wechsel der zuletzt verwendeten Substanzgruppe empfohlen. Dies gilt insbesondere für Therapien innerhalb der letzten 3 Monate [33]. Ferner sollten die im Alter und bei Komorbidität gehäuft auftretenden unerwünschten Effekte der Antiinfektiva berücksichtigt werden. Bei ambulanten Patienten, bei denen eine suffiziente orale Therapie nicht gewährleistet werden kann, kann auch eine ambulante intravenöse Therapie entsprechend den Therapieempfehlungen für hospitalisierte CAP erfolgen [274]. Für Patienten, die trotz Indikation zur Krankenhausaufnahme ambulant behandelt werden, gelten generell die Therapieempfehlungen für hospitalisierte CAP. 
Die Arbeitsgruppe empfiehlt (Empfehlungsgrad A) als Therapie der Wahl für CAP im ambulanten Bereich bei Patienten mit Risikofaktoren die Monotherapie mit einem hochdosierten Aminopenicillin/Betalaktamaseinhibitor-Präparat (s. Tab. 15). Alternativ können bei Therapieversagen oder Unverträglichkeit die Fluorchinolone Levofloxacin oder Moxifloxacin eingesetzt werden. Bei Verdacht auf eine Koinfektion durch Mykoplasmen, Chlamydien oder Legionellen kann auch eine Kombinationstherapie in Form einer Betalaktam-Makrolid-Kombination durchgeführt werden.

\subsubsection{Verlauf bei ambulanten CAP-Patienten mit Risikofaktoren}

Die Arbeitsgruppe empfiehlt (Empfehlungsgrad B): Eine gute häusliche Versorgung und engmaschige Überwachung ist bei Patienten mit CAP in höherem Alter oder mit Komorbiditäten zwingend erforderlich. Die Gewährleistung einer ausreichenden Oxygenierung, einer stabilen Kreislaufsituation und einer sicheren Medikamenteneinnahme und Resorption sind Voraussetzungen für eine ambulante Therapie. Generell sollte auf eine ausreichende Rehydratation geachtet werden. Dies gilt insbesondere für Patienten im Altenheim/Pflegeheim bzw. geriatrische Patienten [14]. Im Zweifelsfall sollte eine kurzfristige Hospitalisierung erwogen werden. Eine Reevaluation der Patienten nach $48(-72) \mathrm{h}$ ist erforderlich. Falls zu diesem Zeitpunkt kein Fieberrückgang und keine klinische Besserung festzustellen sind, müssen Diagnose und eingeleitete Therapie überprüft sowie die stationäre Einweisung erwogen werden.

\section{Therapiedauer:}

Die Arbeitsgruppe empfiehlt (Empfehlungsgrad A): Die antibiotische Therapie kann 48-72 h nach klinischer Besserung mit Entfieberung, jedoch frühestens nach 5 Tagen, beendet werden. Eine Therapiedauer von mehr als 7 Tagen ist im Regelfall nicht erforderlich [263-265].

Radiologische Verlaufsuntersuchung (Empfehlungsgrad D): Für einen Nutzen radiologischer Verlaufskontrollen gibt es keine gute Evidenz, bei Vorliegen von Risikofaktoren für eine Tumorerkrankung kann eine radiologische Abschlussuntersuchung im Verlauf, jedoch nicht vor 2 Wochen nach Therapieende, sinnvoll sein.

Therapieversagen: In Abhängigkeit vom Schweregrad ist bei Therapieversagen eine Hospitalisierung bzw. eine Überweisung an apparativ entsprechend ausgestattete Spezialisten zu empfehlen (B). Die Differenzialdiagnose, das diagnostische Vorgehen und die kalkulierte Behandlung werden in Kapitel 15 besprochen.

\section{Management bei hospitalisierten CAP-Patienten}

$\nabla$

Definition: Patienten mit einer akuten unteren Atemwegsinfektion mit oder ohne lokalisiertem Auskultationsbefund mit Nachweis eines Infiltrates im Röntgenthoraxbild und einem Risikoscore von CRB-65 $\geq 1$ (s. Tab. 11). Ein Alter von > 65 Jahre allein ist jedoch bei leichter Erkrankung und fehlenden instabilen Komorbiditäten kein zwingendes Kriterium zur stationären Behandlung.

Patienten mit mindestens einem Major-Kriterium nach dem modifizierten ATS-Score (s. Tab. 13) sollten auf einer Intensivstation behandelt werden (s. Kap. 14). Die Notwendigkeit zur intensivierten Überwachung (je nach Einrichtung ITS, Intermediärsta- tion bzw. Normalstation mit entsprechender Überwachung) besteht bei 2 positiven Minor-Kriterien (s. Tab. 13) oder einem CRB-65-Index $\geq 2$ (s. $\odot$ Tab. 11). Für eine intensivierte Überwachung kann aber im Einzelfall auch schon ein Minorkriterium bzw. ein CRB-65-Index von 1 ausreichend sein. Notwendig ist eine gründliche klinische Einschätzung des Schweregrads der CAP für die Entscheidung über eine intensivmedizinische Betreuung.

\subsection{Erregerspektrum bei hospitalisierten CAP-Patienten}

Das Erregerspektrum der nicht schweren hospitalisierten CAP unterscheidet sich nicht wesentlich von dem nicht-hospitalisierter Patienten. Die häufigsten Erreger sind S. pneumoniae, $M$. pneumoniae, $H$. influenzae, gramnegative Enterobacteriaceae und respiratorische Viren (siehe Tab. 3) $[26,275,276]$. C. pneumoniae spielt als Erreger der CAP in Deutschland nur eine untergeordnete Rolle [28]. Die Häufigkeit von L. pneumophila ist regional unterschiedlich und beträgt bis zu 6\% [24,277,278]. Enterobacteriaceae werden etwas häufiger nachgewiesen als bei Patienten, bei denen die CAP ambulant behandelt werden kann. Dies kann zum Teil durch die unterschiedlichen Patientencharakteristika (vermehrt ältere Patienten mit Begleiterkrankungen) erklärt werden [25]. Polymikrobielle Infektionen scheinen etwas häufiger im Vergleich zu nicht hospitalisierten Patienten zu sein $[279,280]$. Eine besondere Gruppe bilden Patienten aus einem Pflegeheim/Altersheim oder multimorbide Patienten. Bei antibiotischen Vortherapien und einem eingeschränkten funktionellen Status (chronische Bettlägerigkeit) muss mit einem gehäuften Auftreten (multi-)resistenter Bakterien gerechnet werden [13]. An eine Aspirationspneumonie sollte bei neurologischen Grunderkrankungen und eingeschränkter Dentalhygiene gedacht werden [46].

P. aeruginosa spielt in Deutschland als Erreger der CAP nach aktuellen Daten von CAPNETZ nur eine zahlenmäßig geringe Rolle [26]. Daher ist bei CAP auf Normalstation nur in seltenen Fällen bei Patienten mit Risikofaktoren (insbesondere schwere strukturelle Lungenerkrankungen wie zystische Fibrose, sehr schwere COPD und Bronchiektasenerkrankung mit Antibiotika- und/oder Krankenhausvorbehandlung, siehe Tab.5) eine pseudomonaswirksame Initialtherapie erforderlich. Für die Substanzauswahl wird auf $\bullet$ Tab. 18 im Kapitel sCAP verwiesen. 


\subsection{Diagnostik bei hospitalisierten CAP-Patienten}

Die Arbeitsgruppe empfiehlt (Empfehlungsgrad B) ( $\triangle$ Abb. 5): Die Diagnostik bei hospitalisierten CAP-Patienten umfasst neben der Anamnese und der körperlichen Untersuchung mit Allgemeinzustand, Bewusstseinslage, Blutdruck, Puls, Atemfrequenz folgende Punkte:

\section{- Anamnestische Angaben im Hinblick auf ein spezielles} Erregerspektrum (s. $\odot$ Tab. 4 u. 5)

- Bildgebung (Röntgenthorax in 2 Ebenen): Die konventionelle Röntgenaufnahme des Thorax in posteroanteriorer und lateraler Position ist zum Nachweis von pulmonalen Infiltraten, zur Einschätzung des Schweregrades, zur differenzialdiagnostischen Abklärung, zum Ausschluss von Komplikationen (wie Abszedierung) und zum Nachweis von Begleiterkrankungen bei stationärer Aufnahme obligat [51]. Das Vorliegen eines Pleuraergusses sowie multilobärer Infiltrate sind prognostisch ungünstige Zeichen [281-283].

Die klinische Relevanz eines Computertomogramms der Lungen bei CAP ist unklar, es ist in der Routinediagnostik nicht notwendig [41, 284-285].

- Laborchemische und Blutbilduntersuchungen - Leukozytenzahl und Differenzialblutbild (A): Die Bestimmung von Entzündungsmarkern ist zur differenzialdiagnostischen Abklärung von anderen nicht-infektiösen pulmonalen Infiltraten und zur prognostischen Einschätzung des Krankheitsbildes sinnvoll. Ältere Patienten (> 64 Jahre) mit Zeichen einer systemischen Inflammation (Fieber, Leukozytenanzahl) bei CAP zeigen eine signifikant bessere Prognose als ohne entsprechende inflammatorische Antwort [286].

- Entzündungsparameter im Serum (A): Mit C-reaktivem Protein und Procalcitonin stehen zwei Parameter zur Verfügung. Beide Parameter eignen sich prinzipiell als Verlaufsparameter bei CAP. C-reaktives Protein ermöglicht jedoch keine Differenzierung zwischen einer CAP und einer unteren Atemwegsinfektion ohne Infiltratnachweis sowie zwischen viralen und bakteriellen Infektionen [287, 288]. Persistierend erhöhte CRP-Werte unter einer Antibiotika-Therapie können für ein Therapieversagen oder für eine sekundäre infektiöse Komplikation sprechen [289, 290]. Procalcitonin ist ein relativ spezifischer Parameter für generalisierte bakterielle Infektionen und zeigt eine rasche Kinetik. In einer prospektiven Studie konnte durch eine mittels Procalcitonin-III-Test gesteuerte Antibiotikatherapie bei Patienten mit CAP die Dauer der Antibiotikatherapie bei gleichem Therapieerfolg signifikant gesenkt werden, indem bei einem Procalcitonin von $<0,1 \mu \mathrm{g} / \mathrm{I}$ die Beendigung der Therapie empfohlen wurde [291]. Erhöhte Procalcitoninkonzentrationen sind mit einer ungünstigen Prognose bei CAP assoziiert [292]. Die Bestimmung eines Entzündungsparameters (CRP oder Procalcitonin) im Serum bei Aufnahme und im Verlauf nach 3-5 Tagen wird empfohlen. Bei fehlendem Abfall sollte das Vorliegen eines Therapieversagens (siehe Kapitel 15) oder einer sekundären infektiösen Komplikation überprüft werden, wobei die Beurteilung insbesondere des CRP aufgrund seiner verzögerten Kinetik stets im Kontext mit dem klinischen Verlauf erfolgen muss.

- Laborchemie: Elektrolyte, Serumkreatinin, Serumharnstoff [241], Blutzucker, Transaminasen, $y$-GT (B)

- Arterielle oder kapilläre Blutgase oder Sauerstoffsättigung (A):

Ein $\mathrm{paO}_{2}<60 \mathrm{~mm} \mathrm{Hg}$ bei Aufnahme ist ein Risikofaktor für Therapieversagen [293]. In einer Post-hoc-Analyse einer prospektiven Studie führte eine Kontrolle der Oxygenierung erst $>3 \mathrm{~h}$ nach Aufnahme bei Patienten mit hospitalisierter schwerer CAP zu einem verzögerten Beginn einer adäquaten Antibiotikatherapie und war mit erhöhten Sterberisiko (HR 2.06) verbunden [294].
Mikrobiologische Untersuchungen: Die klinische Bedeutung mikrobiologischer Untersuchungen hinsichtlich der Therapieentscheidung bzw. Prognose bei hospitalisierten CAP-Patienten auf einer Normalstation ist ungesichert [51, 98, 295-297]. Eine prospektive randomisierte Studie fand keinen Vorteil für eine durch umfangreiche mikrobiologische Diagnostik gesteuerte Therapiestrategie bei CAP gegenüber einer rein empirisch gelenkten Therapie [298].

Es wird folgendes Diagnostikprogramm empfohlen:

- Die Entnahme von zwei Blutkulturen (zwei mal zwei

Flaschen) von unterschiedlichen Lokalisationen im Abstand von wenigen Minuten, möglichst vor Einleitung der antimikrobiellen Therapie (C) zur verbesserten prognostischen Einschätzung der Erkrankung, zur Schweregradabschätzung sowie zum Erreger- und Resistenznachweis für die individuelle Therapieführung und aus epidemiologischen Gesichtspunkten. - Diagnostische Pleurapunktion (B): Eine diagnostische Pleurapunktion bei Vorliegen eines Pleuraergusses ( $>5 \mathrm{~cm}$ in der lateralen Röntgenaufnahme) ist aus differenzialdiagnostischen Gründen obligat (Ausschluss eines Pleuraempyems) [51,299]. Die Untersuchung sollte die Bestimmung des pH-Wertes, des Eiweißgehaltes, eine Gramfärbung und eine Bakterienkultur beinhalten [300].

- L. pneumophila-Antigentest (Serogruppe 1) aus Urin (B): Ein Legionella-Antigentest kann bei allen Patienten dieser Risikogruppe empfohlen werden. Diese Empfehlung ist optional. Der Test weist eine Sensitivität von $>90 \%$ auf und führt zu einer signifikant rascheren Diagnosestellung einer Infektion durch L. pneumophila, Serogruppe 1 als die Kultur [113]. Ein verzögerter Therapiebeginn einer Legionellenpneumonie ist mit einer erhöhten Letalität verbunden [301].

- Eine mikrobiologische Sputumuntersuchung wird nur empfohlen bei nicht antibakteriell vorbehandeltem Patienten mit purulentem Sputum und Gewährleistung der notwendigen logistischen Voraussetzungen (Transport und Verarbeitung innerhalb von 2 bis 4 Stunden, s. Kap. 6)

Antigentest im Urin auf S. pneumoniae: Eine routinemäßige Durchführung wird nicht empfohlen, da S. pneumoniae ohnehin von der kalkulierten antimikrobiellen Therapie erfasst werden muss. Ein positiver Ausfall des Antigentests kann zur Erleichterung von Entscheidungen zur Fokussierung der Therapie beitragen, wobei die Möglichkeit polymikrobieller Infektionen zu bedenken ist (Evidenzgrad 5) [302].

Folgende Untersuchungsverfahren werden nicht allgemein empfohlen (B):

- Bronchoskopie (D)

- Serologischer Nachweis von Antikörpern gegen

L. pneumophila, C. pneumoniae, respiratorische Viren

- DNA-Amplifikationsverfahren

\subsection{Therapie bei hospitalisierten CAP-Patienten}

Die Arbeitsgruppe empfiehlt (Empfehlungsgrad B): Eine antimikrobielle Therapie sollte so früh wie möglich eingeleitet werden. Eine Verzögerung der Therapieeinleitung über 8 Stunden und länger nach stationärer Aufnahme geht mit einer erhöhten Letalität einher $[303,304]$. Diagnostische Maßnahmen dürfen den Therapiebeginn nicht verzögern.

Antibiotika mit breitem antimikrobiellem Spektrum sollten für die kalkulierte Initialtherapie Wirkstoffen mit engerem Spektrum vorgezogen werden (A). Hierzu eignen sich in erster Linie Kombinationen aus Betalaktamantibiotika mit Makroliden. Als 
Hospitalisierte CAP-Patienten

auf Normalstation (hosp. CAP)

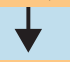

Laboruntersuchungen

ggf. Blutkulturen, Legionellen-

Antigentest, Blutgasanalyse/

$\mathrm{O}_{2}$-Sättigung (Kap. 13.2.)

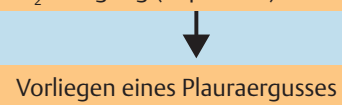

2

$(>10 \mathrm{~mm})$ (Kap. 16.1.)?

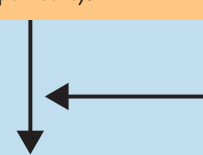

6

ja

Antibiotika-vorbehandelter Patient?

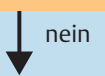

11 ja

Pleurapunktion mit

Bestimmung von $\mathrm{pH}$, Eiweißgehalt, Gramfärbung, Kultur

$\downarrow$

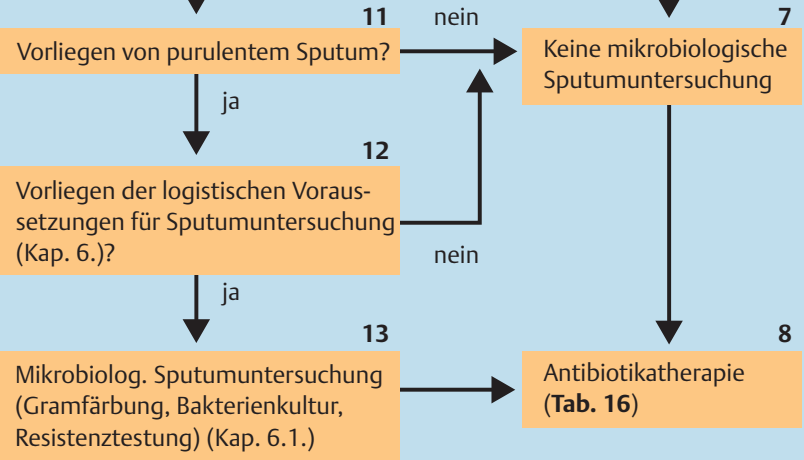

Abb. 5 Algorithmus zur Diagnostik und kalkulierten Therapie bei hospitalisierten CAP-Patienten auf Normalstation (hospitalisierte CAP).

Alternative können die pneumokokkenwirksamen Fluorchinolone Levofloxacin oder Moxifloxacin eingesetzt werden.

Mono- versus Kombinationstherapie: Die überwiegende Anzahl der Studien zur Behandlung von hospitalisierten Patienten mit ambulant erworbener Pneumonie sind als Zulassungsstudien bzw. Phase-3- und 4-Studien durchgeführt worden. Studien zur Monotherapie mit Betalaktamantibiotika erfolgten meist mit den Cephalosporinen Cefuroxim bzw. Ceftriaxon und ergaben bei primärem Studienziel der Nicht-Inferiorität der Prüfsubstanzen im Vergleich zu den jeweiligen Standardbehandlungen vergleichbare klinische und mikrobiologische Ansprechraten.

Mehrere retrospektive Studien zeigen eine Überlegenheit einer Kombinationstherapie bestehend aus einem Betalaktam/Betalaktamaseinhibitor plus einem Makrolid im Vergleich zu einer Monotherapie mit Betalaktamantibiotika (mit oder ohne Betalaktamaseinhibitor) [305,306]. Der Vorteil bezieht sich auf alle Altersgruppen sowie auch auf Patienten mit bakteriämisch verlaufender Pneumokokkenpneumonie [307-309]. Mehrere aktuelle prospektive multizentrische Beobachtungsstudien fanden allerdings bei Patienten mit einer Pneumokokkenpneumonie, die nicht intensivpflichtig waren, keinen signifikanten Überlebensvorteil einer Mono- versus Kombinationstherapie [310-312]. Zwei aktuelle Metaanalysen konnten darüber hinaus keine Überlegenheit von Antibiotikatherapien, welche Chlamydien, Mykoplasmen und Legionellen im antibiotischen Wirkspektrum einschlossen (Fluorchinolone oder Makrolide/Azalide/Ketolide), gegenüber einer Monotherapie mit einem Betalaktam bei Patienten mit leichter bis moderater CAP zeigen [257-258]. Lediglich in der Untergruppe mit gesicherter Legionellenpneumonie fand sich ein Nachteil in der Betalaktamgruppe. Für die generelle Empfehlung einer Kombinationstherapie aus einem Betalaktam und einem Makrolid bei allen hospitalisierten Patienten mit CAP besteht daher keine ausreichende Evidenz.

Vergleichende Untersuchungen zwischen einer Monotherapie mit pneumokokkenwirksamen Fluorchinolonen wie Levofloxacin und Moxifloxacin fanden keinen Unterschied in der klinischen und bakteriologischen Wirksamkeit sowie Verträglichkeit zu einer Kombinationstherapie bestehend aus einem nicht pseudomonasaktiven Betalaktamantibiotikum und einem Makrolid [269, 313 - 315]. In einzelnen Studien konnte sogar ein verbessertes klinisches und bakteriologisches Ansprechen beobachtet werden; Ein Unterschied in der Letalität ließ sich nicht zeigen $[269,313]$.

Eine prospektive, randomisierte Untersuchung mit Azithromycin fand keinen Unterschied zur Vergleichsgruppe (Cefuroxim i.v./ Cefuroxim-Axetil p.o.) in der klinischen und bakteriologischen Wirksamkeit bei hospitalisierten CAP-Patienten auf einer Normalstation [316]. Eine retrospektive Analyse wies für Patienten mit Azithromycin i.v./oral einen kürzeren stationären Aufenthalt im Vergleich zu Antibiotika-Regimen, die den Empfehlungen der American Thoracic Society 2001 entsprachen, nach [317]. Die Studien zeigen, dass auch eine Monotherapie mit den Fluorchinolonen Levofloxacin und Moxifloxacin sowie mit Azithromycin in der Initialtherapie der CAP bei hospitalisierten Patienten auf Normalstation effektiv und sicher ist. Die hohe Makrolidresistenz von S. pneumoniae in Deutschland sowie wiederholt beobachtete Therapieversagen unter Makrolid-Monotherapie bei resistenten Erregern sind allerdings Argumente gegen eine Monotherapie mit Makroliden bei hospitalisierten Patienten (s. Kap. 5). Nachteil der Fluorchinolone ist die zunehmende Selektion von resistenten (zum Teil multiresistenten) Erregern (wie E. coli oder S. aureus) durch den verbreiteten Einsatz dieser Substanzklasse in Klinik und Praxis [34-36].

Zur kalkulierten Initialtherapie bei hospitalisierten Patienten mit CAP geeignete Betalaktamantibiotika sind:

- Aminopenicillin-Betalaktamaseinhibitor-Kombinationen wie Ampicillin-Sulbactam und Amoxicillin-Clavulansäure [256,318]

- Cephalosporine wie Ceftriaxon, Cefotaxim und Cefuroxim [319-321] sowie

- das Carbapenem Ertapenem. In zwei Vergleichsstudien zwischen Ertapenem und Ceftriaxon fand sich kein Unterschied im klinischen Ansprechen in verschiedenen Risikostrata der CAP nach dem PSI-Score [148,322]. Eine weitere Studie verglich Ertapenem mit Cefepim bei Patienten mit CAP aus einem Pflegeheim/Altenheim oder nosokomialer Pneumonie und fand ebenfalls einen vergleichbaren Therapieerfolg [323].

Geeignete Makrolide (als Kombinationspartner)/Azalide sind

- Azithromycin [324]. In einer prospektiven, vergleichenden, nicht randomisierten Studie war die Kombination aus Ceftriaxon plus Azithromycin signifikant günstiger als Ceftriaxon plus Clarithromycin hinsichtlich Letalität und Dauer des stationären Aufenthaltes [325].

- Clarithromycin [326]. In einer doppelblinden, randomisierten Studie war oral verabreichtes Clarithromycin gleich effektiv wie Erythromycin, die Verträglichkeit war günstiger.

- Roxithromycin [327]. Die meisten Studien mit Roxithromycin wurden bei nicht-hospitalisierten Patienten mit CAP durchgeführt und zeigten vergleichbare Ergebnisse zu den Ver- 
gleichssubstanzen. In einer Studie an überwiegend hospitalisierten Patienten mit CAP war die Substanz signifikant weniger wirksam als ein orales Fluorchinolon [328].

- Erythromycin [316,326]. Die Verträglichkeit von Erythromycin (oral) war im Vergleich zu Clarithromycin oder Azithromycin ungünstiger.

Zur Monotherapie geeignete Fluorchinolone sind

- Moxifloxacin [313,329,330].

- Levofloxacin $[315,269]$. Auf eine ausreichende Dosierung von Levofloxacin muss geachtet werden, da Therapieversagen mit einer Dosierung von $1 \times 500 \mathrm{mg}$ pro Tag bei Pneumokokkenpneumonien beschrieben wurden [82,84].

Eine Alternative als Kombinationspartner mit Betalaktamantibiotika ist Doxycyclin wegen der ausgeprägten Wirkung gegen C. pneumoniae und M. pneumoniae. In einer randomisierten Studie fand sich mit Doxycyclin bei hospitalisierten Patienten mit CAP eine vergleichbare Ansprechrate wie mit einer konventionellen Antibiotikatherapie [260]. Aktuelle Daten aus Deutschland fehlen.

Cotrimoxazol kann aufgrund der Resistenzsituation von S. pneumoniae in Deutschland nicht als initiale, kalkulierte Therapie empfohlen werden.

Ein wichtiges differenzialtherapeutisches Entscheidungskriterium ist eine vorausgegangene Antibiotikatherapie. In diesem Fall wird ein Wechsel der zuletzt verwendeten Substanzgruppe empfohlen. Dies gilt insbesondere für Therapien innerhalb der letzten 3 Monate [33].

Die Arbeitsgruppe empfiehlt (Empfehlungsgrad A) bei hospitalisierten CAP-Patienten ein nicht pseudomonasaktives Betalaktamantibiotikum, ggf. plus einem Makrolid.

Alternativ kann eine Therapie mit den Fluorchinolonen Levofloxacin oder Moxifloxacin oder bei ausgewählten Patienten mit dem Carbapenem Ertapenem (ggf. plus Makrolid) erfolgen (s. Tab. 16).

In seltenen Fällen ist bei Vorliegen von Risikofaktoren (siehe - Tab. 5, insbesondere schwere strukturelle Lungenerkrankung in Kombination mit Antibiotikavortherapien/vorangegangener Hospitalisierung) an eine Pneumonie durch $P$. aeruginosa zu denken. Es wird dann eine kalkulierte antibiotische Initialtherapie analog zur sCAP mit Pseudomonasrisiko empfohlen (siehe - Tab. 18).

\section{Orale versus parenterale Therapie:}

Die Arbeitsgruppe empfiehlt (Empfehlungsgrad B) ( $\odot$ Abb. 5): In den ersten Tagen sollte die Verabreichung der Antibiotika parenteral erfolgen.

Eine Ausnahme besteht - je nach klinischer Konstellation - für Fluorchinolone aufgrund der hohen oralen Bioverfügbarkeit [332]. Eine weitere Ausnahme ist die orale Gabe von Makroliden im Rahmen einer Kombinationstherapie mit gleichzeitiger parenteraler Verabreichung der Betalaktamantibiotika [325].

Bei Patienten, die primär aus sozialer Indikation zur Behandlung der CAP stationär aufgenommen wurden, kann entsprechend den Empfehlungen für ambulante Patienten eine orale Therapie durchgeführt werden.
Tab. 16 Therapieempfehlung für die kalkulierte Initialtherapie bei hospitalisierten CAP- Patienten.

\begin{tabular}{|c|c|c|}
\hline $\begin{array}{l}\text { Substanzen für die } \\
\text { Initialtherapie* }\end{array}$ & $\begin{array}{l}\text { Dosierung der Initial- } \\
\text { therapie (pro Tag)* }\end{array}$ & $\begin{array}{l}\text { Gesamtthe- } \\
\text { rapiedauer }\end{array}$ \\
\hline \multicolumn{3}{|l|}{ Betalaktam } \\
\hline Amoxicillin/Clavulansäure & $3 \times 2,2$ gi. v. & 5-7 Tage \\
\hline Ampicillin/Sulbactam & $3 \times 3,0$ gi. $v$ & 5-7 Tage \\
\hline Cefuroxim & $3 \times 1,5$ gi.v. & 5-7 Tage \\
\hline Ceftriaxon & $1 \times 2,0$ gi. $v$ & $5-7$ Tage \\
\hline Cefotaxim & $3 \times 2,0$ gi. v. & $5-7$ Tage \\
\hline mit oder ohne Makrolid** & & 5-7 Tage \\
\hline \multicolumn{3}{|l|}{$\operatorname{oder}^{* * *}$} \\
\hline \multicolumn{3}{|l|}{ Fluorchinolon $* * * *$} \\
\hline Levofloxacin & $1 \times 500$ mg i. v. & 5-7 Tage \\
\hline Moxifloxacin & $1 \times 400$ mg i. v. & 5-7 Tage \\
\hline \multicolumn{3}{|l|}{$\begin{array}{l}\text { oder bei ausgewählten } \\
\text { Patienten }{ }^{* * * * *}\end{array}$} \\
\hline \multicolumn{3}{|l|}{ Carbapenem } \\
\hline Ertapenem & $1 \times 1,0$ gi. v. & 5-7 Tage \\
\hline mit oder ohne Makrolid** & & 5-7 Tage \\
\hline \multicolumn{3}{|c|}{$\begin{array}{l}\text { * Weiterführende Angaben zur Pharmakologie, Verträglichkeit, Interaktionen } \\
\text { und Dosierung finden sich in Kapitel } 7 . \\
\text { ** Je nach klinischer Entscheidung initial parenteral oder oral; die parenterale } \\
\text { Verabreichung wird bevorzugt (B). Für die orale Therapie sollten die modernen } \\
\text { Makrolide (Clarithromycin, Roxithromycin oder Azithromycin) den älteren } \\
\text { Makroliden vorgezogen werden. Dosierung der Makrolide s. Tab. } 8 \text { bzw. } 14 . \\
\text { *** Bei vorausgegangener Antibiotikatherapie innerhalb der letzten } 3 \text { Monate } \\
\text { wird ein Wechsel der zuletzt verwendeten Substanzgruppe empfohlen. } \\
\text { **** Eine initiale orale Behandlung ist einer parenteralen Verabreichung } \\
\text { gleichwertig, die initiale parenterale Gabe wird bevorzugt (B). } \\
\text { **** Patienten mit Risikofaktoren für eine Infektion mit Enterobacteriaceae } \\
\text { inkl. ESBL-Bildnern (außer P. aeruginosa) sowie Patienten, die kürzlich eine } \\
\text { Therapie mit Penicillinen oder Cephalosporinen erhalten haben. }\end{array}$} \\
\hline
\end{tabular}

Orale Sequenztherapie: Ein Umsetzen auf eine orale Sequenztherapie kann rasch (z. B. nach 2 bis 3 Tagen) erfolgen. Eine Sequenztherapie nach drei Tagen ist auch bei schwerer erkrankten Patienten sicher, wenn zu diesem Zeitpunkt klinische Stabilität erreicht wurde [333]. Vorteile sind kürzere Liegezeiten und niedrigere Gesamttherapiekosten bei gleicher klinischer Wirksamkeit [316, 321, 324, 334 - 339]. Im Rahmen einer Sequenztherapie mit Betalaktamantibiotika ist die Therapiefortsetzung mit oralen Präparaten in der Regel mit einer Dosisreduktion verbunden, daher ist eine korrekte Indikationsstellung erforderlich.

Indikation für eine Sequenztherapie sind:

- Herzfrequenz $\leq 100 / \mathrm{min}$

- Atemfrequenz $\leq 24 / \mathrm{min}$

- systolischer Blutdruck $\geq 90 \mathrm{mmHg}$

- Körpertemperatur $\leq 37,8^{\circ} \mathrm{C}$

- Fähigkeit zur oralen Nahrungsaufnahme

- normaler Bewusstseinszustand

- keine Hypoxämie $\left(\mathrm{PO}_{2} \geq 60 \mathrm{mmHg}\right.$ bzw. $\left.\mathrm{SaO}_{2} \geq 90 \%\right)$ und

- sichere orale Medikamenteneinnahme

Die Arbeitsgruppe empfiehlt (Empfehlungsgrad A) eine frühe Therapieumstellung auf eine orale Therapie bei einer parenteralen Initialtherapie, wenn die entsprechenden Voraussetzungen (s. Text) erfüllt sind.

Therapiedauer: Die meisten Studien wurden mit einer Gesamttherapiedauer von 7 bis 10 Tagen durchgeführt. Kleinere Studien fanden bei hospitalisierten Patienten mit milder CAP ähnliche günstige Erfolgsraten mit Azithromycin oral für 3 bis 5 Tage wie 
mit Vergleichssubstanzen über 7 bis 10 Tage [340]. Studien mit parenteralem Azithromycin wurden als parenterale/orale Sequenztherapie über 7 bis 10 Tage durchgeführt [316]. Repräsentative Studien mit kürzerer Therapiedauer bei stationären Patienten sind spärlich. Eine Studie zeigte, dass eine Therapiedauer von 5 Tagen mit höher dosiertem Levofloxacin zum gleichen Therapieerfolg wie eine 10-tägige Standardtherapie führt [263]. Eine Studie zur Kurzzeittherapie bei hospitalisierten Patienten mit überwiegend leichtgradiger Pneumonie existiert auch mit Amoxicillin [264].

In einer Studie bei CAP konnte durch eine mittels serieller Procalcitonin-III-Bestimmung an den Behandlungstagen 0, 4, 6 und 8 gesteuerte Antibiotikatherapie die mediane Dauer der antimikrobiellen Therapie auf 5 Tage bei gleichem Therapieerfolg reduziert werden. Selbst bei schwerer Pneumonie war nur selten eine Therapie von mehr als 8 Tagen erforderlich [291]. Ein Procalcitonin-Spiegel von $<0,1 \mu \mathrm{g} / \mathrm{L}$ im Verlauf spricht daher bei klinischer Besserung für eine Beendigung der Antibiotikatherapie. Eine sinnvolle Strategie ist bei kürzerer Therapiedauer die tägliche klinische Überprüfung von Symptomen, die auf ein Rezidiv hinweisen können.

Die Arbeitsgruppe empfiehlt (Empfehlungsgrad A): Die antibiotische Therapie kann 48-72 h nach klinischer Besserung mit Entfieberung, jedoch frühestens nach 5 Tagen, beendet werden. Eine Therapiedauer von mehr als 7 Tagen ist im Regelfall nicht erforderlich [265]. Bei nachgewiesener Infektion durch P. aeruginosa wird eine Therapiedauer von 8-15 Tagen empfohlen.

Geeignete Parameter für eine verkürzte Therapiedauer (<8 Tagen) sind [264]:

- Besserung des Allgemeinzustandes

- Orale Nahrungsaufnahme möglich

- Besserung der respiratorischen Symptome

- Körpertemperatur $<38,0^{\circ} \mathrm{C}$

\section{Adjuvante Therapie:}

\section{Die Arbeitsgruppe empfiehlt (Empfehlungsgrad A):} Sauerstoffgabe

Bei Patienten mit arterieller Hypoxämie ist die Verabreichung von Sauerstoff entweder über eine Mund-Nasen-Maske oder über eine Nasensonde indiziert. Hypoxämie ist ein Risikofaktor für Letalität bei CAP [341].

Antikoagulation

Eine Thromboseprophylaxe mit Heparin bzw. niedermolekularen Heparin wird bei allen immobilisierten Patienten mit akuten Erkrankungen empfohlen [342].

Mobilisierung und Atemtherapie

Eine frühzeitige Mobilisierung und Atemtherapie wird von der Arbeitsgruppe empfohlen [343].

\subsection{Verlauf bei hospitalisierten CAP-Patienten}

Nach durchschnittlich 2 bis 7 Tagen wird nach Einleitung einer adäquaten Antibiotikatherapie bei der Mehrzahl der Patienten klinische Stabilität erreicht, definiert als

- Herzfrequenz $\leq 100 / \mathrm{min}$,

- Atemfrequenz $\leq 24 / \mathrm{min}$,

- systolischer Blutdruck $\geq 90 \mathrm{~mm} \mathrm{Hg}$

- Körpertemperatur $\leq 37,8^{\circ} \mathrm{C}$,

- Fähigkeit zur oralen Nahrungsaufnahme,

- normaler Bewusstseinszustand,

- keine Hypoxämie $\left(\mathrm{PO}_{2} \geq 60 \mathrm{~mm} \mathrm{Hg}\right.$ bzw. $\left.\mathrm{SaO}_{2} \geq 90 \%\right)$.
Die Zeit bis zur klinischen Stabilisierung variiert nach Risikoklasse: Patienten mit niedrigem Risiko erreichen die klinische Besserung im Durchschnitt nach 3 Tagen, mit mittlerem Risiko nach vier Tagen und mit hohem Risiko nach 6 Tagen [344].

Eine Verlaufskontrolle der Entzündungsparameter (CRP oder Procalcitonin) im Serum nach 3-5 Tagen wird empfohlen. Ein Abfall im Verlauf der Behandlung weist auf einen günstigen klinischen Verlauf hin $[290,291]$. Bei fehlendem Abfall sollte das Vorliegen eines Therapieversagens (siehe Kapitel 15) oder einer sekundären infektiösen Komplikation überprüft werden, wobei die Beurteilung insbesondere des CRP aufgrund seiner verzögerten Kinetik stets im Kontext mit dem klinischen Bild erfolgen muss.

\section{Die Arbeitsgruppe empfiehlt (Empfehlungsgrad A):}

Empfohlene Verlaufsuntersuchungen sind:

tägliche klinische Untersuchung (Auskultation der Lungen, Blutdruck, Herz- und Atemfrequenz, Allgemeinzustand)

- Labor: Elektrolyte, Transaminasen, Serumkreatinin, $\mathrm{O}_{2}$-Sättigung bzw. arterielle oder kapilläre Blutgasbestimmung, Blutbild; Verlaufskontrolle von CRP oder Procalcitonin nach 3-5 Tagen

Entlassung: Die Entscheidung zur Entlassung eines Patienten aus dem Krankenhaus bestimmt die Dauer der stationären Versorgung und ist damit der wichtigste Faktor, der die Gesamtkosten einer Behandlung im Krankenhaus beeinflusst [345]. Bei Erreichen der klinischen Stabilität kann die Beendigung des stationären Aufenthaltes erwogen werden.

Zeichen klinischer Instabilität sind

- Tachypnoe (Atemfrequenz $>24 / \mathrm{min}$ ),

- veränderter Bewusstseinszustand und

- Hypoxämie $\left(\mathrm{PO}_{2}<60 \mathrm{~mm} \mathrm{Hg}\right.$ bzw. $\left.\mathrm{SIO}_{2}<90 \%\right)$

Diese Parameter sind mit einer erhöhten Krankenhausletalität verbunden [284,345,346]. Patienten mit $\geq 1$ Kriterium für klinische Instabilität haben ein signifikant höheres Risiko, nach Entlassung erneut stationär aufgenommen zu werden bzw. zu versterben [347].

\section{Die Arbeitsgruppe empfiehlt (Empfehlungsgrad B):}

Kriterien zur Entlassung von CAP-Patienten nach klinischer Stabilisierung sind:

1. konstant stabile Vitalzeichen (Herzfrequenz $\leq 100 / \mathrm{min}$, Atemfrequenz $\leq 24 / \mathrm{min}$, Körpertemperatur $\leq 37,8^{\circ} \mathrm{C}$, systolischer Blutdruck $\geq 90 \mathrm{mmHg}, \mathrm{SaO}_{2} \geq 90 \%$ bei Raumluftatmung bzw. Normalisierung bis zum Ausgangswert bei Patienten mit chronisch-obstruktiver Lungenerkrankung)

2. Fähigkeit zur oralen Nahrungsaufnahme

3. sichere orale Medikamenteneinnahme

4. normaler Bewusstseinszustand

5. keine anderen klinischen oder psychosozialen Gründe für eine stationäre Behandlung [348].

Für die Entlassung sollten möglichst alle Kriterien erfüllt sein. Ein Abfall von Entzündungsparametern wie PCT oder CRP im Verlauf der Behandlung kann zusätzlich als Surrogatmarker verwendet werden [290, 291].

Zur Beurteilung des klinischen Zustandes wird eine kurzfristige klinische Verlaufskontrolle 3 bis 7 Tage nach Entlassung empfohlen (C).

Röntgenologischer Verlauf: Die Normalisierung des Röntgenthoraxbildes bei CAP ist ein kontinuierlicher Prozess, der sich über Wochen und Monate erstrecken kann [349]. In einer prospekti- 
ven Studie fanden sich nach 2 Wochen noch bei 32\% der Patienten (initial 79 von 81 Patienten) Pneumonie-assoziierte Veränderungen, nach 4 Wochen bei $15 \%$, nach 8 Wochen bei $4,2 \%$ [350,351].

Die Arbeitsgruppe empfiehlt (Empfehlungsgrad B) eine radiologische Abschlussuntersuchung frühestens 2 Wochen nach Ende der Antibiotika-Therapie insbesondere bei aktiven Rauchern, älteren Patienten (> 65 Jahre) bzw. Patienten mit schweren Begleiterkrankungen zum Ausschluss von nicht-infektiösen Lungeninfiltraten (z. B. Lungenkarzinom) [352].

Verlauf nach Entlassung: Nach 30 Tagen berichten 86,5\% der entlassenen CAP-Patienten noch über mindestens eines von fünf Symptomen der Pneumonie (körperliche Schwäche, Husten, Auswurf, Luftnot, Brustschmerzen), meist klagen die Patienten noch über allgemeine Schwäche (72,6\%) bzw. Husten oder Luftnot (47\%). Ca. $82 \%$ bzw. $68 \%$ der Patienten werden innerhalb von 30 Tagen nach Beginn der CAP-Behandlung wieder ihre normale Aktivität bzw. ihre Arbeit aufnehmen. Bei bis zu 10\% der Patienten erfolgt wegen Komplikationen nach Entlassung eine erneute stationäre Aufnahme [276]. Eine vollständige Genesung zum Gesundheitszustand, der vor der Pneumonie vorlag, erfolgt häufig erst nach bis zu 6 Monaten [353]. Zu beachten ist, dass insbesondere bei älteren Patienten im weiteren Verlauf nach einer abgelaufenen CAP die Letalität deutlich erhöht ist [354,355].

\section{Management der schweren ambulant erworbenen Pneumonie (schwere CAP) \\ $\nabla$}

Definition: Indikation für eine intensivmedizinische Überwachung oder Intensivtherapie: Patienten mit einer akuten unteren Atemwegsinfektion mit oder ohne lokalem Auskultationsbefund mit Nachweis eines Infiltrates im Röntgenbild des Thorax und

- mit Vorliegen von $\geq 1$ Major-Kriterium des modifizierten

ATS-Scores (s. $\odot$ Tab. 13) (B)

Indikation für eine intensivierte Überwachung (je nach Einrichtung Intensivstation, Intermediärstation bzw. intensivierte Überwachung auf einer Normalstation): Patienten mit einer akuten unteren Atemwegsinfektion mit oder ohne lokalem Auskultationsbefund mit Nachweis eines Infiltrates im Röntgenthoraxbild und

- mit Vorliegen von $\geq 2$ Minor-Kriterien des modifizierten ATS-Scores (s. $\odot$ Tab. 13) (B) oder

- CRB-65-Index $\geq 2$ (s. Tab. 11).

Für eine intensivierte Überwachung kann im Einzelfall auch ein Minorkriterium des modifizierten ATS-Scores oder ein CRB-65Index von 1 ausreichend sein. Notwendig ist eine gründliche klinische Einschätzung des Schweregrads der CAP für die Entscheidung über eine intensivmedizinische Betreuung.

Einleitung der Intensivtherapie: Eine vitale Bedrohung durch eine CAP entsteht vor allem durch ein Funktionsversagen der erkrankten Lunge oder durch ein extrapulmonales Organversagen infolge einer schweren, durch die CAP bedingten Sepsis. 50 bis 75\% der Todesfälle sind direkt durch die Pneumonie bedingt [250,356]. Die Aufnahme auf die ITS dient der Überwachung von kritisch gestörten Vitalfunktionen und der Therapie des Organversagens [250,357 - 359]. Bei stationär behandelten Patienten beträgt der Anteil schwerer Erkrankungen mit Aufnahme auf die ITS im Mit- tel 10 bis 15\% [249,250,360], bei älteren Patienten über 20\% [360]. Die Aufnahme erfolgt in zwei Drittel der Fälle am ersten Behandlungstag. Die Krankenhausletalität dieser Patienten ist altersabhängig [360] und beträgt etwa $15 \%$ [250] bis zu $60 \%$ $[50,359,361]$.

Die Arbeitsgruppe empfiehlt (Empfehlungsgrad A):

Patienten mit hohem Letalitätsrisiko (zur Risikostratifizierung s. Kap. 11) sollten umgehend einer Intensivüberwachung/-therapie zugeführt werden. Neben dem akuten Notfall (Atemstillstand, Herz-l Kreislaufstillstand) stellen Symptome und Befunde einer akuten Organinsuffizienz eine Indikation zur Intensivtherapie dar. Alle von einem erfahrenen Arzt als Risikopatienten erkannten Erkrankten sollten innerhalb von 4 bis 8 Stunden erneut untersucht werden. Die klinischen Symptome und Befunde, die eine schwere Pneumonie anzeigen, sind in $\bullet$ Tab. 12 aufgeführt [51].

\subsection{Erregerspektrum der schweren ambulant} erworbenen Pneumonie (sCAP)

Zur Ätiologie der SCAP in Deutschland gibt es noch keine Daten. In Studien aus europäischen und nordamerikanischen Ländern findet sich ein breiteres Erregerspektrum als bei weniger schweren Formen [30,44,45,50,59,319,358,362-367]. In fast allen Studien ist S. pneumoniae der mit Abstand häufigste Erreger. Er wird gefolgt von H. influenzae, S. aureus und L. pneumophila. Enterobacteriaceae, vor allem E. coli und Klebsiella spp., seltener Proteus spp., sind ebenfalls von Bedeutung. Im Unterschied zu leichter erkrankten CAP-Patienten treten bei sCAP häufiger bakteriämisch verlaufende Pneumokokkenpneumonien sowie vermehrt Legionellen, S. aureus und polymikrobielle Infektionen (oft mit Beteiligung von $S$. pneumoniae) auf.

C. pneumoniae und M. pneumoniae sind in den meisten Studien selten. Der Anteil viral verursachter CAP beträgt zwischen 0 und $22 \%$ und variiert mit epidemischen Häufungen, aber auch mit Art und Umfang der eingesetzten Diagnostik. Das Influenzavirus wird am häufigsten nachgewiesen. Es kann sowohl eine primäre Viruspneumonie verursachen als auch zu einer sekundär-bakteriellen CAP führen [24,319]. Das Auftreten der Influenza ist saisonal und epidemisch.

Die Rolle von Infektionen durch $P$. aeruginosa bei sCAP ist unklar. Im Rahmen von CAPNETZ konnte P. aeruginosa in Deutschland nur sehr selten als Pneumonieerreger nachgewiesen werden [26], eine spezifische Auswertung bei sCAP erfolgte jedoch noch nicht. Spanische Studien zeigten wiederholt ein erhöhtes Risiko für eine inadäquate empirische Antibiotikatherapie, wenn $P$. aeruginosa als Erreger bei sCAP nachgewiesen wird, was zu einer erhöhten Letalität bei diesen Patienten führte [30,48,368]. P. aeruginosa wird bei Patienten mit speziellen Risikofaktoren nachgewiesen [25,29,30,52,53]. Für Deutschland scheint das Vorliegen von schweren strukturellen Lungenerkrankungen das entscheidende Risiko für eine $P$. aeruginosa-Pneumonie zu sein (siehe Tab. 5). Zur Erhöhung der Therapiesicherheit wird eine empirische Therapie mit pseudomonaswirksamen Substanzen bei Patienten mit diesen Risikofaktoren und schwerer Pneumonie empfohlen. 
0

Schwere ambulant erworbene Pneumonie (SCAP) (Kap. 14.)

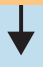

1

Entnahme von 2 Blutkulturen

( $2 \times 2$ BK-Flaschen), Labor,

Blutgasanalyse, Legionellen-

Antigentest,

ggf. Procalcitonin

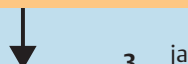

$3 \mathrm{ja}$

Spultumproduktion? $\rightarrow$ Vorliegen der logistischen

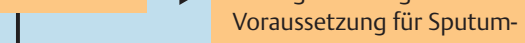

4 ja untersuchung (Kap. 6.)?

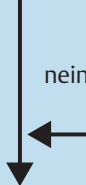

nein

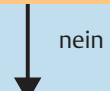

6

Vorliegen eines Pleuraergusses (größer $10 \mathrm{~mm}$ in Seitenlage) (Kap. 16.1.)?
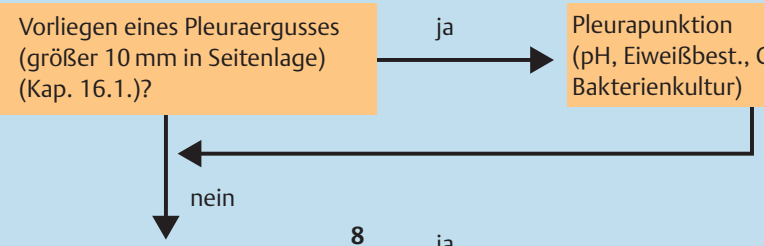

Pleurapunktion

(pH, Eiweißbest., Gramfärbung, Bakterienkultur)

Kriterien für Bronchoskopie (Immunsuppression, Ausschluss Bronchusstenose, v.a. seltene Erreger) erfüllt?

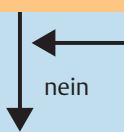

8

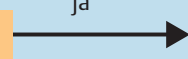

Bronchoskopie

10

Vorliegen von Risikofaktoren für eine $P$. aeruginosa Infektion (Tab. 5)?

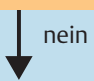

12

Behandlung entspr. den Empfehlungen (Tab. 17)
Abb. 6 Algorithmus zur Diagnostik und kalkulierten Therapie hospitalisierter CAP-Patienten auf einer Intensivstation/Intermediärstation bzw. mit intensivierter Überwachung (sCAP).
Die Arbeitsgruppe empfiehlt (Empfehlungsgrad C) ( $A$ Abb. 6): Patienten mit sCAP werden in zwei Risikogruppen eingeordnet, die wesentlich die Therapieentscheidung bestimmen:

- Patienten mit sCAP ohne Indikation für eine gegen $P$. aeruginosa wirksame empirische Therapie.

- Patienten mit SCAP mit Indikation für eine gegen $P$. aeruginosa wirksame empirische Therapie (s. Tab.5).

Das Auftreten einer Pneumonie durch $P$. aeruginosa ist in Deutschland selten und nur bei Vorliegen von Risikofaktoren $(-$ Tab. 5, insbesondere schwere strukturelle Lungenerkrankung in Kombination mit Antibiotikavortherapien/vorangegangener Hospitalisierung) anzunehmen.

\subsection{Diagnostik bei schwerer ambulant erworbener}

Pneumonie (sCAP)

Die prinzipiellen Empfehlungen zur anamnestischen und laborchemischen Diagnostik entsprechen denen bei hospitalisierter CAP (siehe Kap. 13.2.), wobei in Abhängigkeit vom Schweregrad der Erkrankung erweiterte diagnostische Maßnahmen zum Monitoring der Organfunktionen indiziert sind. Insbesondere die Bestimmung des Procalcitonin im Serum zur Verlaufskontrolle kann bei dieser Patientengruppe aus prognostischen Gründen und zur Therapiesteuerung erwogen werden. Sowohl erhöhte Procalcitoninwerte am Tag 1 als auch ein fehlender Abfall von Tag 1 zu Tag 3 sind mit einer ungünstigen Prognose bei sCAP assoziiert [292,369].Bei fehlendem Abfall sollte das Vorliegen eines Therapieversagens (siehe Kapitel 15) oder einer sekundären infektiösen Komplikation überprüft werden.

Mikrobiologische Untersuchungen sind wünschenswert, die aufgrund rascher Ergebnisse bereits die Ersttherapie beeinflussen. Außerdem können kulturelle mikrobiologische Untersuchungen durchgeführt werden, die im Fall eines Therapieversagens eine gezielte Therapiekorrektur ermöglichen.

In einer randomisierten Studie zur Bedeutung mikrobiologischer Diagnostik für die Prognose der CAP war in der Subgruppe von Patienten mit SCAP, die auf einer Intensivstation behandelt wurden, eine erregergesteuerte Therapie nach mikrobiologischer Diagnostik mit einem Überlebensvorteil im Vergleich zu einer rein empirischen Therapie assoziiert [298]. Ein weiterer Vorteil der Erregeridentifikation liegt in der Möglichkeit der erregerspezifischen Deeskalation der in dieser Patientengruppe meist breiten 
empirischen Initialtherapie mit potenziellen positiven Effekten auf Kosten, Nebenwirkungen und Resistenzselektion [368].

\section{Die Arbeitsgruppe empfiehlt (Empfehlung B) ( $\odot$ Abb. 6): Folgende mikrobiologische Diagnostik wird empfohlen [368]: \\ - Blutkultur (B): Bei der SCAP sind bakteriämische Verläufe häufiger [100]. Die Entnahme von zwei Blutkulturen (zwei mal zwei Flaschen) von unterschiedlichen Lokalisationen im Abstand von wenigen Minuten, wenn möglich vor Einleitung der anti- mikrobiellen Therapie, wird empfohlen. Gründe dafür sind eine verbesserte Therapiesteuerung und Risikoeinschätzung. \\ - Sputum oder Trachealsekret (Mikroskopie, Kultur, Resistenz- testung) (B): Trotz der geringen diagnostischen Ausbeute kann in bis zu $10 \%$ der Patienten ein Befund gewonnen werden, der zu einer therapeutischen Konsequenz führt [370,371]. Sowohl die Gramfärbung als auch die Kultur wird empfohlen. Die Ergebnisse beider Methoden sollen verglichen werden. \\ - Pleurapunktion (B): Eine diagnostische Pleurapunktion bei Vorliegen eines Pleuraergusses $(>5 \mathrm{~cm}$ in der lateralen Röntgen- aufnahme) ist aus differenzialdiagnostischen Gründen obligat (Ausschluss eines Pleuraempyems) [51,299]. Die Untersuchung sollte die Bestimmung des pH-Wertes, des Eiweißgehaltes, eine Gramfärbung und eine Bakterienkultur beinhalten [300]. Die Einzelheiten sind in Kapitel 16 angegeben. \\ - L. pneumophila-Antigentest (Serogruppe 1) aus Urin (B): Empfohlen wird der L. pneumophila-Antigentest bei allen Patien- ten mit sCAP [117,301,372,373]. Ein positives Ergebnis hat Konsequenzen für die Therapiedauer, ein frühzeitiger Therapie- beginn verbessert die Prognose und ein Legionellennachweis führt zu Konsequenzen wie Untersuchung von Infektionsquellen bzw. Meldung nach dem Infektionsschutzgesetz. \\ Bronchoskopie (BAL, geschützte Bürste): Die Bronchoskopie ist bei immunsupprimierten Patienten, bei Verdacht auf Vorliegen eines seltenen Erregers sowie zum Ausschluss einer Bronchus- stenose indiziert (B). Die gezielte Entnahme aus den unteren Atemwegen kann die diagnostische Ausbeute verbessern. Der mögliche Nutzen muss gegen die möglichen Risiken (Zunahme der respiratorischen Insuffizienz, Notwendigkeit der maschinellen Beatmung) abgewogen werden [374, 375]. Eine Verbesserung der Prognose der sCAP durch routinemäßige bronchoskopische Diagnostik konnte bis jetzt nicht nachgewiesen werden [50,365].}

Antigentest im Urin auf S. pneumoniae: Eine routinemäßige Durchführung wird nicht empfohlen, da S. pneumoniae ohnehin von der kalkulierten antimikrobiellen Therapie erfasst werden muss. Ein positiver Ausfall des Antigentests kann zur Erleichterung von Entscheidungen zur Fokussierung der Therapie beitragen, wobei die Möglichkeit polymikrobieller Infektionen zu bedenken ist (Evidenzgrad 5).

Zur Durchführung eines Influenzavirus-Antigenschnelltests s. Kapitel 9.

\subsection{Therapie der schweren ambulant erworbenen Pneumonie (sCAP)}

\section{Kalkulierte Initialtherapie}

\section{Die Arbeitsgruppe empfiehlt (Empfehlungsgrad B):}

Eine antimikrobielle Therapie sollte so früh wie möglich eingeleitet werden. Jede Verzögerung der Therapieeinleitung nach stationäre Aufnahme geht mit einer erhöhten Letalität einher [303, 304, 376] Diagnostische Maßnahmen dürfen den Therapiebeginn nicht verzögern.
Die antimikrobiellen Substanzen müssen die zu erwartenden Erreger erfassen. Eine inadäquate Ersttherapie war in einer Multivarianzanalyse der ungünstigste Prognosefaktor im Hinblick auf die Krankenhausletalität [50].

Antibiotikagruppen mit Aktivität gegenüber den relevanten Erregern der SCAP sind

- Ureidopenicilline in Kombination mit einem Betalaktamaseinhibitor (Piperacillin + Sulbactam oder Tazobactam)

- Breitspektrum-Cephalosporine (Cefotaxim, Ceftriaxon, Cefepim, Ceftazidim)

- Carbapeneme (Imipinem, Meropenem, Ertapenem)

- Makrolide (Azithromycin, Clarithromycin, Erythromycin)

- Fluorchinolone (Ciprofloxacin, Levofloxacin, Moxifloxacin). Eine Monotherapie mit einem Vertreter der genannten Gruppen bei sCAP ist wegen wesentlicher Lücken im antibakteriellen Spektrum mit einer Ausnahme nicht indiziert. Die einzigen Antiinfektiva, die das gesamte bakterielle Spektrum der Erreger der sCAP ohne Pseudomonasrisiko erfassen, sind die Gruppe der pneumokokkenaktiven Fluorchinolone (in parenteraler Form verfügbar: Levofloxacin, Moxifloxacin) [234]. Diese Substanzen kommen daher grundsätzlich für eine Monotherapie infrage.

Eine einzige randomisierte Studie verglich die Wirksamkeit einer Fluorchinolon-Monotherapie mit der einer Kombinationstherapie bei Patienten mit sCAP, die ausschließlich auf einer Intensivstation behandelt wurden. Levofloxacin in der Dosierung $2 \times 500 \mathrm{mg} / \mathrm{d}$ war einer Therapie mit Cefotaxim plus Ofloxacin hinsichtlich der klinischen Effektivität gleichwertig. In der Subgruppe der invasiv beatmeten Patienten zeigte sich jedoch ein Trend zugunsten der Kombinationstherapie. Patienten mit septischem Schock waren von der Studie ausgeschlossen [377].

Eine klinische Prüfung von Fluorchinolonen an weniger homogenen sCAP-Patienten und/oder mit einer Betalaktam-Monotherapie erfolgte in zahlreichen Studien: Ciprofloxacin (zum Teil in Kombination mit Vancomycin) in hoher Dosis $(3 \times 400 \mathrm{mg} / \mathrm{d})$ wurde mit Imipenem bei Patienten mit sCAP verglichen und war äquipotent [378].

Moxifloxacin erwies sich gegenüber Amoxicillin/Clavulansäure mit oder ohne Kombination mit Clarithromycin bei hospitalisierten Patienten überlegen. Mehr als die Hälfte der Patienten litt an einer sCAP, eine Subgruppenanalyse der Therapieergebnisse dieser Population erfolgte aber nicht [313].

Levofloxacin $(2 \times 500 \mathrm{mg} / \mathrm{d})$ war gleichwertig gegenüber Imipenem bei Patienten mit Bakteriämie/Sepsis-Verdacht bei Pneumonie. Beide Therapiearme zeigten gleiche Wirksamkeit [379]. Auch gegenüber Ceftriaxon $(1 \times 4 \mathrm{~g} / \mathrm{d})$ ergab Levofloxacin $(2 \times 500 \mathrm{mg}$ / d) gleich gute Heilungsraten bei hospitalisierten Patienten mit CAP [319]. Levofloxacin wurde in weiteren Studien als äquipotent gegenüber Standardtherapien bei hospitalisierten Patienten mit CAP, darunter auch sCAP, geprüft [19,269,380].

Die Option wird weiter unterstützt durch retrospektive Analysen über den Zusammenhang zwischen der Krankenhausletalität und der Art der kalkulierten antimikrobiellen Therapie bei sCAP [305,306,381]. Dabei war eine Fluorchinolon-Monotherapie gegenüber dem Therapiestandard einer Betalaktam/MakrolidKombination gleichwertig. In einer aktuellen Beobachtungsstudie wurde ebenfalls kein Unterschied in der Letalität bei sCAP zwischen der Mono- (42\% Levofloxacin) und der Kombinationstherapiegruppe festgestellt. Dies galt jedoch nicht für die Subgruppe mit septischem Schock, wo eine Monotherapie mit einer signifikant höheren 28-Tages-Letalität auf ITS assoziiert war [367]. 
Damit ist die empirische Basis für eine Empfehlung einer Fluorchinolon-Monotherapie grundsätzlich gegeben, wobei dies nicht für Patienten mit septischem Schock und/oder invasiver Beatmung gilt.

Ein grundsätzlicher Einwand gegen eine Monotherapie der SCAP sind allerdings Befunde, die zeigen, dass wichtige Erkrankungsgruppen bei Monotherapie eine höhere Letalität als bei Kombinationstherapie aufweisen:

- bakteriämische Pneumokokkenpneumonien

$[307,308,310,382]$. Eine Prüfung gegen eine FluorchinolonMonotherapie erfolgte jedoch nur bei wenigen Patienten.

- schwere Infektionen durch Enterobacteriaceae [29,45].

- schwere Infektionen durch S. aureus [383].

- Pseudomonas-Bakteriämien [384].

Diese Daten sprechen jedoch nur bedingt gegen eine Monotherapie mit einem pneumokokkenwirksamen Fluorchinolon, da diese in den genannten Arbeiten zumeist nicht geprüft wurde.

Viele Angaben aus vergleichenden Studien über sCAP beziehen sich vorwiegend auf Subgruppenanalysen. Zudem entsprechen die Definitionen einer SCAP in diesen Studien nicht den Definitionen der sCAP der American Thoracic Society bzw. nach CRB-65. Daher sind im Hinblick auf eine ausreichende Therapiesicherheit Empfehlungen für den Einsatz einer Monotherapie z.B. von inhibitorgeschützten Aminopenicillinen bei sCAP problematisch.

Die Arbeitsgruppe empfiehlt unter diesem Gesichtspunkt und zur Erfassung des breiten bakteriellen Erregerspektrums der sCAP, grundsätzlich weiterhin an dem Anfang der 90er-Jahre entwickelten und häufig evaluierten Konzept der Kombination von Betalaktamantibiotika mit Nicht-Betalaktamantibiotika festzuhalten [65, 97, 305, 306, 381, 383, 385].

Bei Berücksichtigung der in Deutschland günstigen Resistenzsituation kommen bei Erkrankungen ohne Hinweise auf $P$. aeruginosa-Beteiligung Piperacillin/Betalaktamaseinhibitor-Kombinationen, die Cephalosporine Cefotaxim und Ceftriaxon oder das Carbapenem Ertapenem infrage. Bei Ertapenem ist die Studienerfahrung noch begrenzt $[148,366]$. Als Betalaktamaseinhibitoren können Tazobactam (in fester Kombination) oder Sulbactam (als freier Kombinationspartner) gewählt werden. Klinische Studien wurden nur mit der Kombination Piperacillin/Tazobactam, nicht jedoch mit Sulbactam durchgeführt. In vitro werden Betalaktamasen von Enterobacteriaceae durch Tazobactam wirksamer gehemmt als durch Sulbactam [386]. Daher ist eine Übertragung der In-vitro-Testergebnisse für Piperacillin/Tazobactam auf Piperacillin/Sulbactam nicht zulässig. Es ist jedoch anzunehmen, dass Piperacillin/Tazobactam-sensible Enterobacteriaceae, die auf Piperacillin/Sulbactam resistent sind, bei sCAP selten auftreten, sodass die klinische Relevanz des Wirksamkeitsunterschiedes bei der CAP unsicher ist.

Als Nicht-Betalaktamantibiotika wurden Aminoglykoside (Gentamicin, Tobramycin, Netilmicin, Amikacin), Makrolide (Azithromycin, Clarithromycin, Erythromycin) und Fluorchinolone (Ciprofloxacin, Levofloxacin, Moxifloxacin) eingesetzt.

- Das antimikrobielle Spektrum von Aminoglykosiden ist begrenzt; sie haben ein hohes toxisches Potenzial, verlangen ein Drug-Monitoring und erzeugen niedrige Gewebespiegel in der Lunge. In einer erst kürzlich veröffentlichten Metaanalyse zeigte eine Kombinationstherapie unter Einschluss eines Aminoglykosides keinen Überlebensvorteil, dafür aber eine höhere Rate an unerwünschten Wirkungen [387]. Diese Daten beruhen jedoch nahezu ausschließlich auf älteren Studien unter Verwendung niedrigdosierter Mehrfachgaben der Aminoglykoside, während heute zur Vermeidung subinhibitorischer
Konzentrationen die einmal täglich hochdosierte Applikation favorisiert wird.

- Makrolide wurden umfangreich geprüft und erzielten in Kombination mit Betalaktamen günstigere Therapieergebnisse [305 - 309]. Sie erzeugen hohe pulmonale Gewebespiegel. Ihre Wirkungsweise ist jedoch bakteriostatisch und unter Therapie mit Makroliden wurden Durchbruchsbakteriämien mit $S$. pneumoniae bei Low-Level-Resistenz beschrieben. Die klinische Relevanz Makrolid-resistenter S. pneumoniae (in Deutschland ca. 15\%) im Rahmen einer Kombinationstherapie mit einem Makrolid ist unklar (siehe Kap. 5, 0 Tab. 6).

- Zu den günstigen klinischen Eigenschaften der Fluorchinolone Levofloxacin und Moxifloxacin kommen eine bakterizide Wirkungsweise und ein hoher Gewebsspiegel hinzu. Die Aktivität gegenüber S. pneumoniae ist bei Ciprofloxacin nicht ausreichend, während Levofloxacin und Moxifloxacin diesen Erreger erfassen. Dagegen sind Ciprofloxacin und Levofloxacin aktiver gegen P. aeruginosa. Zur Kombination von Fluorchinolonen mit Betalaktamen liegen jedoch bisher kaum Daten vor. In einer retrospektiven Analyse war diese Kombination mit einer höheren Letalität im Vergleich zu anderen empfohlenen Kombinationstherapien, vorrangig Betalaktam-Makrolid-Kombinationen, bei sCAP assoziiert [388]. Bei Patienten, die auf einer ITS eine Fluorchinolontherapie erhielten, wurden vermehrt Kolonisationen und Infektionen durch multiresistente Erreger beschrieben im Vergleich zu Patienten, die mit anderen Antibiotika, vorrangig Betalaktamen und Aminoglykosiden, behandelt wurden [35].

Bei Pseudomonasbakteriämie bzw. Beatmungs-assoziierter Pneumonie durch Pseudomonas war in retrospektiven Analysen eine adäquate Monotherapie einer adäquaten Kombinationstherapie hinsichtlich der Letalität nicht unterlegen; allerdings fand sich ein erhöhtes Risiko für eine inadäquate Therapie unter Monotherapie, verbunden mit einem signifikanten Letalitätsunterschied bei den Patienten, bei denen eine inadäquate Monotherapie eingesetzt worden war $[389,390]$. Daher und zur Vermeidung einer inadäquaten empirischen Initialtherapie bei Infektion durch resistente $P$. aeruginosa wird bei sCAP mit Risikofaktoren für $P$. aeruginosa initial eine Kombinationstherapie mit zwei gegenüber diesen Erregern wirksamen Antibiotika empfohlen. Bei vorliegendem Erregernachweis mit Empfindlichkeitsprüfung oder nach klinischer Besserung sollte im Regelfall eine Deeskalation auf eine Monotherapie erfolgen. Aminoglykoside sollten aufgrund ihrer erhöhten Nebenwirkungsrate nur kurzzeitig für z.B. 3 Tage als Kombinationspartner eingesetzt werden [387], wegen der fehlenden Wirkung gegenüber Legionellen ist initial die zusätzliche Gabe eines Makrolids erforderlich.

Zur raschen Erzeugung bakterizider Blut- und Gewebsspiegel sind die Antiinfektiva parenteral zu applizieren und hoch zu dosieren.

Das Risiko eines ungünstigen Ausgangs durch eine inadäquate Therapie wegen Vorliegen einer Resistenz ist bei sCAP besonders hoch. Die Beachtung der aktuellen Resistenzdaten hat daher einen besonders hohen Stellenwert. Wichtigstes differenzialtherapeutisches Entscheidungskriterium zwischen den empfohlenen Therapieregimen ist eine vorausgegangene Antibiotikatherapie. In diesem Fall wird ein Wechsel der zuletzt verwendeten Substanzgruppe empfohlen, dies gilt insbesondere für Therapien innerhalb der letzten 3 Monate [33,34]. 
Die Arbeitsgruppe empfiehlt (Empfehlungsgrad B) ( $\odot$ Abb. 6) bei sCAP ohne Risiko für eine Infektion mit $P$. aeruginosa als Therapie der Wahl eine Kombinationstherapie mit einem Breitspektrum-Betalaktamantibiotikum (Cefotaxim, Ceftriaxon, Piperacillin/Tazobactam, Ertapenem) und einem Makrolid (s. Tab. 17). Die Monotherapie mit einem pneumokokkenwirksamen Fluorchinolon (Levofloxacin oder Moxifloxacin) ist eine mögliche Alternative, dies gilt jedoch nur für Patienten ohne septischen Schock bzw. ohne invasive Beatmung.

Die Arbeitsgruppe empfiehlt (Empfehlungsgrad B) ( $\triangle$ Abb. 6) bei Patienten mit Indikation für eine gegen $P$. aeruginosa wirksame empirische Therapie (s. Tab. 5) eine Kombinationstherapie bestehend aus Piperacillin/Tazobactam, Cefepim, Imipenem bzw. Meropenem und einem pseudomonaswirksamen Fluorchinolon (Levofloxacin oder Ciprofloxacin) oder einem Aminoglykosid zusammen mit einem Makrolid (s. Tab. 18). Wesentliches differenzialtherapeutisches Kriterium ist eine vorausgegangene Antibiotikatherapie, die einen Wechsel der Substanzgruppe erforderlich macht [34]. Ceftazidim ist ebenfalls gegenüber $P$. aeruginosa aktiv, verfügt aber im Vergleich zu Cefepim über eine unzureichende Aktivität gegenüber S. pneumoniae und S. aureus [391]. Nach klinischer Besserung und/ oder Erregernachweis mit Empfindlichkeitsprüfung soll im Regelfall eine Deeskalation auf eine Monotherapie erfolgen.

Therapiedauer: Die notwendige Therapiedauer ist nicht bekannt. Daten aus Studien bei nosokomialer Pneumonie zeigen, dass eine 15-tägige Behandlungsdauer einer 8-tägigen Behandlung nicht überlegen war [392]. Bei nachgewiesener Infektion durch nicht fermentierende gramnegative Stäbchen (überwiegend $P$. aeruginosa) war die 15-tägige Behandlungsdauer mit einer geringeren Rezidivrate assoziiert [392]. Eine sorgfältige Abwägung gegen die Vorteile einer kürzeren Therapiedauer hinsichtlich der verminderten Selektion resistenter Erreger und der potenziell reduzierten Toxizität ist erforderlich. Eine sinnvolle Strategie ist bei kürzerer Therapiedauer die tägliche klinische Überprüfung von Symptomen, die auf ein Rezidiv hinweisen können. Eine Steuerung der Antibiotikatherapiedauer ist auch mit einer seriellen Bestimmung von Procalcitonin an den Behandlungstagen 0, 4, 6 und 8 bei schwerer CAP möglich [291]. Ein Procalcitonin-Spiegel von $<0,1 \mu \mathrm{g} / \mathrm{L}$ im Verlauf spricht bei klinischer Besserung für eine Beendigung der Antibiotikatherapie.

Die Arbeitsgruppe empfiehlt (Empfehlungsgrad B) bei Patienten ohne Komplikationen eine Therapiedauer von 8-10 Tagen bzw. 5 Tagen nach Entfieberung. Bei nachgewiesener Infektion durch P. aeruginosa sollte die Therapiedauer 8-15 Tage betragen. Bei sCAP durch S. aureus können ebenfalls längere Therapiedauern erforderlich sein.

Adjuvante Therapie: Das intensivmedizinische Management bei sCAP entspricht prinzipiell dem von anderen Patienten mit Sepsis oder septischem Schock unabhängig von der Lokalisation der Primärinfektion. Zur weiterführenden Information wird auf die aktuelle Leitlinie der Deutschen Sepsis-Gesellschaft und der Deutschen Interdisziplinären Vereinigung für Intensiv- und Notfallmedizin verwiesen [393].

In einer prospektiv randomisierten Studie bei sCAP führte die Gabe von Hydrocortison zusätzlich zur Standardtherapie zu einer Reduktion der Krankenhausletalität [394]. Die Studie weist allerdings methodische Probleme auf und bedarf der Bestätigung
Tab. 17 Therapieempfehlung für die kalkulierte Initialtherapie bei hospitalisierten Patienten mit schwerer ambulant erworbener Pneumonie (sCAP) ohne Indikation für eine gegen $P$. aeruginosa wirksame empirische Therapie (s. Tab. 5)

\begin{tabular}{|c|c|c|}
\hline $\begin{array}{l}\text { Substanzen für die } \\
\text { Initialtherapie* }\end{array}$ & $\begin{array}{l}\text { Dosierung der Initial- } \\
\text { therapie (pro Tag)* }\end{array}$ & $\begin{array}{l}\text { Gesamtthe- } \\
\text { rapiedauer }\end{array}$ \\
\hline \multicolumn{3}{|l|}{ Mittel der Wahl** } \\
\hline $\begin{array}{l}\text { Betalaktam } \\
\text { - Piperacillin/Tazobactam } \\
\text { - Ceftriaxon } \\
\text { - Cefotaxim } \\
\text { - Ertapenem } \\
\text { plus Makrolid**** }\end{array}$ & $\begin{array}{l}3 \times 4,5 \text { gi.v. } \\
1 \times 2,0 \text { gi. } . \\
3 \times 2,0 \text { gi.v. } \\
1 \times 1,0 \text { gi.v. }\end{array}$ & $\begin{array}{l}8-10 \text { Tage } \\
8-10 \text { Tage } \\
8-10 \text { Tage } \\
8-10 \text { Tage } \\
8-10 \text { Tage }\end{array}$ \\
\hline \multicolumn{3}{|l|}{ Alternative*** } \\
\hline $\begin{array}{l}\text { Fluorchinolon***** } \\
\text { Levofloxacin } \\
\text { Moxifloxacin }\end{array}$ & $\begin{array}{l}2 \times 500 \mathrm{mg} \text { i. v. } \\
1 \times 400 \mathrm{mg} \text { i. } .\end{array}$ & $\begin{array}{l}8-10 \text { Tage } \\
8-10 \text { Tage }\end{array}$ \\
\hline $\begin{array}{l}\text { * Weiterführende Angaben zu } \\
\text { und Dosierung finden sich in } \\
*_{* *} \text { Bei vorausgegangener Ant } \\
\text { wird ein Wechsel der zuletzt } \\
*_{* * *} \text { Patienten mit Risikofakto } \\
\text { ESBL-Bildnern (außer P. aerugi } \\
\text { mit Penicillinen oder Cephalo } \\
\text { **** Die initiale parenterale } \\
\text { Makrolide s. Tab. } 8 \text { bzw. } 14 .\end{array}$ & $\begin{array}{l}\text { harmakologie, Verträglichl } \\
\text { itel } 7 \text {. } \\
\text { otikatherapie innerhalb der } \\
\text { vendeten Substanzgruppe } \\
\text { für eine Infektion mit Enter } \\
\text { a) sowie Patienten, die kür } \\
\text { rinen erhalten haben. } \\
\text { abreichung wird bevorzugt }\end{array}$ & $\begin{array}{l}\text { Interaktionen } \\
\text { zzten } 3 \text { Monate } \\
\text { ipfohlen. } \\
\text { acteriaceae inkl. } \\
\text { heine Therapie } \\
\text { Dosierung der } \\
\text { r Beatmung ist }\end{array}$ \\
\hline
\end{tabular}

Tab. 18 Therapieempfehlung für die kalkulierte Initialtherapie bei hospitalisierten Patienten mit schwerer ambulant erworbener Pneumonie (sCAP) mit Indikation für eine gegen $P$. aeruginosa wirksame empirische Therapie.

\begin{tabular}{|c|c|c|}
\hline $\begin{array}{l}\text { Substanzen für die } \\
\text { Initialtherapie* }\end{array}$ & $\begin{array}{l}\text { Dosierung der Initial- } \\
\text { therapie (pro Tag)* }\end{array}$ & $\begin{array}{l}\text { Gesamtthe- } \\
\text { rapiedauer }\end{array}$ \\
\hline \multicolumn{3}{|l|}{ pseudomonasaktives } \\
\hline Betalaktam & $3 \times 4,5$ gi.v. & $8-15$ Tage \\
\hline - Piperacillin/Tazobactam & $3 \times 2,0$ gi.v. & $8-15$ Tage \\
\hline - Cefepim & $3 \times 1,0$ gi.v. & $8-15$ Tage \\
\hline - Imipenem & $3 \times 1,0$ gi.v. & $8-15$ Tage \\
\hline \multicolumn{3}{|l|}{ - Meropenem } \\
\hline plus Fluorchinolon & $2 \times 500 \mathrm{mg}$ i.v. & $* *$ \\
\hline - Levofloxacin & $3 \times 400 \mathrm{mg}$ i.v. & $* *$ \\
\hline \multicolumn{3}{|l|}{ - Ciprofloxacin } \\
\hline \multicolumn{3}{|l|}{$\operatorname{oder}^{* * *}$} \\
\hline \multicolumn{3}{|l|}{$\begin{array}{l}\text { plus Aminoglykosid und } \\
\text { Makrolid } *_{* * *}\end{array}$} \\
\hline - Amikacin & 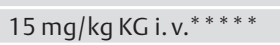 & 3 Tage $^{* *}$ \\
\hline - Gentamicin & $5-7 \mathrm{mg} / \mathrm{kg} \mathrm{KG} \mathrm{i.v.}$ & 3 Tage** \\
\hline - Tobramycin & $5-7 \mathrm{mg} / \mathrm{kg} \mathrm{KG} \mathrm{i} . \mathrm{v}$. & 3 Tage $^{* *}$ \\
\hline \multicolumn{3}{|c|}{$\begin{array}{l}\text { *Weiterführende Angaben zur Pharmakologie, Verträglichkeit, Interaktionen } \\
\text { und Dosierung finden sich in Kapitel } 7 . \\
\text { ** Bei klinischem Ansprechen ist eine Deeskalation auf eine Therapie mit } \\
\text { Betalaktam/Makrolid oder ein Fluorchinolon, wenn möglich unter Berücksich- } \\
\text { tigung der Antibiotika-Empfindlichkeitsprüfung, indiziert. Aminoglykoside } \\
\text { sollten wegen erhöhter Toxizität im Regelfall nicht länger als } 3 \text { Tage verab- } \\
\text { reicht werden. } \\
\text { *** Bei vorausgegangener Antibiotikatherapie innerhalb der letzten } 3 \text { Monate } \\
\text { wird ein Wechsel der zuletzt verwendeten Substanzgruppe empfohlen, dies } \\
\text { gilt insbesondere für eine vorausgegangene Fluorchinolontherapie. } \\
\text { **** Dosierung der Makrolide s. Tab. } 8 \text { bzw. 14. } \\
\text { ***** Weitere Dosierung nach Spiegelbestimmung. }\end{array}$} \\
\hline
\end{tabular}

durch weitere Untersuchungen, bevor eine Hydrocortisontherapie bei Patienten mit sCAP ohne septischen Schock oder Nebennierenrindeninsuffizienz empfohlen werden kann. 
Therapieversagen: Die Differenzialdiagnose, das diagnostische Vorgehen und die kalkulierte Therapie sind in Kapitel 15 ausgeführt.

\section{Therapieversagen bei CAP}

Deskriptiv lassen sich mehrere Formen des Therapieversagens unterscheiden. Aus prognostischer und therapeutischer Sicht ist die Unterteilung des primären Therapieversagens in die progrediente Pneumonie und die klinisch verzögert ansprechende Verlaufsform sinnvoll [252, 283, 344,395].

Progrediente Pneumonie (progressive pneumonia): Eine progrediente Pneumonie ist definiert als klinische Zustandsverschlechterung mit Entwicklung einer respiratorischen Insuffizienz und/ oder einer schweren Sepsis oder eines septischen Schockes trotz empirischer antimikrobieller Therapie [252]. Ein Krankheitsprogress tritt meist innerhalb der ersten 72 Stunden nach Therapiebeginn ein und ist mit einer hohen Letalität assoziiert [282,283]. Ein radiologischer Progress der Infiltrate weist nur bei gleichzeitig progredienter klinischer Symptomatik auf ein Therapieversagen hin.

Verzögert ansprechende Pneumonie (non-responding pneumonia): Eine verzögert ansprechende Pneumonie ist definiert als fehlendes Erreichen klinischer Stabilität nach $72 \mathrm{~h}$ antimikrobieller Therapie. Klinische Stabilität ist definiert als

- Herzfrequenz $\leq 100 / \mathrm{min}$,

- Atemfrequenz $\leq 24 / \mathrm{min}$,

- systolischer Blutdruck $\geq 90 \mathrm{~mm} \mathrm{Hg}$

- Körpertemperatur $\leq 37,8^{\circ} \mathrm{C}$,

- keine Hypoxämie $\left(\mathrm{PO}_{2} \geq 60 \mathrm{~mm} \mathrm{Hg}\right.$ bzw. $\left.\mathrm{SaO}_{2} \geq 90 \%\right)$.

$[252,283,344]$

Sonderformen: Sonderformen des Therapieversagens stellen das sekundäre Therapieversagen (initiales Ansprechen und erneute Verschlechterung), die persistierende Pneumonie (slowly resolving pneumonia) sowie die rezidivierende Pneumonie (mindestens zwei voneinander getrennte Episoden binnen eines Jahres, recurrent pneumonia) dar [252,396,397]. Die letztere ist im strengen Sinne kein Therapieversagen nach obiger Definition, da es zunächst zu einer vollständigen Abheilung der Pneumonie kommt. Im Falle des sekundären Therapieversagens ist das Vorhandensein einer nosokomialen Pneumonie oder Immunsuppression auszuschließen (D). Eine persistierende Pneumonie liegt dann vor, wenn eine vollständige Rückbildung des Infiltrats $>30$ Tage nach Pneumoniebeginn ausbleibt [252]. Die Normalisierung des Röntgenthoraxbildes ist abhängig von Lebensalter, Komorbidität, Schweregrad der Pneumonie und ursächlichem Erreger und kann sich über 2 bis 16 Wochen erstrecken. Das prämorbide Niveau des Wohlbefindens und der Leistungsfähigkeit wird allerdings in der Mehrzahl der Fälle nicht vor Ablauf von mindestens 30 Tagen und häufig sogar erst nach bis zu 6 Monaten erreicht. Nach schweren Verlaufsformen kann eine vollständige restitutio ad integrum unter Umständen auch ausbleiben [350,353, 398-400].
15.1. Häufigkeit und Ursachen des Therapieversagens Die mediane Zeit zum Erreichen klinischer Stabilität bei hospitalisierten Patienten betrug in einer Studie 3 Tage [344]. Ein fehlendes Ansprechen ohne progrediente klinische Symptomatik innerhalb der ersten $72 \mathrm{~h}$ wird daher nicht als Therapieversagen klassifiziert [252]. Bei 5-10\% aller Patienten mit hospitalisierter CAP entwickelt sich eine progrediente Pneumonie [282,283].

Die möglichen Gründe für ein Therapieversagen beinhalten infektiöse und nicht-infektiöse Ursachen $[252,283]$. In etwa $2 / 3$ der Fälle mit definierten Gründen liegen infektiologische Erklärungen für ein Therapieversagen vor, wobei bei jeweils 10 bis $20 \%$ der Patienten neu diagnostizierte Erreger (initial ohne Erregernachweis), persistierende Erreger oder neu identifizierte nosokomiale Erreger ursächlich infrage kommen [48, 283]. Eine bisher unerkannte HIV-Infektion kann ebenfalls Ursache für eine progrediente Pneumonie sein [401]. Ein klinischer Progress später als 72 h nach Krankenhausaufnahme ist häufig mit einer nosokomialen Superinfektion (sekundäres Therapieversagen) oder einer nicht-infektiösen Ursache assoziiert [252].

In bis zu zwei Dritteln der Fälle mit verzögert ansprechender oder progredienter Pneumonie wird eine intensivmedizinische Behandlung notwendig [48]. Nach Erreichen klinischer Stabilität sinkt die Rate auf annähernd 1\% [344]. Eine progrediente Pneumonie führt zu einer bis zu 10-fach erhöhten Letalität bei hospitalisierten Patienten $[48,282,283]$. Besonders hoch ist die Letalität auch bei Therapieversagen infolge einer sekundären, nosokomial erworbenen Pneumonie [48, 402].

Als Risikofaktoren für ein Therapieversagen wurden in Studien das Vorliegen eines höheren Pneumonieschweregrades, multilobärer oder abszedierender Infiltrate, eines Pleuraergusses, einer Leukopenie oder einer Lebererkrankung, der Nachweis von Legionellen oder Enterobacteriaceae sowie eine inadäquate antimikrobielle Initialtherapie identifiziert [282,283].

\subsection{Diagnostisches Vorgehen}

Progrediente Pneumonie: Bei der progredienten Pneumonie stehen das intensivmedizinische Management zur Stabilisierung bzw. Sicherstellung der Organfunktion und die rasche Umstellung der antimikrobiellen Therapie im Vordergrund. Diagnostische Maßnahmen dürfen die Therapieoptimierung nicht verzögern. Die Diagnostik sollte sich bei progredienter Pneumonie vorwiegend auf infektiöse Ursachen konzentrieren [48]. Als Erreger progredienter Pneumonien kommen in Betracht: S. pneumoniae, Legionella spp., S. aureus (auch MRSA), P. aeruginosa und Acinetobacter spp. Weiterhin sind ungewöhnliche bzw. seltene Erreger zu berücksichtigen: $M$. tuberculosis, atypische Mykobakterien, Nokardien (insbesondere bei immunsupprimierten Patienten) $[282,403,404]$.

Verzögernd ansprechende Pneumonie: Bei Nichtansprechen auf eine initiale Therapie ohne klinische Progression liegt in der Hälfte der Fälle lediglich eine verzögert abheilende CAP vor, bei den übrigen Patienten sind vorwiegend seltene oder ungewöhnliche Erreger wie Mykobakterien, Pilze, Nokardien und nicht-infektiöse Ursachen zu annähernd gleichen Teilen nachweisbar. Neben der Überprüfung der korrekten Wahl und Dosierung sowie regelmäßigen Verabreichung bzw. Einnahme des Antibiotikums ist in Abhängigkeit von der Klinik eine Abklärung der Differenzialdiagnosen mittels erweiterter bildgebender Diagnostik (Thorax-CT, Sonografie, Echokardiografie) sowie einer Bronchoskopie mit BAL und/oder transbronchialer Biopsie bzw. transthorakaler Lungenbiopsie indiziert $[262,352,405]$. 


\section{Diagnostische Prinzipien:}

Die Arbeitsgruppe empfiehlt (Empfehlungsgrad B) bei Therapieversagen folgendes diagnostisches Vorgehen:

1. Anamnese, klinische Untersuchung, Einbeziehung epidemiologischer Daten

2. Ausschluss einer Infektion außerhalb des Respirationstraktes

3. Überprüfung der bisherigen Antibiotikaauswahl und -dosierung

Weitere Untersuchungen können im Einzelfall indiziert sein:

4. Mikrobiologische Sputumdiagnostik bei purulentem Sputum und Gewährleistung der notwendigen logistischen Voraussetzungen (Transport und Verarbeitung innerhalb von 2 bis 4 Stunden, s. Kap. 6) mit Gramfärbung, Bakterienkultur mit Resistenztestung, abhängig von klinischer Situation und Vorgeschichte Färbungen und Spezialkulturen auf seltene Erreger wie Mykobakterien, Pilze

5. Entnahme von zwei Blutkulturen (zwei mal zwei Flaschen) von unterschiedlichen Lokalisationen im Abstand von wenigen Minuten

6. Gegebenenfalls Bronchoskopie mit bronchoalveolärer Lavage mit Gramfärbung, quantitativer Bakterienkultur mit Empfindlichkeitsprüfung, abhängig von klinischer Situation und Vorgeschichte Färbungen und Spezialkulturen auf seltene Erreger wie Mykobakterien, Legionellen, Pilze, Viren, Nokardien $[48,405]$

7. L. pneumophila-Antigentest (Serogruppe 1) aus Urin

8. Nachweis von Antikörpern gegen M. pneumoniae [138]

9. Diagnostische Pleurapunktion bei Vorliegen eines Pleuraergusses ( $>5 \mathrm{~cm}$ in der lateralen Röntgenthorax-Aufnahme) mit Gramfärbung, Bakterienkultur und Empfindlichkeitsprüfung, Bestimmung von $\mathrm{pH}$ und Gesamteiweiß, abhängig von klinischer Situation und Vorgeschichte Färbungen und Spezialkulturen auf seltene Erreger wie Mykobakterien, Pilze

10. Bildgebung: Computertomografie der Lungen $[406,407]$, transthorakale Echokardiografie

11. Ggf. transbronchiale bzw. transthorakale Lungenbiopsie oder Video-assistierte Thorakoskopie

12. Ausschluss einer Immunsuppression (z. B. HIV-Test)

13. Bestimmung von Procalcitonin: Verlaufskontrollen des Procalcitonin i. S. am Tag 3 sind prognostisch von Bedeutung. Ansteigende Werte sind mit einer erhöhten Letalität, niedrige Werte mit einem günstigen Outcome verbunden [369]

\subsection{Antibiotikatherapie bei Therapieversagen}

Progrediente Pneumonie: Infektiöse Ursachen sind die häufigsten Gründe für ein Therapieversagen. Ein empirisches Vorgehen wird empfohlen, da Ergebnisse der mikrobiologischen Untersuchungen nicht vor 48 Stunden zur Verfügung stehen. Eine nosokomiale Infektion und/oder eine Immunsuppression sollten ausgeschlossen werden.

\section{Die Arbeitsgruppe empfiehlt (Empfehlungsgrad B):}

Im Vordergrund stehen die Überwachung und rasche Stabilisierung der Organfunktionen sowie die prompte parenterale Verabreichung einer adäquaten empirischen antibiotischen Kombinationstherapie entsprechend der Empfehlungen für eine sCAP. Bei einem septischen Schock führt jede Verzögerung der Applikation einer adäquaten Antibiotikatherapie zu einer signifikant erhöhten Letalität [376]. Häufig ist nach erneuter Risikostratifizierung die Verlegung auf eine Intensivstation erforderlich [48].

Verzögert ansprechende Pneumonie: Bei fehlender klinischer Stabilität nach 72 h sollte sich das Vorgehen an den Ergebnissen der initialen und im Rahmen der Evaluation des Therapieversagens durchgeführten diagnostischen Maßnahmen orientieren. Eine abwartende Haltung nach Ausschluss nicht-infektiöser Ur- sachen kann bei risikoadaptierter Leitlinien-gerechter antimikrobieller Therapie zunächst gerechtfertigt sein.

Therapieprinzipien: Grundsätzlich sollten folgende Prinzipien bei der Versagertherapie beachtet werden.

Die Arbeitsgruppe empfiehlt (Empfehlungsgrad B):

Folgende Therapieoptionen kommen infrage:

1. Prompte Umstellung auf eine Antibiotikatherapie gemäß den Empfehlungen dieser Leitlinie im Falle einer nicht Leitliniengerechten initialen kalkulierten Behandlung

2. Aufgrund einer möglichen Selektion resistenter Erreger Wechsel der Substanzklassen

3. Überprüfung der initialen Antibiotikatherapie auf bestehende Erregerlücken im antimikrobiellen Spektrum

4. Parenterale Verabreichung

5. Kombinationstherapie

Eine Wirksamkeit gegen S. pneumoniae sollte auf jeden Fall auch nach der Umstellung beibehalten und Antibiotika-Kombinationen mit einem breiten antimikrobiellen Spektrum unter Einschluss von P. aeruginosa, S. aureus (MRSA), Legionella spp. und Anaerobiern verabreicht werden.

Die folgenden Substanzklassen stellen potenzielle Kombinationspartner dar:

- ausreichend pseudomonaswirksame Betalaktame:

Piperacillin, Imipenem, Meropenem, Cefepim, Ceftazidim

(cave: keine ausreichende Wirkung gegen S. pneumoniae und S. aureus)

- ausreichend pseudomonaswirksame Fluorchinolone:

Ciprofloxacin, Levofloxacin

- ausreichend pneumokokkenwirksame Fluorchinolone:

Moxifloxacin, Levofloxacin

- parenterale Makrolide

- Aminoglykoside

- bei Nachweis bzw. begründetem Verdacht (z. B. bekannte Kolonisation) auf MRSA-Pneumonie: siehe Kap. 17.3.

\section{Besondere Verlaufsformen der CAP}

7

\subsection{Pleuraerguss}

Die Therapie des parapneumonischen Ergusses verfolgt die zentralen Ziele der Kontrolle der Infektion, der Drainage des infizierten Ergusses, der (Re-) Expansion der Lunge und der Vermeidung der Ausbildung von Pleuraschwarten.

Die therapeutische Basis ist die suffiziente, erregergerechte antimikrobielle Therapie mit dem Ziel, die zugrunde liegende Infektion zu kontrollieren. Zur Frage der Antibiotikatherapie existieren keine kontrollierten klinischen Studien. Die kalkulierte antimikrobielle Therapie sollte grampositive Kokken, gramnegative Erreger (ggf. inkl. P. aeruginosa) und Anaerobier einschließen. Um sicher ausreichend hohe Serum- und Pleurakonzentrationen zu erreichen, wird initial eine parenterale Applikation bevorzugt. Zur Dauer der antimikrobiellen Therapie existieren keine Daten. Grundsätzlich sollte sie mindestens bis zur vollständigen Drainage des infizierten Ergusses fortgeführt werden. Längere Therapiedauern von mehreren Wochen sind häufig notwendig.

Ein Grundprinzip der Therapie des komplizierten parapneumonischen Ergusses ist die effektive und vollständige Drainage der infizierten Flüssigkeit. Hierfür wird folgendes differenzialtherapeutischen Verfahren vorschlagen [300]: 
- keine Intervention

- Entlastungspunktion

- Anlage einer Thoraxsaugdrainage ohne lokale Fibrinolyse

- Anlage einer Thoraxsaugdrainage mit lokaler Fibrinolyse

- Video-assistierte Thorakoskopie mit postinterventioneller Thoraxsaugdrainage

- chirurgische Exploration (Thorakotomie mit oder ohne Dekortikation bzw. Rippenresektion)

Eine randomisierte Studie bei Patienten mit kompliziertem parapneumonischem Erguss zeigte keinen Vorteil einer lokalen Fibrinolysetherapie mit Streptokinase nach Drainageanlage gegenüber Placebo hinsichtlich der Letalität oder der Notwendigkeit einer chirurgischen Intervention. Es fand sich jedoch ein Trend zu einer höheren Nebenwirkungsrate bei der mit Streptokinase therapierten Gruppe [408]. Die Studie wies jedoch einige methodische Probleme auf (z. B. fehlende Standardisierung der Indikation zur Thoraxchirurgie, fehlende Stratifizierung nach Septierung) sodass die Datenlage insgesamt als noch nicht eindeutig einzuschätzen ist. Als Option besteht bei Patienten, bei denen eine alleinige Drainageanlage kein rasches Entfernen der infizierten Pleuraflüssigkeit erreicht, insbesondere die Video-assistierte Thorakoskopie (VATS) sowie ggf. ein zeitlich begrenzter Versuch mittels lokaler Fibrinolyse.

\section{Risikostratifizierung:}

- Ergussmenge

A 0: minimaler Erguss ( $<5$ cm im lateralen Röntgenbild) [299]

bzw. Thorax-Sonografie

A 1: mittelgroßer, frei auslaufender Erguss ( $>5 \mathrm{~cm}$ und

$<1 / 2$ Hemithorax)

A 2: Großer, frei auslaufender Erguss ( $>1 / 2$ Hemithorax), gekammerter Erguss oder Ergussbildung mit verdickter Pleura

- Bakteriologie der Ergussflüssigkeit

B x: Gramfärbung bzw. Kultur nicht bekannt

B 0: negative Kultur und Gramfärbung

B 1: positive Kultur oder Gramfärbung

B 2: Eiter

- klinische Chemie der Ergussflüssigkeit

$\mathrm{Cx}$ : pH unbekannt

$\mathrm{C} 0: \mathrm{pH}>7,2$

$\mathrm{C} 1: \mathrm{pH}<7,2$

Das zusätzliche Risiko für den Patienten durch einen Pleuraerguss wird anhand der folgenden Parameter eingeschätzt: Verlängerter Krankenhausaufenthalt, erhöhte Morbidität durch FolgeInterventionen, verlängerte körperliche Beeinträchtigung, erhöhtes Risiko einer respiratorischen Beeinträchtigung, erhöhtes Risiko einer lokalen Entzündungsreaktion, Letalität [300].

Die Arbeitsgruppe empfiehlt (Empfehlungsgrad C):

Kategorie 1 (sehr niedriges Risiko):

Vorliegen von A 0, B x oder C x: keine Drainage

Kategorie 2 (niedriges Risiko):

Vorliegen von A 1, B 0 oder C 0 : keine Drainage

Kategorie 3 (mittleres Risiko):

Vorliegen von A 2, B 1 oder C 1: Drainage indiziert

Kategorie 4 (hohes Risiko):

Vorliegen von B 2: Drainage indiziert

Für Patienten der Kategorien 3 und 4 scheint eine Entlastungspunk-

tion in aller Regel unzureichend zu sein, es ist daher die Anlage eine Thoraxdrainage indiziert. Bei gekammertem Erguss oder Patienten der Kategorie 4 sind lokale Fibrinolyse und video-assistierte Thorakoskopie die am meisten geeigneten Verfahren.

\subsection{Aspirationspneumonie}

Aspirationspneumonien werden unterteilt in schleichend rezidivierende Aspirationen und akute Aspirationen von Mageninhalt [409]. Die Erstgenannten fallen oft nicht als solche auf, kommen jedoch gehäuft vor bei älteren Patienten [410], bei Patienten mit neurologischen Grunderkrankungen, die zu einer Bettlägerigkeit mit oder ohne Bewusstseinstrübung führen oder den Schluckreflex beeinträchtigen sowie bei eingeschränkter Dentalhygiene $[46,411,412]$. Die Aspiration von Mageninhalt (Mendelson-Syndrom) ist dagegen eher selten.

In beiden Fällen ist ein Erregernachweis oft schwierig, meist liegt jedoch eine polymikrobielle Ätiologie mit Nachweis von aeroben und anaeroben Erregern vor. Bei außerhalb des Krankenhauses erfolgten Aspirationen sind grampositive Erreger wahrscheinlich, bei multimorbiden Patienten mit vielfachen Krankenhausaufenthalten und antimikrobiellen Therapien in der Vorgeschichte finden sich dagegen meist gramnegative Erreger oder polymikrobielle Infektionen, zum Teil mit Anaerobiern [413].

Die Arbeitsgruppe empfiehlt (Empfehlungsgrad D):

Eine vorausgegangene Aspiration ist ein Risikofaktor für das Auftreten von Enterobacteriaceae [29]. Da eine zusätzliche ätiologische Rolle von anaeroben Bakterien bei der Aspirationspneumonie nicht ausgeschlossen ist und die überwiegende Anzahl der Anaerobier Betalaktamase produzieren, sollte ein Betalaktam-Antibiotikum mit einem Betalaktamaseinhibitor kombiniert werden. Alternativ kann eine Kombination aus einem Cephalosporin (Cefotaxim, Ceftriaxon) mit Clindamycin, das Fluorchinolon Moxifloxacin oder ein Carbapenem (Ertapenem) eingesetzt werden.

\subsection{Retentionspneumonie}

Die häufigste Ursache einer Retentionspneumonie ist eine bronchiale Obstruktion durch ein Lungenkarzinom. Mammakarzinom, Hypernephrom und gastrointestinale Tumore können mit der Entwicklung endobronchial wachsender Metastasen einhergehen und sind somit nach dem Lungenkarzinom führende Ursachen der Retentionspneumonie [414]. Andere mögliche Ursachen der Retention sind eine ausgeprägte Kardiomegalie sowie Pleuraergüsse, die zu einer funktionellen Einengung der Unterlappensegmentostien führen. Fremdkörperaspirationen sind bei Erwachsenen selten. Gelegentlich kommen Torquierungsstenosen bei chronisch-deformierender Bronchitis, Zustand nach lungenresektiven Eingriffen oder Mischstaub-Pneumokoniosen vor. Die Behandlung entspricht den schweregradadaptierten Empfehlungen bei CAP.

\subsection{Lungenabszess}

Lungenabszesse können anhand der Pathogenese in verschiedene Formen eingeteilt werden. Die Unterscheidung von „nekrotisierender Pneumonie“ und „abszedierender“ Pneumonie durch das Kriterium der Abszessgröße $(<2 \mathrm{~cm})$ erscheint dagegen wenig hilfreich. Die meisten Publikationen zu diesem Thema unterscheiden aber zumindest eine primäre und eine sekundäre Form. Die Pathogenese der primären Lungenabszesse beruht auf der Aspiration und entsprechender Virulenz der Erreger bzw. verminderter Immunkompetenz des Patienten. Risikofaktoren für die Aspiration sind unter anderem Bewusstseinstrübungen, Alkoholabusus, Schluckstörungen und/oder ösophageale Pathologien [415]. Sekundäre Lungenabszesse finden sich bei bronchialer Obstruktion durch Neoplasien oder Fremdkörper mit poststenotischer Pneumonie, durch Einschmelzung und Superinfektion 
von Infarktpneumonien und selten auch bei Bakteriämien. Da es für die Ätiologie von Bedeutung zu sein scheint, wurde eine erweiterte Klassifikation vorgeschlagen, die zusätzlich in Lungenabszesse bei immunkompetenten und nicht immunkompetenten Patienten unterscheidet $[416,417]$.

Die Ätiologie des Lungenabszesses ist fast ausschließlich infektiös, wobei Bakterien mit Abstand die größte Rolle spielen. Andere Ätiologien wie Pilze (z.B. nekrotisierende Aspergillose) und Echinococcus spp. müssen jedoch in Betracht gezogen werden. Die Einschmelzung im Rahmen der Lungentuberkulose wird üblicherweise getrennt als tuberkulöse Kavitation angesehen, erfüllt jedoch das Definitionskriterium des Lungenabszesses. Bakterielle Mischinfektionen überwiegen, und in $20-90 \%$ werden obligate Anaerobier nachgewiesen [417-422].

\section{Die Arbeitsgruppe empfiehlt (Empfehlungsgrad C):}

Die Bronchoskopie ist bei Verdacht auf Lungenabszess unerlässlich, um eine bronchiale Obstruktion auszuschließen und ggf. auch zu beseitigen. In gleicher Sitzung kann eine gründliche Bronchialtoilette durchgeführt werden. Eine Ableitung des Sekretes ist notwendig, wobei die Drainage spontan durch Abhusten, als interne bronchoskopische oder als transthorakale Drainage erfolgen kann. Eine mikrobiologische Diagnostik des bronchoskopisch gewonnenen unteren Atemwegsmaterials mit Grampräparat, aerober und anaerober Kultur sowie Diagnostik auf Mykobakterien sollte dabei stets erfolgen.

Die Anfertigung einer CT des Thorax wird stets empfohlen, um die Lokalisation und die Größe der Abszesse sowie ihre Nähe zu angrenzenden Strukturen (Pleura) beurteilen zu können.

Es muss darauf hingewiesen werden, dass alle bronchoskopischen Eingriffe bei Patienten mit Lungenabszessen mit dem Risiko eines Übertritts von infektiösem Material in bisher gesunde Lungenabschnitte auf der ipsi- und/oder kontralateralen Seite verbunden sind [423].

Die Arbeitsgruppe empfiehlt (Empfehlungsgrad B) folgende Therapieschemata zur Behandlung des Lungenabszesses [424, 425]: Aminopenicillin + Betalaktamasehemmer oder

Clindamycin (3-4×600 mg/d) plus Cephalosporin (Cefuroxim, Ceftriaxon, Cefotaxim).

In einer randomisierten Prüfung dieser beiden Therapien konnte kein signifikanter Unterschied für den klinischen Erfolg oder für die bakterielle Eradikation gefunden werden [426].

Die Dauer der antimikrobiellen Therapie muss individuell gesteuert werden. Grundsätzlich sollte sie bis zur vollständigen Rückbildung der Abszesshöhle sowie der begleitenden Infiltrate fortgesetzt werden. Eine vorzeitige Beendigung der Therapie kann zu Rezidiven führen. Dies bedeutet im Regelfall eine Therapiedauer von vier bis acht Wochen, in einzelnen Fällen aber auch von drei bis sechs Monaten. Initial sollte stets intravenös behandelt werden. Nach klinischem Ansprechen und radiologisch dokumentierter Rückbildung der Abszesshöhlengröße kann auf eine orale Therapie umgestellt werden [427].

Nach wie vor führt die Antibiotika-Therapie eines Lungenabszesses in 75-90\% der Patienten zur Ausheilung. Eine mögliche weitere Option zur Behandlung von Therapieversagern bieten intrapulmonale Drainagen. Die Katheter-Einlageverfahren sind vielfältig und umfassen das Einlegen unter Durchleuchtungs- oder
CT-Kontrolle [428]. Die Erfolgsrate dieses Verfahrens ist sehr hoch, ein Pleuraempyem als Komplikation selten. Dabei ist darauf zu achten, dass die Drainage nicht durch gesundes Lungengewebe geführt werden darf. In der bisher größten Serie von 19 Patienten betrug die Erfolgsrate in Bezug auf die Drainage und Beherrschung der Sepsis 100\%. Nur 3/19 (16\%) der Patienten mussten anschließend aufgrund von Pleuraverwachsungen operativ saniert werden [429].

Die chirurgische Therapie hat nur noch zwei Indikationen: Die chirurgische Sanierung von Komplikationen (pulmonale Blutung, Empyem durch Fistelbildung, konservativ nicht beherrschbare Sepsis) und die Entfernung großer, unter konservativer Therapie nicht schließender Resthöhlen.

\subsection{Pseudo-Therapieversager durch nicht-infektiöse} Lungenerkrankungen, die initial wie eine Pneumonie imponieren

$\mathrm{Zu}$ diesen gehören vor allem interstitielle Lungenerkrankungen wie die kryptogen organisierende Pneumonie (COP) (wobei die COP durch Infektionserreger ausgelöst sein kann), die exogen-allergische Alveolitis, die Sarkoidose, die Histiocytosis X, die eosinophile Pneumonie sowie Lungenbeteiligungen im Rahmen von Autoimmunerkrankungen (SLE, rheumatoide Arthritis, M. Wegener u.a.). Des Weiteren sind maligne Erkrankungen, vor allem das bronchiolo-alveoläre Karzinom, die Lymphangiosis carcinomatosa sowie maligne Lymphome in Betracht zu ziehen. Darüber hinaus können eine Lungenstauung bzw. -überwässerung sowie ein Lungeninfarkt nach Lungenembolie vorliegen. Seltener sind durch Medikamente induzierte Alveolitiden (z.B. Amiodaron) [262]. Klinische Hinweise auf eine nicht-infektiöse Ursache umfassen: schleichende Verläufe, Husten ohne Auswurf, normale oder nur gering erhöhte Leukozytenzahl, Eosinophilie, extrapulmonale Manifestationen (z.B. renal) sowie diffuser Infiltratcharakter ohne Nachweis eines Bronchopneumogramms.

\section{Besonderheiten der Therapie der CAP bei bekanntem Erreger \\ v}

\subsection{Legionellen}

Eine bislang empfohlene Therapie bei einer Pneumonie durch Legionellen war hochdosiertes parenterales Erythromycin. Diese Empfehlung fußte auf historischen Kollektiven, denn aufgrund der niedrigen Inzidenz gibt es bis zum jetzigen Zeitpunkt keine prospektiven randomisierten oder gar doppelblinden Studien [430,431]. Auch die neueren Makrolide besitzen eine hervorragende Aktivität in vitro gegenüber Legionellen und können, sofern sie als parenterale Zubereitung zur Verfügung stehen, zur Behandlung der Legionellenpneumonie eingesetzt werden [431]. Drei neuere prospektive Beobachtungsstudien zeigten jedoch einen Vorteil einer Fluorchinolontherapie (überwiegend Levofloxacin) gegenüber einer Makrolidtherapie bei Patienten mit Legionellenpneumonie: Unter Fluorchinolontherapie wurden eine signifikant raschere Entfieberung bzw. eine niedrigere Rate an Komplikationen und ein kürzerer Krankenhausaufenthalt beobachtet [432 -434]. In Verbindung mit der hervorragenden In-vitro-Aktivität aller Fluorchinolone gegenüber Legionellen ist diese Substanzklasse daher Mittel der Wahl bei Legionellenpneumonie.

Für eine Kombinationstherapie (zum Beispiel mit Rifampicin) bei Legionellenpneumonie besteht keine Evidenz [435]. 


\subsection{Chlamydien und Mykoplasmen}

Im Gegensatz zur Infektion mit Legionellen stehen für Chlamydien und Mykoplasmen keine spezifischen Schnelltests zur Verfügung. Prospektive randomisierte Therapiestudien fehlen bei beiden Ätiologien. In vitro sind Tetracycline, Makrolide, Azalide, Ketolide und Fluorchinolone wirksam. In einer retrospektiven Subgruppenanalyse einer prospektiv randomisierten Studie bei CAP [263] wurden die Daten von 117 Patienten mit CAP durch Mykoplasmen und Chlamydien analysiert und die Therapien mit $750 \mathrm{mg} / \mathrm{d}$ Levofloxacin über fünf Tage und $500 \mathrm{mg} / \mathrm{d}$ Levofloxacin über 10 Tage verglichen [436]. Beide Therapien waren gleich wirksam, wie auch in anderen randomisierten Studien, bei denen ein Makrolid geprüft worden war. Zur Länge der Therapie existieren ebenfalls keine Daten. In einer randomisierten offenen Studie wurde bei Pneumonie, verursacht durch Chlamydien, Legionellen und/oder Mykoplasmen, eine Einmalgabe von $1500 \mathrm{mg}$ Azithromycin gegen die dreimalige Gabe von $500 \mathrm{mg}$ verglichen [437]. Die Heilungsrate war in beiden Gruppen gleich hoch, dennoch sollte aufgrund dieser einen Studie die empfohlene Dauer der Therapie bei Infektionen mit Mykoplasmen und Chlamydien nicht unterschritten werden.

\subsection{Ambulant erworbener methicillin-resistenter Staphylococcus aureus}

Beim Nachweis von MRSA aus respiratorischen Sekreten von Patienten mit CAP ist zwischen den häufigen nosokomial erworbenen Erregern und den in Deutschland bisher sehr seltenen, „echten“ ambulant erworbenen MRSA (c-MRSA - englisch für „,community-acquired MRSA“) zu unterscheiden. Meist liegt eine nosokomiale Besiedlung nach einem vorhergehenden Krankenhausaufenthalt vor. Vor dem Beginn einer MRSA-wirksamen Therapie muss daher sorgfältig geprüft werden, ob es sich tatsächlich um den kausalen Erreger handelt (siehe Kap. 6). Es sollte zunächst ein Infektiologe oder klinisch versierter Mikrobiologe konsultiert werden.

Die Erreger „echter“ c-MRSA-Pneumonien sind genetisch von den nosokomialen Stämmen verschieden, zeigen häufig nur eine Resistenz gegenüber Penicillin G und Oxacillin (bzw. eine Oligoresistenz) und können schwere nekrotisierende Pneumonien durch die Produktion von Virulenzfaktoren, wie Panton-Valentine-Leukozidin, verursachen [438-440]. In Deutschland wurden diese Stämme ebenfalls nachgewiesen, sind als Erreger der CAP aber z.Z. sehr selten [441].

Bei nachgewiesener MRSA-Pneumonie sollte bei intakter Nierenfunktion mit Vancomycin (bei MHK $<2 \mathrm{mg} / \mathrm{l}$ ), alternativ mit dem Oxazolidinon Linezolid behandelt werden $[442,443]$. Inwiefern die zusätzliche Gabe von Rifampicin oder Fosfomycin die Behandlungsergebnisse mit Vancomycin bei MRSA-Pneumonie verbessert, ist unsicher und sollte daher Einzelfallentscheidung sein [444].

Um ein gutes Behandlungsergebnis mit Vancomycin zu erzielen, sind ausreichende Serumtalspiegel $(>4-5$-Faches der MHK, in der Regel entsprechend $\sim 10-12 \mathrm{mg} / \mathrm{l})$ notwendig. Vancomycin führt zu vermehrter Nephrotoxizität bei höheren Talspiegeln, nach längerer Behandlungsdauer und bei gleichzeitiger Verabreichung anderer potenziell nephrotoxischer Substanzen (z. B. Aminoglycoside). Bei bereits vorliegender Nierenfunktionseinschränkung, erheblichen Risiken hierfür oder der Notwendigkeit, höhere als allgemein empfohlene Dosen von Vancomycin verabreichen zu müssen, ist bei nachgewiesener Empfindlichkeit Linezolid die bevorzugte Alternative [445 - 447]. Hierbei sind die Unverträglichkeitsreaktionen durch Linezolid (hämatologische To- xizität, Neuropathie) und die Begrenzung der Therapiedauer auf 14 Tage zu beachten.

Bei Patienten mit entsprechenden Risikofaktoren muss beachtet werden, dass das Wirkungsspektrum auch für gramnegative Bakterien beibehalten wird.

Bei CAP durch Methicillin-sensible S. aureus (MSSA) ist dagegen das Isoxazolyl-Penicillin Oxacillin bzw. Flucloxacillin als Therapie mit der höchsten Wirksamkeit den neueren Antibiotika vorzuziehen.

\subsection{Pseudomonas aeruginosa}

Die optimale Behandlung einer CAP durch P. aeruginosa ist nicht gesichert. Argumente für eine Betalaktam-Aminoglykosid-Kombination sind:

- ein additiver bis synergistischer Effekt dieser Kombination in In-vitro-Abtötungskinetiken (Literatur bei [384]).

- In einer Metaanalyse fand sich für Patienten mit einer Bakteriämie durch P. aeruginosa ein signifikanter Überlebensvorteil für die mit einer Betalaktam-Aminoglykosid-Kombination behandelten Patienten [384]. Der Überlebensvorteil dieser Kombination bei Bakteriämien durch P. aeruginosa betrug OR 0,5 (CI 0,3-0,79). Der Anteil an pneumogener Bakteriämie durch $P$. aeruginosa lag in den zur Metaanalyse herangezogenen Studien zwischen 0 und > 50\%. Das Ergebnis dieser Metaanalyse beruht jedoch hauptsächlich auf einer Studie [448], die nach heutigen Kriterien methodisch unzulänglich ist.

Argumente gegen eine Betalaktam-Aminoglykosid-Kombination sind:

- der fehlende Überlebensvorteil einer Betalaktam-Aminoglykosid-Kombination bei immunkompetenten Patienten mit Sepsis; Die Beobachtung bezog sich auch auf eine Subgruppenanalyse mit $P$. aeruginosa-Sepsis [387]. Diese Analyse stützte sich auf einen anderen Datensatz an klinischen Studien als die Metaanalyse von Safdar et al. [384].

- eine erhöhte Rate an unerwünschten Wirkungen (Nephround Ototoxizität) einer Betalaktam-Aminoglykosid-Kombination bei immunkompetenten Patienten mit Sepsis [387],

- die Notwendigkeit eines Drug-Monitorings.

Argumente für eine Betalaktam-Fluorchinolon-Kombination sind:

- der Nachweis eines Synergismus und additiver Effekte in In-vitro-Abtötungskinetiken (allerdings zum Teil auch Antagonismen) (Literatur bei [384]).

- die gute Gewebepenetration der Fluorchinolone.

Argumente gegen eine Betalaktam-Fluorchinolon-Kombination sind:

- die vermehrte Resistenz von P. aeruginosa gegenüber Fluorchinolonen sowie das im Vergleich zu anderen Antibiotika gehäufte Auftreten multiresistenter Erreger unter Fluorchinolontherapie [35], insbesondere auch die rasche Resistenzselektion bei P. aeruginosa [34].

- Klinische Studien zu dieser Kombination fehlen. Eine retrospektive Studie fand mit einer Kombinationstherapie bestehend aus einem Betalaktam-Antibiotikum und einem Fluorchinolon eine erhöhte 30-Tage-Letalität bei sCAP-Patienten [388].

Wichtigstes differenzialtherapeutisches Entscheidungskriterium zwischen den Therapieregimen ist eine vorausgegangene Antibiotikatherapie innerhalb der letzten 3 Monate, die einen Wechsel der zuletzt verwendeten Substanzklasse erforderlich macht. 
Bei einer gesicherten Pneumonie durch $P$. aeruginosa (insbesondere bei positiven Blutkulturen) wird aufgrund folgender Erwägungen initial eine Kombinationstherapie aus zwei pseudomonaswirksamen Antibiotika empfohlen (Empfehlungsgrad D):

- Vorteil einer initialen Kombinationstherapie gegenüber einer

Monotherapie in einer retrospektiven Beobachtungsstudie [389].

- Vermeiden einer inadäquaten initialen empirischen Therapie bei Infektionen durch resistente $P$. aeruginosa [390].

- Möglicherweise Reduktion von Resistenzentwicklungen unter Therapie $[378,449]$.

\subsection{Coxiella burnetii}

Infektionen mit C. burnetii sind erstmals in der Form des Q-Fiebers 1935 bei Schlachthofarbeitern beschrieben worden [450]. Weitere Manifestationsformen sind selbst limitierendes Fieber, Pneumonie, Hepatitis und Infektionen des ZNS. Es handelt sich um eine Anthropozoonose (Schafe, Rinder, Katzen, Hunde und Tauben). C. burnetii kann außerhalb eines Organismus überleben, ist aber nur als Zellparasit vermehrungsfähig. Die Infektion tritt gehäuft epidemisch auf, zuletzt 2003 im Landkreis Soest, wo etwa 150 Menschen erkrankten. Ungefähr 1\% der ambulant erworbenen Pneumonien sind Q-Fieber-Pneumonien [451], der direkte Erregernachweis ist jedoch schwierig, sodass der Antikörpernachweis ausschlaggebend ist (s. Kap. 6). Die empfohlenen Antiinfektiva bei Q-Fieber-Pneumonie sind Tetracycline (z.B. Doxycyclin $2 \times 100 \mathrm{mg}$ ) [450], da eine Erythromycin-Resistenz beschrieben ist [452] und die Patienten schneller entfiebern [453]. Alternativen sind die neueren Makrolide und/oder Azalide sowie Fluorchinolone ggf. in Kombination mit Rifampicin. Über eine Flurochinolon-Resistenz durch Punktmutation ist bei C. burnetii berichtet worden [454].

\section{Prävention der CAP}

$\nabla$

\subsection{Influenzavirus-Impfung}

Die am weitesten verbreitete Influenza-Vakzine ist die Spaltvirus-Vakzine, sie enthält Hämagglutinin- und Neuraminidasebestandteile von drei jährlich auf der Basis der epidemiologischen Daten des Vorjahres neu zusammengestellten Influenzastämmen.

Als Marker für eine ausreichende Impfwirkung wird ein Hämagglutinin-hemmender Titer von $\geq 40$ herangezogen. Auch wenn dieser Surrogatmarker keineswegs in jedem Fall einen sicheren Impfschutz anzeigt, kommt es durch die Impfung zu einem protektiven Titer gegen Influenzavirus A und B in 70 bis $100 \%$ gesunder Erwachsener. Die Immunantwort bei älteren Patienten ist weniger gut und liegt bei 30 bis $70 \%$. Eine doppelte Dosierung oder eine zusätzliche Boosterdosis des Impfstoffes führt zu einem mittleren Anstieg der IgG-Antikörper-Antwort um ca. 15\% [455 457].

Die Impfstoffe mit inaktiviertem Virus sind gut verträglich und führen nur in ca. $6 \%$ der Fälle zu systemischen, unerwünschten Wirkungen. Diese Häufigkeit liegt dicht oberhalb derjenigen der Plazebogabe. In ca. 15 bis $20 \%$ der Fälle (ca. doppelt so hoch wie bei Plazebo) kommt es zu leichtgradigen Lokalreaktionen $[455,456,458]$.

In einer Metaanalyse, die elf Studien mit 4088 Impfungen einschloss, waren ein Lebend- und ein inaktivierter Impfstoff gleich gut wirksam mit einer Schutzwirkung von 70 bis $80 \%$ gegenüber Kultur-positiver Influenza bei Personen im Alter von 1 bis 65 Jahren. Für ältere Personen liegt eine randomisierte Plazebo-kon- trollierte Studie vor $[455,456]$. In dieser Studie mit 1838 Personen über 60 Jahre ohne Hochrisikomorbidität führte eine Spaltvirus-Vakzine zu einer Schutzwirkung gegenüber einer serologisch nachgewiesenen Influenza in $50 \%$ der Fälle, einer klinisch manifesten Influenza in $47 \%$ der Fälle und gegenüber einer Kombination von beidem in $58 \%$ der Fälle. In einer Metaanalyse, die 20 Kohorten-Studien zwischen 1974 und 1992 umfasste [459], zeigte sich eine Schutzwirkung der Vakzine von $56 \%$ für respiratorische Erkrankungen, 53\% für Pneumonien, 50\% für die Hospitalisation und 68\% für einen tödlichen Ausgang. Ähnliche Daten wurden von anderen Autoren mitgeteilt $[460,461]$. Die absolute Risikoreduktion ist dabei zwei- bis fünfmal höher bei Hochrisikogruppen als bei gesunden älteren Personen. Eine aktuelle Kohortenstudie untersuchte erstmals den Einfluss der Influenzaimpfung bei hospitalisierten CAP-Patienten und demonstrierte eine reduzierte Krankenhausletalität nach vorausgegangener Immunisierung [462].

Jährlich wiederholte Impfungen führen nicht zu einer verminderten Immunantwort bzw. Schutzwirkung [463]. Ebenso kommt es nicht zu vermehrten unerwünschten Wirkungen.

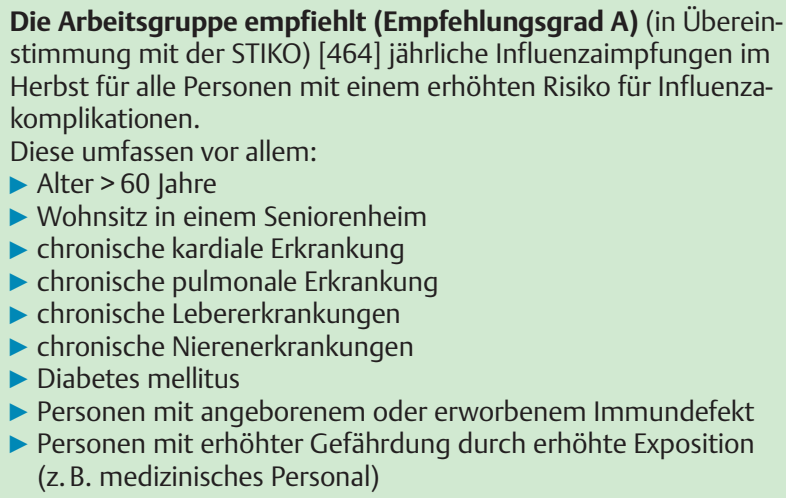

Die Impfung erfolgt vorzugsweise intramuskulär. Zeitabstände zu anderen Impfungen müssen nicht eingehalten werden. Die einzigen Kontraindikationen bestehen in einer HühnereiweißAllergie und bei Vorliegen einer akuten Infektion.

\subsection{Pneumokokken-Impfung}

Aktuell sind zwei Pneumokokkenimpfstoffe verfügbar. Es handelt sich zum einen um einen 23-valenten kapsulären PolysaccharidImpfstoff, der etwa 90\% aller Serotypen beinhaltet, die eine invasive Pneumokokkenerkrankung verursachen. Zum anderen ist ein 7-valenter Protein-Polysaccharid-Konjugat-Impfstoff verfügbar, der speziell bei Kleinkindern zur Anwendung kommt.

Insgesamt ist die Immunantwort auf den Polysaccharid-Impfstoff in jüngeren und älteren Populationen vergleichbar. Allerdings weisen $20 \%$ der älteren Population eine schlechte Immunantwort auf. Antikörper sind zwischen drei und zehn Jahren nach der Impfung nachweisbar. Ein „protektiver“ Antikörper-IgG-Spiegel oder andere Surrogatmarker für effektive Impfungen gegen Pneumokokkenerkrankungen sind nicht bekannt. Allgemein gelten jedoch hohe Antikörperspiegel und die Ausbildung eines mindestens 4-fachen Antikörperanstieges als Zeichen eines ausreichenden Impfschutzes [465 - 467].

Lokalreaktionen sind etwas häufiger als bei der Influenzaimpfung, schwere systemische unerwünschte Reaktionen sind jedoch extrem selten [468]. Die Lokalreaktionen bestehen in einer 
leichten Schwellung und Rötung, diese können in bis zu 50\% der Fälle auftreten, bilden sich jedoch rasch zurück.

Die Effektivität der Pneumokokken-Polysaccharid-Impfung ist in zahlreichen Metaanalysen bzw. Reviews untersucht worden [469-471]. Leider weisen viele Studien eine geringe Aussagekraft hinsichtlich des präventiven Effektes der PneumokokkenImpfung in der älteren Population auf. Die Studien zeigen, dass der Polysaccharid-Impfstoff wirksam bakteriämische Pneumokokken-Pneumonien verhindert, die Schutzwirkung beträgt ca. 70 bis $80 \%$ bei jungen gesunden Erwachsenen. In einer weiteren Metaanalyse konnte eine $42 \%$ ige Reduktion des Risikos für eine gesicherte Pneumokokken-Pneumonie bei geimpften Personen $>55$ Jahre demonstriert werden [472]. Ebenso wurde eine Verminderung von invasiven Pneumokokkenerkrankungen durch resistente Erreger gezeigt [473]. Aktuelle Studien konnten auch für die Gesamtgruppe von Patienten mit hospitalisierter CAP nachweisen, dass eine vorausgegangene Pneumokokkenimpfung mit einer ca. 40\% niedrigeren Letalität sowie einer geringeren Komplikationsrate und einem kürzeren Krankenhausaufenthalt assoziiert ist [474-477].

Eine Studie demonstrierte darüber hinaus bei mit dem Pneumokokken-Polysaccharid-Impfstoff geimpften Personen (> 65 Jahre) auch eine Reduktion der Gesamtrate an Pneumonien [475].

Anders als bei der Influenzaimpfung ist der Effekt einer Revakzination kaum untersucht. Lokale, überwiegend milde Reaktionen sind bei Revakzinationen häufiger als bei Erstimpfungen, schwere unerwünschte Wirkungen sind unverändert selten. Es wird auf die Empfehlungen der STIKO verwiesen [464].

Die Arbeitsgruppe empfiehlt (Empfehlungsgrad A) (in Übereinstimmung mit der STIKO) [464] eine Pneumokokkenschutzimpfung für alle Personen mit einem erhöhten Risiko für eine Pneumokokkenerkrankung.

Risikofaktoren für eine Pneumokokkenerkrankung sind:

- Alter > 60 Jahre

Wohnsitz in einem Seniorenheim

chronische kardiale Erkrankung

chronische pulmonale Erkrankung

- chronische Lebererkrankungen

- chronische Nierenerkrankungen

chronische zerebrovaskuläre Erkrankungen, Demenzen

Diabetes mellitus

Personen mit angeborenem oder erworbenem Immundefekt

$\checkmark$ Liquorfistel

- Personen mit erhöhter Gefährdung durch erhöhte Exposition (z. B. medizinisches Personal)

Geimpft werden sollten darüber hinaus auch Personen vor Organtransplantation sowie elektiver Splenektomie. Die Impfung erfolgt vorzugsweise intramuskulär. Zeitabstände zu anderen Impfungen müssen nicht eingehalten werden.

Simultanimpfung Influenza/Pneumokokken: Die Simultanimpfung hat sich in einer großen Studie an 259627 Personen mit einem Alter über 65 Jahre in Stockholm County als sehr effektiv in der Verminderung der Hospitalisationsrate aufgrund einer Influenza-Infektion (46\% Reduktion), einer Pneumonie (29\% Reduktion), einer Pneumokokken-Pneumonie (36\% Reduktion) sowie einer invasiven bakteriämischen Pneumokokken-Infektion (52\% Reduktion) erwiesen. Ebenso konnte eine deutliche Reduktion der Letalität bei entsprechend geimpften Personen nachgewiesen werden (57\% Reduktion) [478].
Die Arbeitsgruppe empfiehlt (Empfehlungsgrad A) eine Influenza- und Pneumokokken-Impfung bei Risikopersonen.

\subsection{Sonstige präventive Maßnahmen}

Die Arbeitsgruppe empfiehlt (Empfehlungsgrad A):

Zigarettenrauchen ist als Risikofaktor bekannt [479]. Aufgabe des inhalativen Tabakkonsums sollte daher angestrebt werden.

Für andere präventive Maßnahmen wie z.B. Antibiotikaprophylaxe, Gabe von Bakterienextrakten zur Immunmodulation sowie Spurenelemente konnte bisher kein Wirkungsnachweis erbracht werden. Eine Empfehlung kann zum gegenwärtigen Zeitpunkt nicht gegeben werden.

\section{Pharmakoökonomische Bewertung der Evidenzlage zur CAP}

Siebzig Millionen Deutsche sind GKV-versichert. Der Umfang ihrer medizinischen Versorgung wird - im niedergelassenen und stationären Bereich - durch das fünfte Sozialgesetzbuch (SGB V) bestimmt. Hiernach müssen Leistungen „ausreichend, zweckmäßig und wirtschaftlich sein.“ (§12 SGB V). Eine Vielzahl von leistungsrechtlichen Regelungen, wie die für den niedergelassenen Arzt verbindlichen Arzneimittelrichtlinien des Gemeinsamen Bundesausschusses, regionale Arzneimittelvereinbarungen zwischen Krankenkassen und Kassenärztlichen Vereinigungen und Wirtschaftlichkeitsprüfungen, zielen auf eine Optimierung der Wirtschaftlichkeit der Versorgung ab. Lediglich die Regelung zur Entlassmedikation nach $\S 115 \mathrm{c}$ SGB V ist auch für den Krankenhausarzt gesetzlich verpflichtend.

Die genannten Regelungen fokussieren bis dato noch kaum auf Antiinfektiva. Die vorliegende Leitlinie zur CAP kann ein auf Wirtschaftlichkeit ausgerichtetes Management der Patienten unterstützen.

Eine irrationale Antibiotikatherapie kann Therapieversager und Resistenzen nach sich ziehen und damit hohe Folgekosten verursachen. Je günstiger die Therapieerfolge ausfallen, desto höher ist bei Behandlung der CAP der Nutzen für den Patienten und seine Lebensqualität, und desto geringer fallen grundsätzlich die Gesamtkosten der Therapie aus. Es ist daher sinnvoll, bei der Erarbeitung von klinischen Therapieempfehlungen auch pharmakoökonomische Studien heranzuziehen, in denen die Gesamtkosten der Therapie und Outcomes synoptisch analysiert werden, um auf dieser Grundlage kosteneffektive Therapien zu identifizieren.

Die aktuell vorhandene pharmakoökonomische Literatur kann die Erstellung einer Empfehlung nur bedingt unterstützen, da nur eine kleine Menge relevanter Therapieszenarien abgedeckt werden, kaum Head-to-Head-Vergleiche von in Deutschland konkurrierenden Therapien vorliegen, die Therapiebedingungen nicht auf deutsche Verhältnisse bzw. den Therapiealltag übertragbar sind, die untersuchten Patientengruppen keine validen Schlussfolgerungen für die Praxis zulassen oder die gewählte Methodik intransparent oder im Sinne des Auftraggebers der Studie ausgerichtet ist.

Im Folgenden werden daher einige grundsätzliche, für eine kosteneffektive Therapie aus der Literatur abgeleitete Erwägungen dargestellt. 
Die Bewertung der Kosteneffektivität kann je nach Perspektive erheblich variieren. Für den niedergelassenen Arzt stehen Regressgefahr und damit die reinen Präparatekosten im Vordergrund. Die Verlagerung von Therapien ins Krankenhaus kann sein Richtgrößenvolumen gegebenenfalls entlasten und die „Wirtschaftlichkeit“ seiner Arzneimitteltherapie nach der Auslegung des Gesetzes optimieren. Der Krankenhausapotheker hat gegenüber der Krankenhausleitung die Höhe des Arzneimittelbudgets zu verantworten und muss daher primär an einer Reduktion der Einkaufspreise und verabreichten Arzneimittelmengen interessiert sein. Die Krankenhausleitung strebt ein optimales Kosten-Vergütungsverhältnis an. Dieses kann im DRG-System auf verschiedenen Wegen realisiert werden. Der Krankenhausarzt unterstützt die Bemühungen der Krankenhausleitung um ein optimales Kosten-Vergütungsverhältnis und trägt vielfach die Mitverantwortung für die stationsbezogenen Antibiotikakosten. Die Krankenkassen sind an einer geringen Zahl von Krankenhauseinweisungen und einer kurzen Krankenhausverweildauer interessiert.

Vor diesem Hintergrund ergeben sich verschiedene Ansatzpunkte zur Optimierung der Wirtschaftlichkeit.

Eine grundlegende Beeinflussung der Therapiekosten ist durch eine rationale Entscheidung über die Notwendigkeit einer Krankenhauseinweisung möglich [480]. Außerdem ist die Länge des Krankenhausaufenthaltes kostenbestimmend. In praxi treten hierbei zwischen verschiedenen Regimen jedoch kaum Unterschiede auf bzw. sie sind nicht signifikant, wurden nicht auf Signifikanz getestet oder die Signifikanztestungen wurden nicht publiziert. Aufenthalte auf Intensivstation können die Kosten eines Krankenhausaufenthaltes weiter in die Höhe treiben [481]. Der Verzicht auf eine weitere Hospitalisierung von Niedrigrisikopatienten nach Umstellung von intravenöser auf perorale Therapie ist nach den Ergebnissen vieler Studien kostensparend [337,482]. Die meisten Untersuchungen dieser Art stammen jedoch aus den USA, wo die Nachsorge der Patienten teils anders gestaltet ist und die Ergebnisse somit nicht automatisch auf Deutschland übertragen werden können. Unabhängig davon können jedoch kostenintensive Komplikationen wie eine Venenkathetersepsis durch eine frühzeitige Entlassung vermieden werden.

In vielen Studien - leider meist nur mäßiger Qualität - konnte gezeigt werden, dass die Einhaltung von Leitlinien, oft in Verbindung mit der Einrichtung eines infektiologischen Beratungsangebots, die Antibiotika- und Applikationskosten bei gleichbleibender Therapiequalität senkt und $\mathrm{zu}$ einer Prozessoptimierung führt [483-489]. Es gibt jedoch Patientengruppen, bei denen die Einhaltung von Leitlinien die Arzneimittelkosten erhöht $[3,483,490]$, oder sie nicht beeinflusst [491]. Die Umstellung der CAP-Therapie auf britische oder amerikanische Leitlinien kann die Menge und Kosten der verordneten Antibiotika erhöhen [492].

Hilfreich bei der Kostenkontrolle ist auch die Einrichtung und Einhaltung von standardisierten Entscheidungswegen bzw. klinischen Behandlungspfaden („clinical pathways“). Sie können die Krankenhausverweildauer und Antibiotikatherapie verkürzen und die Anzahl verabreichter Antibiotika verringern [19].

Zahlreiche Studien konnten zeigen, dass eine Sequenztherapie zu früheren Entlassungen führt [324,339,493]. Dies gilt auch für schwere Verlaufsformen der CAP [333]. In den meisten Studien wurde jedoch nicht überprüft, ob und wie der Patient nach Entlassung therapiert wird. Einzelne Studien deuten auf eine verlängerte Nachbehandlung hin, wenn die Krankenhausverweildauer kürzer ist [494]. Somit werden die Kosten im ambulanten Bereich erhöht und parallel hierzu die Kosten der Behandlung im Krankenhaus gesenkt [495]. Eine Monotherapie kann unter der Voraussetzung eines gleichen Outcomes zu niedrigeren Kosten und einer verkürzten Krankenhausverweildauer führen und sollte bei leichteren Verläufen der CAP im ambulanten Bereich empfohlen werden [496,497].

Der Einsatz von Procalcitonin führt zwar zu einer Reduktion der Antibiotikatherapie, erhöht jedoch signifikant die Gesamttherapiekosten [291].

Wo möglich, sollte auch eine Fokussierung auf wenige (in Leitlinien empfohlene) Präparate stattfinden. Sie verbessert im Krankenhaus die Einkaufskonditionen und senkt damit die Arzneimittelkosten. Im niedergelassenen Bereich erleichtert die Einrichtung einer „Hausapotheke“ in der Praxissoftware auf der Basis von Leitlinienempfehlungen und der Arzneimittelrichtlinien des Gemeinsamen Bundesausschusses den Überblick über die verfügbaren, preiswertesten Präparate und hilft, Regresse zu vermeiden.

Dabei lohnt sich ein Preisvergleich zwischen wirkstoffgleichen Präparaten. Ein vermehrter Einsatz von Generika hilft damit insbesondere dem niedergelassenen Arzt, ohne Qualitätseinbußen die Therapiekosten zu senken [498]. Wählt er selbst eines der preiswertesten Präparate aus, verhindert er außerdem, dass der Apotheker gemäß seiner gesetzlichen Pflicht das verschriebene Präparat substituiert und damit möglicherweise die Compliance beeinträchtigt wird.

Aus verschiedenen Indikationsbereichen existieren Hinweise auf die kostenreduzierende Wirkung einer guten Patientencompliance. Die korrekte Einnahme von Antibiotika scheint Rückfällen und Resistenzbildung vorzubeugen [499-506]. Eine Reduktion der Therapiedauer kann bei gleichem Therapieerfolg die Kosten senken [505]. Das Gleiche gilt für den bevorzugten Einsatz von Antibiotika, bei denen eine niedrige Verabreichungsfrequenz erforderlich ist.

Wo immer möglich, sollte auf die kostenintensive intravenöse Gabe von Antibiotika zugunsten einer peroralen Gabe verzichtet werden [506,507]. Von Interesse ist auch die nähere Betrachtung der finanziellen Verantwortung und des Sozialstatus des Patienten. Die erhöhte finanzielle Verantwortung, z.B. im Rahmen von HMO-Modellen, veranlasst Ärzte nicht zwangsläufig, einen übermäßigen Gebrauch von Antibiotika - auch bei viralen Atemwegsinfektionen - zu reduzieren [508]. Ein niedriger Sozialstatus führt zu höheren Krankenhauskosten [509]. Selbst bei gleichem Schweregrad und gleichen Outcomes findet man eine längere Krankenhausverweildauer bei sozial schwachen Patienten, da sich hierbei die Nachbehandlung schwierig gestaltet.

\section{CAP als terminales Ereignis bei hohem Lebensalter und/oder schwerer fortgeschrittener Komorbidität}

$\nabla$

Die Auswertung von Daten aus der bundesweiten externen Qualitätssicherung durch die Bundesgeschäftsstelle für Qualitätssicherung (BQS) hat ergeben, dass 2005 und 2006 lediglich ca. $15 \%$ der an CAP verstorbenen Patienten im Verlauf ihrer stationären Behandlung eine (nicht-invasive oder invasive) Beatmung erhalten haben. Dies lässt darauf schließen, dass bei einem erheblichen Anteil an Patienten mit CAP die Pneumonie als terminales Ereignis bei sehr hohem Lebensalter und/oder einer schweren Erkrankung gewertet und eine entsprechende Therapielimitation praktiziert wird. 
Offenkundig gelten die Regeln der Behandlung einer CAP, wie in dieser Leitlinie ausgeführt, für diese Patientengruppe nur eingeschränkt. Andererseits fehlt es an Empfehlungen, wie eine solche Therapielimitation begründet, durchgeführt und dokumentiert werden sollte. Zweifellos ist der Umgang mit Therapielimitationen noch durch inhaltlich-medizinische und rechtliche Unsicherheiten belastet. Andererseits kann man vor der Forderung nicht die Augen verschließen, dass in einer hochentwickelten Gesellschaft mit hoher Lebenserwartung auch Regeln für die Zulassung des natürlichen Todes im Rahmen einer akuten Komplikation am Lebensende geschaffen werden müssen. Die besondere Herausforderung im Zusammenhang mit der CAP besteht darin, dass es sich um eine akute Erkrankung handelt, die naturgemäß jede Entscheidungsfindung von dieser Tragweite vor besondere Probleme stellt. Hier steht die Medizin erst am Anfang einer Entwicklung, sodass hier nur Anstöße für die Gestaltung und Weiterentwicklung der eigenen Praxis auf diesem Gebiet gegeben werden können [510].

Im deutschen Sprachraum wird eine angesichts einer infausten Prognose nicht mehr auf die Erhaltung des Lebens, sondern auf die Zulassung und lindernde Begleitung des natürlichen Todes aufgrund einer unheilbaren Erkrankung abzielende Behandlung auch „palliative“ (im Gegensatz zu „kurative“) Behandlung genannt. Eine palliative Behandlung umfasst dabei alle Maßnahmen, die zu einer Linderung der Beschwerden eines Patienten beitragen, also durchaus auch möglicherweise die Gabe von antimikrobiellen Substanzen.

(Dieser Sprachgebrauch unterscheidet sich vom angelsächsischen Gebrauch, der von „palliativer“ Behandlung nur spricht, wenn keine differente Therapie mehr zur Anwendung kommt. Dies gilt es im Interesse einer Vermeidung von Mißverständnissen in der internationalen Diskussion zu berücksichtigen).

Eine Änderung des Therapiezieles im Sinne eines palliativen Behandlungskonzeptes kann auf vielen Ebenen, zum Beispiel durch Verzicht oder durch Initiierung bestimmter medizinischer und pflegerischer Maßnahmen, erfolgen. Beispiele dafür umfassen:

\section{A. Verzicht auf:}

- initiales Monitoring bei hohem Schweregrad

- umfassende Reevaluation nach Therapieversagen

- Umstellung auf zweite antimikrobielle Therapie

- Aufnahme Intermediate Care Station

- Aufnahme Intensivstation

- invasive Beatmung

nicht-invasive Beatmung

- Therapie eines MODS

- Reanimation

Die Leitliniengruppe hält aktuell folgende Regeln für die palliative Behandlung für angemessen:

1. Initiale Identifizierung der Patienten, bei denen eine palliative Behandlung als ärztlich und medizinisch sinnvoll betrachtet wird.

a) Gerade wenn an eine palliative Behandlung bereits bei Aufnahme gedacht ist, erscheint eine gewissenhafte klinische und apparative Dokumentation des Zustands des Patienten bei Aufnahme zwingend erforderlich. Selbstverständlich kann und muss sich der behandelnde Arzt dabei auf das notwendige Minimum beschränken, ohne den Patienten unnötig zu belasten. Als Basis für eine informierte Entscheidungsfindung sind zu fordern: die Diagnosestellung einer CAP sowie die Erhebung des Schweregrads nach CRB-65. Ebenso sollte der funktionale Status des Patienten erhoben werden (optimal anhand objektiver Scores, z. B. ADI und/oder Barthel).

b) Entsprechend geltender Rechtsprechung ist für alle Behandlungsentscheidungen der Wille des Patienten entscheidend. Dieser muss daher zwingend eingeholt werden. Bei fehlender Urteilsfähigkeit des Patienten ist die Aussage des von diesem Bevollmächtigten bzw. des gesetzlichen Betreuers über den Willen des Patienten einzuholen. In einigen Fällen (bei besonderem Zeitdruck) kann es erforderlich sein, den mutmaßlichen Willen des Patienten zu erkunden. Dabei ist eine Berücksichtigung der bekannten Lebensanschauungen eines Patienten, insbesondere seiner religiösen, spirituellen und ideellen Überzeugungen, und die Bemühung um Kenntnisnahme der jeweiligen Sichtweisen auf den Umgang mit dem Lebensende geboten [511]. Hier ist die Kommunikation mit den nächsten Angehörigen und engen Freunden von besonderer Bedeutung.

c) Die Entscheidung zu einer palliativen Behandlung im Einklang mit dem Willen des Patienten bzw. seines Bevollmächtigten bzw. gesetzlichen Betreuers sollte in der Patientenakte dokumentiert sein. Es wird empfohlen, diese Dokumentation durch mindestens zwei Fachärzte als Beleg für eine medizinisch gut begründete und ethisch konsensuell getragene Entscheidung abzuzeichnen.

2. Identifizierung des Patienten, der eine palliative Behandlung erfahren soll, im Verlauf.

a) In nicht wenigen Fällen wird eine palliative Behandlung erst im Verlauf erwogen. In diesen Fällen kommt einer Zwischendokumentation hohe Bedeutung zu, die den Zustand des Patienten zu diesem kritischen Zeitpunkt wiedergibt.

b) In Zweifelsfällen wird nachdrücklich empfohlen, ethische Konsile einzuberufen und in diesem Rahmen eine Klärung herbeizuführen. Im Rahmen dieser Konsile sollten auch die Aspekte der Langzeitprognose und der Lebensqualität, mithin des Wohlergehens des Patienten wichtige Maßstäbe für die zu treffende Entscheidung sein.

c) Als letzte Möglichkeit kommt die Erwirkung einer richterlichen Entscheidung in Betracht. Eine richterliche Entscheidung ist dabei nur in den seltenen Fällen erforderlich, wenn zwischen dem in einer Patientenverfügung niedergelegten, aber auf die aktuelle Situation nicht unbedingt zutreffenden Patientenwillen oder dem von Angehörigen mitgeteilten Willen des Patienten einerseits und der Auffassung des behandelnden Arztes andererseits ein klarer Dissens besteht.

Selbstverständlich impliziert eine palliative Behandlung eine optimale medizinische und pflegerische Versorgung. Dies gilt umso mehr, als einige Patienten auch im Falle einer palliativen Behandlung die akute Komplikation CAP dennoch überleben werden.

B. Für eine angemessene palliative medizinische und pflegerische Versorgung des Patienten ist neben der Berücksichtigung der psychologischen, spirituellen und sozialen Dimension des Leidens im Bereich der physischen Beschwerden eine optimale Symptomenkontrolle wesentlich. Als häufigste Symptome sind hier Dyspnoe, Fieber, Husten, Schwäche, Schmerzen und neuropsychiatrische Beschwerden mit Verwirrtheit, Agitation und Unruhe zu nennen. Im Einzelnen dienen folgende therapeutische Optionen zur Linderung von belastenden Beschwerden und zur Verbesserung der Lebensqualität. 
Dyspnoe: Als nicht-pharmakologische Maßnahmen zur Behandlung der Luftnot sind hier zunächst die Zufuhr von frischer Luft, der Einsatz von (Mini-)Ventilatoren und nicht zuletzt die persönliche Zuwendung als gut validiert zu nennen [512]. Darüber hinaus sind atemtherapeutische Übungen hilfreich. Die Sauerstoffgabe sollte den hypoxischen Patienten vorbehalten bleiben, als generelle Maßnahme unabhängig von der Blutgasanalyse ist sie nicht indiziert [513]. Bei anhaltender Luftnot sollten darüber hinaus pharmakologische Maßnahmen zum Einsatz kommen. Opioide dienen zum Ökonomisieren der Atemarbeit und haben eine anxiolytische Wirkung [514]. Sie werden in einer Dosierung von 5-10 mg Morphin p.o. bzw. 2,5 - 5 mg Morphin s.c. bei opioidnaiven Patienten verabreicht. Bei mit Opioiden vorbehandelten Patienten sollte bei einer Dyspnoeattacke ein kurzwirksames Opioid in ca. $1 / 6$ der bestehenden Tagesdosis verabreicht werden. Bei anhaltenden Beschwerden sind darüber hinaus Benzodiazepine wie Lorazepam oder Midazolam zur Anxiolyse indiziert. Im Einzelfall kann bei entsprechender Komorbidität wie einer COPD oder einer Lymphangiosis carcinomatosa die Steroidgabe sinnvoll sein. In bestimmten, individuell zu bestimmenden Situationen kann auch eine nicht-invasive Beatmung zur Vermeidung einer orotrachealen Intubation bzw. Tracheostomie am Lebensende bei schwerer Luftnot als palliatives Verfahren durchgeführt werden [515].

Fieber: Fieber kann ein subjektiv und objektiv belastendes Symptom bei Palliativpatienten sein und mit Schüttelfrost, Schweißausbruch, allgemeiner Schwäche und Verwirrtheit einhergehen. Als Basismaßnahmen einer symptomatischen Behandlung des Fiebers dienen Flüssigkeitszufuhr und pflegerisch-physikalische Maßnahmen (z.B. Kühlung der Leisten, Unterarme und Unterschenkel sowie Waschungen mit Salbeitee). Als pharmakologische Maßnahmen sind nicht-steroidale Antiphlogistika, Metamizol, Paracetamol und Steroide zur Coupierung von febrilen $\mathrm{Zu}$ ständen zu nennen. Das Neuroleptikum Chlorpromazin kann Fieber auf direkte Weise senken.

Husten: Trockener Husten, nächtlicher produktiver Husten, der den Schlaf stört, und produktiver Husten bei Patienten, die zu schwach zum Abhusten sind, wird von Patienten mit fortgeschrittenen unheilbaren Erkrankungen als unangenehm empfunden. Als symptomatische Therapie des trockenen Hustens dienen reizlindernde Arzneimittel (z.B. pflanzlicher Hustensaft aus Thymian oder Efeublätter-Extrakten) bzw. bei anhaltenden Beschwerden Opioide wie Codein als Antitussiva. Bei produktivem Husten kann die Unterstützung des Abhustens, z.B. durch Physiotherapie oder mittels NaCl-Verneblung, hilfreich sein. Schließlich kommen Expectoranzien wie ätherische Öle (z. B. Eukalyptusöl), Mucolytika und ebenfalls Antitussiva (Codein) zur Anwendung.

Schwäche: Über die mit interkurrenten Erkrankungen wie einer CAP einhergehende Schwäche leiden Palliativpatienten häufig an Fatigue im Sinne eines subjektiven Gefühls unüblicher Müdigkeit, das sich auf Körper, Gefühle und mentale Funktion auswirkt. Eine infektbedingte Schwäche wird in der Regel ohne kausale Therapie der Inflammation therapeutisch kaum beeinflussbar sein. Hilfreich kann es dennoch sein, das Leiden wahrzunehmen und den Patienten dabei zu unterstützen, mit dem vorhandenen Energiekonto günstiger umzugehen, in dem das richtige Maß an Ruhe und Bewegung gefunden wird [516].
Schmerzen: Bezüglich der Schmerztherapie bei Palliativpatienten mit ambulant erworbenen Pneumonien sei an dieser Stelle auf das WHO-Stufenschema zur Behandlung von Tumorschmerzen, welches inzwischen auch für andere Schmerzarten anerkannt ist, verwiesen $[517,518]$. Wichtige Voraussetzung für eine erfolgreiche Schmerztherapie ist ein regelmäßiges Assessment von Schmerz mit den gängigen Messmethoden (z.B. NRS oder VAS bzw. bei in der Kommunikation eingeschränkten Patienten die DoloPlus-Skala; $\$$ Tab. 19) [519].

Tab. 19 Doloplus-Skala (Die Doloplus-Skala ist ein Instrument zur Beurteilung von Schmerzen bei Älteren) [521].

Somatische Parameter
- verbaler Schmerzausdruck
- Schonhaltung in Ruhe
- Schutz von schmerzhaften Körperzonen
Psychomotorische Parameter
- Mimik
- Schlaf
- Waschen und Ankleiden
- Bewegungen/Mobilität
Psychosoziale Parameter
- Kommunikation (verbal/nonverbal)
- soziale Aktivitäten
- Verhaltensstörungen
Jeder Parameter kann mit 0 bis 3 Punkten bewertet werden. Insgesamt kön-
nen maximal 30 Punkte erreicht werden. Ab $\geq 5$ Punkten ist von Schmerzen
auszugehen.

Neuropsychiatrische Symptome - Verwirrung, Agitation und Unruhe: Die Betreuung verwirrter, agitierter und unruhiger Patienten stellt hohe Anforderungen an das multiprofessionelle Team dar. Hier ist ein hoher personeller Beistand erforderlich, um dem Patienten und seinen Angehörigen das Gefühl der Sicherheit wieder zu vermitteln. Häufig sind neuropsychiatrische Symptome Ausdruck anderer Beschwerden wie Luftnot, Schmerz oder Angst. Hier gilt es im intensiven Kontakt mit dem Palliativpatienten nach Ursachen zu suchen. Zur symptomatischen Therapie stehen in erster Linie Neuroleptika zur Verfügung. Wobei den niedrigen bis mäßig potenten Neuroleptika (z.B. Melperon) oder auch den neueren atypischen Neuroleptika (z.B. Risperidon) der Vorzug zu geben ist, wenn Unruhe und Verwirrtheit im Vordergrund stehen. Prägen hingegen Wahnbildung und halluzinatorisches Erleben die Symptomatik, sind höher potente Neuroleptika, insbesondere Haloperidol anzuwenden.

Palliativmedizin zeichnet sich durch eine bedürfnisorientierte Behandlung schwerstkranker und sterbender Patienten aus, wobei keine evidenzbasierten Kriterien existieren, diese Phase des Lebens hinreichend genau zu definieren. Als mögliche Unterstützung in der Entscheidungsfindung könnte hier die Anwendung des „Liverpool Care Pathways“ (= LCP) dienen [520] (weitere Informationen unter www.mcpcil.org.uk bzw. lcp.enquiries@rlbuht.nhs.uk). Als multiprofessioneller Qualitätsstandard ist der LCP ein gemeinsames Dokumentationssystem, welches den Weg vom gemeinsamen Diagnostizieren der Sterbephase, dem Assessment der vordringlichen Probleme bis zum gemeinsamen koordinierten Vorgehen in der Sterbephase bestimmt, wobei Empathie, Intuition und individuelle Entscheidungsfindung für das Behandlungsteam im Vordergrund stehen sollten. 


\section{Anhang}

7

\subsection{Autoren der Leitlinie}

Herr Prof. Dr. med. G. Höffken (federführend),

Sprecher für die Paul-Ehrlich-Gesellschaft

für Chemotherapie e.V.

Universitätsklinikum Carl Gustav Carus Dresden,

Medizinische Klinik I

Fetscherstr. 74

01307 Dresden

Fachkrankenhaus Coswig, Neuscoswiger Str. 21, 01640 Coswig

Tel. 0351/458 3417

Fax 0351/458 5765

E-Mail: gert.hoeffken@uniklinikum-dresden.de

Herr Prof. Dr. med. J. Lorenz,

Sprecher für die Deutsche Gesellschaft für Pneumologie

und Beatmungsmedizin e.V.

Kreiskrankenhaus Lüdenscheid, Abt. Innere II

Paulmannshöher Straße 14

58515 Lüdenscheid

Tel. 02351/46-3360

Fax 02351/46-3366

E-Mail: Innere2@kkh-luedenscheid.de

Herr Prof. Dr. med. W. Kern,

Sprecher für die Deutsche Gesellschaft für Infektiologie e.V.

Medizinische Uniklinik Freiburg

Infektiologie Abt. Innere Medizin II

Hugstetter Straße 55

79106 Freiburg

Tel. 0761/2701819

Fax 0761/2701820

E-Mail: kern@medizin.ukl.uni-freiburg.de

Herr Prof. Dr. med. T. Welte,

Sprecher für das Kompetenz-Netzwerk CAPNETZ

Deutschland e.V.

Medizinische Hochschule Hannover

Zentrum Innere Medizin - Abt. Pneumologie

Carl Neuberg-Str. 1

30625 Hannover

Tel. 0511/532-3530 oder $0511 / 532-3531$

Fax 0511/532-3353

E-Mail: welte.tobias@mh-hannover.de

Herr Prof. Dr. med. T. Bauer

Helios Klinikum Emil-von-Behring

Lungenklinik Heckeshorn, Berlin

Herr Prof. Dr. med. K. Dalhoff

Medizinische Klinik III

Universitätsklinik Lübeck

Frau Dr. rer. nat. E. Dietrich

HealthEcon Ltd. Basel, Schweiz

Herr Prof. Dr. med. S. Ewig

Thoraxzentrum Ruhrgebiet, Kliniken für Pneumologie und Infektiologie

Ev. Krankenhaus Herne und Augusta-Kranken-Anstalt, Bochum
Frau Prof. Dr. med. P. Gastmeier

Institut für Hygiene und Umweltmedizin,

Campus Benjamin Franklin

Charité Universitätsmedizin Berlin

Frau Dr. med. B. Grabein

Max von Pettenkofer-Institut für Hygiene

und Med. Mikrobiologie

Außenstelle Großhadern, München

Frau PD Dr. med. E. Halle

Institut für Mikrobiologie und Hygiene

Charité Universitätsmedizin, Berlin

Herr Dr. med. M. Kolditz (Sekretär)

Medizinische Klinik und Poliklinik I, Bereich Pneumologie

Universitätsklinikum Carl Gustav Carus, Dresden

Herr Prof. Dr. med. R. Marre

Klinikumsvorstand, Leitender Ärztlicher Direktor

Universitätsklinikum Ulm

Herr PD Dr. med. H. Sitter

Institut für Theoretische Chirurgie

Klinikum Lahnberge-Philipps-Universität, Marburg

21.2. Zur Konsensuskonferenz am 9. 12. 2008 eingeladene und vertretene* Fachgesellschaften und Einrichtungen

- Berufsverband der Pneumologen e.V., BDP Dachverband der Landesverbände der Pneumologen Deutschlands/

Heidenheim $^{* 1}$,

- Deutsche Atemwegsliga e.V./Bad Lippspringe*1,

- Deutsche Gesellschaft für Allgemeinmedizin und Familienmedizin (DEGAM) e.V./Düsseldorf*1,

- Deutsche Gesellschaft für Anästhesiologie und Intensivmedizin (DGAI) e.V./Nürnberg*

- Deutsche Gesellschaft für Hygiene und Mikrobiologie DGHM e.V./Würzburg*,

- Deutsche Gesellschaft für Innere Medizin (DGIM) e.V./Wiesbaden

- Deutsche Gesellschaft für Internistische Intensivmedizin und Notfallmedizin (DGIIN) e.V./Leipzig*1,

- Deutsche Interdisziplinäre Vereinigung für Intensiv- + Notfallmedizin (DIVI) e.V./München ${ }^{1}$

- Deutsche Sepsis-Gesellschaft (DSG) e.V./Jena*1

- Gesellschaft für Virologie (GfV) e.V./Erlangen ${ }^{1}$

- Patientenliga Atemwegserkrankungen/Dienheim*1

\subsection{Teilnehmer der Konsensuskonferenz}

\section{stimmberechtigte Teilnehmer:}

- Herr Dr. med. A. Altiner, Düsseldorf, für die Deutsche Gesellschaft für Allgemeinmedizin und Familienmedizin (DEGAM)

- Herr Prof. Dr. med. T. Bauer, Berlin, für die Leitlinien-Arbeitsgruppe

- Herr Prof. Dr. med. H.-R. Brodt, Frankfurt, für die Paul-EhrlichGesellschaft für Chemotherapie

\footnotetext{
${ }^{1}$ Autorisierung der aktualisierten Leitlinie durch den Vorstand der Fachgesellschaft.
} 
- Herr Prof. Dr. med. K. Dalhoff, Lübeck, für die LeitlinienArbeitsgruppe

- Frau Dr. med. M. Deja, Berlin, für die Deutsche Gesellschaft für Anästhesiologie und Intensivmedizin (DGAI)

- Frau Dr. rer. nat. E. Dietrich, Hamburg, für die Leitlinien-Arbeitsgruppe

- Herr Prof. Dr. med. S. Ewig, Bochum, für die Leitlinien-Arbeitsgruppe

- Frau Prof. Dr. med. P. Gastmeier, Berlin, für die Leitlinien-Arbeitsgruppe

- Frau Dr. med. B. Grabein, München, für die Leitlinien-Arbeitsgruppe

- Frau PD Dr. med. E. Halle, Berlin, für die Leitlinien-Arbeitsgruppe

- Herr Prof. Dr. med. G. Höffken, Dresden, für die Leitlinien-Arbeitsgruppe

- Herr Prof. Dr. med. W. Kern, Freiburg i. Br., für die Leitlinien-Arbeitsgruppe

- Herr Dr. med. M. Köhler, Gau-Algesheim, für die Patientenliga Atemwegserkrankungen

- Herr Dr. med. M. Kolditz, Dresden, für die Leitlinien-Arbeitsgruppe

- Herr Prof. Dr. med. J. Lorenz, Lüdenscheid, für die Leitlinien-Arbeitsgruppe

- Herr PD Dr. med. K. Mayer, Gießen, für die Deutsche Sepsis-Gesellschaft (DSG)

- Herr Prof. Dr. med. E. Straube, Jena, für die Deutsche Gesellschaft für Hygiene und Mikrobiologie (DGHM)

- Herr Dr. med. M. Weber, Starnberg, für den Berufsverband der Pneumologen (BDP)

- Herr Prof. Dr. med. T. Welte, Hannover, für die Leitlinien-Arbeitsgruppe und die Deutsche Gesellschaft für Internistische Intensivmedizin und Notfallmedizin (DGIIN)

- Herr Prof. Dr. med. H. Worth, Fürth, für die Deutsche Atemwegsliga

\section{Moderation der Konferenz:}

Herr PD Dr. med. H. Sitter, Marburg, für die Arbeitsgemeinschaft für Medizinische Wissenschaftliche Fachgesellschaften AWMF

\section{Protokollführer:}

Herr Dr. med. M. Kolditz, Dresden,

für die Leitlinien-Arbeitsgruppe (Sekretär)

\subsection{Erklärung über mögliche Interessenkonflikte}

Das Steering-Komitee hat von jedem Autor ein ausgefülltes Formular „Erklärung über mögliche Interessenskonflikte“ erhalten, in dem alle Beziehungen zu Einrichtungen der pharmazeutischen Industrie und zu Medizinprodukteherstellern anzugeben waren. Die Angaben wurden durch das Steering-Komitee bewertet, dabei wurden keine Interessenskonflikte festgestellt, die die fachliche Unabhängigkeit der Autoren im Hinblick auf die Erstellung der Leitlinie beeinträchtigen könnten.

\subsection{Abkürzungsverzeichnis \\ AECOPD Akute Exazerbation einer chronischen obstruktiven Bronchitis \\ ATS American Thoracic Society \\ ATS-Score Score zur Identifizierung einer schweren CAP, S. $\odot$ Tab. 14 \\ AWMF Arbeitsgemeinschaft Wissenschaftlicher Medizinischer Fachgesellschaften \\ BAL Bronchoalveoläre Lavage \\ BQS Bundesgeschäftsstelle für Qualitätssicherung \\ CAP Ambulant erworbene Pneumonie \\ (engl. „community-acquired pneumonia“) \\ aCAP ambulant erworbene Pneumonie, die nach Risiko- stratifizierung ambulant behandelt werden kann (ambulante CAP) \\ sCAP ambulant erworbene Pneumonie, die nach Risiko- stratifizierung unter intensivierter Überwachung behandelt werden soll (schwere CAP) \\ CDC Centers for Disease Control, Atlanta, USA \\ CLSI Clinical and Laboratory Standards Instiute \\ c-MRSA ambulant erworbener Methicillin-resistenter Staphylococcus aureus \\ (engl. „community-acquired MRSA“) \\ COPD Chronische obstruktive Lungenerkrankung (engl. „chronic obstructive pulmonary disease“) \\ CRB-65 Score zur Risikostratifizierung der CAP in der Arzt- praxis (die Akronyme stehen für confusion, respiratory rate, blood pressure, Alter $\geq 65$ Jahre), s. Tab. 12 \\ CURB Score zur Risikostratifizierung der CAP in der Notaufnahme (die Akronyme stehen für confusion, Urea-N [Harnstoff-N], respiratory rate, blood pressure), s. $\odot$ Tab. 12 \\ CT Computertomografie \\ DIF Direkter Immunfluoreszenztest \\ EIA Enzym-Immuno-Assay \\ ESBL engl. „extended spectrum $\beta$-lactamases“ \\ FEV1 forciertes Expirationsvolumen in 1 Sekunde GKV gesetzliche Krankenversicherung}

HMO-Modell engl. für „Health Maintenance Organisation“: Organisationen, bei denen Versicherte durch Einschreibung ein definiertes Leistungspaket zur medizinischen Versorgung mit Basis- und ergänzenden Behandlungsangeboten sowie Versicherungsschutz erhalten

ICT Immunchromatografischer Schnelltest

IDSA Infectious Diseases Society of America

ITS Intensivstation

MHK Minimale Hemmkonzentration

MRSA Methicillin-(Oxacillin-)resistenter Staphylococcus aureus

NAT Nukleinsäure-Amplifikations-Technik

PCR Polymerase-Kettenreaktion (engl. „polymerase chain reaction“)

PSI engl. „pneumonia severity index“

SARS Schweres akutes respiratorisches Syndrom (engl. „severe acute respiratory syndrome“) 
Die nach der Literaturstelle in Klammern gesetzte Ziffer mit Buchstaben bezieht sich auf die Evidenzbewertung nach Oxford Centre of Evidence Based Medicine (1999).

\section{Literaturverzeichnis}

1 Capelastegui A, Espana PP, Quintana JM et al. Improvement of processof-care and outcomes after implementing a guideline for the management of community-acquired pneumonia: a controlled beforeand-after design study. Clin Infect Dis 2004; 39: 955 - 963 (2b)

2 Dean NC, Silver MP, Bateman KA et al. Decreased mortality after implementation of a treatment guideline for community-acquired pneumonia. Am J Med 2001; 110: 451 - 457 (2b)

3 Gleason PP, Kapoor WN, Stone RA et al. Medical outcomes and antimicrobial costs with the use of the American Thoracic Society guidelines for outpatients with community-acquired pneumonia. JAMA 1997; 278: $32-39(2 \mathrm{c})$

4 Al Eidan FA, McElnay JC, Scott MG et al. Use of a treatment protocol in the management of community-acquired lower respiratory tract infection. J Antimicrob Chemother 2000; 45: 387 - 394 (2b)

5 Brown RB, Iannini P, Gross P, Kunkel M. Impact of initial antibiotic choice on clinical outcomes in community-acquired pneumonia: analysis of a hospital claims-made database. Chest 2003; 123: 1503 $1511(2 \mathrm{~b})$

6 Lorenz W, Ollenschläger G. Das Leitlinien-Manual. Z Arztl Fortbild Qualitatssich 2001; 95: 1-84 (5)

7 American Thoracic Society. Hospital-acquired pneumonia in adults: Diagnosis, assessment, initial therapy, and prevention: A consensus statement. Am J Respir Crit Care Med 1996; 153: 1711 - 1725 (5)

8 American Thoracic Society. Guidelines for the Management of Adults with Hospital-acquired, Ventilator-associated, and Healthcare-associated Pneumonia. Am J Respir Crit Care Med 2005; 171: 388 - 416 (5)

9 Tablan OC, Anderson LJ, Besser $R$ et al. Guidelines for preventing health-care-associated pneumonia, 2003: recommendations of CDC and the Healthcare Infection Control Practices Advisory Committee. MMWR Recomm Rep 2004; 53: 1 - 36 (5)

10 Toubes E, Singh K, Yin D et al. Risk factors for antibiotic-resistant infection and treatment outcomes among hospitalized patients transferred from long-term care facilities: does antimicrobial choice make a difference? Clin Infect Dis 2003; 36: 724-730 (2c)

11 Kollef MH, Shorr A, Tabak YP et al. Epidemiology and outcomes of health-care-associated pneumonia: results from a large US database of culture-positive pneumonia. Chest 2005; 128: $3854-3862$ (2c)

12 Carratala J, Mykietiuk A, Fernandez-Sabe $N$ et al. Health care-associated pneumonia requiring hospital admission: epidemiology, antibiotic therapy, and clinical outcomes. Arch Intern Med 2007; 167: 1393 1399 (2b)

13 El Solh AA, Pietrantoni C, Bhat A et al. Indicators of potentially drugresistant bacteria in severe nursing home-acquired pneumonia. Clin Infect Dis 2004; 39: 474-480 (2b)

14 Loeb M, Carusone SC, Goeree R et al. Effect of a Clinical Pathway to Reduce Hospitalizations in Nursing Home Residents With Pneumonia: A Randomized Controlled Trial. JAMA: The Journal of the American Medical Association 2006; 295: 2503 - 2510 (1b)

15 Worth G, Buhl R, Cegla U et al. Leitlinie der Deutschen Atemwegsliga und der Deutschen Gesellschaft für Pneumologie zur Diagnostik und Therapie von Patienten mit chronisch obstruktiver Bronchitis und Lungenemphysem (COPD). Pneumologie 2002; 56: 704 - 738 (4)

16 Vogelmeier C, Buhl R, Criee CP et al. Leitlinie der Deutschen Atemwegsliga und der Deutschen Gesellschaft für Pneumologie und Beatmungsmedizin zur Diagnostik und Therapie von Patienten mit chronisch obstruktiver Bronchitis und Lungenemphysem (COPD). Pneumologie 2007; 61: e1 - e40 (5)

17 Dalhoff K, Ewig S, Höffken $G$ et al. Empfehlungen zur Diagnostik, Therapie und Prävention von Pneumonien bei erworbenem Immundefizit. Pneumologie 2003; 56: 807-831 (5)

18 Lopez AD, Murray CC. The global burden of disease, 1990-2020. Nat Med 1998; 4: 1241 -1243 (5)

19 Marrie TJ, Lau CY, Wheeler SL et al. A controlled trial of a critical pathway for treatment of community-acquired pneumonia. CAPITAL Study Investigators. Community-Acquired Pneumonia Intervention Trial Assessing Levofloxacin. JAMA 2000; 283: 749-755 (1b)

20 Bauer TT, Ewig S, Marre R et al. CRB-65 predicts death from community-acquired pneumonia. J Intern Med 2006; 260: 93 - 101 (2c)
21 Buist AS, McBurnie MA, Vollmer WM et al. International variation in the prevalence of COPD (the BOLD Study): a population-based prevalence study. Lancet 2007; 370: $741-750$ (2c)

22 Nowak D, Dietrich ES, Oberender P et al. Krankheitskosten von COPD in Deutschland. Pneumologie 2004; 58: 837-844 (4)

23 Fang GD, Fine M, Orloff J et al. New and emerging etiologies for community-acquired pneumonia with implications for therapy. A prospective multicenter study of 359 cases. Medicine 1990; 69: $307-$ $316(4)$

24 Lim WS, Macfarlane JT, Boswell TC et al. Study of community acquired pneumonia aetiology (SCAPA) in adults admitted to hospital: implications for management guidelines. Thorax 2001; 56: 296-301 (4)

25 Ruiz M, Ewig S, Marcos MA et al. Etiology of community-acquired pneumonia in hospitalized patients: Impact of age, comorbidity and severity. Am J Respir Crit Care Med 1999; 160: 397-405 (2c)

26 Welte T, Marre R, Suttorp N. What is new in the treatment of community-acquired pneumonia? Med Klin (Munich) 2006; 101: 313 - 320 (4)

27 Baum $H$ von, Ewig S, Marre $R$ et al. Community-acquired Legionella pneumonia: new insights from the German competence network for community acquired pneumonia. Clin Infect Dis 2008; 46: 1356 $1364(4)$

28 Wellinghausen N, Straube E, Freidank $H$ et al. Low prevalence of Chlamydia pneumoniae in adults with community-acquired pneumonia. Int J Med Microbiol 2006; 296: 485 - 491 (4)

29 Arancibia F, Bauer TT, Ewig S et al. Community-acquired Pneumonia caused by Gram-negative bacteria: Incidence and risk and prognosis. Arch Intern Med 2002; 162: 1849-1858 (2c)

30 Bodi M, Rodriguez A, Sole-Violan J et al. Antibiotic Prescription for Community-Acquired Pneumonia in the Intensive Care Unit: Impact of Adherence to Infectious Diseases Society of America Guidelines on Survival. Clinical Infectious Diseases 2005; 41: 1709-1716 (2c)

31 Bartlett JG, Mundy LM. Community-Acquired Pneumonia. The New England Journal of Medicine 1995; 333: 1618 - 1624 (5)

32 Clavo-Sanchez AJ, Giron-Gonzalez JA, Lopez-Prieto D et al. Multivariate analysis of risk factors for infection due to penicillin-resistant and multidrug-resistant Streptococcus pneumoniae: A multicenter study. Clin Infect Dis 1997; 24: $1052-1059$ (2c)

33 Vanderkooi OG, Low DE, Green K et al. Predicting antimicrobial resistance in invasive pneumococcal infections. Clin Infect Dis 2005; 40: $1288-1297$ (2c)

34 Ray GT, Baxter R, DeLorenze GN. Hospital-level rates of fluoroquinolone use and the risk of hospital-acquired infection with ciprofloxacin-nonsusceptible Pseudomonas aeruginosa. Clin Infect Dis 2005; 41: $441-449(2 \mathrm{c})$

35 Nseir S, Di PC, Soubrier S et al. First-generation fluoroquinolone use and subsequent emergence of multiple drug-resistant bacteria in the intensive care unit. Crit Care Med 2005; 33: 283 - 289 (2c)

36 LeBlanc L, Pepin J, Toulouse K et al. Fluoroquinolones and risk for methicillin-resistant Staphylococcus aureus, Canada. Emerg Infect Dis 2006; $12: 1398-1405(2 c)$

37 Charbonneau P, Parienti JJ, Thibon $P$ et al. Fluoroquinolone use and methicillin-resistant Staphylococcus aureus isolation rates in hospitalized patients: a quasi experimental study. Clin Infect Dis 2006; 42: $778-784(2 \mathrm{~b})$

38 Paterson DL, Ko WC, Von GA et al. International prospective study of Klebsiella pneumoniae bacteremia: implications of extended-spectrum beta-lactamase production in nosocomial Infections. Ann Intern Med 2004; 140: 26 - 32 (2c)

39 Lück PC, Lobeck G, Stenzel G et al. Legionella pneumonia after travel to Mediterranean countries. Z Ärztl Fortbild (Jena) 1994; 88: 433 - 436 (4)

40 Höffken G, Steinhoff D, Lode H et al. Ätiologie von ambulant erworbenen Pneumonien bei älteren Menschen. Chemotherapie J 1995; 4: $13-19(4)$

41 Garcia-Ordonez MA, Garcia-Jimenez JM, Paez F et al. Clinical aspects and prognostic factors in elderly patients hospitalised for community-acquired pneumonia. Eur J Clin Microbiol Infect Dis 2001; 20: 14 $19(2 \mathrm{c})$

42 Woodhead M. Pneumonia in the elderly. J Antimicrob Chemother 1994; 34 Suppl A : 85 - 92 (5)

43 Riquelme R, Torres A, El-Ebiary $M$ et al. Community-acquired pneumonia in the elderly: a multivariate analysis of risk and prognostic factors. Am J Respir Crit Care Med 1996; 154: 1450 - 1455 (2c) 
44 Paganin F, Lilienthal F, Bourdin A et al. Severe community-acquired pneumonia: assessment of microbial aetiology as mortality factor. European Respiratory Journal 2004; 24: 779 - 785 (2c)

45 El Solh AA, Sikka P, Ramadan F, Davies J. Etiology of severe pneumonia in the very elderly. Am J Respir Crit Care Med 2001; 163: 645-651 (2c)

46 Quagliarello V, Ginter S, Han L et al. Modifiable risk factors for nursing home-acquired pneumonia. Clin Infect Dis 2005; 40: 1 -6 (2c)

47 Sopena N, Sabria M, Pedro-Botet ML et al. Prospective study of community-acquired pneumonia of bacterial etiology in adults. Eur J Clin Microbiol Infect Dis 1999; 18: 852 - 858 (4)

48 Arancibia F, Ewig S, Martinez JA et al. Antimicrobial treatment failures in patients with community-acquired pneumonia: Causes and prognostic implications. Am J Respir Crit Care Med 2000; 162: 154-160 (2c)

49 Bartlett JG, Dowell SF, Mandell LA et al. Practice guidelines for the management of community-acquired pneumonia in adults. Infectious Diseases Society of America. Clin Infect Dis 2000; 31: 422 - 425 (5)

50 Leroy 0 , Santre C, Beuscart $C$ et al. A five-year study of severe community-acquired pneumonia with emphasis on prognosis in patients admitted to an intensive care unit. Intensive Care Med 1995; 21: 24-31 (2c)

51 Niederman MS, Mandell LA, Anzueto A et al. Guidelines for the Management of Adults with Community-acquired Pneumonia. Diagnosis, assessment of severity, antimicrobial therapy, and prevention. Am J Respir Crit Care Med 2001; 163: 1730-1754 (5)

52 Nseir S, Di PC, Cavestri B et al. Multiple-drug-resistant bacteria in patients with severe acute exacerbation of chronic obstructive pulmonary disease: Prevalence, risk factors, and outcome. Crit Care Med 2006; 34: 2959-2966 (2c)

53 Rello J, Rodriguez A, Torres A. Implications of COPD in patients admitted to the intensive care unit by community-acquired pneumonia. Eur Respir J 2006; 27: 1210-1216 (3b)

54 Kobashi Y, Okimoto N, Matsushima T, Soejima R. Clinical analysis of community-acquired pneumonia in the elderly. Intern Med 2001; 40: $703-707$ (4)

55 Falsey AR, Walsh EE. Viral pneumonia in older adults. Clin Infect Dis 2006; 42: $518-524(5)$

56 de Roux A, Marcos MA, Garcia E et al. Viral Community-Acquired Pneumonia in Nonimmunocompromised Adults. Chest 2004; 125 : $1343-1351(2 \mathrm{c})$

57 Angeles MM, Camps M, Pumarola T et al. The role of viruses in the aetiology of community-acquired pneumonia in adults. Antivir Ther 2006; $11: 351-359$ (2b)

58 Robertson L, Caley JP, Moore J. Importance of Staphylococcus aureus in pneumonia in the 1957 epidemic of influenza A. Lancet 1958; 2: $233-236(4)$

59 Ruiz M, Ewig S, Torres A et al. Severe community-acquired pneumonia. Risk factors and follow-up epidemiology. Am J Respir Crit Care Med 1999; 160: 923 -929 (2c)

60 Deeks SL, Palacio R, Ruvinsky R et al. Risk factors and course of illness among children with invasive penicillin-resistant Streptococcus pneumoniae.The Streptococcus pneumoniae Working Group. Pediatrics 1999; 103: 409-413 (2c)

61 Henriques B, Kalin M, Ortqvist A et al. Molecular epidemiology of Streptococcus pneumoniae causing invasive disease in 5 countries. J Infect Dis 2000; 182: $833-839$ (4)

62 Moroney JF, Fiore AE, Harrison LH et al. Clinical outcomes of bacteremic pneumococcal pneumonia in the era of antibiotic resistance. Clin Infect Dis 2001; 33: 797 - 805 (2c)

63 Pallares $R$, Linares J, Vadillo $M$ et al. Resistance to penicillin and cephalosporin and mortality from severe pneumococcal pneumonia in Barcelona, Spain. N Engl J Med 1995; 333: $474-480$ (4)

64 Yu VL, Chiou CC, Feldman C et al. An international prospective study of pneumococcal bacteremia: correlation with in vitro resistance, antibiotics administered, and clinical outcome. Clin Infect Dis 2003; 37: $230-237(2 c)$

65 Feikin DRJ, Schuchat A, Kolczak M et al. Mortality from invasive pneumococcal pneumonia in the era of antibiotic resistance, 1995-1997. Am J Public Health 2000; 90: 223 - 229 (2b)

66 Reinert RR, Al-Lahham A, Lemperle $M$ et al. Emergence of macrolide and penicillin resistance among invasive pneumococcal isolates in Germany. J Antimicrob Chemother 2002; 49: 61 - 68 (4)

67 Reinert RR, Al-Lahham A, Lutticken R et al. Characterization of clinical Streptococcus pneumoniae strains from Germany with decreased susceptibility to fluoroquinolones. J Antimicrob Chemother 2002; 49: 1015 - 1018 (4)

68 Reinert RR, Reinert S, van der Linden $M$ et al. Antimicrobial susceptibility of Streptococcus pneumoniae in eight European countries from 2001 to 2003. Antimicrob Agents Chemother 2005; 49: 2903 $2913(4)$

69 van der Linden M, Al-Lahham A, Haupts S, Reinert RR. Clonal spread of mef-positive macrolide-resistant Streptococcus pneumoniae isolates causing invasive disease in adults in Germany. Antimicrob Agents Chemother 2007; 51: 1830 - 1834 (4)

70 van der Linden $M$, Heeg C, Imöhl M, Reinert RR. Annual report of the National Reference Centre for Streptococci, 2007. International Journal of Medical Microbiology 2008; 298S2: RKP04 (4)

71 Fogarty C, Goldschmidt R, Bush K. Bacteremic pneumonia due to multidrug-resistant pneumococci in 3 patients treated unsuccessfully with azithromycin and successfully with levofloxacin. Clin Infect Dis 2000; 31: 613-615 (4)

72 Kelley MA, Weber DJ, Gilligan P, Cohen MS. Breakthrough pneumococcal bacteremia in patients being treated with azithromycin and clarithromycin. Clin Infect Dis 2000; 31: 1008 - 1011 (4)

73 Waterer GW, Wunderink RG, Jones CB. Fatal pneumococcal pneumonia attributed to macrolide resistance and azithromycin monotherapy. Chest 2000; 118: 1839 - 1840 (4)

74 Kays MB, Wack MF, Smith DW, Denys GA. Azithromycin treatment failure in community-acquired pneumonia caused by Streptococcus pneumoniae resistant to macrolides by a 23S rRNA mutation. Diagn Microbiol Infect Dis 2002; 43: 163 - 165 (4)

75 Musher DM, Dowell ME, Shortridge VD et al. Emergence of macrolide resistance during treatment of pneumococcal pneumonia. N Engl J Med 2002; 346: 630-631 (4)

76 Lonks JR, Garau J, Gomez L et al. Failure of macrolide antibiotic treatment in patients with bacteremia due to erythromycin-resistant Streptococcus pneumoniae. Clin Infect Dis 2002; 35: 556 - 564 (3b)

77 Van Kerkhoven D, Peetermans WE, Verbist L, Verhaegen J. Breakthrough pneumococcal bacteraemia in patients treated with clarithromycin or oral beta-lactams. J Antimicrob Chemother 2003; 51: $691-696(4)$

78 Daneman N, McGeer A, Green K, Low DE. Macrolide resistance in bacteremic pneumococcal disease: implications for patient management. Clin Infect Dis 2006; 43: $432-438$ (2c)

79 Malhotra-Kumar S, Lammens C, Coenen $S$ et al. Effect of azithromycin and clarithromycin therapy on pharyngeal carriage of macrolide-resistant streptococci in healthy volunteers: a randomised, doubleblind, placebo-controlled study. Lancet 2007; 369: 482 - 490 (1b)

80 Descheemaeker $P$, Chapelle S, Lammens $C$ et al. Macrolide resistance and erythromycin resistance determinants among Belgian Streptococcus pyogenes and Streptococcus pneumoniae isolates. J Antimicrob Chemother 2000; 45: 167 - 173 (4)

81 Johnson DM, Sader HS, Fritsche TR et al. Susceptibility trends of haemophilus influenzae and Moraxella catarrhalis against orally administered antimicrobial agents: five-year report from the SENTRY Antimicrobial Surveillance Program. Diagn Microbiol Infect Dis 2003; 47: $373-376(4)$

82 Davidson $R$, Cavalcanti R, Brunton JL et al. Resistance to levofloxacin and failure of treatment of pneumococcal pneumonia. N Engl J Med 2002; 346: 747 - 750 (4)

83 Ross JJ, Worthington MG, Gorbach SL. Resistance to levofloxacin and failure of treatment of pneumococcal pneumonia. N Engl J Med 2002; 347: $65-67$ (4)

84 Anderson KB, Tan JS, File TM Jr. et al. Emergence of levofloxacin-resistant pneumococci in immunocompromised adults after therapy for community-acquired pneumonia. Clin Infect Dis 2003; 37: 376- 381 (4)

85 Felmingham $D$, Reinert RR, Hirakata $Y$, Rodloff $A$. Increasing prevalence of antimicrobial resistance among isolates of Streptococcus pneumoniae from the PROTEKT surveillance study, and compatative in vitro activity of the ketolide, telithromycin. J Antimicrob Chemother 2002; 50 Suppl S1: 25 - 37 (4)

86 Canton R, Morosini M, Enright MC, Morrissey I. Worldwide incidence, molecular epidemiology and mutations implicated in fluoroquinolone-resistant Streptococcus pneumoniae: data from the global PROTEKT surveillance programme. J Antimicrob Chemother 2003; 52: $944-952$ (4)

87 Reinert RR, Rodloff AC, Halle E et al. Antibacterial resistance of community-acquired respiratory tract pathogens recovered from pa- 
tients in Germany and activity of the Ketolide Telithromycin: results from the PROTEKT surveillance study (1999-2000). Chemotherapy 2004; 50: 143 - 151 (4)

88 Jacobs MR, Felmingham D, Appelbaum PC, Gruneberg RN. The Alexander Project 1998-2000: susceptibility of pathogens isolated from community-acquired respiratory tract infection to commonly used antimicrobial agents. J Antimicrob Chemother 2003; 52: 229-246 (4)

89 Johnson AP, Sheppard CL, Harnett SJ et al. Emergence of a fluoroquinolone-resistant strain of Streptococcus pneumoniae in England. J Antimicrob Chemother 2003; 52: 953 - 960 (4)

90 Blosser-Middleton R, Sahm DF, Thornsberry C et al. Antimicrobial susceptibility of 840 clinical isolates of Haemophilus influenzae collected in four European countries in 2000-2001. Clin Microbiol Infect 2003; 9: 431 - 436 (4)

91 Kresken M, Hafner D, Schmitz FJ, Wichelhaus TA für die Studiengruppe. Resistenzsituation bei klinisch wichtigen Infektionserregern gegenüber Antibiotika in Deutschland und im mitteleuropäischen Raum. Bericht über die Ergebnisse einer multizentrischen Studie der $\mathrm{Ar}$ beitsgemeinschaft Empfindlichkeitsprüfungen \& Resistenz der PaulEhrlich-Gesellschaft für Chemotherapie e.V. aus dem Jahr 2004. ISBN 3-00-018413-9 2006

92 Mertens T, Haller O, Klenk HD. Diagnostik und Therapie von Viruskrankheiten: Leitlinien der Gesellschaft für Virologie. 2. Auflage. 2004 (5)

93 Mauch H, Wagner J, Marklein G et al. MIQ 7 Qualitätsstandards in der mikrobiologisch-infektiologischen Diagnostik - Infektionen der unteren Atemwege. Teil 1. München: Urban \& Fischer, 1999: 30 - 50 (5)

94 Murray PR, Washington JA. Microscopic and bacteriologic analysis of expectorated sputum. Mayo Clin Proc 1975; 50: 339- 344 (4)

95 Geckler RW, Gremillion DH, McAllister CK, Ellenbogen C. Microscopic and bacteriological comparison of paired sputa and transtracheal aspirates. J Clin Microbiol 1977; 6: 396-399 (4)

96 Roson B, Carratala J, Verdaguer R et al. Prospective study of the usefulness of sputum Gram stain in the initial approach to communityacquired pneumonia requiring hospitalization. Clin Infect Dis 2000; 31: $869-874(2 \mathrm{~b})$

97 Mandell LA, Marrie TJ, Grossman RF et al. Canadian guidelines for the initial management of community-acquired pneumonia: an evidence-based update by the Canadian Infectious Diseases Society and the Canadian Thoracic Society. The Canadian Community-Acquired Pneumonia Working Group. Clin Infect Dis 2000; 31: 385-421 (5)

98 Theerthakarai $R$, El Halees W, Ismail $M$ et al. Nonvalue of the Initial Microbiological Studies in the Management of Nonsevere CommunityAcquired Pneumonia. Chest 2001; 119: 181 - 184 (4)

99 Chalasani NP, Valdecanas MA, Gopal AK et al. Clinical utility of blood cultures in adult patients with community-acquired pneumonia without defined underlying risks. Chest 1995; 108: 932 - 936 (4)

100 Waterer GW, Wunderink RG. The influence of the severity of community-acquired pneumonia on the usefulness of blood cultures. Respir Med 2001; 95: 78-82 (4)

101 Lentino JR, Lucks DA. Nonvalue of sputum culture in the management of lower respiratory tract infections. J Clin Microbiol 1987; 25: 758 $762(2 \mathrm{~b})$

102 Dominguez JA, Matas L, Manterola JM et al. Comparison of radioimmunoassay and enzyme immunoassay kits for detection of Legionella pneumophila serogroup 1 antigen in both concentrated and nonconcentrated urine samples. J Clin Microbiol 1997; 35: 1627-1629 (2b)

103 Gutierrez F, Masia M, Rodriguez JC et al. Evaluation of the Immunochromatographic Binax NOW Assay for Detection of Streptococcus pneumoniae Urinary Antigen in a Prospective Study of CommunityAcquired Pneumonia in Spain. Clin Infect Dis 2003; 36: 286 - 292 (4)

104 Dominguez J, Gali N, Blanco S et al. Detection of Streptococcus pneumoniae Antigen by a Rapid Immunochromatographic Assay in Urine Samples. Chest 2001; 119: 243-249 (2b)

105 Smith MD, Derrington P, Evans $R$ et al. Rapid diagnosis of bacteremic pneumococcal infections in adults by using the Binax NOW Streptococcus pneumoniae urinary antigen test: a prospective, controlled clinical evaluation. J Clin Microbiol 2003; 41: 2810 - 2813 (2b)

106 Marcos MA, Jimenez de Anta MT, de la Bellacasa JP et al. Rapid urinary antigen test for diagnosis of pneumococcal community-acquired pneumonia in adults. Eur Respir J 2003; 21: 209-214 (2b)

107 Ishida T, Hashimoto T, Arita $M$ et al. A 3-Year prospective study of a urinary antigen-detection for Streptoccus pneumoniae in community acquired pneumonia: utility and clinical impact on the reported etiology. J Infect Chemother 2004; 10: 359-363 (1b)
108 Murdoch DR, Laing RT, Mills GD et al. Evaluation of a rapid immunochromatographic test for detection of Streptococcus pneumoniae antigen in urine samples from adults with community-acquired pneumonia. J Clin Microbiol 2001; 39: 3495-3498 (2b)

109 Murdoch DR, Laing RT, Cook JM. The NOW S. pneumoniae urinary antigen test positivity rate 6 weeks after pneumonia onset and among patients with COPD. Clin Infect Dis 2003; 37: 153-154 (4)

110 Edelstein PH, Meyer RD, Finegold SM. Laboratory diagnosis of Legionnaires' disease. Am Rev Respir Dis 1980; 121: 317- 327 (2b)

111 Zuravleff JJ, Yu VL, Shonnard JW et al. Diagnosis of Legionnaires' disease. An update of laboratory methods with new emphasis on isolation by culture. JAMA: The Journal of the American Medical Association 1983; 250: 1981 - 1985 (2b)

112 Murdoch DR. Nucleic acid amplification tests for the diagnosis of pneumonia. Clin Infect Dis 2003; 36: 1162 - 1170 (4)

113 Helbig JH, Uldum SA, Bernander S et al. Clinical utility of urinary antigen detection for diagnosis of community-acquired, travel-associated, and nosocomial legionnaires' disease. J Clin Microbiol 2003; 41: $838-840$ (4)

114 Dowell SF, Garman RL, Liu G et al. Evaluation of Binax NOW, an assay for the detection of pneumococcal antigen in urine samples, performed among pediatric patients. Clin Infect Dis 2001; 32: 824- 825 (1b)

115 Kashuba $A D$, Ballow $C H$. Legionella urinary antigen testing: potential impact on diagnosis and antibiotic therapy. Diagn Microbiol Infect Dis 1996; 24 : 129-139(5)

116 Wever PC, Yzerman EP, Kuijper EJ et al. Rapid diagnosis of Legionnaires' disease using an immunochromatographic assay for Legionella pneumophila serogroup 1 antigen in urine during an outbreak in the Netherlands. J Clin Microbiol 2000; 38: 2738 -2739 (4)

117 Helbig JH, Uldum SA, Luck PC, Harrison TG. Detection of Legionella pneumophila antigen in urine samples by the BinaxNOW immunochromatographic assay and comparison with both Binax Legionella Urinary Enzyme Immunoassay (EIA) and Biotest Legionella Urin Antigen EIA. J Med Microbiol 2001; 50: 509-516 (4)

118 Guerrero C, Toldos CM, Yague G et al. Comparison of diagnostic sensitivities of three assays (Bartels enzyme immunoassay [EIA], Biotest EIA, and Binax NOW immunochromatographic test) for detection of Legionella pneumophila serogroup 1 antigen in urine. J Clin Microbiol 2004; 42: 467-468 (2b)

119 Yzerman EP, Den Boer JW, Lettinga KD et al. Sensitivity of three urinary antigen tests associated with clinical severity in a large outbreak of Legionnaires' disease in The Netherlands. J Clin Microbiol 2002; 40: $3232-3236(1 \mathrm{~b})$

120 Kessler HH, Reinthaler FF, Pschaid A et al. Rapid detection of Legionella species in bronchoalveolar lavage fluids with the EnviroAmp Legionella PCR amplification and detection kit. J Clin Microbiol 1993; 31: $3325-3328$ (2c)

121 Weir SC, Fischer SH, Stock F, Gill VJ. Detection of Legionella by PCR in respiratory specimens using a commercially available kit. Am J Clin Pathol 1998; 110: 295-300 (2b)

122 Cloud JL, Carroll KC, Pixton P et al. Detection of Legionella species in respiratory specimens using PCR with sequencing confirmation. J Clin Microbiol 2000; 38: 1709-1712 (2b)

123 Murdoch DR, Anderson TP, Beynon KA et al. Evaluation of a PCR Assay for Detection of Streptococcus pneumoniae in Respiratory and Nonrespiratory Samples from Adults with Community-Acquired Pneumonia. J Clin Microbiol 2003; 41: 63-66 (4)

124 Reischl U, Linde HJ, Lehn $N$ et al. Direct detection and differentiation of Legionella spp. and Legionella pneumophila in clinical specimens by dual-color real-time PCR and melting curve analysis. J Clin Microbiol 2002; 40: $3814-3817(2 \mathrm{~b})$

125 Templeton KE, Scheltinga SA, Sillekens $P$ et al. Development and clinical evaluation of an internally controlled, single-tube multiplex realtime PCR assay for detection of Legionella pneumophila and other Legionella species. J Clin Microbiol 2003; 41: 4016-4021 (2b)

126 Welti M, Jaton K, Altwegg $M$ et al. Development of a multiplex realtime quantitative PCR assay to detect Chlamydia pneumoniae, Legionella pneumophila and Mycoplasma pneumoniae in respiratory tract secretions. Diagn Microbiol Infect Dis 2003; 45: 85-95 (2b)

127 Kallings I, Nordstrom K. The pattern of immunoglobulins with special reference to IgM in Legionnaires' disease patients during a 2 year follow-up period. Zentralbl Bakteriol Mikrobiol Hyg [A] 1983; 255: 27 32 (4) 
128 Monforte R, Estruch R, Vidal J, Cervera R, Urbano-Marquez A. Delayed seroconversion in Legionnaire's disease. Lancet 1988; 2: $513-(4)$

129 Plouffe JF, File TM Jr, Breiman RF et al. Reevaluation of the definition of Legionnaires' disease: use of the urinary antigen assay. Community Based Pneumonia Incidence Study Group. Clin Infect Dis 1995; 20: $1286-1291$ (4)

130 Boswell TC, Marshall LE, Kudesia G. False-positive legionella titres in routine clinical serology testing detected by absorption with campylobacter: implications for the serological diagnosis of legionnaires' disease. J Infect 1996; 32: 23-26 (4)

131 Musso D, Raoult D. Serological cross-reactions between Coxiella burnetii and Legionella micdadei. Clin Diagn Lab Immunol 1997; 4: 208 $212(4)$

132 Waterer GW, Baselski VS, Wunderink RG. Legionella and communityacquired pneumonia: a review of current diagnostic tests from a clinician's viewpoint. Am J Med 2001; 110: 41 - 48 (5)

133 Ieven $M$, Goossens $H$. Relevance of nucleic acid amplification techniques for diagnosis of respiratory tract infections in the clinical laboratory. Clin Microbiol Rev 1997; 10: 242 - 256 (5)

134 Ponka A, Ponka T, Sarna S, Penttinen K. Questionable specificity of lipid antigen in the Mycoplasma pneumoniae complement fixation test in patients with extrapulmonary manifestations. J Infect 1981; 3: $332-338(4)$

135 Ruuskanen O, Nohynek H, Ziegler T et al. Pneumonia in childhood: etiology and response to antimicrobial therapy. Eur J Clin Microbiol Infect Dis 1992; 11: 217-223 (4)

136 Taylor-Robinson D. Infections due to species of Mycoplasma and Ureaplasma: an update. Clin Infect Dis 1996; 23: 671 -682 (5)

137 Watkins-Riedel T, Stanek G, Daxboeck F. Comparison of SeroMP IgA with four other commercial assays for serodiagnosis of Mycoplasma pneumoniae pneumonia. Diagn Microbiol Infect Dis 2001; 40: 21 25 (1b)

138 Schmidt-Ioanas $M$, Bender $M$, Roth A et al. Serologic early diagnosis of pneumonia caused by Mycoplasma pneumoniae. Dtsch Med Wochenschr 2006; 131: 613-617 (2b)

139 Stralin $K$, Holmberg $H$. Usefulness of the Streptococcus pneumoniae urinary antigen test in the treatment of community-acquired pneumonia. Clin Infect Dis 2005; 41: 1209-1210 (2b)

140 Ieven M, Ursi D, Van Bever H et al. Detection of Mycoplasma pneumoniae by two polymerase chain reactions and role of M. pneumoniae in acute respiratory tract infections in pediatric patients. J Infect Dis 1996; 173: $1445-1452$ (2b)

141 Abele-Horn M, Busch U, Nitschko $\mathrm{H}$ et al. Molecular approaches to diagnosis of pulmonary diseases due to Mycoplasma pneumoniae. J Clin Microbiol 1998; 36: 548-551 (2b)

142 Dorigo-Zetsma JW, Zaat SA, Wertheim-van Dillen PM et al. Comparison of PCR, culture, and serological tests for diagnosis of Mycoplasma pneumoniae respiratory tract infection in children. J Clin Microbiol 1999; 37: $14-17(2 \mathrm{~b})$

143 Dorigo-Zetsma JW, Verkooyen RP, van Helden HP et al. Molecular detection of Mycoplasma pneumoniae in adults with communityacquired pneumonia requiring hospitalization. J Clin Microbiol 2001; 39: $1184-1186(4)$

144 Loens K, Ieven M, Ursi D et al. Detection of Mycoplasma pneumoniae by real-time nucleic acid sequence-based amplification. J Clin Microbiol 2003; 41: 4448 - 4450 (2b)

145 Ursi D, Dirven K, Loens K et al. Detection of Mycoplasma pneumoniae in respiratory samples by real-time PCR using an inhibition control. J Microbiol Methods 2003; 55: 149-153 (2b)

146 Templeton KE, Scheltinga SA, Graffelman AW et al. Comparison and evaluation of real-time PCR, real-time nucleic acid sequence-based amplification, conventional PCR, and serology for diagnosis of Mycoplasma pneumoniae. J Clin Microbiol 2003; 41: 4366 - 4371

147 Loens K, Ursi D, Goossens H, Ieven M. Molecular diagnosis of Mycoplasma pneumoniae respiratory tract infections. J Clin Microbiol 2003; 41: $4915-4923$ (5)

148 Ortiz-Ruiz G, Vetter $N$, Isaacs $R$ et al. Ertapenem versus ceftriaxone for the treatment of community-acquired pneumonia in adults: combined analysis of two multicentre randomized, double-blind studies. J Antimicrob Chemother 2004; 53 (Suppl. 2): ii59-ii66 (1b)

149 Tompkins LS, Schachter J, Boman J et al. Collaborative multidisciplinary workshop report: detection, culture, serology, and antimicrobial susceptibility testing of Chlamydia pneumoniae. J Infect Dis 2000; 181 (Suppl. 3): S460 - S461 (5)
150 Mandell LA, Bartlett JG, Dowell SF et al. Update of practice guidelines for the management of community-acquired pneumonia in immunocompetent adults. Clin Infect Dis 2003; 37: 1405-1433 (5)

151 Dowell SF, Peeling RW, Boman J et al. Standardizing Chlamydia pneumoniae assays: recommendations from the Centers for Disease Control and Prevention (USA) and the Laboratory Centre for Disease Control (Canada). Clin Infect Dis 2001; 33: $492-503$ (5)

152 Dowell J, Pitkethly M, Bain J, Martin S. A randomised controlled trial of delayed antibiotic prescribing as a strategy for managing uncomplicated respiratory tract infection in primary care. Br J Gen Pract 2001; 51: $200-205(1 \mathrm{~b})$

153 Reischl U, Lehn N, Simnacher U et al. Rapid and standardized detection of Chlamydia pneumoniae using LightCycler real-time fluorescence PCR. Eur J Clin Microbiol Infect Dis 2003; 22: 54-57 (2b)

154 Bartlett JG, Breiman RF, Mandell LA, File TM Jr. Practice Guidelines for the Management of Community-Acquired Pneumonia in Adults. Clin Infect Dis 1998; 26: $811-838$ (5)

155 Steininger C, Kundi M, Aberle SW et al. Effectiveness of reverse transcription-PCR, virus isolation, and enzyme-linked immunosorbent assay for diagnosis of influenza A virus infection in different age groups. J Clin Microbiol 2002; 40: 2051 - 2056 (2b)

156 Mahony JB. Detection of respiratory viruses by molecular methods. Clin Microbiol Rev 2008; 21: 716-747 (5)

157 Schrag SJ, Pena C, Fernandez J et al. Effect of short-course, high-dose amoxicillin therapy on resistant pneumococcal carriage: a randomized trial. JAMA 2001; 286: 49-56 (1b)

158 Pepin J, Saheb N, Coulombe MA et al. Emergence of fluoroquinolones as the predominant risk factor for Clostridium difficile-associated diarrhea: a cohort study during an epidemic in Quebec. Clin Infect Dis 2005; $41: 1254-1260(2 c)$

159 Dhalla IA, Mamdani MM, Simor AE et al. Are broad-spectrum fluoroquinolones more likely to cause Clostridium difficile-associated disease? Antimicrob Agents Chemother 2006; 50: 3216-3219 (3b)

160 Loo VG, Poirier L, Miller MA et al. A predominantly clonal multi-institutional outbreak of Clostridium difficile-associated diarrhea with high morbidity and mortality. N Engl J Med 2005; 353: 2442 - 2449 (3b)

161 Diehr P, Wood RW, Bushyhead J et al. Prediction of pneumonia in outpatients with acute cough - a statistical approach. J Chronic Dis 1984; 37: $215-225$ (4)

162 Gennis P, Gallagher J, Falvo C et al. Clinical criteria for the detection of pneumonia in adults: guidelines for ordering chest roentgenograms in the emergency department. J Emerg Med 1989; 7: 263 - 268 (4)

163 Heckerling PS, Tape TG, Wigton RS et al. Clinical prediction rule for pulmonary infiltrates. Ann Intern Med 1990; 113: 664-670 (4)

164 Melbye H, Straume B, Aasebo U, Dale K. Diagnosis of pneumonia in adults in general practice. Relative importance of typical symptoms and abnormal chest signs evaluated against a radiographic reference standard. Scand J Prim Health Care 1992; 10: 226 - 233 (2b)

165 Metlay JP, Kapoor WN, Fine MJ. Does this patient have communityacquired pneumonia? Diagnosing pneumonia by history and physical examination. JAMA 1997; 278: 1440-1445 (5)

166 Wipf JE, Lipsky BA, Hirschmann JV et al. Diagnosing pneumonia by physical examination: relevant or relic? Arch Intern Med 1999; 159: $1082-1087(2 b)$

167 Schilling RS, Hughes JP, Dingwall-Fordyce I. Disagreement between observers in an epidemiological study of respiratory disease. Br Med J 1955; 4905: 65-68 (4)

168 Spiteri MA, Cook DG, Clarke SW. Reliability of eliciting physical signs in examination of the chest. Lancet 1988; 1: 873-875 (2b)

169 Emerman CL, Dawson N, Speroff $T$ et al. Comparison of physician judgment and decision aids for ordering chest radiographs for pneumonia in outpatients. Ann Emerg Med 1991; 20: 1215-1219 (4)

170 Heckerling PS. The need for chest roentgenograms in adults with acute respiratory illness. Clinical predictors. Arch Intern Med 1986; 146: $1321-1324(4)$

171 Metlay JP, Schulz R, Li YH et al. Influence of age on symptoms at presentation in patients with community-acquired pneumonia. Arch Intern Med 1997; 157: 1453-1459 (2c)

172 Melbye H, Dale K. Interobserver variability in the radiographic diagnosis of adult outpatient pneumonia. Acta Radiol 1992; 33: 79-81 (2b)

173 Young M, Marrie TJ. Interobserver variability in the interpretation of chest roentgenograms of patients with possible pneumonia. Arch Intern Med 1994; 154: 2729-2732 (2b) 
174 Speets AM, Hoes AW, van der Graaf $Y$ et al. Chest radiography and pneumonia in primary care: diagnostic yield and consequences for patient management. Eur Respir J 2006; 28: 933 -938 (2b)

175 Falguera M, Martin M, Ruiz-Gonzalez A et al. Community-acquired pneumonia as the initial manifestation of serious underlying diseases. Am J Med 2005; 118: 378 - 383 (3b)

176 Altiner A, Haag H, Schraven C et al. Akuter Husten: Was erwarten die Patienten? Z Allg Med 2002; 78: 19-23 (4)

177 van Driel ML, De SA, Deveugele $M$ et al. Are sore throat patients who hope for antibiotics actually asking for pain relief? Ann Fam Med 2006; 4: 494-499 (2c)

178 Little P, Rumsby K, Kelly J et al. Information leaflet and antibiotic prescribing strategies for acute lower respiratory tract infection: a randomized controlled trial. JAMA 2005; 293: 3029-3035 (1b)

179 Altiner A, Brockmann S, Sielk M et al. Reducing antibiotic prescriptions for acute cough by motivating GPs to change their attitudes to communication and empowering patients: a cluster-randomized intervention study. J Antimicrob Chemother 2007; 60: 638-644 (1b)

180 Johnston SL, Blasi F, Black PN et al. The effect of telithromycin in acute exacerbations of asthma. N Engl J Med 2006; 354: 1589-1600 (1b)

181 Fahey T, Stocks N, Thomas T. Quantitative systematic review of randomised controlled trials comparing antibiotic with placebo for acute cough in adults. BMJ 1998; 316: $906-910$ (1a)

182 Gonzales R, Steiner JF, Sande MA. Antibiotic prescribing for adults with colds, upper respiratory tract infections, and bronchitis by ambulatory care physicians. JAMA 1997; 278: $901-904$ (2c)

183 Gonzales R, Steiner JF, Lum A, Barrett PH Jr. Decreasing antibiotic use in ambulatory practice: impact of a multidimensional intervention on the treatment of uncomplicated acute bronchitis in adults. JAMA 1999; 281: $1512-1519$ (2b)

184 Hayden FG, Osterhaus AD, Treanor JJ et al. Efficacy and safety of the neuraminidase inhibitor zanamivir in the treatment of influenzavirus infections. GG167 Influenza Study Group. N Engl J Med 1997; 337: $874-880$ (1b)

185 Monto AS, Fleming DM, Henry D et al. Efficacy and safety of the neuraminidase inhibitor zanamivirin the treatment of influenza $A$ and $B$ virus infections. J Infect Dis 1999; 180: 254-261 (1b)

186 Treanor JJ, Hayden FG, Vrooman PS et al. Efficacy and safety of the oral neuraminidase inhibitor oseltamivir in treating acute influenza: a randomized controlled trial. US Oral Neuraminidase Study Group. JAMA 2000; 283: 1016 - 1024 (1b)

187 Nicholson KG, Aoki FY, Osterhaus AD et al. Efficacy and safety of oseltamivir in treatment of acute influenza: a randomised controlled trial. Neuraminidase Inhibitor Flu Treatment Investigator Group. Lancet 2000; 355: 1845 - 1850 (1b)

188 Monto AS, Webster A, Keene O. Randomized, placebo-controlled studies of inhaled zanamivir in the treatment of influenza A and B: pooled efficacy analysis. J Antimicrob Chemother 1999; 44 (Suppl. B): 23-29 (1a)

189 McGeer A, Green KA, Plevneshi A et al. Antiviral therapy and outcomes of influenza requiring hospitalization in Ontario, Canada. Clin Infect Dis 2007; 45: 1568 - 1575 (2c)

190 Ohmit SE, Moler FW, Monto AS, Khan AS. Ribavirin utilization and clinical effectiveness in children hospitalized with respiratory syncytial virus infection. J Clin Epidemiol 1996; 49: 963 -967 (2c)

191 Anthonisen NR, Manfreda J, Warren CPW et al. Antibiotic therapy in exacerbations of chronic obstructive pulmonary disease. Ann Intern Med 1987; 106: 196-204 (2b)

192 Stockley RA, O'Brien C, Pye A, Hill SL. Relationship of sputum color to nature and outpatient management of acute exacerbations of COPD. Chest 2000; 117: $1638-1645$ (2b)

193 Seemungal T, Harper-Owen R, Bhowmik A et al. Respiratory Viruses, Symptoms, and Inflammatory Markers in Acute Exacerbations and Stable Chronic Obstructive Pulmonary Disease. Am J Respir Crit Care Med 2001; 164: 1618 - 1623 (2b)

194 Rohde G, Wiethege A, Borg I et al. Respiratory viruses in exacerbations of chronic obstructive pulmonary disease requiring hospitalization a case-control study. Thorax 2003; 58: 37-42 (2b)

195 Papi A, Bellettato CM, Braccioni $F$ et al. Infections and airway inflammation in chronic obstructive pulmonary disease severe exacerbations. Am J Respir Crit Care Med 2006; 173: 1114-1121 (2c)

196 Wedzicha JA. Role of viruses in exacerbations of chronic obstructive pulmonary disease. Proc Am Thorac Soc 2004; 1: 115 - 120 (5)
197 Sethi S, Evans N, Grant BJ, Murphy TF. New strains of bacteria and exacerbations of chronic obstructive pulmonary disease. N Engl J Med 2002; 347: 465 - 471 (3b)

198 Sethi S, Wrona C, Grant BJ, Murphy TF. Strain-specific immune response to Haemophilus influenzae in chronic obstructive pulmonary disease. Am J Respir Crit Care Med 2004; 169: 448 - 453 (4)

199 Sethi S, Wrona C, Eschberger K et al. Inflammatory profile of new bacterial strain exacerbations of chronic obstructive pulmonary disease. Am J Respir Crit Care Med 2008; 177: 491 - 497 (2c)

200 Sethi S, Sethi R, Eschberger Ket al. Airway bacterial concentrations and exacerbations of chronic obstructive pulmonary disease. Am J Respir Crit Care Med 2007; 176: 356 - 361 (4)

201 Chodosh S, McCarty J, Farkas S et al. Randomized, double-blind study of ciprofloxacin and cefuroxime axetil for treatment of acute bacterial exacerbations of chronic bronchitis. The Bronchitis Study Group. Clin Infect Dis 1998; 27: $722-729$ (1b)

202 Angrill J, Agusti C, de Celis R et al. Bacterial colonisation in patients with bronchiectasis: microbiological pattern and risk factors. Thorax 2002; 57: $15-19(2 \mathrm{~b})$

203 Eller J, Ede A, Schaberg T et al. Infective exacerbations of chronic bronchitis: relation betwen bacteriologic etiology and lung function. Chest 1998; 113: $1542-1548$ (4)

204 Miravitlles M, Espinosa C, Fernandez-Laso E et al. Relationship between bacterial flora in sputum and functional impairment in patients with acute exacerbations of COPD. Study Group of Bacterial Infection in COPD. Chest 1999; 116: 40-46 (2c)

205 Anzueto A, Niederman MS, Tillotson GS. Etiology, susceptibility, and treatment of acute bacterial exacerbations of complicated chronic bronchitis in the primary care setting: ciprofloxacin $750 \mathrm{mg}$ b.i.d. versus clarithromycin $500 \mathrm{mg}$ b.i.d. Bronchitis Study Group. Clin Ther 1998; 20: 885-900 (1b)

206 Fagon JY, Chastre J, Trouillet JL et al. Characterization of distal bronchial microflora during acute exacerbation of chronic bronchitis. Use of the protected specimen brush technique in 54 mechanically ventilated patients. Am Rev Respir Dis 1990; 142: 1004-1008 (4)

207 Soler N, Torres A, Ewig S et al. Bronchial microbial patterns in severe exacerbations of chronic obstructive pulmonary disease (COPD) requiring mechanical ventilation. Am J Respir Crit Care Med 1998; 157: $1498-1505(3 \mathrm{~b})$

208 Blasi F, Damato S, Cosentini R et al. Chlamydia InterAction with COPD (CIAC) Study Group. Chlamydia pneumoniae and chronic bronchitis: association with severity and bacterial clearance following treatment. Thorax 2002; 57: 672-676 (5)

209 Blasi F, Legnani D, Lombardo VM et al. Chlamydia pneumoniae infection in acute exacerbations of COPD. Eur Respir J 1993; 6: 19-22 (3b)

210 Buscho RO, Saxtan D, Shultz PS et al. Infections with viruses and Mycoplasma pneumoniae during exacerbations of chronic bronchitis. J Infect Dis 1978; 137: 377-383 (4)

211 Mogulkoc N, Karakurt S, Isalska B et al. Acute purulent exacerbation of chronic obstructive pulmonary disease and Chlamydia pneumoniae infection. Am J Respir Crit Care Med 1999; 160: 349 - 353 (3b)

212 Lieberman D, Lieberman D, Shmarkov 0 et al. Serological evidence of Legionella species infection in acute exacerbation of COPD. Eur Respir J 2002; 19: 392 - 397 (3b)

213 Kessler R, Faller M, Fourgaut $G$ et al. Predictive factors of hospitalization for acute exacerbation in a series of 64 patients with chronic obstructive pulmonary disease. Am J Respir Crit Care Med 1999; 159: $158-164(2 \mathrm{c})$

214 Anon JM, Garcia DL, Zarazaga A et al. Mechanical ventilation of patients on long-term oxygen therapy with acute exacerbations of chronic obstructive pulmonary disease: prognosis and cost-utility analysis. Intensive Care Med 1999; 25: 452 - 457 (4)

215 Chu CM, Chan VL, Lin AWN et al. Readmission rates and life threatening events in COPD survivors treated with non-invasive ventilation for acute hypercapnic respiratory failure. Thorax 2004; 59: $1020-$ 1025 (2c)

216 Groenewegen KH, Schols AMWJ, Wouters EFM. Mortality and Mortality-Related Factors After Hospitalization for Acute Exacerbation of COPD. Chest 2003; 124: 459-467 (2c)

217 Patil SP, Krishnan JA, Lechtzin N, Diette GB. In-hospital mortality following acute exacerbations of chronic obstructive pulmonary disease. Arch Intern Med 2003; 163: 1180-1186 (2c)

218 Ferrer M, Ioanas M, Arancibia F et al. Microbial airway colonization is associated with noninvasive ventilation failure in exacerbation of 
chronic obstructive pulmonary disease. Crit Care Med 2005; 33 : $2003-2009$ (3b)

219 Donaldson GC, Seemungal TA, Bhowmik A, Wedzicha JA. Relationship between exacerbation frequency and lung function decline in chronic obstructive pulmonary disease. Thorax 2002; 57: 847-852 (3b)

220 Wilkinson TMA, Patel IS, Wilks M et al. Airway Bacterial Load and FEV1 Decline in Patients with Chronic Obstructive Pulmonary Disease. Am J Respir Crit Care Med 2003; 167: 1090 (3b)

221 Stolz D, Christ-Crain M, Bingisser R et al. Antibiotic treatment of exacerbations of COPD: a randomized, controlled trial comparing procalcitonin-guidance with standard therapy. Chest 2007; 131: 9-19 (1b)

222 Christ-Crain M, Jaccard-Stolz D, Bingisser R et al. Effect of procalcitonin-guided treatment on antibiotic use and outcome in lower respiratory tract infections: cluster-randomised, single-blinded intervention trial. Lancet 2004; 363: 600-607 (2b)

223 Nicotra MB, Rivera M, Awe RJ. Antibiotic therapy of acute exacerbations of chronic bronchitis. A controlled study using tetracycline. Ann Intern Med 1982; 97: 18 - 21 (1b)

224 Nouira S, Marghli S, Belghith M et al. Once daily oral ofloxacin in chronic obstructive pulmonary disease exacerbation requiring mechanical ventilation: a randomised placebo-controlled trial. Lancet 2001; 358: 2020-2025 (1b)

225 Sachs AP, Koeter GH, Groenier KH et al. Changes in symptoms, peak expiratory flow, and sputum flora during treatment with antibiotics of exacerbations in patients with chronic obstructive pulmonary disease in general practice. Thorax 1995; 50: $758-763$ (1b)

226 Jorgensen AF, Coolidge J, Pedersen PA et al. Amoxicillin in treatment of acute uncomplicated exacerbations of chronic bronchitis. A doubleblind, placebo-controlled multicentre study in general practice. Scand J Prim Health Care 1992; 10: 7-11 (1b)

227 Ram FS, Rodriguez-Roisin R, Granados-Navarrete A et al. Antibiotics for exacerbations of chronic obstructive pulmonary disease. Cochrane Database Syst Rev 2006; CD004403: (1a)

228 Soler N, Agusti C, Angrill J et al. Bronchoscopic validation of the significance of sputum purulence in severe exacerbations of chronic obstructive pulmonary disease. Thorax 2007; 62: 29-35 (2b)

229 Chodosh S, Schreurs A, Siami G et al. Efficacy of oral ciprofloxacin vs. clarithromycin for treatment of acute bacterial exacerbations of chronic bronchitis. The Bronchitis Study Group. Clin Infect Dis 1998; 27: $730-738(1 \mathrm{~b})$

230 Adams SG, Melo J, Luther M, Anzueto A. Antibiotics are associated with lower relapse rates in outpatients with acute exacerbations of COPD. Chest 2000; 117: 1345-1352 (4)

231 Wilson R, Schentag JJ, Ball P, Mandell L. A comparison of gemifloxacin and clarithromycin in acute exacerbations of chronic bronchitis and long-term clinical outcomes. Clin Ther 2002; 24: 639-652 (1b)

232 Wilson R, Allegra L, Huchon G et al. Short-term and Long-term Outcomes of Moxifloxacin Compared to Standard Antibiotic Treatment in Acute Exacerbations of Chronic Bronchitis. Chest 2004; 125: 953 $964(1 \mathrm{~b})$

233 Murphy TF, Brauer AL, Eschberger K et al. Pseudomonas aeruginosa in chronic obstructive pulmonary disease. Am J Respir Crit Care Med 2008; 177: $853-860$ (4)

234 Zhanel GG, Ennis K, Vercaigne L et al. A critical review of the fluoroquinolones: focus on respiratory infections. Drugs 2002; 62: 13-59 (5)

235 Neuhauser MM, Weinstein RA, Rydman R et al. Antibiotic resistance among gram-negative bacilli in US intensive care units: implications for fluoroquinolone use. JAMA 2003; 289: $885-888$ (4)

236 Drobnic ME, Sune P, Montoro JB et al. Inhaled Tobramycin in Non-Cystic Fibrosis Patients with Bronchiectasis and Chronic Bronchial Infection with Pseudomonas aeruginosa. The Annals of Pharmacotherapy 2005; 39: $39-44$ (1b)

237 Barker AF, Couch L, Fiel SB et al. Tobramycin solution for inhalation reduces sputum Pseudomonas aeruginosa density in bronchiectasis. Am J Respir Crit Care Med 2000; 162: 481 - 485 (1b)

238 Zervos MJ, Heyder AM, Leroy B. Oral telithromycin $800 \mathrm{mg}$ once daily for 5 days versus cefuroxime axetil $500 \mathrm{mg}$ twice daily for 10 days in adults with acute exacerbations of chronic bronchitis. J Int Med Res 2003; 31: 157-169 (1b)

239 Masterton RG, Burley CJ. Randomized, double-blind study comparing 5- and 7-day regimens of oral levofloxacin in patients with acute exacerbation of chronic bronchitis. Int J Antimicrob Agents 2001; 18: $503-512(1 \mathrm{~b})$
240 Schonhofer B, Kohler D. Prevalence of deep-vein thrombosis of the leg in patients with acute exacerbation of chronic obstructive pulmonary disease. Respiration 1998; 65: 173 - 177 (4)

241 Lim WS, van der Eerden MM, Laing R et al. Defining community acquired pneumonia severity on presentation to hospital: an international derivation and validation study. Thorax 2003; 58: 377 - 382 (2c)

242 Lim WS, Lewis S, Macfarlane JT. Severity prediction rules in community acquired pneumonia: a validation study. Thorax 2000; 55: 219 223 (3b)

243 British Thoracic Society and the Public Health Laboratory Service. Community-acquired pneumonia in adults in British hospitals in 1982 -1983: A survey of aetiology, mortality, prognostic factors and outcome. Q J Med 1987; 62: 195-200 (2c)

244 Neill AM, Martin IR, Weir R et al. Community-acquired pneumonia: aetiology and usefulness of severity criteria on admission. Thorax 1996; 51: $1010-1016$ (4)

245 Capelastegui A, Espana PP, Quintana JM et al. Validation of a predictive rule for the management of community-acquired pneumonia. Eur Respir J 2006; 27: 151 - 157 (2b)

246 Ewig S, Kleinfeld T, Bauer TT et al. Comparative validation of prognostic rules for community-acquired pneumonia in an elderly population. Eur Respir J 1999; 14: 370 - 375 (4)

247 Ewig S, de Roux A, Bauer T et al. Validation of predictive rules and indices of severity for community acquired pneumonia. Thorax 2004; 59: $421-427(4)$

248 Yan MS, Lee N, Ip M et al. Prospective comparison of three predictive rules for assessing severity of community-acquired pneumonia in Hong Kong. Thorax 2007; 62: $348-353$ (2c)

249 Ewig S, Ruiz M, Mensa J et al. Severe community-acquired pneumonia: Assessment of severity criteria. Am J Respir Crit Care Med 1998; 158: $1102-1108(4)$

250 Angus DC, Marrie TJ, Obrosky DS et al. Severe community-acquired pneumonia: use of intensive care services and evaluation of American and British Thoracic Society Diagnostic criteria. Am J Respir Crit Care Med 2002; 166: 717-723 (2b)

251 Espana PP, Capelastegui A, Gorordo I et al. Development and validation of a clinical prediction rule for severe community-acquired pneumonia. Am J Respir Crit Care Med 2006; 174: 1249-1256 (2c)

252 Mandell LA, Wunderink RG, Anzueto A et al. Infectious Diseases Society of America/American Thoracic Society Consensus Guidelines on the Management of Community-Acquired Pneumonia in Adults. Clinical Infectious Diseases 2007; 44: S27-S72 (5)

253 Rivers E, Nguyen B, Havstad S et al. Early goal-directed therapy in the treatment of severe sepsis and septic shock. N Engl J Med 2001; 345: $1368-1377(1 b)$

254 Mansel JK, Rosenow EC III, Smith TF, Martin JW Jr. Mycoplasma pneumoniae pneumonia. Chest 1989; 95: 639-646 (4)

255 Petitpretz P, Arvis P, Marel M et al. Oral moxifloxacin vs. high-dosage amoxicillin in the treatment of mild-to-moderate, community-acquired, suspected pneumococcal pneumonia in adults. Chest 2001; 119: $185-195(1 \mathrm{~b})$

256 Petitpretz P, Chidiac C, Soriano F et al. The efficacy and safety of oral pharmacokinetically enhanced amoxycillin-clavulanate 2000/ $125 \mathrm{mg}$, twice daily, versus oral amoxycillin-clavulanate 1000/ $125 \mathrm{mg}$, three times daily, for the treatment of bacterial communityacquired pneumonia in adults. Int J Antimicrob Agents 2002; 20: $119-129(1 \mathrm{~b})$

257 Mills GD, Oehley MR, Arrol B. Effectiveness of beta lactam antibiotics compared with antibiotics active against atypical pathogens in nonsevere community acquired pneumonia: meta-analysis. BMJ 2005; 330: 456 (1a)

258 Shefet D, Robenshtok E, Paul M, Leibovici L. Empirical atypical coverage for inpatients with community-acquired pneumonia: systematic review of randomized controlled trials. Arch Intern Med 2005; 165: $1992-2000$ (1a)

259 Tellier G, Niederman MS, Nusrat R et al. Clinical and bacteriological efficacy and safety of 5 and 7 day regimens of telithromycin once daily compared with a 10 day regimen of clarithromycin twice daily in patients with mild to moderate community-acquired pneumonia. J Antimicrob Chemother 2004; 54: 515-523 (1b)

260 Ailani RK, Agastya G, Ailani RK et al. Doxycycline is a cost-effective therapy for hospitalized patients with community-acquired pneumonia. Arch Intern Med 1999; 159: 266-270 (2b) 
261 Gordon JJ, Kauffman CA. Superinfection with Streptococcus pneumoniae during therapy with ciprofloxacin. Am J Med 1990; 89: $383-384$ (5)

262 Kuru T, Lyons JP 3. Nonresolving or slowly resolving pneumonia. Clin Chest Med 1999; 20: 623-651 (4)

263 Dunbar LM, Wunderink RG, Habib MP et al. High-dose, short-course levofloxacin for community-acquired pneumonia: a new treatment paradigm. Clin Infect Dis 2003; 37: 752 - 760 (1b)

264 El Moussaoui R, de Borgie CA, van den Broek P et al. Effectiveness of discontinuing antibiotic treatment after three days versus eight days in mild to moderate-severe community acquired pneumonia: randomised, double blind study. BMJ 2006; 332: 1355 (1b)

265 Li JZ, Winston LG, Moore DH, Bent S. Efficacy of short-course antibiotic regimens for community-acquired pneumonia: a meta-analysis. Am J Med 2007; 120: 783 - 790 (1a)

266 Campbell SG, Marrie TJ, Anstey R et al. The Contribution of Blood Cultures to the Clinical Management of Adult Patients Admitted to the Hospital With Community-Acquired Pneumonia: A Prospective Observational Study. Chest 2003; 123: 1142 -1150 (1b)

267 Lode H, Magyar P, Muir JF et al. Once-daily oral gatifloxacin vs threetimes-daily co-amoxiclav in the treatment of patients with community-acquired pneumonia. Clin Microbiol Infect 2004; 10: 512 - 520 (1b)

268 Okimoto N, Kurihara T, Honda $N$ et al. Clinical effect of ampicillin with beta-lactamase inhibitor (sulbactam/ampicillin) on communityacquired pneumonia in the elderly. J Infect Chemother 2003; 9: $183-186(2 b)$

269 File TM Jr, Segreti J, Dunbar L et al. A multicenter, randomized study comparing the efficacy and safety of intravenous and/or oral levofloxacin versus ceftriaxone and/or cefuroxime axetil in treatment of adults with community-acquired pneumonia. Antimicrob Agents Chemother 1997; 41: 1965-1972 (1b)

270 Gotfried MH, Dattani D, Riffer E et al. A controlled, double-blind, multicenter study comparing clarithromycin extended-release tablets and levofloxacin tablets in the treatment of community-acquired pneumonia. Clin Ther 2002; 24: 736-751 (1b)

271 Hoeffken G, Meyer HP, Winter J, Verhoef L. The efficacy and safety of two oral moxifloxacin regimens compared to oral clarithromycin in the treatment of community-acquired pneumonia. Respir Med 2001; 95: $553-564(1 \mathrm{~b})$

272 Scheld WM. Maintaining fluoroquinolone class efficacy: review of influencing factors. Emerg Infect Dis 2003; 9: 1 -9 (5)

273 Zuck P, Rio Y, Ichou F. Efficacy and tolerance of cefpodoxime proxetil compared with ceftriaxone in vulnerable patients with bronchopneumonia. J Antimicrob Chemother 1990; 26 (Suppl. E): 71 - 77 (2b)

274 Paladino JA, Eubanks DA, Adelman MH, Schentag IJ. Once-daily cefepime versus ceftriaxone for nursing home-acquired pneumonia. J Am Geriatr Soc 2007; 55: 651 - 657 (1b)

275 Bohte R, van Furth $R$, van den Broek PJ. Aetiology of community-acquired pneumonia: a prospective study among adults requiring admission to hospital. Thorax 1995; 50: $543-547$ (4)

276 Fine MJ, Stone RA, Singer DE et al. Processes and outcomes of care for patients with community-acquired pneumonia: results from the Pneumonia Patient Outcomes Research Team (PORT) cohort study. Arch Intern Med 1999; 159: 970 - 980 (4)

277 Allewelt $M$, Steinhoff D, Rahlwes $M$ et al. Wandel im Erregerspektrum ambulant-erworbener Pneumonien (1982-1992). Dtsch Med Wochenschr 1997; 122: 1027-1032 (4)

278 Welte T, Marre R, Suttorp N. Das Kompetenznetzwerk Ambulant erworbene Pneumonie (CAPNETZ). Ein erster Zwischenbericht. Internist (Berl) 2004; 45: 393 - 401 (4)

279 Mundy LM, Auwaerter PG, Oldach D et al. Community-acquired pneumonia. Impact of immune status. Am J Respir Crit Care Med 1995; 152: $1309-1315(4)$

280 Lieberman D, Schlaeffer F, Boldur I et al. Multiple pathogens in adult patients admitted with community-acquired pneumonia: a one year prospective study of 346 consecutive patients. Thorax 1996; 51: $179-184(4)$

281 Fine MJ, Auble TE, Yealy DM et al. A prediction rule to identify low-risk patients with community-acquired pneumonia. N Engl J Med 1997; 336: $243-250$ (2c)

282 Roson B, Carratala J, Fernandez-Sabe $N$ et al. Causes and factors associated with early failure in hospitalized patients with communityacquired pneumonia. Arch Intern Med 2004; 164: 502 - 508 (2c)
283 Menendez R, Torres A, Zalacain R et al. Risk factors of treatment failure in community acquired pneumonia: implications for disease outcome. Thorax 2004; 59: 960 - 965 (2c)

284 Syrjala H, Broas M, Suramo I et al. High-resolution computed tomography for the diagnosis of community-acquired pneumonia. Clin Infect Dis 1998; 27: $358-363$ (4)

285 Fine MJ, Smith MA, Carson CA et al. Prognosis and outcomes of patients with community-acquired pneumonia. A meta-analysis. JAMA 1996; 275: 134 - 141 (2a)

286 Ahkee S, Srinath L, Ramirez J. Community-acquired pneumonia in the elderly: association of mortality with lack of fever and leukocytosis. South Med J 1997; 90: 296-298 (2b)

287 Almirall J, Bolibar I, Toran P et al. Contribution of C-Reactive Protein to the Diagnosis and Assessment of Severity of Community-Acquired Pneumonia. Chest 2004; 125: 1335 - 1342 (3c)

288 van der Meer V, Neven AK, van den Broek PJ, Assendelft WJ. Diagnostic value of $C$ reactive protein in infections of the lower respiratory tract: systematic review. BMJ 2005; 331: 26 (1a)

289 Smith RP, Lipworth BJ, Cree IA et al. C-reactive protein. A clinical marker in community-acquired pneumonia. Chest 1995; 107: 1028-1031 (2b)

290 Coelho L, Povoa P, Almeida E et al. Usefulness of C-reactive protein in monitoring the severe community-acquired pneumonia clinical course. Crit Care 2007; 11: R92 - R100 (3b)

291 Christ-Crain M, Stolz D, Bingisser R et al. Procalcitonin guidance of antibiotic therapy in community-acquired pneumonia: a randomized trial. Am J Respir Crit Care Med 2006; 174: 84-93 (1b)

292 Masia M, Gutierrez F, Shum C et al. Usefulness of procalcitonin levels in community-acquired pneumonia according to the patients outcome research team pneumonia severity index. Chest 2005; 128 : $2223-2229$ (2b)

293 Hoogewerf M, Oosterheert JJ, Hak E et al. Prognostic factors for early clinical failure in patients with severe community-acquired pneumonia. Clin Microbiol Infect 2006; 12: 1097 - 1104 (2c)

294 Blot SI, Rodriguez A, Sole-Violan J et al. Effects of delayed oxygenation assessment on time to antibiotic delivery and mortality in patients with severe community-acquired pneumonia. Crit Care Med 2007; 35: $2509-2514(2 \mathrm{c})$

295 Josephson MA, Agger WA, Bennett CL et al. Performance measurement in pneumonia care: beyond report cards. Mayo Clin Proc 1998; $73: 5-$ 9 (4)

296 Sanyal S, Smith PR, Saha AC et al. Initial microbiologic studies did not affect outcome in adults hospitalized with community-acquired pneumonia. Am J Respir Crit Care Med 1999; 160: 346 - 348 (4)

297 Wunderink RG, Waterer GW. Appropriate microbiological testing in community-acquired pneumonia. Chest 2001; 119: 5 -7 (5)

298 van der Eerden MM, Vlaspolder F, de Graaff CS et al. Comparison between pathogen directed antibiotic treatment and empirical broad spectrum antibiotic treatment in patients with community acquired pneumonia: a prospective randomised study. Thorax 2005; 60: 672 678 (1b)

299 Metersky ML. Is the lateral decubitus radiograph necessary for the management of a parapneumonic pleural effusion? Chest 2003; 124: 1129 - 1132 (5)

300 Colice GL, Curtis A, Deslauriers J et al. Medical and surgical treatment of parapneumonic effusions: an evidence-based guideline. Chest 2000; 118: 1158 - 1171 (5)

301 Heath CH, Grove DI, Looke DF. Delay in appropriate therapy of Legionella pneumonia associated with increased mortality. Eur J Clin Microbiol Infect Dis 1996; 15: 286-290 (2c)

302 Guchev IA, Yu VL, Sinopalnikov A et al. Management of Nonsevere Pneumonia in Military Trainees with the Urinary Antigen Test for Streptococcus pneumoniae: An Innovative Approach to Targeted Therapy. Clinical Infectious Diseases 2005; 40: 1608-1616 (2b)

303 Gacouin A, Le Tulzo Y, Lavoue S et al. Severe pneumonia due to Legionella pneumophila: prognostic factors, impact of delayed appropriate antimicrobial therapy. Intensive Care Med 2002; 28: 686-691 (2c)

304 Meehan TP, Fine MJ, Krumholz HM et al. Quality of care, process, and outcomes in elderly patients with pneumonia. JAMA 1997; 278 : $2080-2084(2 c)$

305 Gleason PP, Meehan TP, Fine JM et al. Associations between initial antimicrobial therapy and medical outcomes for hospitalized elderly patients with pneumonia. Arch Intern Med 1999; 159: 2562 - 2572 (2c) 
306 Houck PM, MacLehose RF, Niederman MS, Lowery JK. Empiric antibiotic therapy and mortality among medicare pneumonia in patients in 10 western states: 1993, 1995, and 1997. Chest 2001; 119: 1420 $1426(4)$

307 Martinez JA, Horcajada JP, Almela M et al. Addition of a macrolide to a beta-lactam-based empirical antibiotic regimen is associated with lower in-hospital mortality for patients with bacteremic pneumococcal pneumonia. Clin Infect Dis 2003; 36: 389 - 395 (2c)

308 Mufson MA, Stanek RJ. Bacteremic pneumococcal pneumonia in one American City: a 20-year longitudinal study, 1978-1997. Am J Med 1999; 107: 34S-43S (4)

309 Stahl JE, Barza M, DesJardin J et al. Effect of macrolides as part of initial empiric therapy on length of stay in patients hospitalized with community-acquired pneumonia. Arch Intern Med 1999; 159: 2576 $2580(2 \mathrm{c})$

310 Baddour LM, Yu VL, Klugman KP et al. Combination antibiotic therapy lowers mortality among severely ill patients with pneumococcal bacteremia. Am J Respir Crit Care Med 2004; 170: 440 - 444 (2c)

311 Aspa J, Rajas 0, Rodriguez de CF et al. Impact of initial antibiotic choice on mortality from pneumococcal pneumonia. Eur Respir J 2006; 27: $1010-1019(2 \mathrm{c})$

312 Dwyer R, Ortqvist A, Aufwerber E et al. Addition of a macrolide to a sslactam in bacteremic pneumococcal pneumonia. Eur J Clin Microbiol Infect Dis 2006; 25: $518-521$ (2c)

313 Finch $R$, Schurmann D, Collins 0 et al. Randomized controlled trial of sequential intravenous (i.v.) and oral moxifloxacin compared with sequential i.v. and oral co-amoxiclav with or without clarithromycin in patients with community-acquired pneumonia requiring initial parenteral treatment. Antimicrob Agents Chemother 2002; 46: $1746-1754$ (1b)

314 Correa JC, Badaro R, Bumroongkit C et al. Randomized, open-label, parallel-group, multicenter study of the efficacy and tolerability of IV gatifloxacin with the option for oral stepdown gatifloxacin versus IV ceftriaxone (with or without erythromycin or clarithromycin) with the option for oral stepdown clarithromycin for treatment of patients with mild to moderate community-acquired pneumonia requiring hospitalization. Clin Ther 2003; 25: 1453 - 1468 (1b)

315 Frank E, Liu J, Kinasewitz G et al. A multicenter, open-label, randomized comparison of levofloxacin and azithromycin plus ceftriaxone in hospitalized adults with moderate to severe community-acquired pneumonia. Clin Ther 2002; 24: 1292 -1308 (1b)

316 Vergis EN, Indorf A, File TM Jr et al. Azithromycin vs. cefuroxime plus erythromycin for empirical treatment of community-acquired pneumonia in hospitalized patients: a prospective, randomized, multicenter trial. Arch Intern Med 2000; 160: 1294-1300 (1b)

317 Feldman RB, Rhew DC, Wong JY et al. Azithromycin monotherapy for patients hospitalized with community-acquired pneumonia: a 31/2year experience from a veterans affairs hospital. Arch Intern Med 2003; 163: 1718 - 1726 (4)

318 Williams D, Perri M, Zervos MJ. Randomized comparative trial with ampicillin/sulbactam versus cefamandole in the therapy of community acquired pneumonia. Eur J Clin Microbiol Infect Dis 1994; 13 : $293-298$ (1b)

319 Norrby SR, Petermann W, Willcox PA et al. A comparative study of levofloxacin and ceftriaxone in the treatment of hospitalized patients with pneumonia. Scand J Infect Dis 1998; 30: 397-404 (1b)

320 Dansey RD, Jacka PJ, Strachan SA, Hay M. Comparison of cefotaxime with ceftriaxone given intramuscularly 12-hourly for communityacquired pneumonia. Diagn Microbiol Infect Dis 1992; 15: $81-84$ (1b)

321 Van den Brande P, Vondra V, Vogel F et al. Sequential therapy with cefuroxime followed by cefuroxime axetil in community-acquired pneumonia. Chest 1997; 112: $406-415$ (1b)

322 Vetter N, Cambronero-Hernandez E, Rohlf J et al. A prospective, randomized, double-blind multicenter comparison of parenteral ertapenem and ceftriaxone for the treatment of hospitalized adults with community-acquired pneumonia. Clin Ther 2002; 24: 1770-1785 (1b)

323 Yakovlev SV, Stratchounski LS, Woods GL et al. Ertapenem versus cefepime for initial empirical treatment of pneumonia acquired in skilled-care facilities or in hospitals outside the intensive care unit. Eur J Clin Microbiol Infect Dis 2006; 25: 633-641 (1b)

324 Plouffe J, Schwartz DB, Kolokathis A et al. Clinical efficacy of intravenous followed by oral azithromycin monotherapy in hospitalized patients with community-acquired pneumonia. The Azithromycin In- travenous Clinical Trials Group. Antimicrob Agents Chemother 2000; 44: $1796-1802$ (1b)

325 Sanchez F, Mensa J, Martinez JA et al. Is azithromycin the first-choice macrolide for treatment of community-acquired pneumonia? Clin Infect Dis 2003; 36: 1239-1245 (2b)

326 Chien SM, Pichotta P, Siepman N, Chan CK. Treatment of communityacquired pneumonia. A multicenter, double-blind, randomized study comparing clarithromycin with erythromycin. Canada-Sweden Clarithromycin-Pneumonia Study Group. Chest 1993; 103: 697 - 701 (2b)

327 Salvarezza CR, Mingrone H, Fachinelli H, Kijanczuk S. Comparison of roxithromycin with cefixime in the treatment of adults with community-acquired pneumonia. J Antimicrob Chemother 1998; 41 (Suppl. B): $75-80$ (1b)

328 Ortqvist A, Valtonen $M$, Cars $O$ et al. Oral empiric treatment of community-acquired pneumonia. A multicenter, double-blind, randomized study comparing sparfloxacin with roxithromycin. The Scandinavian Sparfloxacin Study Group. Chest 1996; 110: 1499-1506 (1b)

329 Welte T, Petermann W, Schurmann D et al. Treatment with sequential intravenous or oral moxifloxacin was associated with faster clinical improvement than was standard therapy for hospitalized patients with community-acquired pneumonia who received initial parenteral therapy. Clin Infect Dis 2005; 41: 1697-1705 (1b)

330 Anzueto A, Niederman MS, Pearle J et al. Community-Acquired Pneumonia Recovery in the Elderly (CAPRIE): efficacy and safety of moxifloxacin therapy versus that of levofloxacin therapy. Clin Infect Dis 2006; 42: $73-81$ (1b)

331 Oosterheert JJ, Bonten MJM, Hak E et al. How good is the evidence for the recommended empirical antimicrobial treatment of patients hospitalized because of community-acquired pneumonia? A systematic review. J Antimicrob Chemother 2003; 52: 555 - 563 (2a)

332 Wasserfallen JB, Erard V, Cometta A et al. Cost-effectiveness of fullcourse oral levofloxacin in severe community-acquired pneumonia. European Respiratory Journal 2004; 24: 644-648 (1b)

333 Oosterheert JJ, Bonten MJ, Schneider MM et al. Effectiveness of early switch from intravenous to oral antibiotics in severe community acquired pneumonia: multicentre randomised trial. BMJ 2006; 333: $1193-1197$ (1b)

334 Castro-Guardiola A, Viejo-Rodriguez AL, Soler-Simon S et al. Efficacy and safety of oral and early-switch therapy for community-acquired pneumonia: a randomized controlled trial. Am J Med 2001; 111: $367-374(1 \mathrm{~b})$

335 Ramirez JA, Srinath L, Ahkee S et al. Early switch from intravenous to oral cephalosporins in the treatment of hospitalized patients with community-acquired pneumonia. Arch Intern Med 1995; 155: 1273 $1276(4)$

336 Paladino JA, Gudgel LD, Forrest A, Niederman MS. Cost-effectiveness of IV-to-oral switch therapy: azithromycin vs cefuroxime with or without erythromycin for the treatment of community-acquired pneumonia. Chest 2002; 122: 1271 - 1279 (1b)

337 Rhew DC, Hackner D, Henderson L et al. The clinical benefit of in-hospital observation in 'low-risk' pneumonia patients after conversion from parenteral to oral antimicrobial therapy. Chest 1998; 113 : $142-146$ (4)

338 Rhew DC, Tu GS, Ofman J et al. Early switch and early discharge strategies in patients with community-acquired pneumonia: a meta-analysis. Arch Intern Med 2001; 161: 722 - 727 (1a)

339 Siegel RE, Halpern NA, Almenoff PL et al. A prospective randomized study of inpatient i.v. antibiotics for community-acquired pneumonia. The optimal duration of therapy. Chest 1996; 110: 965 -971 (1b)

340 Bohte R, van't Wout JW, Lobatto S et al. Efficacy and safety of azithromycin versus benzylpenicillin or erythromycin in community-acquired pneumonia. Eur J Clin Microbiol Infect Dis 1995; 14: 182-187 (2b)

341 Fine MJ, Hanusa BH, Lave JR et al. Comparison of a disease-specific and a generic severity of illness measure for patients with communityacquired pneumonia. J Gen Intern Med 1995; 10: 359- 368 (4)

342 Samama MM, Cohen AT, Darmon JY et al. A comparison of enoxaparin with placebo for the prevention of venous thromboembolism in acutely ill medical patients. Prophylaxis in Medical Patients with Enoxaparin Study Group. N Engl J Med 1999; 341: 793 - 800 (1b)

343 Mundy LM, Leet TL, Darst K et al. Early mobilization of patients hospitalized with community-acquired pneumonia. Chest 2003; 124: $883-889$ (1b) 
344 Halm EA, Fine MJ, Marrie TJ et al. Time to clinical stability in patients hospitalized with community-acquired pneumonia: implications for practice guidelines. JAMA 1998; 279: 1452 - 1457 (4)

345 Fine MJ, Smith DN, Singer DE. Hospitalization decision in patients with community-acquired pneumonia: a prospective cohort study. Am J Med 1990; 89: 713-721 (4)

346 Fine MJ, Singer DE, Hanusa BH et al. Validation of a pneumonia prognostic index using the MedisGroups Comparative Hospital Database. Am J Med 1993; 94: 153-159 (4)

347 Halm EA, Fine MJ, Kapoor WN et al. Instability on hospital discharge and the risk of adverse outcomes in patients with pneumonia. Arch Intern Med 2002; 162: 1278-1284 (4)

348 Halm EA, Teirstein AS. Clinical practice. Management of communityacquired pneumonia. N Engl J Med 2002; 347: 2039-2045 (5)

349 Torres A, Serra BJ, Ferrer A et al. Severe community-acquired pneumonia. Epidemiology and prognostic factors. Am Rev Respir Dis 1991; 144: 312 - 318 (4)

350 Mittl RLJr, Schwab RJ, Duchin JS et al. Radiographic resolution of community-acquired pneumonia. Am J Respir Crit Care Med 1994; 149: $630-635(2 \mathrm{c})$

351 Bruns AH, Oosterheert JJ, Prokop M et al. Patterns of resolution of chest radiograph abnormalities in adults hospitalized with severe community-acquired pneumonia. Clin Infect Dis 2007; 45: 983 - 991 (2c)

352 Feinsilver SH, Fein AM, Niederman MS et al. Utility of fiberoptic bronchoscopy in non-resolving pneumonia. Chest 1990; 98: 1322-1326 (4)

353 El Moussaoui R, Opmeer BC, de Borgie CA et al. Long-term symptom recovery and health-related quality of life in patients with mild-to-moderate-severe community-acquired pneumonia. Chest 2006; 130: $1165-1172(2 \mathrm{~b})$

354 Waterer GW, Kessler LA, Wunderink RG. Medium-Term Survival after Hospitalization with Community-Acquired Pneumonia. Am J Respir Crit Care Med 2004; 169: 910-914 (2c)

355 Mortensen EM, Kapoor WN, Chang CCH, Fine MJ. Assessment of mortality after long-term follow-up of patients with community-acquired pneumonia. Clin Infect Dis 2003; 37: 1617-1624 (3b)

356 Mortensen EM, Coley CM, Singer DE et al. Causes of death for patients with community-acquired pneumonia: results from the Pneumonia Patient Outcomes Research Team cohort study. Arch Intern Med 2002; 162: 1059-1064 (2c)

357 Baudouin SV. The pulmonary physician in critical care. 3: critical care management of community acquired pneumonia. Thorax 2002; 57 267-271 (5)

358 Dahmash NS, Chowdhury MN. Re-evaluation of pneumonia requiring admission to an intensive care unit: a prospective study. Thorax 1994; 49: $71-76(4)$

359 Hook EWII, Horton CA, Schaberg DR. Failure of intensive care unit support to influence mortality from pneumococcal bacteremia. JAMA 1983; 249: 1055-1057 (2b)

360 Kaplan V, Angus DC, Griffin MF et al. Hospitalized community-acquired pneumonia in the elderly: age- and sex-related patterns of care and outcome in the United States. Am J Respir Crit Care Med 2002; 165: $766-772(4)$

361 Leroy 0 , Vandenbussche C, Coffinier C et al. Community-acquired aspiration pneumonia in intensive care units. Epidemiological and prognosis data. Am J Respir Crit Care Med 1997; 156: 1922 - 1929 (2c)

362 Cosentini $R$, Blasi F, Raccanelli $R$ et al. Severe community-acquired pneumonia: a possible role for Chlamydia pneumoniae. Respiration 1996; 63: $61-65$ (4)

363 Feldman C, Ross S, Goolam Mahomed A et al. The aetiology of severe community-acquired pneumonia and its impact on intial, empiric, antimicrobial treatment. Respir Med 1995; 89: 187-192 (4)

364 Marik PE. The clinical features of severe community-acquired pneumonia presenting as septic shock. Norasept II Study Investigators. J Crit Care 2000; 15: 85-90 (4)

365 Moine $P$, Vercken JB, Chevret $S$ et al. Severe community-acquired pneumonia. Etiology, epidemiology, and prognosis factors. Chest 1994; 105: 1487-1495 (4)

366 Ortiz-Ruiz G, Caballero-Lopez J, Friedland IR et al. Protocol 018 Ertapenem Community-Acquired Pneumonia Study Group. A study evaluating the efficacy, safety, and tolerability of ertapenem versus ceftriaxone for the treatment of community-acquired pneumonia in adults. Clin Infect Dis 2002; 34: 1076-1083 (1b)
367 Rodriguez A, Mendia A, Sirvent JM et al. Combination antibiotic therapy improves survival in patients with community-acquired pneumonia and shock. Crit Care Med 2007; 35: 1493 -1498 (2c)

368 Rello J, Bodi M, Mariscal D et al. Microbiological Testing and Outcome of Patients With Severe Community-Acquired Pneumonia. Chest 2003; 123: $174-180$ (4)

369 Boussekey N, Leroy O, Alfandari S et al. Procalcitonin kinetics in the prognosis of severe community-acquired pneumonia. Intensive Care Med 2006; 32: 469-472 (2c)

370 Bandyopadhyay T, Gerardi DA, Metersky ML. A comparison of induced and expectorated sputum for the microbiological diagnosis of community acquired pneumonia. Respiration 2000; 67: 173 -176 (4)

371 Ewig S, Schlochtermeier M, Göke N, Niederman MS. Applying sputum as a diagnostic tool in pneumonia: Limited yield, minimal impact on treatment decisions. Chest 2002; 121: 1486-1492 (1b)

372 Formica $N$, Yates $M$, Beers $M$ et al. The impact of diagnosis by legionella urinary antigen test on the epidemiology and outcomes of Legionnaires' disease. Epidemiol Infect 2001; 127: 275 - 280 (5)

373 Ruf B, Schurmann D, Horbach I et al. Prevalence and diagnosis of Legionella pneumonia: a 3-year prospective study with emphasis on application of urinary antigen detection. J Infect Dis 1990; 162: $1341-1348(2 b)$

374 Jimenez $P$, Saldias $F$, Meneses $M$ et al. Diagnostic fiberoptic bronchoscopy in patients with community-acquired pneumonia. Comparison between bronchoalveolar lavage and telescoping plugged catheter cultures. Chest 1993; 103: 1023-1027 (2b)

$375 \mathrm{Kahn}$ FW, Jones JH. Analysis of bronchoalveolar lavage specimens from immunocompromized patients with a protocol applicable in the microbiology Iaboratory. J Clin Microbiol 1988; 26: 1150 - 1155 (4)

376 Kumar A, Roberts D, Wood KE et al. Duration of hypotension before initiation of effective antimicrobial therapy is the critical determinant of survival in human septic shock. Crit Care Med 2006; 34 : $1589-1596(2 \mathrm{c})$

377 Leroy O, Saux P, Bedos JP, Caulin E. Comparison of levofloxacin and cefotaxime combined with ofloxacin for ICU patients with communityacquired pneumonia who do not require vasopressors. Chest 2005; 128: $172-183(1 \mathrm{~b})$

378 Fink MP, Snydman DR, Niederman MS et al. Severe Pneumonia Study Group. Treatment of severe pneumonia in hospitalized patients: Results of a multicenter, randomized, double blind trial comparing intravenous ciprofloxacin with imipenem/cilastatin. J Antimicrob Chemother 1994; 38: 547-557 (1b)

379 Geddes A, Thaler M, Schonwald S et al. Levofloxacin in the empirical treatment of patients with suspected bacteraemia/sepsis: comparison with imipenem/cilastatin in an open, randomized trial. J Antimicrob Chemother 1999; 44: 799-810 (1b)

380 Leophonte P, Veyssier P. Levofloxacin in the treatment of communityacquired pneumococcal pneumonia. Presse Med 1999; 28: 19751979 (4)

381 Rello J, Catalan M, Diaz E et al. Associations between empirical antimicrobial therapy at the hospital and mortality in patients with severe community-acquired pneumonia. Intensive Care Med 2002; 28: $1030-1035$ (2b)

382 Waterer GW, Somes GW, Wunderink RG. Monotherapy may be suboptimal for severe bacteremic pneumococcal pneumonia. Arch Intern Med 2001; 161: 1837-1842 (2c)

383 Bartlett JG. Empirical therapy of community-acquired pneumonia: macrolides are not ideal choices. Semin Respir Infect 1997; 12: 329 $333(5)$

384 Safdar N, Handelsman J, Maki DG. Does combination antimicrobial therapy reduce mortality in Gram-negative bacteraemia? A metaanalysis. Lancet Infect Dis 2004; 4: 519-527 (1a)

385 Lim WS, Macfarlane JT. A prospective comparison of nursing home acquired pneumonia with community acquired pneumonia. Eur Respir J 2001; 18: 362 - 368 (2c)

386 Grimm H, Funke G. Bedeutung der antibakteriellen Eigenaktivität von Sulbactam und Tazobactam für die Empfindlichkeitsprüfung von Inhibitor-geschützten Penicillinen. Chemother J 2004; 13: 238 - 241 (2b)

387 Paul M, Benuri-Silbiger I, Soares-Weiser K, Leibovici L. $\beta$-lactam monotherapy versus $\beta$-lactam-aminoglycoside combination therapy for sepsis in immunocompetent patients: systematic review and meta-analysis of randomised trials. BMJ 2004; 328: 668-670 (1a) 
388 Mortensen E, Restrepo M, Anzueto A, Pugh J. The impact of empiric antimicrobial therapy with a beta-lactam and fluoroquinolone on mortality for patients hospitalized with severe pneumonia. Critical Care 2006; 10: R8-R15 (2c)

389 Chamot E, Boffi El Amari E, Rohner P, Van Delden C. Effectiveness of Combination Antimicrobial Therapy for Pseudomonas aeruginosa Bacteremia. Antimicrob Agents Chemother 2003; 47: 2756- 2764 (2c)

390 Garnacho-Montero J, Sa-Borges M, Sole-Violan J et al. Optimal management therapy for Pseudomonas aeruginosa ventilator-associated pneumonia: an observational, multicenter study comparing monotherapy with combination antibiotic therapy. Crit Care Med 2007; 35: $1888-1895(2 \mathrm{c})$

391 Chapman TM, Perry CM. Cefepime: a review of its use in the management of hospitalized patients with pneumonia. Am J Respir Med 2003; $2: 75-107$ (5)

392 Chastre J, Wolff M, Fagon JY et al. Comparison of 8 vs 15 days of antibiotic therapy for ventilator-associated pneumonia in adults: a randomized trial. JAMA 2003; 290: 2588 - 2598 (2a)

393 Reinhart $K$, Brunkhorst F, Bone H et al. Diagnosis and therapy of sepsis: guidelines of the German Sepsis Society Inc. and the German Interdisciplinary Society for Intensive and Emergency Medicine. Anaesthesist 2006; 55 Suppl 1: 43-56 (5)

394 Confalonieri M, Urbino R, Potena A et al. Hydrocortisone infusion for severe community-acquired pneumonia: a preliminary randomized study. Am J Respir Crit Care Med 2005; 171: 242 - 248 (1b)

395 Fein AM, Feinsilver SH, Niederman MS et al. When pneumonia doesn't get better. Clin Chest Med 1987; 8: 529-541 (5)

396 Kirtland SH, Winterbauer $\mathrm{RH}$. Slowly resolving, chronic, and recurrent pneumonia. Clin Chest Med 1991; 12: 303 - 318 (5)

397 Ortqvist A, Hedlund J, Grillner L et al. Aetiology, outcome and prognostic factors in patients with community acquired pneumonia requiring hospitalisation. Eur Respir J 1990; 3: 1105 -1113 (4)

398 Marrie T. Normal resolution of community-acquired pneumonia. Semin Respir Infect 1992; 7: 289-293 (4)

$399 \mathrm{El} \mathrm{Sohl} \mathrm{AA,} \mathrm{Aquilina} \mathrm{AT,} \mathrm{Gunen} \mathrm{H,} \mathrm{Ramadan} \mathrm{F.} \mathrm{Radiographic} \mathrm{resolution}$ of community-acquired bacterial pneumonia in the elderly. J Am Geriatr Soc 2004; 52: 224-229 (4)

400 Metlay JP, Fine MJ, Schulz R et al. Measuring symptomatic and functional recovery in patients with community-acquired pneumonia. J Gen Intern Med 1997; 12: 423-430 (4)

401 Pedro-Botet ML, Sabria M, Sopena $N$ et al. Legionnaires Disease and HIV Infection. Chest 2003; 124: $543-547$ (2c)

402 Pereira Gomes JC, Pedreira JW Jr, Araujo EM et al. Impact of BAL in the management of pneumonia with treatment failure: positivity of BAL culture under antibiotic therapy. Chest 2000; 118: 1739-1746 (2b)

403 Menendez R, Perpina M, Torres A. Evaluation of nonresolving and progressive pneumonia. Semin Respir Infect 2003; 18: 103 -111 (5)

404 Muder RR. Pneumonia in residents of long-term care facilities: epidemiology, etiology, management, and prevention. Am J Med 1998; 105: $319-330(5)$

405 van der Eerden MM, Vlaspolder F, de Graaff CS et al. Value of intensive diagnostic microbiological investigation in low- and high-risk patients with community-acquired pneumonia. Eur J Clin Microbiol Infect Dis 2005; 24: $241-249$ (2b)

406 Franquet $T$. Imaging of pneumonia: trends and algorithms. Eur Respir J 2001; 18: 196-208 (5)

407 Tomiyama N, Muller NL, Johkoh T et al. Acute parenchymal lung disease in immunocompetent patients: diagnostic accuracy of high-resolution CT. AJR Am J Roentgenol 2000; 174: 1745 -1750 (2b)

408 Maskell NA, Davies CW, Nunn AJ et al. U.K. Controlled trial of intrapleural streptokinase for pleural infection. N Engl J Med 2005; 352: $865-874(1 \mathrm{~b})$

409 Marik PE. Aspiration pneumonitis and aspiration pneumonia. N Engl ] Med 2001; 344: 665-671 (5)

410 Kikuchi R, Watabe N, Konno T et al. High incidence of silent aspiration in elderly patients with community-acquired pneumonia. Am J Respir Crit Care Med 1994; 150: 251 - 253 (4)

411 Loeb M, McGeer A, McArthur M et al. Risk factors for pneumonia and other lower respiratory tract infections in elderly residents of longterm care facilities. Arch Intern Med 1999; 159: 2058 - 2064 (2c)

412 Nakagawa T, Sekizawa K, Arai $\mathrm{H}$ et al. High incidence of pneumonia in elderly patients with basal ganglia infarction. Arch Intern Med 1997; 157: $321-324(4)$
413 El Solh AA, Pietrantoni C, Bhat A et al. Microbiology of severe aspiration pneumonia in institutionalized elderly. Am J Respir Crit Care Med 2003; 167: 1650 - 1654 (2c)

414 Matthay RA, Arroliga AC. Resection of pulmonary metastases. Am Rev Respir Dis 1993; 148: 1691 - 1696 (5)

415 Mwandumba HC, Beeching NJ. Pyogenic lung infections: factors for predicting clinical outcome of lung abscess and thoracic empyema. Curr Opin Pulm Med 2000; 6: 234-239 (5)

416 Ewig S, Schäfer H. Lungenabszesse neu betrachtet. Eine klinisch handlungsanleitende Klassifikation. Pneumologie 2001; 55: 195-201 (5)

417 Mansharamani N, Balachandran D, Delaney D et al. Lung abscess in adults: clinical comparison of immunocompromised to non-immunocompromised patients. Respir Med 2002; 96: 178 - 185 (3b)

418 Hammond JM, Potgieter PD, Hanslo $D$ et al. The etiology and antimicrobial susceptibility patterns of microorganisms in acute community-acquired lung abscess. Chest 1995; 108: 937-941 (4)

419 Mansharamani NG, Koziel H. Chronic lung sepsis: lung abscess, bronchiectasis, and empyema. Curr Opin Pulm Med 2003; 9: 181 - 185 (5)

420 Porta G, Rodriguez-Carballeira M, Gomez L et al. Thoracic infection caused by Streptococcus milleri. Eur Respir J 1998; 12: 357 - 362 (4)

421 Wong CA, Donald F, Macfarlane JT. Streptococcus milleri pulmonary disease: a review and clinical description of 25 patients. Thorax 1995; 50: 1093 - 1096 (4)

422 Yang PC, Luh KT, Lee YC et al. Lung abscesses: US examination and USguided transthoracic aspiration. Radiology 1991; 180: 171 -175 (4)

423 Hammer DL, Aranda CP, Galati V, Adams FV. Massive intrabronchial aspiration of contents of pulmonary abscess after fiberoptic bronchoscopy. Chest 1978; 74: 306 - 307 (4)

424 Gudiol F, Manresa F, Pallares R et al. Clindamycin vs. penicillin for anaerobic lung infections. High rate of penicillin failures associated with penicillin-resistant Bacteroides melaninogenicus. Arch Intern Med 1990; 150: $2525-2529$ (1b)

425 Levison ME, Mangura CT, Lorber B et al. Clindamycin compared with penicillin for the treatment of anaerobic lung abscess. Ann Intern Med 1983; 98: 466 - 471 (2b)

426 Allewelt M, Schuler P, Bolcskei PL et al. Ampicillin + sulbactam vs. clindamycin \pm cephalosporin for the treatment of aspiration pneumonia and primary lung abscess. Clin Microbiol Infect 2004; 10: 163 - 170 (1b)

427 Fernandez-Sabe N, Carratala J, Dorca J et al. Efficacy and safety of sequential amoxicillin-clavulanate in the treatment of anaerobic lung infections. Eur J Clin Microbiol Infect Dis 2003; 22: 185-187 (4)

428 Klein JS, Schultz S, Heffner JE. Interventional radiology of the chest: image-guided percutaneous drainage of pleural effusions, lung abscess, and pneumothorax. AJR Am J Roentgenol 1995; 164: 581 - 588 (5)

429 van Sonnenberg E, D'Agostino HB, Casola G et al. Lung abscess: CTguided drainage. Radiology 1991; 178: 347-351 (4)

430 Fraser DW, Tsai TR, Orenstein W et al. Legionnaires' disease: description of an epidemic of pneumonia. N Engl J Med 1977; 297: 11891197 (5)

431 Ewig S, Tuschy P, Fätkenheuer G. Diagnostik und Therapie der Legionellen-Pneumonie. Pneumologie 2003; 56: 695-703 (5)

432 Sabria M, Pedro-Botet ML, Gomez J et al. Fluoroquinolones vs. macrolides in the treatment of Legionnaires disease. Chest 2005; 128: $1401-1405$ (2b)

433 Mykietiuk A, Carratala J, Fernandez-Sabe $N$ et al. Clinical outcomes for hospitalized patients with Legionella pneumonia in the antigenuria era: the influence of levofloxacin therapy. Clin Infect Dis 2005; 40: $794-799$ (3b)

434 Blazquez Garrido RM, Espinosa Parra FJ, Alemany FL et al. Antimicrobial chemotherapy for Legionnaires' disease: levofloxacin versus macrolides. Clin Infect Dis 2005; 40: 800-806 (3b)

$435 \mathrm{Grau}$ S, Antonio JM, Ribes $E$ et al. Impact of rifampicin addition to clarithromycin in Legionella pneumophila pneumonia. Int J Antimicrob Agents 2006; 28: 249-252 (4)

436 Dunbar LM, Khashab MM, Kahn JB et al. Efficacy of 750-mg, 5-day levofloxacin in the treatment of community-acquired pneumonia caused by atypical pathogens. Curr Med Res Opin 2004; 20: 555-563 (4)

437 Schonwald S, Kuzman I, Oreskovic K et al. Azithromycin: single $1.5 \mathrm{~g}$ dose in the treatment of patients with atypical pneumonia syndrome - a randomized study. Infection 1999; 27: 198 -202 (2c)

438 Gorak EJ, Yamada SM, Brown JD. Community-acquired methicillin-resistant Staphylococcus aureus in hospitalized adults and children without known risk factors. Clin Infect Dis 1999; 29: 797 - 800 (4) 
439 Nimmo GR, Playford EG. Community-acquired MRSA bacteraemia: four additional cases including one associated with severe pneumonia. Med J Aust 2003; 178: 245 (4)

440 Dufour P, Gillet Y, Bes $M$ et al. Community-acquired methicillin-resistant Staphylococcus aureus infections in France: emergence of a single clone that produces Panton-Valentine leukocidin. Clin Infect Dis 2002; 35: 819-824 (4)

441 Witte W, Cuny C, Strommenger B et al. Emergence of a new community acquired MRSA strain in Germany. Euro Surveill 2004; 9: 1 - 2 (5)

442 Rubinstein E, Cammarata S, Oliphant T, Wunderink RG, Linezolid Nosocomial Pneumonia Study Group. Linezolid (PNU-100766) versus vancomycin in the treatment of hospitalized patients with nosocomial pneumonia: a randomized, double-blind, multicenter study. Clin Infect Dis 2001; 32: $402-412$ (1b)

443 Stevens $D L$, Herr D, Lampiris $H$ et al. Linezolid versus vancomycin for the treatment of methicillin-resistant Staphylococcus aureus infections. Clin Infect Dis 2002; 34: 1481 - 1490 (1b)

444 Bliziotis IA, Ntziora F, Lawrence KR, Falagas ME. Rifampin as adjuvant treatment of Gram-positive bacterial infections: a systematic review of comparative clinical trials. Eur J Clin Microbiol Infect Dis 2007; 26 : $849-856(1 \mathrm{a})$

445 Hidayat LK, Hsu DI, Quist R et al. High-dose vancomycin therapy for methicillin-resistant Staphylococcus aureus infections: efficacy and toxicity. Arch Intern Med 2006; 166: 2138 - 2144 (2c)

446 Jeffres $M N$, Isakow W, Doherty JA et al. A retrospective analysis of possible renal toxicity associated with vancomycin in patients with health care-associated methicillin-resistant Staphylococcus aureus pneumonia. Clin Ther 2007; 29: 1107 -1115 (4)

447 Brier ME, Stalker DJ, Aronoff GR et al. Pharmacokinetics of linezolid in subjects with renal dysfunction. Antimicrob Agents Chemother 2003; 47: 2775 - 2780 (3b)

448 Hilf M, Yu VL, Sharp JT et al. Antibiotic therapy for Pseudomonas aeruginosa bacteremia: outcome correlations in a prospective study of 200 patients. Am J Med 1989; 87: 540-546 (4)

449 Torres A, Bauer TT, Leon C et al. Spanish Nosocomial Pneumonia Study Group. Treatment of severe nosocomial pneumonia requiring mechanical ventilation: A prospective randomized comparison of intravenous ciprofloxacin with imipenem/cilastatin. Thorax 2000; 55: $1033-1039$ (1b)

450 Marrie TJ. Q fever pneumonia. Current Opinion in Infectious Diseases 2004; 17: 137 - 142 (5)

451 British Thoracic Society. BTS Guidelines for the Management of Community Acquired Pneumonia in Adults. Thorax 2001; 56: 1iv-64iv (5)

452 Raoult $D$, Torres $H$, Drancourt $M$. Shell-vial assay: evaluation of a new technique for determining antibiotic susceptibility, tested in 13 isolates of Coxiella burnetii. Antimicrob Agents Chemother 1991; 35 : $2070-2077$ (4)

453 Gikas A, Kofteridis DP, Manios A et al. Newer Macrolides as Empiric Treatment for Acute Q Fever Infection. Antimicrob Agents Chemother 2001; 45: 3644 - 3646 (4)

454 Musso D, Drancourt M, Osscini S, Raoult D. Sequence of quinolone resistance-determining region of gyrA gene for clinical isolates and for an in vitro-selected quinolone-resistant strain of Coxiella burnetii. Antimicrob Agents Chemother 1996; 40: 870-873 (4)

455 Beyer WE, Palache AM, de Jong JC, Osterhaus AD. Cold-adapted live influenza vaccine versus inactivated vaccine: systemic vaccine reactions, local and systemic antibody response, and vaccine efficacy. A meta-analysis. Vaccine 2002; 20: 1340-1353 (1a)

456 Govaert TM, Sprenger MJ, Dinant GJ et al. Immune response to influenza vaccination of elderly people. A randomized double-blind placebocontrolled trial. Vaccine 1994; 12: 1185-1189 (1b)

457 Roos-Van Eijndhoven DG, Cools HJ, Westendorp RG et al. Randomized controlled trial of seroresponses to double dose and booster influenza vaccination in frail elderly subjects. J Med Virol 2001; 63: 293-298 (1b)

458 Allsup SJ, Gosney M, Regan M et al. Side effects of influenza vaccination in healthy older people: a randomised single-blind placebo-controlled trial. Gerontology 2001; 47: 311 - 314 (1b)

459 Gross PA, Hermogenes AW, Sacks HS et al. The efficacy of influenza vaccine in elderly persons. A meta-analysis and review of the literature. Ann Intern Med 1995; 123: 518 - 527 (1a)

460 Nichol KL, Margolis KL, Wuorenma J, Von Sternberg T. The efficacy and cost effectiveness of vaccination against influenza among elderly persons living in the community. N Engl J Med 1994; 331: $778-784$ (2b)
461 Nichol KL, Wuorenma J, Von Sternberg T. Benefits of influenza vaccination for low-, intermediate-, and high-risk senior citizens. Arch Intern Med 1998; 158: 1769-1776 (2b)

462 Spaude KA, Abrutyn E, Kirchner C et al. Influenza vaccination and risk of mortality among adults hospitalized with community-acquired pneumonia. Arch Intern Med 2007; 167: 53 - 59 (2c)

463 Beyer WE, de Bruijn IA, Palache AM et al. Protection against influenza after annually repeated vaccination: a meta-analysis of serologic and field studies. Arch Intern Med 1999; 159: 182 - 188 (2a)

464 STIKO. Empfehlungen der Ständigen Impfkommission (STIKO) am Robert Koch-Institut; Stand: Juli 2008. Epidemiol Bull 2008; 30: 235 254 (5)

465 Hedlund JU, Kalin ME, Ortqvist AB, Henrichsen J. Antibody response to pneumococcal vaccine in middle-aged and elderly patients recently treated for pneumonia. Arch Intern Med 1994; 154: 1961 - 1965 (4)

466 Carson PJ, Nichol KL, O'Brien J et al. Immune function and vaccine responses in healthy advanced elderly patients. Arch Intern Med 2000; 160: 2017 - 2024 (4)

467 Konradsen HB. Quantity and avidity of pneumococcal antibodies before and up to five years after pneumococcal vaccination of elderly persons. Clin Infect Dis 1995; 21: 616-620 (4)

468 Jackson LA, Benson P, Sneller VP et al. Safety of revaccination with pneumococcal polysaccharide vaccine. JAMA 1999; 281: 243 - 248 (4)

469 Fine MJ, Smith MA, Carson CA et al. Efficacy of pneumococcal vaccination in adults. A meta-analysis of randomized controlled trials. Arch Intern Med 1994; 154: 2666 - 2677 (1a)

470 Watson L, Wilson BJ, Waugh N. Pneumococcal polysaccharide vaccine: a systematic review of clinical effectiveness in adults. Vaccine 2002; 20: $2166-2173$ (1a)

471 Moore RA, Wiffen PJ, Lipsky BA. Are the pneumococcal polysaccharide vaccines effective? Meta-analysis of the prospective trials. BMC Fam Pract 2000; 1: 1 - 10 (1a)

472 Cornu C, Yzebe D, Leophonte P et al. Efficacy of pneumococcal polysaccharide vaccine in immunocompetent adults: a meta-analysis of randomized trials. Vaccine 2001; 19: 4780-4790 (1a)

473 Talbot TR, Poehling KA, Hartert TV et al. Reduction in high rates of antibiotic-nonsusceptible invasive pneumococcal disease in Tennessee after introduction of the pneumococcal conjugate vaccine. Clin Infect Dis 2004; 39: 641 - 648 (4)

474 Fisman DN, Abrutyn E, Spaude KA et al. Prior pneumococcal vaccination is associated with reduced death, complications, and length of stay among hospitalized adults with community-acquired pneumonia. Clin Infect Dis 2006; 42: 1093 - 1101 (2c)

475 Vila-Corcoles A, Ochoa-Gondar O, Hospital I et al. Protective effects of the 23-valent pneumococcal polysaccharide vaccine in the elderly population: the EVAN-65 study. Clin Infect Dis 2006; 43: 860-868 (2c)

476 Mykietiuk A, Carratala J, Dominguez A et al. Effect of prior pneumococcal vaccination on clinical outcome of hospitalized adults with community-acquired pneumococcal pneumonia. Eur J Clin Microbiol Infect Dis 2006; 25: 457 - 462 (4)

477 Johnstone J, Marrie TJ, Eurich DT, Majumdar SR. Effect of pneumococcal vaccination in hospitalized adults with community-acquired pneumonia. Arch Intern Med 2007; 167: 1938-1943 (2c)

478 Christenson B, Lundbergh P, Hedlund J, Ortqvist A. Effects of a largescale intervention with influenza and 23-valent pneumococcal vaccines in adults aged 65 years or older: a prospective study. Lancet 2001 ; 357: $1008-1011$ (2b)

479 Trosini-Desert V, Germaud P, Dautzenberg B. Tobacco smoke and risk of bacterial infection. Rev Mal Respir 2004; 21: 539- 547 (2c)

480 Dietrich ES, Brockmann S, Frank UWE, Daschner FD. The economic impact of unnecessary hospital admissions of patients with community acquired pneumonia. 15th Annual Meeting of the ISTAHC 1999; (2c)

481 Oostenbrink J, Buijs-Van der Woude T, van Agthoven $M$ et al. Unit costs of inpatient hospital days. Pharmacoeconomics 2003; 21: 263-271 (4)

482 Ramirez JA, Vargas S, Ritter GW et al. Early switch from intravenous to oral antibiotics and early hospital discharge: a prospective observational study of 200 consecutive patients with community-acquired pneumonia. Arch Intern Med 1999; 159: 2449 - 2454 (4)

483 Simpson SH, Marrie TJ, Majumdar SR. Do guidelines guide pneumonia practice? A systematic review of interventions and barriers to best practice in the management of community-acquired pneumonia. Respir Care Clin N Am 2005; 11: 1 - 13 (2a) 
484 Suwangool P, Moola-Or P, Waiwatana A et al. Effect of a selective restriction policy on antibiotic expenditure and use: an institutional model. J Med Assoc Thai 1991; 74: 272 - 275 (4)

485 Dietrich ES, Schmid M, Bucher A, Lemmen SW. Kostenreduktion in der Antibiotika-Therapie. Krankenhauspharmazie 1998; 19: 287-292 (4)

486 O'Hanley $P$, Rodondi L, Coleman R. Efficacy and cost-effectiveness of antibiotic monitoring at a Veterans Administration hospital. Chemotherapy $1991 ; 37: 22-25$ (2b)

487 Coley KC, Skledar SJ, Fine MJ et al. Changing physician prescribing behavior: the community-acquired pneumonia intervention trial. Am J Health Syst Pharm 2000; 57: 1506 - 1510 (2b)

488 Böhmer W, Loos U, Heissenberg A, Kullmann KH. Leitliniengesteuertes infektiologisches Qualitätsmanagement auf einer internistischen Allgemeinstation bei Patienten mit ambulant erworbener Pneumonie. Chemother J 2002; 11: 83 - 86 (2b)

489 Lemmen SW, Hafner H, Kotterik $S$ et al. Influence of an infectious disease service on antibiotic prescription behavior and selection of multiresistant pathogens. Infection 2000; 28: $384-387$ (4)

490 Dietrich ES, Jopp R, Schreier $U$ et al. Kosten einer leitliniengerechten Arzneimitteltherapie in Deutschland. Gesundh ökon Qual manag 2005; 10: 35 - 43 (4)

491 Menendez R, Reyes S, Martinez R et al. Economic evaluation of adherence to treatment guidelines in nonintensive care pneumonia. Eur Respir J 2007; 29: 751 - 756 (2b)

492 Oosterheert JJ, Bonten MJ, Schneider MM, Hoepelman IM. Predicted effects on antibiotic use following the introduction of British or North American guidelines for community-acquired pneumonia in The Netherlands. Clin Microbiol Infect 2005; 11: 992 - 998 (4)

493 Omidvari K, de Boisblanc BP, Karam G et al. Early transition to oral antibiotic therapy for community-acquired pneumonia: duration of therapy, clinical outcomes, and cost analysis. Respir Med 1998; 92: $1032-1039$ (1b)

494 Ambrose PG, Quintiliani R, Nightingale $C H$, Nicolau DP. Continuous vs. intermittent infusion of cefuroxime for the treatment of communityacquired pneumonia. Infect Dis Clin Pract 1998; 7: 463 - 470 (2b)

495 Schädlich PK, Huppertz E, Brecht JG. Levofloxacin versus relevant alternatives in inpatient treatment of community-acquired pneumonia: results of a german economic evaluation. (Abstract T105). Antiinfect Drugs Chemother 1998; 16: 62 (4)

496 Richerson MA, Ambrose PG, Quintiliani $R$ et al. Pharmacoeconomic evaluation of alternative antibiotic regimens in hospitalized patients with community-acquired pneumonia. Infect Dis Clin Pract 1998; 7: $227-233$ (2b)

497 Hasali MA, Ibrahim MI, Sulaiman SA et al. A clinical and economic study of community-acquired pneumonia between single versus combination therapy. Pharm World Sci 2005; 27: 249-253 (1b)

498 Jäcker A. Was sparen Generika wirklich? - Eine Analyse aus volkswirtschaftlicher Perspektive. Ges Pol 2004; 2004: 1 - 4 (5)

499 Standing Medical Advisory Committee. The Path of Least Resistance. 1998: (5)

500 Kaptchuk TJ. The placebo effect in alternative medicine: can the performance of a healing rutual have clinical significance? Ann Intern Med 2002; 136: $817-825$ (5)

501 Wandstrat TL, Kaplan B. Pharmacoeconomic impact of factors affecting compliance of antibiotic regimens in the treatment of acute otitis media. Pediatr Infect Dis J 1997; 16: S27 - S29 (4)

502 Einarsson S, Kristjansson M, Kristinsson KG et al. Pneumonia caused by penicillin-non-susceptible and penicillin-susceptible pneumococci in adults: a case-control study. Scand J Infect Dis 1998; 30: 253-256 (3b)

503 de Klerk GJ, van Steijn JH, Lobatto $S$ et al. A randomised, multicentre study of ceftriaxone versus standard therapy in the treatment of lower respiratory tract infections. Int J Antimicrob Agents 1999; 12: $121-127$ (1b)

504 Dietrich ES, Joseph U, Vogel F et al. Cost-effectiveness of ceftriaxone $1 \mathrm{~g}$ vs. second-generation cephalosporins in the treatment of pneumonia in general medical wards in Germany. Infection 1999; 27: 148 - 154 (2b)

505 Siegel RE, Alicea M, Lee A, Blaiklock R. Comparison of 7 versus 10 days of antibiotic therapy for hospitalized patients with uncomplicated community-acquired pneumonia: A prospective, randomized, double-blind study. Am J Ther 1999; 6: 217-222 (1b)

506 Groth JJ. A pahrmacoeconomic study: clarithromycin in bronchitis and pneumonia. Klinikarzt 1998; 4: 22-24 (2b)

507 Huber SL, Wood JS, Weston JS et al. Antibiotic therapy in communityacquired pneumonia and the role of the hospital pharmacist. Am J Man Care 1999; 5: S555 -S569 (4)

508 Hueston WJ, Mainous AG, Brauer N, Mercuri J. Evaluation and treatment of respiratory infections: does managed care make a difference? J Fam Pract 1997; 44: 572-577 (4)

509 Stelianides S, Golmard JL, Carbon C, Fantin B. Influence of socioeconomic status on features and outcome of community-acquired pneumonia. Eur J Clin Microbiol Infect Dis 1999; 18: $704-708$ (2c)

510 Ewig $S$ für die BQS-Arbeitsgruppe Pneumonie. Therapiebegrenzung: Herausforderung für die ärztliche Urteilskraft. Dt Ärztebl 2008; 105 : A878 - A879 (5)

511 Bulow HH, Sprung CL, Reinhart K et al. The world's major religions' points of view on end-of-life decisions in the intensive care unit. Intensive Care Med 2008; 34: 423-430 (5)

512 Bausewein C, Booth S, Gysels M, Higginson I. Non-pharmacological interventions for breathlessness in advanced stages of malignant and non-malignant diseases. Cochrane Database Syst Rev 2008; 2: CD005623 (1a)

513 Bruera E, Sweeney C, Willey J et al. A randomized controlled trial of supplemental oxygen versus air in cancer patients with dyspnea. Palliat Med 2003; 17: 659-663 (2b)

514 Clemens KE, Klaschik E. Symptomatic therapy of dyspnea with strong opioids and its effect on ventilation in palliative care patients. J Pain Symptom Manage 2007; 33: 473 - 481 (4)

515 Perrin C, Jullien V, Duval Y, Defrance C. Noninvasive ventilation in palliative care and near the end of life. Rev Mal Respir 2008; 25: 1227 $1236(5)$

516 Headley JA, Ownby KK, John LD. The effect of seated exercise on fatigue and quality of life in women with advanced breast cancer. Oncol Nurs Forum 2004; 31: 977 - 983 (2b)

517 Fallon M, Hanks G, Cherny N. Principles of control of cancer pain. BMJ 2006; 332: 1022 - 1024 (5)

518 Sorgatz H, Hege-Scheuing G, Kopf A et al. Langzeitanwendung von Opioiden bei nicht-tumorbedingten Schmerzen. Dtsch Ärztebl 2002; 99: 1743 - 1746 (5)

519 Zwakhalen SM, Hamers JP, Berger MP. The psychometric quality and clinical usefulness of three pain assessment tools for elderly people with dementia. Pain 2006; 126: 210-220 (2b)

520 Davies $L$. Integrated care of the patient dying of nonmalignant respiratory disease. Breathe 2008; 5: 155 - 157 (5)

521 Holen JC, Saltvedt I, Fayers PM et al. Doloplus-2, a valid tool for behavioural pain assessment? BMC Geriatr 2007; 7: 29-37 (2b) 